\title{
EFFECTS OF ORIENTATION ON THE ROLLING AND RECRYSTALLIZATION BEHAVIOR OF TANTALUM SINGLE CRYSTALS
}

\author{
W. B. Snyder, Jr \\ Metallurgical Development Department \\ Y-12 Development Division
}

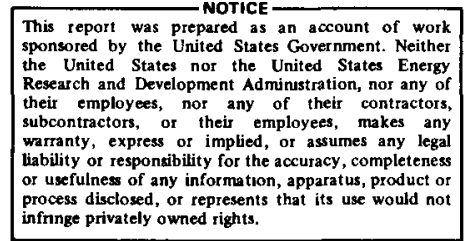

Adapted from a thesis that was submitted to the University of Tennessee in partial fulfillment of the requirements for the degree Doctor of Philosophy.

Oak Ridge $Y-12$ Plant

P. O. Box Y, Oak Ridge, Tennessee 37830

Prepared for the US Energy Research and Development Administration

Under US Government Contract W-7405-eng-26 


\section{DISCLAIMER}

This report was prepared as an account of work sponsored by an agency of the United States Government. Neither the United States Government nor any agency Thereof, nor any of their employees, makes any warranty, express or implied, or assumes any legal liability or responsibility for the accuracy, completeness, or usefulness of any information, apparatus, product, or process disclosed, or represents that its use would not infringe privately owned rights. Reference herein to any specific commercial product, process, or service by trade name, trademark, manufacturer, or otherwise does not necessarily constitute or imply its endorsement, recommendation, or favoring by the United States Government or any agency thereof. The views and opinions of authors expressed herein do not necessarily state or reflect those of the United States Government or any agency thereof. 


\section{DISCLAIMER}

Portions of this document may be illegible in electronic image products. Images are produced from the best available original document. 


\section{ABSTRACT}

Some deformed single crystals are more difficult to recrystallize than others.

Tantalum single crystals were rolled unidirectionally at room temperature to a thickness reduction of $80 \%$. Optical and electron metallography, $X$-ray line broadening and pole figure analyses, and microhardness testing were used to study the deformed, recovered, and recrystallized structures of these crystals.

Crystal stability, reorientation, and deformation banding was interpreted in terms of the Taylor theory of plasticity as applied to pencil glide in body-centered-cubic metals. Experimental results were in partial agreement with the theory.

Nucleation of recrystallization was found to occur by the polygonization and growth of dislocation cells originally present in the deformed structure. Impingement of these growing nuclei resulted in a fully recrystallized structure whose orientations were present in the deformed crystal. 


\section{CONTENTS}

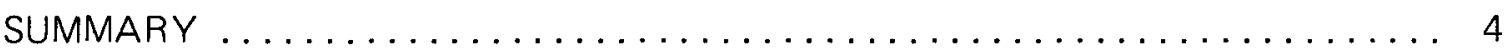

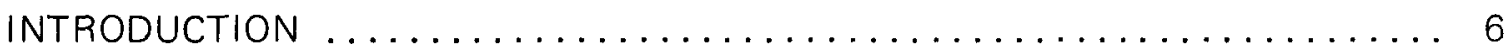

EFFECTS OF ORIENTATION ON THE BEHAVIOR OF

TANTALUM SINGLE CRYSTALS ................... 7

Literature Survey $\ldots \ldots \ldots \ldots \ldots \ldots \ldots \ldots \ldots \ldots \ldots \ldots \ldots \ldots \ldots$

Nature of Deformation of Body-Centered-Cubic Metals . . . . . . . . . . . 7

Annealing Behavior of Body-Centered-Cubic Metals . . . . . . . . . . . . . . . 10

Experimental Procedures . . . . . . . . . . . . . . . . . . . . . . 17

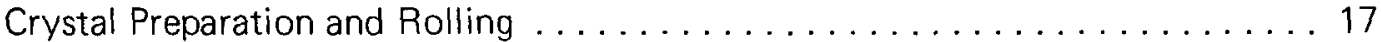

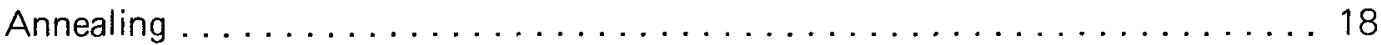

Optical Metallography, Grain Size, and Microhardness . . . . . . . . . . . . 19

X-Ray Diffraction Techniques ....................... 21

Transmission Electron Microscopy ....................... 22

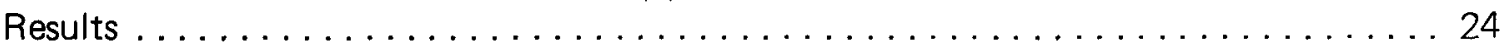

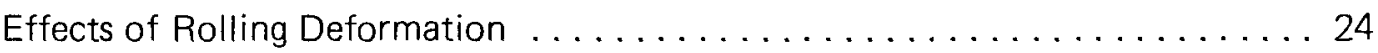

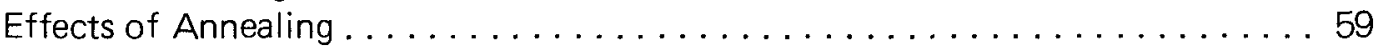

Discussion of Results. . . . . . . . . . . . . . . . . . . . . . . 86

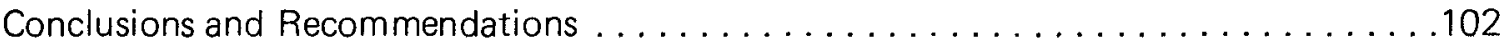

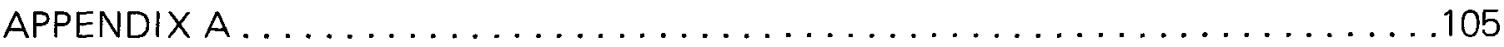

Optical Metallographic Techniques ..........................105

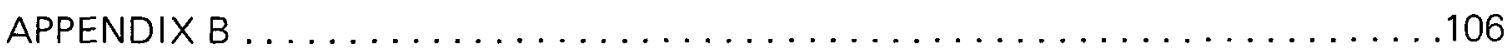

Dislocation-Cell-Area Measurements . . . . . . . . . . . . . 106

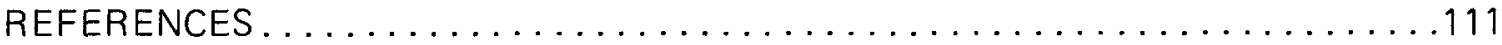

ACKNOWLEDGEMENTS $\ldots \ldots \ldots \ldots \ldots \ldots \ldots \ldots \ldots \ldots \ldots \ldots \ldots \ldots$ 


\section{SUMMARY}

The purpose of this research, conducted at the Oak Rıdge Y-12 Plant, (a) was to determıne why some deformed single crystals are more difficult to recrystallize than others Specifically, the recrystallization behavior of rolled sıngle crystals was studied to determıne the effects of texture diffuseness or sharpness, crystal reorientation, and deformation band formation Tantalum single crystals having inıtial orientations of (001)[110], (112)[1 $\overline{10}]$, (111)[1 $\overline{10}]$, and (110)[1 $\overline{10}]$ were rolled unidirectionally at room temperature to a thickness reduction of $80 \%$ Optical and electron metallography, X-ray lıne broadenıng and pole figure analyses, and microhardness testing were used to study the deformed, recovered, and recrystallized structures of these crystals

Upon rollıng, the (001)[1T0] and (112)[1T0] crystals were stable and maintained their original orientation There was very little orientation spread withın the deformed crystals $X$-ray line broadening and microhardness increased slightly from the undeformed state, suggestıng that little stored energy was present in the cold-worked crystals Transmission electron microscopy of the rolled crystals showed a more or less uniform distribution of dislocations, with no clearly defined dislocatıon cells

The (111)[1 $\overline{10}]$ crystal reoriented approximately 10 degrees toward the (112)[1 $\overline{10}]$ orientation durıng rollıng. A greater spread in orientation was found in this crystal than in either of the stable crystals A dislocation cell structure was evident It was concluded that the moderate reorientation of the $(111)[1 \overline{1} 0]$ crystal produced significantly greater amounts of lattice curvature and stored energy than in the stable (001) [1 $\overline{10}$ or (112)[1 $\overline{10}$ ] crystals

Complex reorientation and deformation band formation occurred in the (110) [1 10$]$ crystal during rolling Deformation bands were of alternate $\{001\}<010>$ and $\{111\}<110>$ to $<112>$ orientations and were separated by a region consisting of mixed orientations Dislocation cell structures were present in the deformation bands Deformation banding created multıple textures, more texture diffuseness, lattice curvature, and stored energy than in the case of a simple reorientation

Crystal stability, reorientation, and deformation banding was interpreted in terms of the Taylor theory of plasticity as applied to pencil glide in body-centered-cubic metals Experımental results were in partial agreement with the theory

Recovery processes produced large, slıghtly misoriented subgraıns in the stable crystals whose initial dislocation distributions were uniform Natural recrystallization only occurred in crystals which contained dislocation cell structures after rolling A lower temperature of recrystallization and a finer recrystallızed graın sıze were exhıbited by crystals which contaıned deformation bands These attributes were interpreted as resulting from the greater amounts of lattice curvature and stored energy created by the complex reorientation that occurred when deformation bands were formed

(a) Operated by the Union Carbide Corporation's Nuclear Division for the US Energy Research and Development Admınıstration 
Nucleation of recrystallization was found to occur by the polygonization and growth of dislocation cells originally present in the deformed structure. Impingement of these growing nuclei resulted in a fully recrystallized structure whose orientations were present in the deformed crystal. 


\section{INTRODUCTION}

Knowledge that a metal will harden when permanently deformed and soften when subsequently heated dates from the primitive era of man. During the ensuing centuries (most notably the present), a vast wealth of information has been gathered concerning the nature of the processes of plastic deformation and annealing, and the variables which influence them.

Though much is now understood about the phenomena of deformation and annealing, many aspects of these processes are not completely understood. The question of the origin of the nearly strain-free grains which serve as nuclei for recrystallization has been the subject of much research and debate for half a century. As a first step toward the understanding of deformation and annealing behavior in polycrystals, much effort has been devoted to studies of single crystals. A widely differing recrystallization behavior has been observed. For example, in the rolling and recrystallization of single crystals of body-centered cubic metals it was observed that those crystals which showed a very small spread in orientation during deformation were extremely difficult to recrystallize. On the other hand, those crystals which showed a greater spread in orientation or multiple orientations, recrystallized more easily. Though this fact was qualitatively observed many years ago and a number of suggestions have been made to explain these results, a quantitative explanation for this behavior has not been found.

Because of some differences in stability and texture development in single crystals of body-centered cubic metals, $\mathrm{Hu}(1)$ has suggested the possibility of a texture transition in the rolling-texture development of body-centered cubic metals. He suggests that texture development might occur by a change in slip planes, rather than a change in slip direction, as in the case of face-centered cubic metals. Though such a possibility seems plausible, no strong evidence for such a transition has been presented.

The present investigation was undertaken to determine the reason, or reasons, why some deformed single crystals are more difficult to recrystallize than others. A major objective was to establish what significance texture diffuseness, or sharpness, and crystal reorientation, or deformation band formation, play in this recrystallization behavior. As a secondary objective, the experiment was intended to fill a gap in the present knowledge of refractory-metal single crystals which, in some aspects, have exhibited deformation behavior different from one another and from other body-centered cubic single crystals (eg, Fe-Si).

Based upon previous studies of iron-silicon crystals, $(\eta)$ the orientations selected for this study had a common [1T0] rolling direction and a rolling plane varying from (001) through (112) and (111) to (110). During rolling to $80 \%$ reduction in thickness, the (001), (112), and (111) crystals of this group maintained their initial orientations within ten degrees, with an increasing spread in orientation from the (001) to the (111). Upon moving from (111) to (110), a complex texture and crystal reorientation occurred, concomitant with deformation banding. With an increasingly more complex rolling texture, recrystallization was quite drastically different during annealing. X-ray diffraction, optical metallography, electron metallography, and microhardness were used to study the reasons for such widely different recrystallization behavior. 


\section{EFFECTS OF ORIENTATION ON THE BEHAVIOR OF TANTALUM SINGLE CRYSTALS}

\section{LITERATURE SURVEY}

\section{Nature of Deformation of Body-Centered-Cubic Metals}

In general, plastic deformation of a metal results in the formation of two types of defects: dislocations and point defects (vacancies and interstitials). Upon heating a deformed metal, both of these types of defects interact and are involved in the processes of recovery and recrystallization. Thus, an understanding of the deformed state is necessary in order to evaluate the role of these defects in the subsequent recovery and recrystallization processes.

Slip systems in body-centered-cubic metals have been in dispute for many years. The slip vector for body-centered-cubic metals is the a/2 $\langle 111\rangle$ type. (2) Because of the wavy nature of slip traces found in body-centered-cubic metals, the assignment of indicies to a specific slip plane has been difficult. Andrade and Chow ${ }^{(3)}$ reported a correlation between the operative slip plane and the ratio of the test temperature to the absolute melting point. For tungsten and molybdenum, they assigned the $\{112\}$ slip planes in the temperature range of $T / T_{m}-0.08-0.24$; and for molybdenum, the $\{110\}$ slip planes in the temperature range of $0.26-0.50$. Elam, (4) however, suggested that slip lines may be formed by alternate slipping on nonparallel $\{110\}$ planes, and not by slip on planes of higher indicies. Similar conclusions were reached by Maddin and Chen $(5)$ from the behavior of molybdenum single crystals deformed in bending and tension, and niobium single crystals deformed in tension and compression. Conflicting results have been given for the operative slip planes in tantalum single crystals. Rose, et al, (6) extended tantalum crystals in the temperature range from 77 to $300 \mathrm{~K}$ and reported that deformation occurred exclusively on $\{110\}$ planes in the $\langle 111\rangle$ directions. Mordike $(7)$ investigated tantalum single crystals over the same temperature range and concluded that slip occurred on both the $\{110\}$ and $\{112\}$ planes. Spitzig and Mitchell, $(8)$ in investigations of yielding of tantalum crystals at $373 \mathrm{~K}$, detected dislocations on the $\{110\}$ planes with $<111>$ slip vectors.

Advent of the transmission electron microscope (TEM) in recent years has allowed the direct observation of dislocation structures produced by plastic deformation. Typically, upon heavily cold working polycrystalline body-centered-cubic metals, a dislocation substructure is produced which is characterized as having heavy dislocation concentrations in localized areas, with much lower concentration in others. This structure is best described as a cell structure with the cell walls being regions of higher dislocation density. $(9,10)$ Under the circumstances of lower temperature, higher strain rate, or alloy additions, dislocations are more uniformly distributed and show less tendency to cell formation. Such a behavior is noted in all refractory metals strained at their respective homologous temperatures. $(9-12)$

During plastic straining, a polycrystalline aggregate develops certain preferred orientations in individual grains relative to the deformation axes. Crystal axes of the individual grains rotate into specific orientations during the deformation. Once a grain has assumed a stable orientation, additional deformation does not alter its orientation. Thus, during rolling, a texture is developed in a metal relative to the rolling plane normal and the rolling direction. 
The rolling texture of polycrystalline body-centered-cubic metals has been described variously by different workers. Most workers are agreed that $\{100\}<011>$ (b) is the main component of the texture, while the orientations $\{112\}<110>,\{111\}<110>$, and $\{111\}<112>$ have been used to describe the remainder of the texture.

As a first step toward understanding of texture formation in polycrystals, much effort has been made in the study of texture development in single crystals. Single crystals of body-centered-cubic metals were first studied by Barrett and Levenson. (13) Since this work, a number of investigators have studied the rolling deformation of a wide range of initial orientations under various conditions. By far the vast majority of this work has been done on iron and the iron-silicon and iron-aluminum alloys. In general, the stable orientations of rolled single crystals are those which are found to be components of the polycrystalline texture; ie, orientations between (111) and (001), with a [1 10$]$ rolling direction and the (111) [1 $1 \overline{1} 2]$ orientation.

Crystals of particular interest to this research are those which have a [1 10$]$ rolling direction, with rolling planes from (001) to (110), as illustrated in Figure 1. Some of these orientations, as mentioned previously, make up a major portion of the polycrystalline texture. (14) In an iron-3.12 weight percent silicon (Fe-3.12 Si) crystal, rolled $80 \%$ at room temperature after prior hot working at $800^{\circ} \mathrm{C}$, the (001)[1 $\overline{1} 0$ ] crystal forms a very sharp rolling texture. (15) As movement is made from the (001)[110] toward the (110) by rotating around the rolling direction, these crystals do not change their original orientation, but their respective pole figures show an increasing spread in orientation. At the (110) [1 $1 \overline{10}$ ] orientation, which is not a component of the polycrystalline texture, the pole figure becomes more complex. (1)

It is entirely possible that other body-centered-cubic metals will not behave during rolling like iron-silicon. Present data are not sufficient to establish a possible texture transition in body-centered-cubic metals. A small amount of work has been done in the last decade on the rolling textures of refractory-metal single crystals. Most of this work has concentrated on tungsten and molybdenum, while no prior work could be found on the rolling texture of tantalum single crystals. It appears that there is some lack of agreement between the rolling texture of molybdenum single crystals and iron-silicon crystals. Blickensderfer, et al, (16) and Mochalov, et al, (17) both rolied molybdenum crystals of the (001) [110] orientation. $A$ rotation of the initial orientation of $14-18$ degrees about the rolling plane normal was observed in both instances. This result is in sharp contrast to the very stable (001)[1T0] crystals of iron-silicon. Mochalov also rolled crystals having the $(110)[1 \overline{10}]$ orientation. They reported that unidirectional rolling without reversing ends created a complex texture containing the (001)[100] and (111) [1 $\overline{10}$ ] components-the latter being more prevalent. Upon reverse rolling with heavier reductions, Mochalov, et al, reported that the (001)[100] component became less well defined and less intense.

(b) It is a common practice in the study of textures to describe the preferred orientations developed in rolling by "ideal orientations". The standard convention is to use a specific crystallographic plane as the rolling plane, with a specific crystallographic direction being parallel to the rolling direction. One or, in most cases, several ideal orientations are needed to describe a texture. This convention will be used throughout this discussion. 

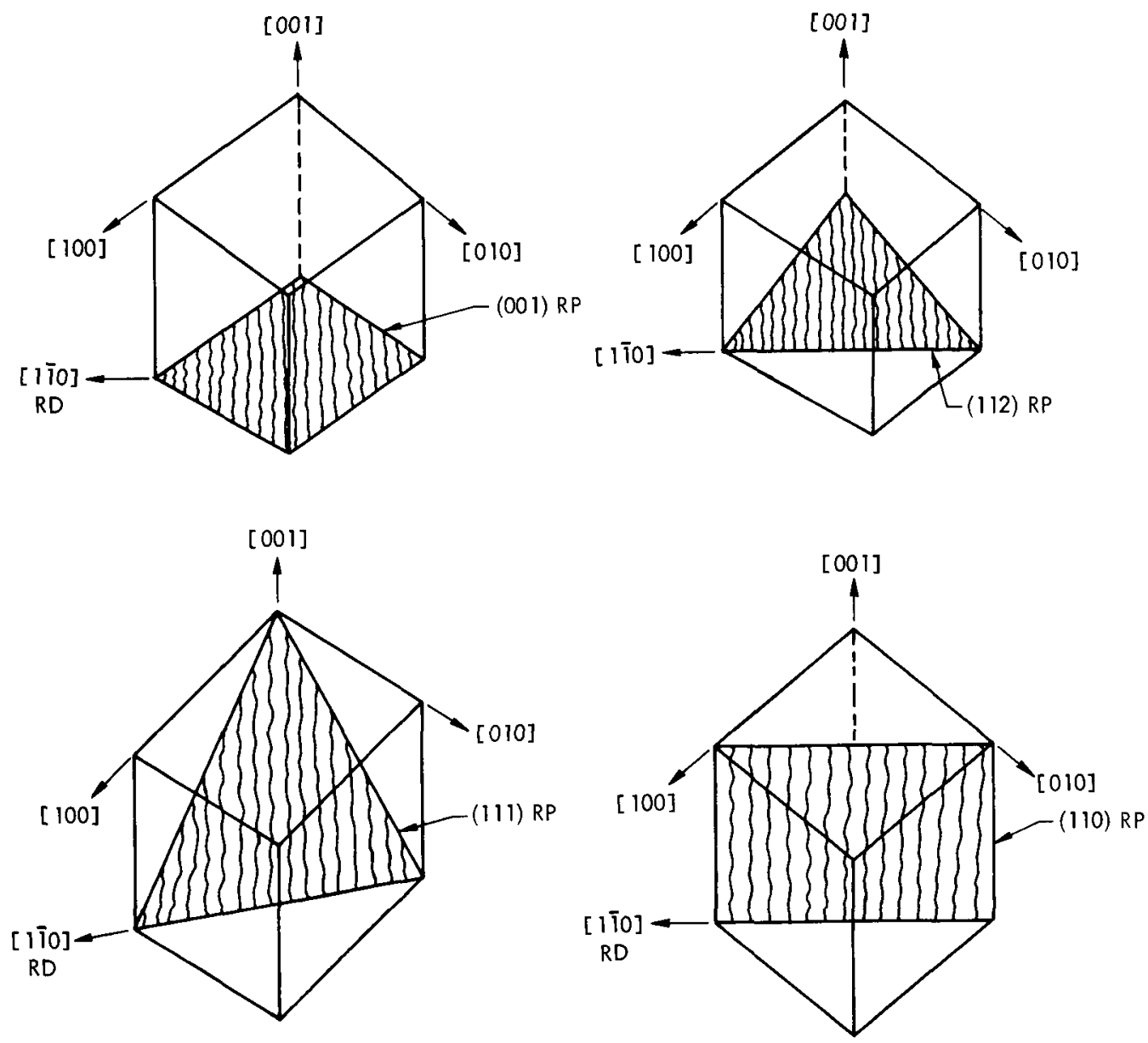

FIgure 1. ILLUSTRATIONS OF CRYSTAL ORIENTATIONS USED IN THIS INVESTIGATION.

Raymond and Neuman (18) have deformed tungsten single crystals of both the (001)[110] and $(110)[1 \overline{1} 0]$ orientations by rolling at $1000^{\circ} \mathrm{C}(0.35 \mathrm{Tm})$. Though they did not do pole-figure analyses of their rolled crystals, they deduced from Laue patterns that the (001) [1 $1 \overline{1} 0$ ] crystal did not change its orientation while the (110) [1 $\overline{10}$ ] underwent complex deformation and reorientation.

Though Raymond and Neuman did not observe the microstructures of their crystals, they did look closely at some of the variables involved in rolling single crystals. One of the variables studied was reductions per pass. They found that with a small reduction per pass, the $(110)[1 \overline{1} 0]$ and $(001)$ [ $1 \overline{1} 0$ ] crystals deform by duplex slip; while, at reductions of $50 \%$ per pass, these crystals deform by multiple slip. The amount of reduction per pass is only one of many variables which must be controlled, but which have been nearly ignored in past work. Other considerations are the: crystal width-to-height ratio, roll diameter-to-crystal thickness ratio, coefficient of friction, effective strain rate, total reduction, temperature of rolling, and effect of transverse constraints. Very few of these variables have been systematically studied themselves. Rather, what is normally done is to keep these variables constant (yet, at the same time, recognizing their importance) while studying other variables such as initial orientation or alloy content. 
An important phenomenon in the deformation of body-centered-cubic metals which has revived much interest is that of "deformation" or "transition banding". Barrett and Levenson, (13) during a study of the development of compression textures of iron single crystals, found that crystals oriented near (110) broke up into regions that reoriented to the (111) positions while adjacent portions reoriented to near (001). Differently oriented regions of the crystal were separated by distinct boundaries and referred to as "deformation bands". More recently, Hu(15) has made a rather comprehensive study of the influence of initial crystal orientation on the formation of deformation bands during rolling. Rolling iron-silicon crystals of $(001)[1 \overline{10}$ ] and (001)[100] orientations, Hu found that the (001)[110] crystal maintained its orientation during rolling and contained a substructure which consisted of a more or less uniform, dense array of dislocations. The (001)[100] crystal on the other hand developed well-defined deformation bands whose boundaries were comprised of what Hu called "microbands". The microbands consisted of narrow, elongated dislocation cells whose relative orientation differed by only two or three degrees. The total orientation change accommodated by the microbands was of the order of $30-40$ degrees. As will be discussed in a following section, these microstructures recrystallized in considerably different ways.

Though it is not clear that each is distinctly different, Dillamore $(19)$ has proposed four ways in which deformation bands may arise: (1) as a result of local differences in the strain state (perhaps due to frictional effects), different parts of the crystal undergo different strains with some relative rotation; (2) different combinations of slip systems may separately yield the imposed strain in different parts of the crystal and cause relative rotation; (3) an imposed shape change may be achieved for a lower total-strain-energy expenditure if the total strain is subdivided such that regions undergo different strains and rotate relative to each other; (4) a crystal may be oriented such that it would not normally rotate when subjected to a specified strain, but small displacements in opposite directions might result in two orientations which would continue to rotate relative to each other with continued straining. Using arguments similar to Method 3, Chin and Wonsiewicz (20) have mathematically shown that the deformation bands observed by Ahlborn (1) in wire-drawn, face-centered-cubic single crystals resulted in a lower total strain energy than would be expected from homogeneous, axisymmetric straining of the crystal. Though some theories have been moderately successful in predicting the stability or instability of various crystal orientations, $(21-23)$ no theory has yet been set forth to successfully predict when deformation band formation will occur in body-centered-cubic metals. Jago and Hatherly (21) have recently suggested that deformation bands occur in all crystals regardless of their orientation stability. The fact remains that the present experimental and theoretical knowledge of deformation banding is severely limited.

\section{Annealing Behavior of Body-Centered-Cubic Metals}

Recovery - As mentioned previously, the process of plastically deforming a metal creates within the metal both line defects and point defects. Associated with the creation of these defects during deformation is a storage of energy in the lattice which renders it thermodynamically unstable when subjected to subsequent heating. Recovery then consists in the annihilation of a portion of these defects prior to the formation of a new, strain-free recrystallized grain. (1) If there is a desire to study the formation of recrystallization nuclei, the amount of recovery or release of stored energy which has preceded nuclei formation must necessarily be taken into account. (15) 
Much of the lattice-curvature and interplanar-spacing variation resulting from deformation is removed during recovery and results in a decrease in the width of the Bragg diffraction peaks. Thus, measuring the recovery of $X$-ray line broadening as a function of temperature and time of annealing can permit a kinetic analysis and determination of the activation energy of recovery. (11)

Accompanying the recovery of $X$-ray line broadening, changes in dislocation distribution can be observed through the use of TEM. In deformed metals, the early recovery stage is characterized by dislocations within cell walls interacting with less numerous dislocations in the cell interiors and attracting them to the walls. The cell walls become sharper and narrower as the recovery process continues.

Such dislocation rearrangements are thought to occur by annihilation of dislocation dipoles, climb of edge dislocations out of their slip planes, and cross-slip of screw dislocations. Edge-dislocation climb takes place by vacancy migration. Due to the relatively high activation energy for vacancy diffusion, such rearrangements would be expected to occur at moderate recovery temperatures. Screw dislocations, under the influence of internal stresses, might be able to cross slip with the addition of thermal energy. This type of dislocation movement has been called "thermally activated cross slip".

A wide range of activation energies for recovery in body-centered-cubic metals has been reported in the literature. In general, these activation energies are observed to increase with the temperature and degree of recovery. (11) Such data seem to support the idea that a variety of processes from thermally activated cross slip to self diffusion are occurring during recovery.

Recrystallization - Many models have been derived to explain the experimental observations of recrystallization. Originally, Volmer's concept of classical homogeneous nucleation was first applied to recrystallization. (1) The model assumes that, by some process of random thermal fluctuations, an embryo is formed. Thermodynamically, the stability of the embryo is determined by a balance between the surface-free energy and the volume-free energy (ie, stored energy of cold work) as shown in the equation:

$$
\Delta \mathrm{G} \cdot 4 \pi \mathrm{r}^{2} \mathrm{dr}=\gamma \cdot 8 \pi \mathrm{rdr}
$$

where:

$r$ represents the embryo radius,

$\Delta G$ the free energy gained per unit volume by destruction of the cold worked structure, and

$\boldsymbol{\gamma}$ the specific boundary energy of the interface between the embryo and the matrix. 
At a critical radius, $r_{C}=2 \gamma / \Delta G$, a fractional decrease in stored energy would more than offset the energy required to increase the boundary area, and the nucleus could continue growing. Orowan(24) has shown that, in moderately deformed copper, the critical radius would be of five $\mu \mathrm{m}$ and the activation energy of the process would be approximately $10^{8} \mathrm{eV}$. Even if an order-of-magnitude variation in the results is allowed, the activation energy is much too high for such a process to occur with any reasonable frequency at the temperature involved. Though the formation of recrystallization nuclei by simple random thermal processes appears unlikely, the concept of the energy requirements of a critical nucleus for continued growth is thermodynamically necessary.

Another recrystallization nucleation model was proposed by Beck and Sperry (25) and later energetically analyzed by Bailey and Hirsch. (26) This model has been termed "strain-induced boundary migration" by the former investigators and "bulge nucleation" by the latter. Beck's model of the process is illustrated in Figure 2(a) and shows that a grain which contains a coarser subgrain size (lower dislocation density) can grow into a grain with a finer subgrain size because the area of subgrain destroyed is greater than that created. Using the model in Figure 2(b), Bailey and

A

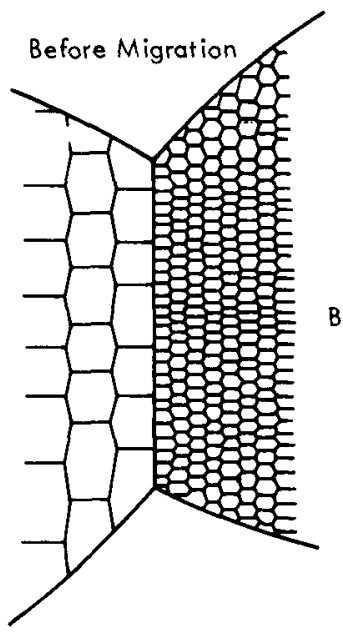

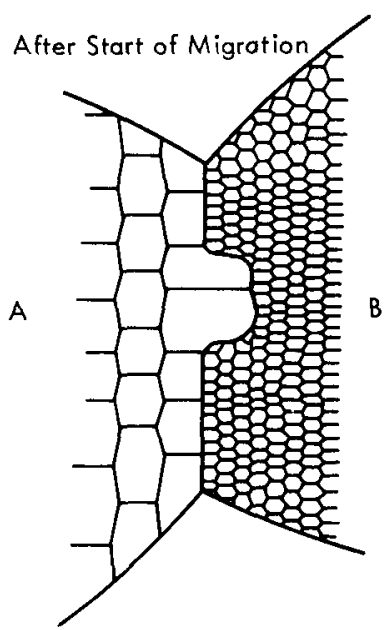

(a) Model of Stroin-Induced Boundary Migration. (after Beck and Sperry ${ }^{(25)}$ )

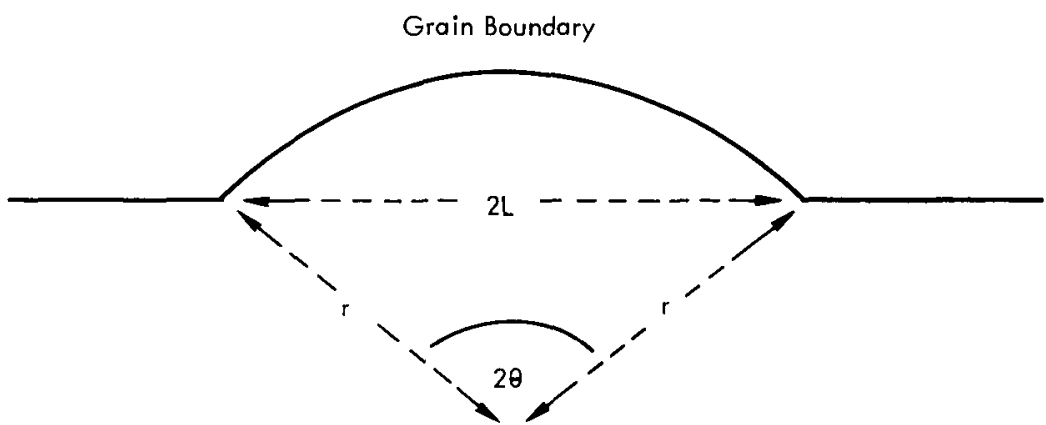

(b) Model for Energy Analysis. (after Bailey and Hirsch ${ }^{(26)}$ )

Figure 2. ILLUSTRATIONS OF STRAIN-INDUCED BOUNDARY MIGRATION. 
Hirsch analyzed the energetics of the process with an argument similar to the homogeneous nucleation concept. They showed that a bulge will grow when $\Delta G-(2 \gamma / L) \sin \theta$ is positive for all values of Angle $\theta$. In this expression, $\Delta G$ is the difference in the stored energy per unit volume between the grains, and $\gamma$ is the specific boundary energy. Bailey and Hirsch and, more recently, Bellier (27) have given experimental verification that the bulge nucleation mechanism operates in moderately deformed polycrystalline metals. Obviously, this concept has no application to recrystallization in single crystals.

A somewhat different approach to the formation of a recrystallization nucleus was offered by the model of Burgers and Verbraak. (28) Their model is known as the "martensitic shear" model and requires that certain small volumes of the lattice undergo a cooperative-shear process similar to that which happens during the formation of a nucleus in a martensitic-phase transformation. As a result of the shear process, an entire small volume of the lattice (the nucleus) acquires, at the same time, a completely different lattice reorientation. After shearing, the nucleus is surrounded from the outset by high-angle grain boundaries which are then able to migrate during annealing. Essentially no experimental evidence has been found to substantiate the belief that localized shears of the type required by the martensitic-shear model actually occur.

Early in the search for the origin of recrystallization nuclei it was felt that nuclei might already be present in the deformed matrix and simply grow upon annealing. Such processes, called "preformed nucleus" theories, do away with the need for random thermal fluctuations of the classical nucleation theory. Cahn (29) was the first to suggest that dislocations could be rearranged into walls as sub-boundaries by the process of polygonization. According to Cahn's theory, the highly curved regions (regions of highest stored energy) in a deformed crystal would be the first to polygonize. A polygonized domain, or subgrain, could then grow at the expense of the surrounding deformed matrix by the migration of subgrain boundaries. Eventually, a recrystallized grain would be formed.

Cottrell $(30)$ pointed out that the presence of a severe lattice curvature is not, in itself, a sufficient condition for nucleation. In order for growth to continue, the region of nucleus formation should contain a high angle boundary which would have the freedom to grow in arbitrary directions. Cottrell then proposed that the polygonized domain would grow slowly at first by consuming other adjacent domains and increasing their misfit angles. Eventually, some of the domains would acquire enough mobility to grow at a disproportionate rate, relative to their neighbors. Finally, the growing domain would emerge as a strain-free grain, separated from neighboring domains by high angle boundaries. Cahn $(31)$ has more recently reviewed the concept of subgrain boundary migration and points out that a subgrain will grow if it satisfies either of the conditions that it have: (1) a size significantly larger than its neighbors, or (2) a significant misorientation relative to its neighbors. As indicated in Figure $3(a)$, the large subgrain, seen here, will grow because its triple points depart from the 120-degree equilibrium configuration. This argument assumes the unlikely condition of equal energy for all subboundaries. On the otherhand, a highly misoriented subgrain of any size will grow into surrounding material. Cahn suggests that a moderately large angle subboundary consumes dislocations more efficiently than a small-angle boundary. 
A variant to the "preformed nucleus" model of nucleation is that of subgrain coalescence, first proposed by $\mathrm{Hu}(15)$ and energetically analyzed by $\mathrm{Li}$.(32) The coalescence of two subgrains takes place by the gradual disappearance of their common boundary through the movement of dislocations from the disappearing boundary to the surrounding boundaries, as illustrated in Figure 3(b). This action results in a subgrain of large size which, due to the rotation during coalescence, has a different orientation. Continued coalescence takes place until a subgrain emerges, surrounded by a higher-angle boundary and continues to grow through normal grainboundary migration. $\mathrm{Li}$ showed thermodynamically that a subgrain can rotate naturally such that the lower angle boundaries decrease their angle of misfit to allow higher angle boundaries to increase their angles of misfit. Twist and asymmetric boundaries decrease their angles of misfit to allow tilt and symmetric boundaries to increase their angles of misfit. From a kinetic standpoint, Li showed that either the cooperative climb of dislocations in the disappearing boundary or the lattice diffusion of jog-created vacancies to sinks will be the rate-controlling step, depending on the boundary angle. An important point of the coalescence mechanism is that it provides for nuclei of differing orientations than the orientation of the deformed matrix. One criticism to the coalescence theory is that motion of a subboundary will result in shear strains which will give rise to elastic back stresses in the surrounding boundaries. (33-35) At the temperatures involved in dislocation climb, however, it seems quite possible that the elastic back stresses could be relieved by dislocation rearrangements in surrounding grain boundaries. The accommodation of such

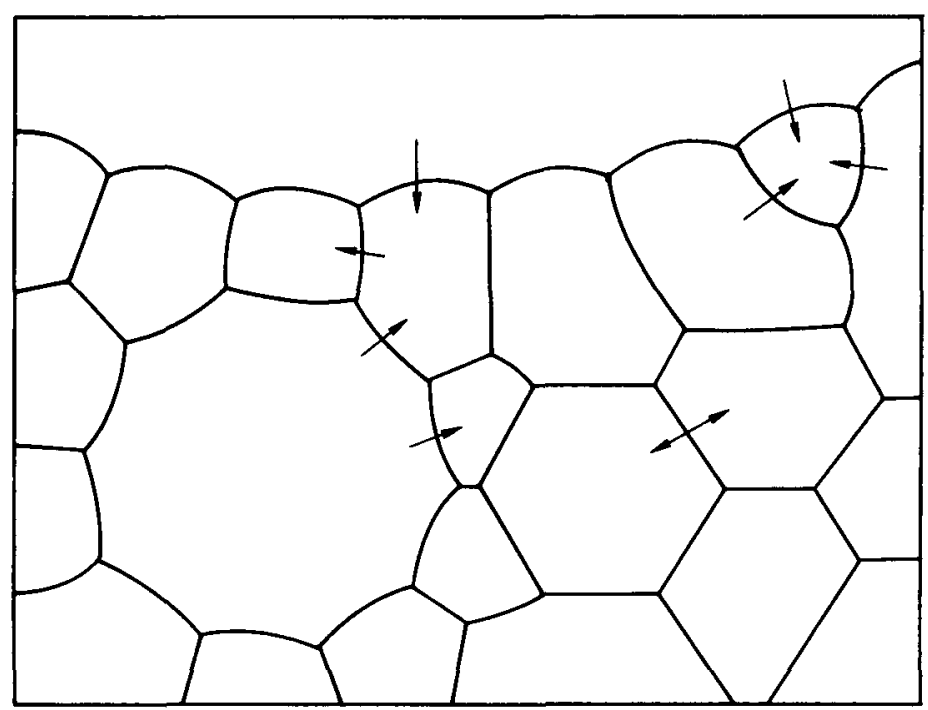

(a) Subgrain Boundary Migration. (arrows indicate direction of boundary migration)

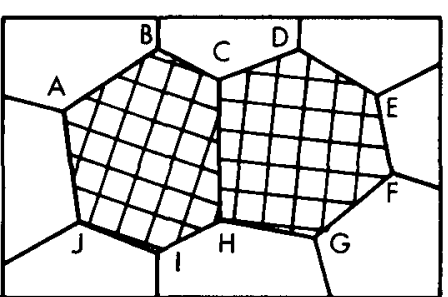

(1) The original subgrain structure before coolescence.

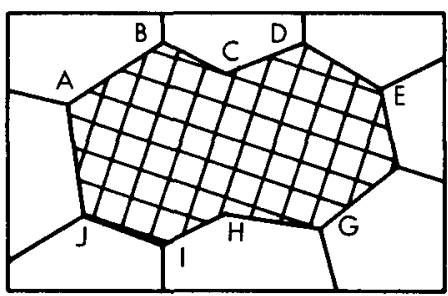

(3) The subgrain structure just after coalescence.

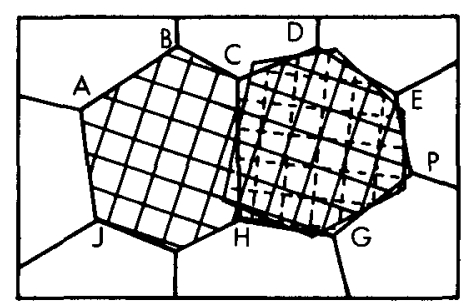

(2) One subgrain is undergoing a rotation.

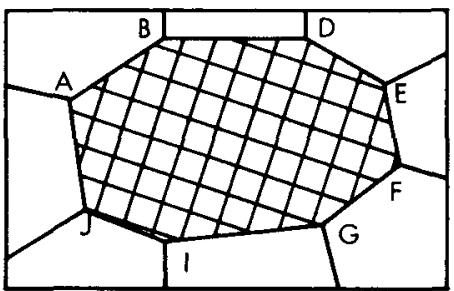

(4) The final subgrain structure after some subboundary migration. (b) Subgrain Coalescence. (after $\mathrm{Li}^{(32)}$ )

Figure 3. ILLUSTRATIONS OF SUBGRAIN GROWTH. 
rearrangements would depend upon the exact nature of the surrounding boundaries and would perhaps serve as a selection process for coalescence events.

An abundance of evidence has been presented to support the concepts of subgrain boundary migration $(15,27,31,36-38)$ and coalescence. $(15,39-45)$ Indeed, it appears that both mechanisms can operate perhaps even in similar materials with slightly different impurity and solute contents or strained under different conditions.

The mobility of low-angle grain boundaries is of direct importance to the idea of nucleation. Recent experiments by Viswanathan and Bauer $(46)$ on copper bicrystals have reinforced thinking in this area. Two types of boundaries were studied: (1) simple-tilt boundaries which, during migration, could be described as arrays of edge dislocations (Type 1), and (2) simple-tilt boundaries whose dislocations had to acquire screw components during migration (Type II). At angles of 18 degrees or more, the boundaries were quite mobile, independent of their character. At misorientations up to five degrees, the mobility of both Type $I$ and Type II boundaries was several orders of magnitude lower than the high-angle boundaries. At nine degrees misorientation, boundaries of Type I remained relatively immobile while the Type 11 boundaries approached the mobility of the higher-angle boundaries $\left(>18^{\circ}\right)$. Conclusions were that high-angle boundaries can move by single-atom jumps, while low-angle boundaries must move by cooperative glide. Cooperative glide requires a shape change of the two adjacent crystals which might be easy in bicrystals, but will be opposed by three-dimensional subboundaries in recovered crystals. In short, it appears that a nucleus must attain a misorientation of nine to eighteen degrees from the material into which it grows.

Severe lattice curvatures in deformed metals would appear to be necessary for the nucleation of new grains. One means of achieving such localized strain is the deformation or transition band mentioned in the previous section. $\mathrm{Hu}(15)$ and Walter and Koch(15) ran independent experiments on rolled silicon-iron single crystals of the $(001)[100]$ and (001)[1 $\overline{10}$ ] orientations. The (001)[1T0] crystal produced a dense, uniform array of dislocations and did not recrystallize after annealing at $8000 \mathrm{C}$. Upon rolling, the (001)[100] crystal formed deformation bands which were separated by microbands, as discussed previously. Conclusions concerning the microband region were:

1. The large orientation difference $\left(\sim 30^{\circ}\right)$ between adjacent macrobands is accommodated by the microbands, which serve as a transition region from one macroband to the other.

2. The orientation variation across a microband is gradual, but not necessarily uniform. The maximum observed misorientation between two neighboring segments or elongated subgrains was of the order of three to four degrees. No high-angle boundaries were produced by the deformation.

3. The boundaries of the microband segments are low-angle boundaries.

Nucleation was observed to occur in the microband region, with subsequent grain-boundary migration into the adjoining macrobands. Hu concluded that nucleation within the microband occurred by coalescence of subgrains, whereas Walter and Koch maintained that nucleation was by subgrain-boundary migration. The basic disagreement of these two very 
similar studies stems from the fact that Hu maintains the subgrain boundaries are of the general type and, as such, are immobile. Walter and Koch, on the other hand, maintain that the subgrain boundaries are of a simple tilt nature and are quite mobile.

Dillamore $(47)$ has measured the rate of subgrain growth in polycrystalline iron and found it to be much faster than that predicted by Li's model. He has subsequently proposed a model for nucleation from microbands which involved no coalescence. Referring to Figure 4 , he

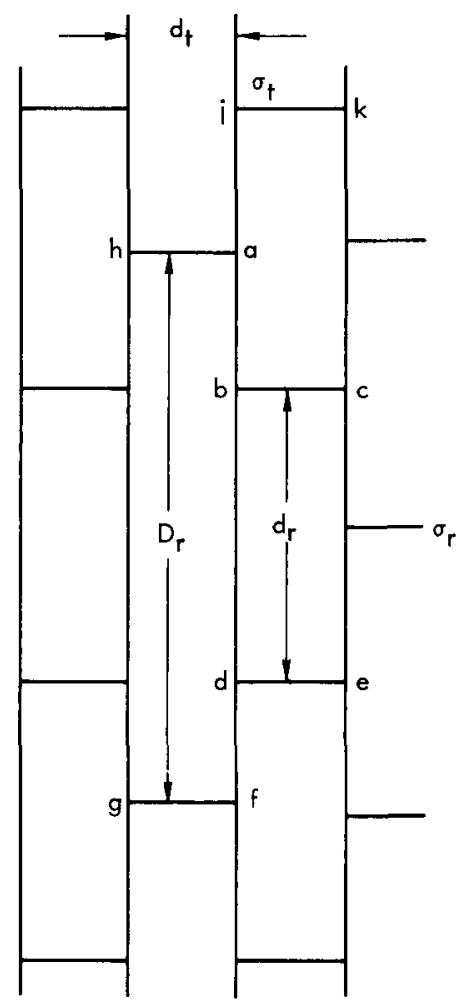

(a) As Formed.

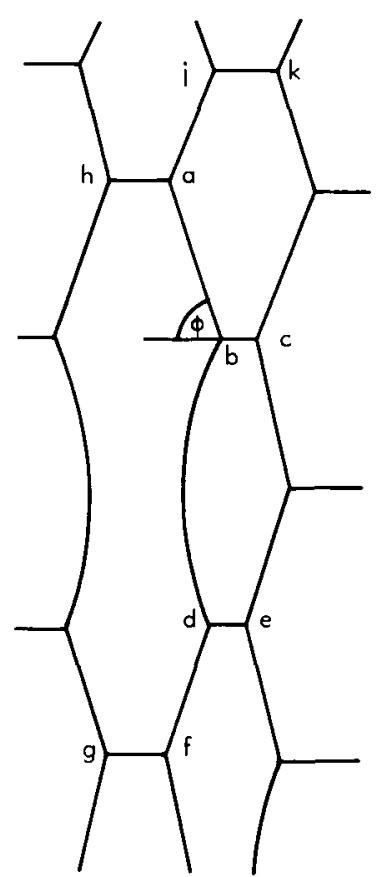

(b) Annealed.

Figure 4. ILLUSTRATIONS OF NUCLEATION IN A MICROBAND OR TRANSITION BAND.

proposes that nucleation will occur if boundary bc is eliminated before the structure relaxes into the equilibrium (annealed) configuration. Though this model offers a means of nucleation by boundary migration, the boundaries ha, bc, de,..., could just as well have disappeared by coalescence.

In another study of the annealing of rolled single crystals of iron-silicon, Dunn and Koh (38) observed that there appeared to be a qualitative correlation of recrystallization reluctancy with the increased sharpness of the cold-rolled texture. The rate of recrystallization increased and the size of recrystallized grains decreased with decreasing sharpness of the texture. Such an observation had been made by other investigators, but there has yet to be a comprehensive study of the reasons for such a tendency. Hu has proposed an explanation, based upon his coalescence model for nucleation. (15) The selection of a particular subgrain boundary which disappears through the coalescence process depends on the angle of misfit 
of the boundary compared with the angle of misfit of the other boundaries which surround the subgrains. If all subgrains are only very slightly disoriented with respect to one another (ie, the texture is very sharp), then coalescence of any two subgrains ought to be different because the driving force for coalescence will be small. Though such an explanation seems quite plausible, further experimentation is necessary in order to verify and understand the reasons for this phenomenon. The present experiment was undertaken to determine the reason or reasons for this behavior.

\section{EXPERIMENTAL PROCEDURES}

\section{Crystal Preparation and Rolling}

Because tantalum single crystals of adequate size could not be obtained by standard crystal-growing techniques, crystals for this experiment were obtained from very-largegrained, double-electron-beam melted stock. A chemical analysis of the material is given in Table 1 for those elements in excess of one part per million on a weight basis. Silver, gold, clorine, molybdenum, and zirconium were determined by spark-source mass spectrometry, oxygen by neutron activation analysis, niobium and tungsten by atomic absorption measurements, and carbon by gravimetric combustion analysis.

To obtain small crystals for the experiment, large grains were cut from the stock,

Table 1

CHEMICAL ANALYSIS OF TANTALUM SINGLE CRYSTALS

\begin{tabular}{cc}
\hline Element & $\begin{array}{c}\text { Concentration } \\
\text { (W ppm) }\end{array}$ \\
\hline $\mathrm{Ag}$ & 1.0 \\
$\mathrm{Au}$ & 3.0 \\
$\mathrm{C}$ & 5.0 \\
$\mathrm{Cl}$ & 6.0 \\
$\mathrm{Mo}$ & 20 \\
$\mathrm{Nb}$ & 400 \\
$\mathrm{O}$ & 125 \\
$\mathrm{~W}$ & 150 \\
$\mathrm{Zr}$ & 40 \\
\hline
\end{tabular}
chemically polished, mounted in a two-axis goniometer, and photographed using the Laue back-reflection technique. From the original orientation, crystals were reoriented such that the X-ray beam was parallel to either the (001), (112), (111), or (110) directions. To obtain slices of the large crystal having the desired normal, the goniometer and crystal were placed on the table of a traveling-wire electrical discharge machine. Cut and polished crystal slices were mounted on the X-ray generator, marked, and cut into rectangles $2.54 \mathrm{~mm}$ thick by $12.7 \mathrm{~mm}$ wide by $19.0 \mathrm{~mm}$ long, with the [1TO] parallel to the long edges. Figure 5 illustrates the sequence of events in taking a crystal from a large grain.

After cutting, crystals were metallographically and chemically polished on all sides and checked for asterism, using Laue photographs. Crystals with less than one degree of orientation spread were oriented to within two degrees of the desired directions. Figure 6 is a Lang photograph, showing the typically large subgrains responsible for the Laue asterism.

Using a $5 \%$ reduction per pass, crystals were rolled unidirectionally to $80 \%$ reduction in thickness. The crystals were turned 180 degrees about the rolling direction after each pass. A four-high rolling mill, with a work-roll diameter of $61.0 \mathrm{~mm}$ and a surface speed of $63.8 \mathrm{~mm} / \mathrm{sec}$, was used to roll the crystals. With some exceptions, all crystals were rolled at room temperature without lubricant. For those crystals rolled with lubricant, mineral oil was used and liberally applied to both rolls and the crystal. A fixture was 
constructed to present the crystals to the rolls perpendicularly to prevent turning of the crystals during rolling. Thickness measurements were made after each pass, while width measurements were performed at intervals of $20 \%$ in thickness reduction.

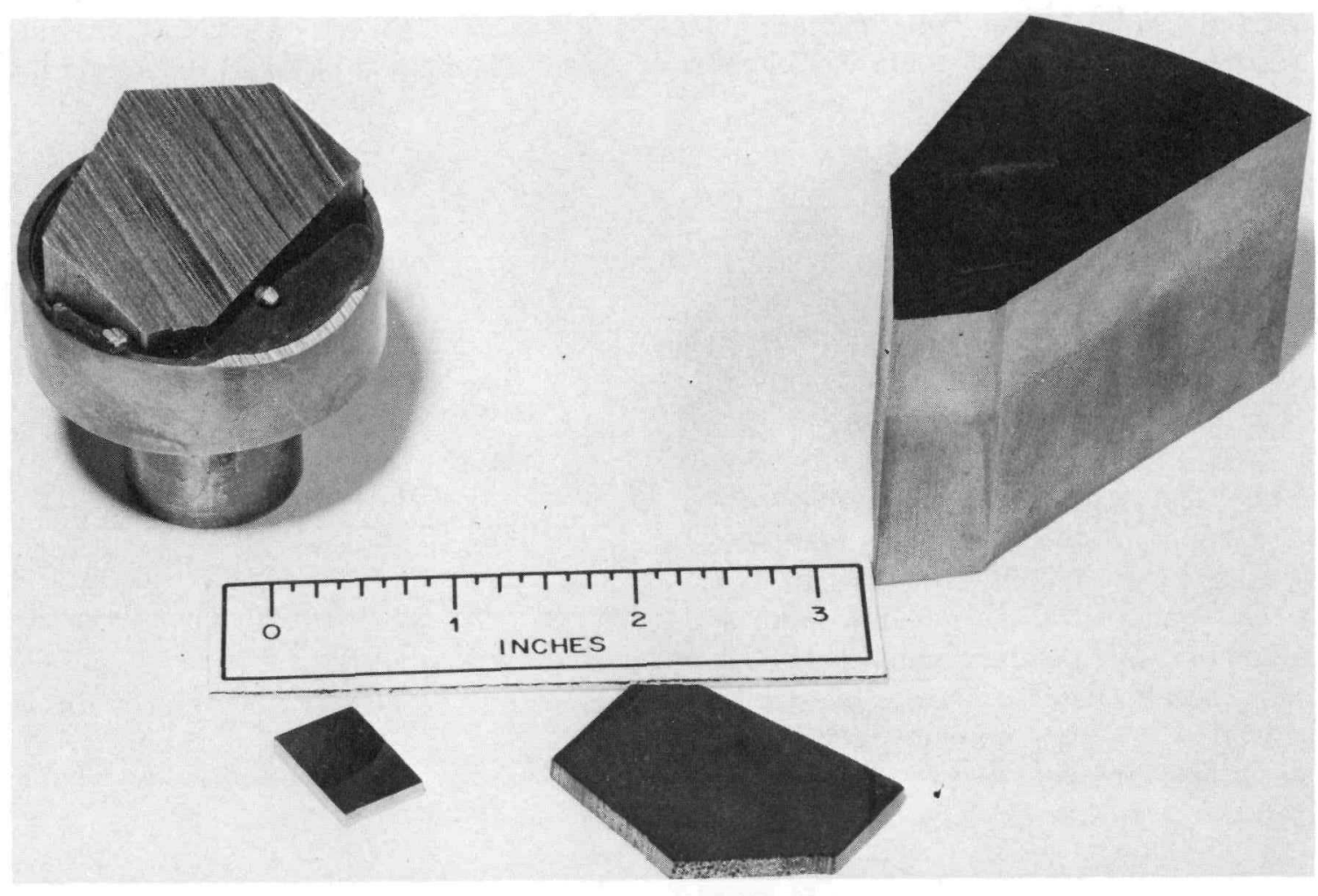

Figure 5. TECHNIQUE USED IN OBTAINING SINGLE CYRSTALS.

\section{Annealing}

After rolling, crystals were cut, using a Buehler low-speed saw, into 13 by $13-\mathrm{mm}$ squares, scribed in one corner, and chemically etched in a solution of two parts concentrated lactic acid, one part concentrated nitric acid, and one part concentrated hydrofluoric acid, to remove $0.025 \mathrm{~mm}$ of total thickness. Initially, annealing was performed in a vertical-tube furnace shown, schematically, in Figure 7. Specimens were cleaned in absolute ethanol, wrapped in tantalum foil, and held in the upper portion of the furnace until the furnace temperature equilbrated. When the furnace reached less than $1 \times 10^{-6} \mathrm{~mm}, \mathrm{Hg}$, the sample was lowered into the furnace hot zone, held a specified time, and finally lowered onto a water-cooled block attached to the furnace.

Microhardness measurements of crystals annealed for one hour at $1200^{\circ} \mathrm{C}$ or higher indicated an increase above the as-rolled hardness. This increase was attributed to oxygen contamination from the furnace atmosphere. To avoid contamination, all subsequent specimens were wrapped in tantalum foil and placed in a tantalum can. The can was sealed by electron-beam welding at a pressure of less than $10^{-5} \mathrm{~mm}, \mathrm{Hg}$, and subsequently given the specified annealing treatment in a vacuum of less than $10^{-7} \mathrm{~mm}, \mathrm{Hg}$. Specimens annealed in this manner showed no indication of oxygen contamination. 

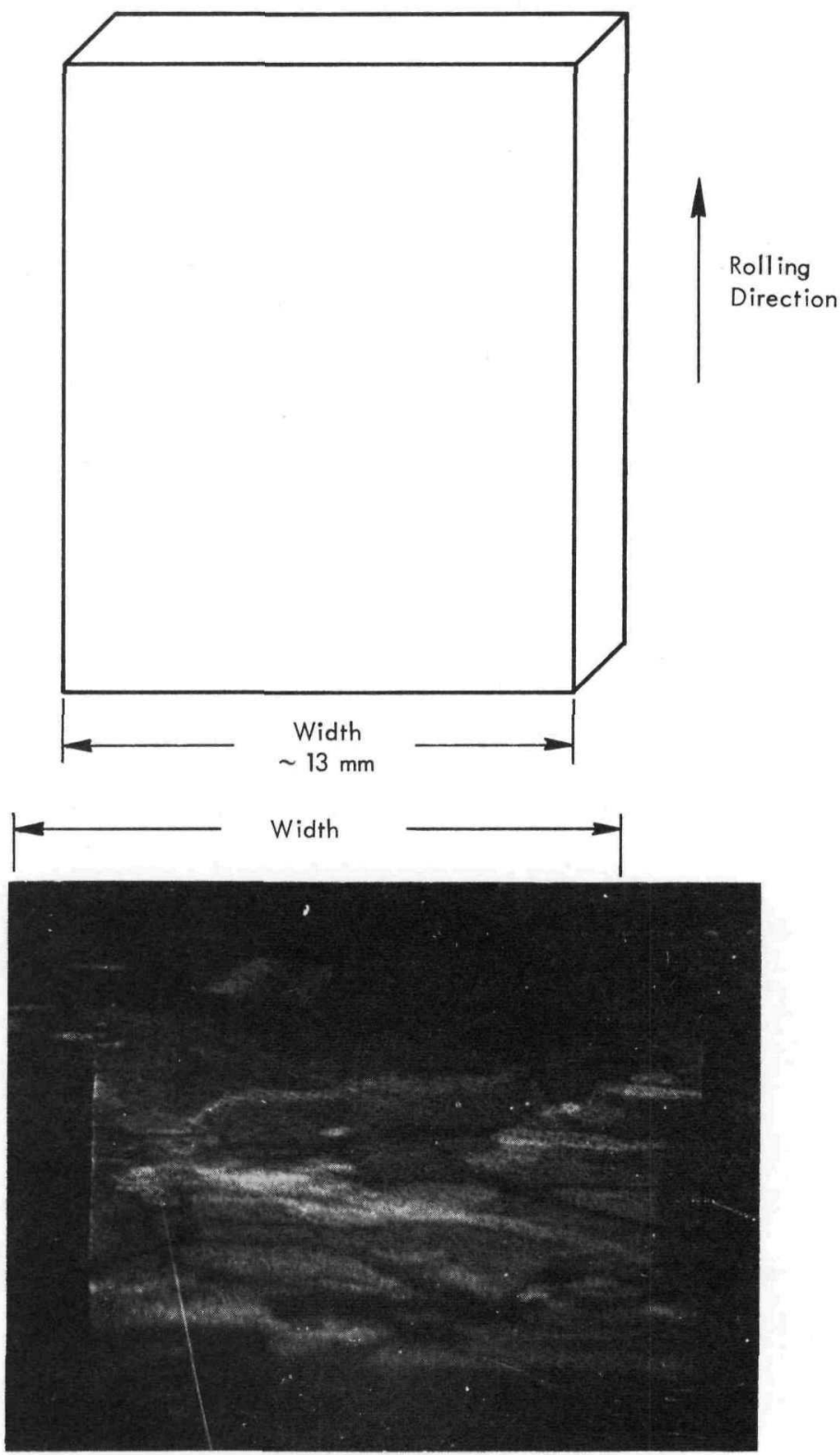

Figure 6. LANG PHOTOGRAPH OF THE FULL WIDTH OF A (001)[110] CRYSTAL, ILLUSTRATING THE SUBSTRUCTURE PRESENT. [Photograph was Taken, Using (200) Reflection; 2.5X]

\section{Optical Metallography, Grain Size, and Microhardness}

Specimens of rolled and annealed crystals were mounted flat in Shell 815 epoxy prior to wet grinding through several grades of silicon carbide paper. After rough polishing, specimens were vibratory polished in alumina (aluminum oxide) slurries to remove prior scratches. During the course of this experiment, it was fortuitously discovered that annealed tantalum crystals could be made optically active to polarized light by extensive room-temperature vibratory polishing in the latter solution. Appendix A contains a more detailed description of the technique used and observations on the surface structure. 


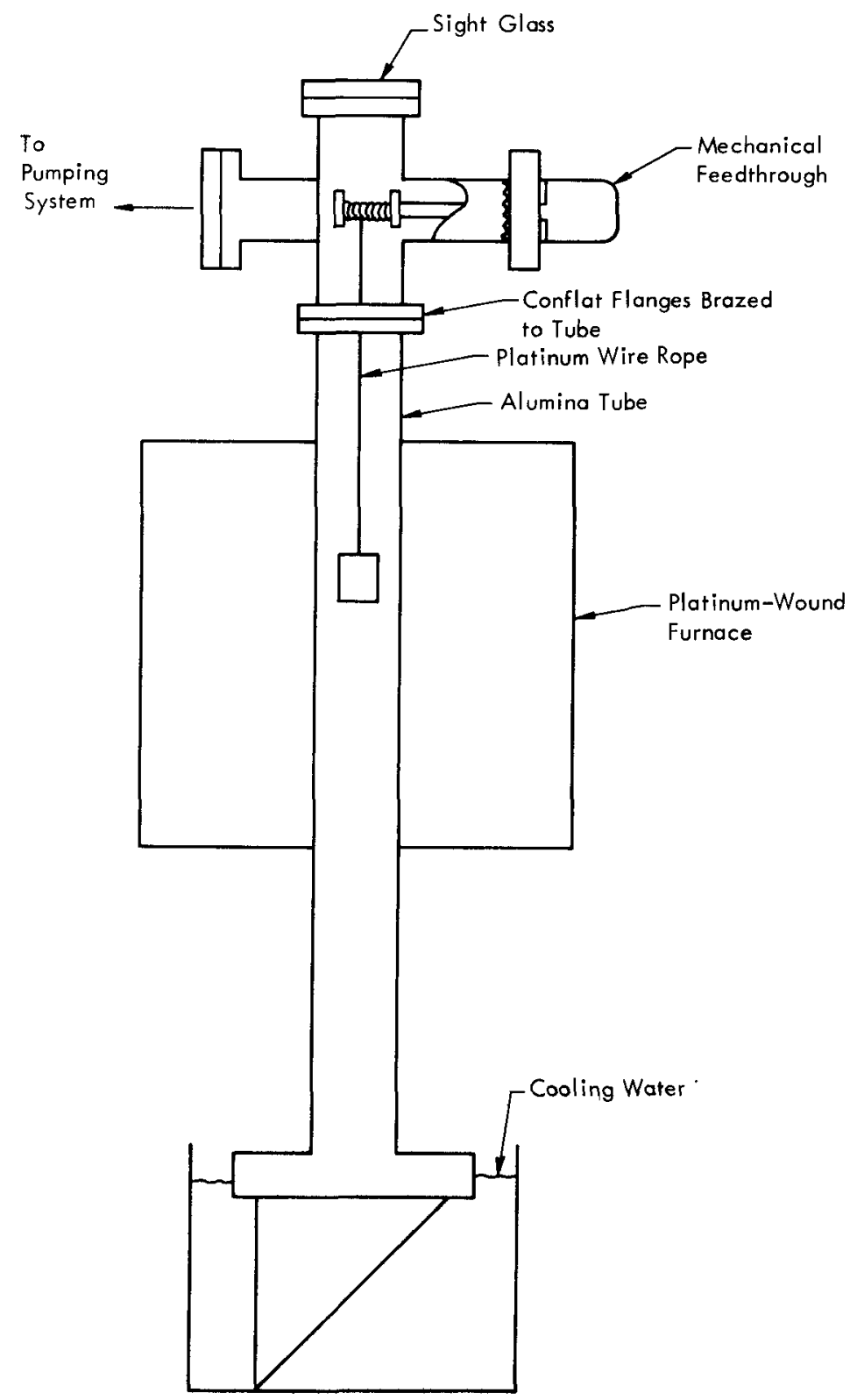

Figure 7. COMPONENTS OF THE ANNEALING FURNACE.

Because chemical etching failed to delineate many low-angle grain boundaries in annealed specimens, all metallographic specimens were photographed in polarized light. Each specimen was photographed at 15-degree increments, from zero to ninety degrees, to show all orientations present. Grain-size measurements were then made using the Heyn intercept method on photomicrographs of representative areas of each sample. $(48,49)$

Hardness measurements were made on crystals, prior to rolling, at intervals of $20 \%$ thickness reduction during rolling and after annealing. Diamond pyramid hardness (DPH) values were made on the surface of crystals using a 500-gram load and 50X objective on a Tukon microhardness tester. Knoop hardness measurements were taken on the cross section of the 
(110) [1 $1 \overline{1} 0]$ crystal after rolling and annealing, using a 100-gram load and $50 \mathrm{X}$ objective. Calibration of the hardness tester was checked periodically by determining the hardness of unrolled crystal standards. Because of the asymmetry of indentions, one of the indenter diagonals was kept parallel to the rolling direction and a simple average of the diagonals taken. A minimum of six readings were taken for each data point and a $95 \%$ confidence interval calculated for each observed mean. These intervals are indicated by error bars on the hardness diagrams.

\section{X-ray Diffraction Techniques}

Pole-Figure Analyses - Using nickel-filtered $\mathrm{CuK}_{a}$ radiation and the Schulz reflection geometry, illustrated in Figure 8, (200), (110), (222), and (112) pole figures were determined on both rolled and recrystallized specimens, utilizing two separate instruments. $(50,51)$

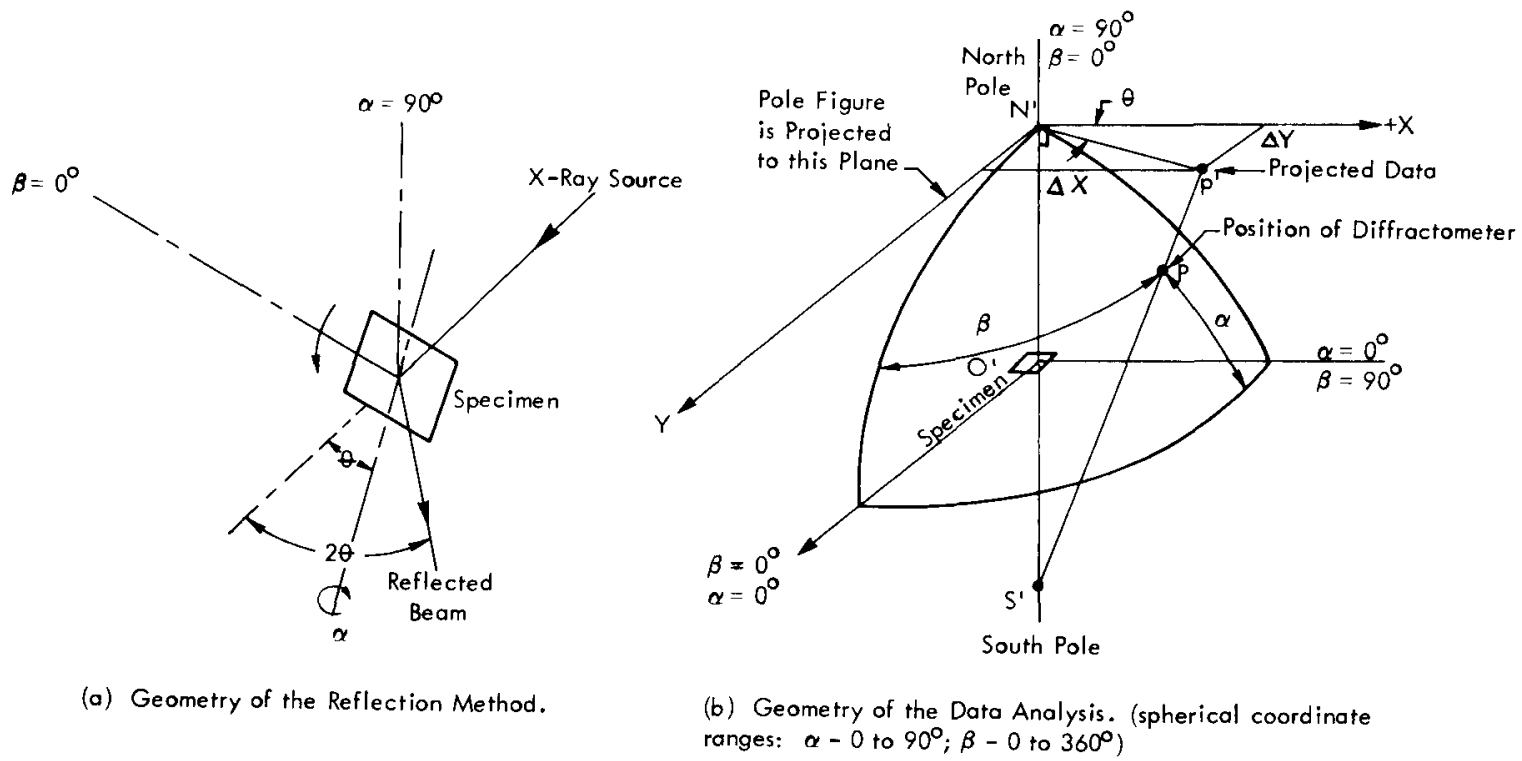

Figure 8. GEOMETRY OF THE SCHULZ REFLECTION METHOD AND DATA ANALYSIS.

One instrument is located in the Laboratory Development Department of the Oak Ridge Y-12 Plant. The Y-12 instrument consists of a Seimens Type F diffractometer equipped with a four-axis gon ometer and an integrating specimen holder manufactured by Electronics and Alloys Industries. A PDP-8I computer (Digital Equipment Corporation) is interfaced to the diffractometer and standard counting equipment consisting of a scintillation detector, preamplifier, linear amplifier, pulse he,ght discriminator, and rate meter. Slits measuring 1.2 and $0.3 \mathrm{~mm}$ were used to restrict the horizontal and vertical divergence of the incident beam, respectively, while 3.8 and $0.3-\mathrm{mm}$ slits were used on the detector to block the diffracted beam horizontally and vertically. The computer was programmed to divide the hemisphere of projection into 2000 equal spherical areas, position the $\alpha, \beta$, and $\theta$ motions, and count for a fixed period of time at the center of each area. Data were taken from 90 degrees of alpha (diffraction vector parallel to specimen normal) to fifteen degrees of alpha. (52) From intensity measurements of a random specimen at 15, 40, 
65, and 90 degrees of alpha, a linear interpolation of random intensity was made at each alpha angle After appropriate background corrections, intensity data were directly plotted as discrete multiple values of random intensity Contours of constant intensity were drawn manually

A second instrument is located in the X-ray laboratory of the Metals and Ceramics Division of the Oak Ridge Natıonal Laboratory This instrument is a standard Norelco vertical diffractometer, equipped with a Norelco preferred orientation ring with an integratıng specimen holder Counting equipment consists of a proportional counter, preamplifier, lınear amplifier, pulse-height discrimınator, and rate meter Both diffractometer and countıng circuits are interfaced to a PDP-8I computer Data points are taken in a spıral path around the hemisphere of projection by starting at $a=90^{\circ}$ and continuously increasing such that a total increase of $72^{\circ}$ of $a$ is accomplished in each circuit Data are taken in intervals of beta and punched directly onto paper tape Paper tape is converted to magnetic tape, using a PDP-10 computer, and further processed through an IBM 360/91 computer (53) Magnetıc-tape output from the IBM computer is then run through a tape reader to a Calcomp plotter which plots the pole figure in contours of multiple random intensities Several specimens were run on both instruments to verify that the texture results were essentially the same from both sources

Specımens which were examined for texture through their depth were masked with electroplating tape on one surface and etched with a solution of five parts concentrated sulfurıc acıd, two parts concentrated nitric acid, and two parts concentrated hydrofluoric acid

Line Profile Analysis - X-ray diffraction profiles were taken of the (200) planes for the

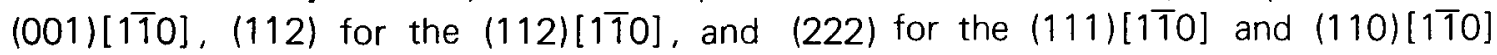
crystals Nickel-filtered CuK $_{a}$ radiation was used on a General Electric $X$ ray spectrogonımeter, equipped with a single crystal orienter A doubly bent graphite monochromater was used in the diffracted beam, with counting circuitry consisting of a scintillation detector, preamplifier, linear amplifier, pulse height discriminator, and rate meter This instrument was tıme shared with the previously described ORNL pole figure Instrument on a PDP-8I computer

\section{Transmission Electron Microscopy}

Specimen Preparation - Rolled crystals Intended for TEM were mounted in an Adolph Buehler Isomet waferıng saw and cut into 30 by $30-\mathrm{mm}$ squares Annealed crystals were first mounted in epoxy and polished for optical metallography, as previously described Later TEM examınation of these specimens revealed that consıderable deformation had been introduced during the mechanical polıshing step Subsequent specımens were carefully cast in epoxy, cut with the wafering saw, and the epoxy dissolved in methylene chloride without metallographıc polıshıng

Specımens were thınned for TEM examınatıon electrolytıcally by a two step method sımılar to that developed by DuBose and Stiegler (54) This method consists of first "dimpling" the specimens on both sides with a $10 \mathrm{~mm}$ jet of electrolyte such that a center thickness of $005-0076 \mathrm{~mm}$ remains Secondly, the thin sections required for TEM are obtained by 
electropolishing the dimpled wafers in a standard electropolishing cell until preforation occurs. Table 2 lists the solutions and parameters that were utilized to produce the specimens. Etching was encountered during electropolishing if water was allowed to condense in the solutions. To avoid condensation, electropolishing was carried out in a room controlled to a $10 \%$ relative humidity.

Table 2

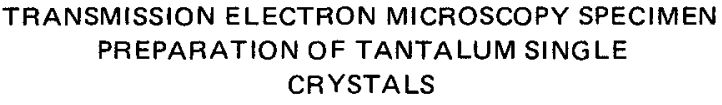

\begin{tabular}{|c|c|c|c|}
\hline Operation & $\begin{array}{c}\text { Solution } \\
\text { Composition } \\
\text { (vol \%) }\end{array}$ & Conditions & Remarks \\
\hline Jet Polishing & $\begin{array}{l}2 \mathrm{HF} \\
18 \mathrm{H}_{2} \mathrm{SO}_{4} \\
80 \mathrm{CH}_{3} \mathrm{OH}\end{array}$ & $180 \mathrm{~mA}$ at $300 \mathrm{~V}$ & Cool to $<10^{\circ} \mathrm{C}$. \\
\hline Electropolishing & $\begin{array}{l}10 \mathrm{HF} \\
1 \mathrm{HClO}_{4} \\
89 \mathrm{CH}_{3} \mathrm{OH} \\
\text { (absolute) }\end{array}$ & $26 \mathrm{~mA}$ at $20 \mathrm{~V}$ & $\begin{array}{l}\text { Cool to }<-40^{\circ} \mathrm{C} \text {; } \\
\text { wash in cold } \\
\text { absolute } \mathrm{CH}_{3} \mathrm{OH} \text {. }\end{array}$ \\
\hline
\end{tabular}

Though practically all of the foils were examined in a Hitachi HU200 electron microscope, some specimens were observed in a Hitachi HU650 microscope. Both microscopes were equipped with a rotating and tilting stage for precise alignment of the foils and a decontamination device to keep specimen oxidation to a minimum.

Dislocation Cell Size Measurements - Using a felt tip marker, the midpoint of the dislocation cell walls was delineated on bright-field micrographs. These micrographs were then analyzed using a Hewlett-Packard 9830 computer and digitizer. Essentially, the digitizer was used as an electronic planimeter in which the enclosed area of each cell was continously measured. This information was retained on magnetic tape and later plotted as a histogram and distribution function.

Dislocation Density Measurements - No cellular structure was observed for the (001) [1 $\overline{10}]$ crystal; therefore, measurements of dislocation density were performed. Dislocations were imaged using $\{200\}$-type relfections which will give $\underline{g} \cdot \underline{b} \neq 0$ for all $\langle 111\rangle$-type dislocations. $(55,56)$ Bright-field micrographs of the specimen were placed in the scanner of an image-anaiyzing microscope (Image Analyzing Computers, Ltd), contrast adjusted to differentiate the dislocations, and their area fraction (total line length) measured. Using this method, the projected line length of dislocations was obtained and corrected to total line length by multiplying by $4 / \pi$. (55) Foil thickness was determined by counting the thickness fringes from the edge of the perforated hole and using the extinction distance, calculated by the formulae of Hirsch (55) corrected for relativistic effects, which gave a thickness of approximately $1500 \AA$ for most foils. The actual dislocation density, $\rho$ is given by:

$$
\rho=\left(\frac{4}{\pi}\right) \Lambda /(\mathrm{At})
$$


where
$\Lambda$ represents the projected line length,
A the area of the micrographs, and
t the foll thickness

Several sources of error are possible in such an analysis, and a few of them will be discussed Perhaps the most serious error is the movement of dislocations from the foll as material is removed during thinning Another source of error is the possibility that dislocations from the reaction $a / 2\langle 111\rangle+a / 2\langle 111\rangle \rightarrow$ a $<100\rangle$ will be out of contrast For a given [200] diffraction vector, approximately $1 / 3$ of the possible $a<100>$ dislocations will be out of contrast $\overline{(g} \cdot \bar{b}=0)$ However, the fraction of dislocations with a $<100>$ Burgers vector is expected to be quite small, thus causing only a small error (56) Other minor errors are expected from the dislocation overlap and resolution of the dislocation line width Brandon and Komen $(57)$ have estımated the error in the last two factors to be about $40 \%$ for densities greater than $33 \times 10^{9} \mathrm{~cm} / \mathrm{cm}^{3}$ Consideration of the combined errors in the dislocation density analysis indicates that a maximum error of $50 \%$ could arise from physical measurements This method is not accurate for densities greater than $5 \times 10^{10} \mathrm{~cm} / \mathrm{cm}^{3}$

\section{RESULTS}

\section{Effects of Rolling Deformation}

All crystals were rolled unidirectionally at room temperature to a total thickness reduction of $80 \%$ Figure 9 shows the extent of lateral widening which the crystals underwent during rolling In addition, Figure 10 illustrates the increase in microhardness of the crystals as they were rolled to the final $80 \%$ reduction Table 3 lists the integral breadth of the varıous crystals compared to an unrolled crystal standard of the same orientation

(001)[110] Crystal - As is evident from Figures 9 and 10, the (001) crystal increased very little in etther transverse strain or hardness when compared to the other orientations. Much of the change occurred in the first $20 \%$ of the rolling reduction The increase in integral breadth of only $197 \%$ also substantiated that the crystal was able to undergo considerable strain with a very small increase in stored energy Figure 11 is a (200) pole figure of the deformed crystal which indicated essentially no change in crystal orientation and very little orientation spread $X$-ray intensity from this crystal was such that the incident-beam intensity had to be reduced considerably to avoid overloading the counting circuitry Transmission electron microscopy (TEM) of the deformed crystal, Figure 12, revealed that the microstructure consisted of a fairly uniform distribution of highly tangled dislocations, with an apparently low density of small loops Measured dislocation density of the crystal was $28 \times 10^{10} \mathrm{~cm} / \mathrm{cm}^{3}$ Selected area diffraction (SAD) patterns indicated that the foil normal is $(001)$, with essentially no rotation or splitting of diffraction spots withın areas of several square $\mu \mathrm{m}$ (Inset of Figure 12) Optical microscopy of deformed crystals of the $(001)$ orientation falled to reveal any structural features whatsoever 



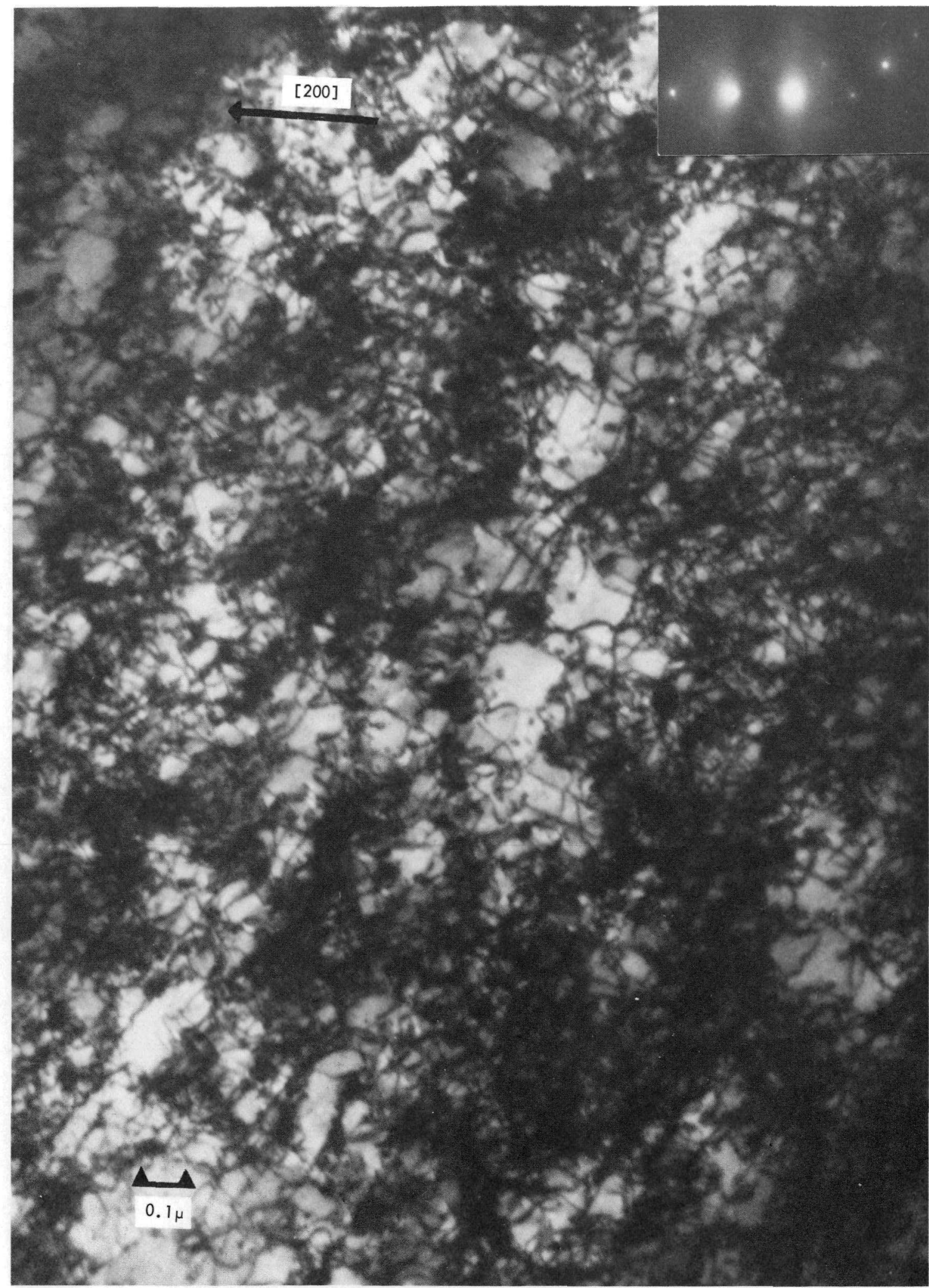

Figure 12. ELECTRON MICROSTRUCTURE OF THE DEFORMED (001) [1 $\overline{10}]$ CRYSTAL. $(\bar{g}=[002] ;$ [001] Zone) 
(112)[110] Crystal- Upon rolling, hardness of the (112) crystal increased rapidly initially and then increased more slowly to a final hardness $29 \%$ higher than that of the 1001$)$ crystal. Initial examination of the width strain showed a rather large value of $12.5 \%$. In addition to transverse normal strain, both the (112) and (111) crystals deformed by transverse shear strains. An illustration of the shape change is given in Figure 13, together with the strains involved and definition of terms. During rolling, the value, $\left(w-y_{0}\right) / y_{0}$, was measured and is plotted in Figure 9. After correcting for shear strain, the (112) crystal had a transverse normal strain of $3.3 \%(0.033)$.

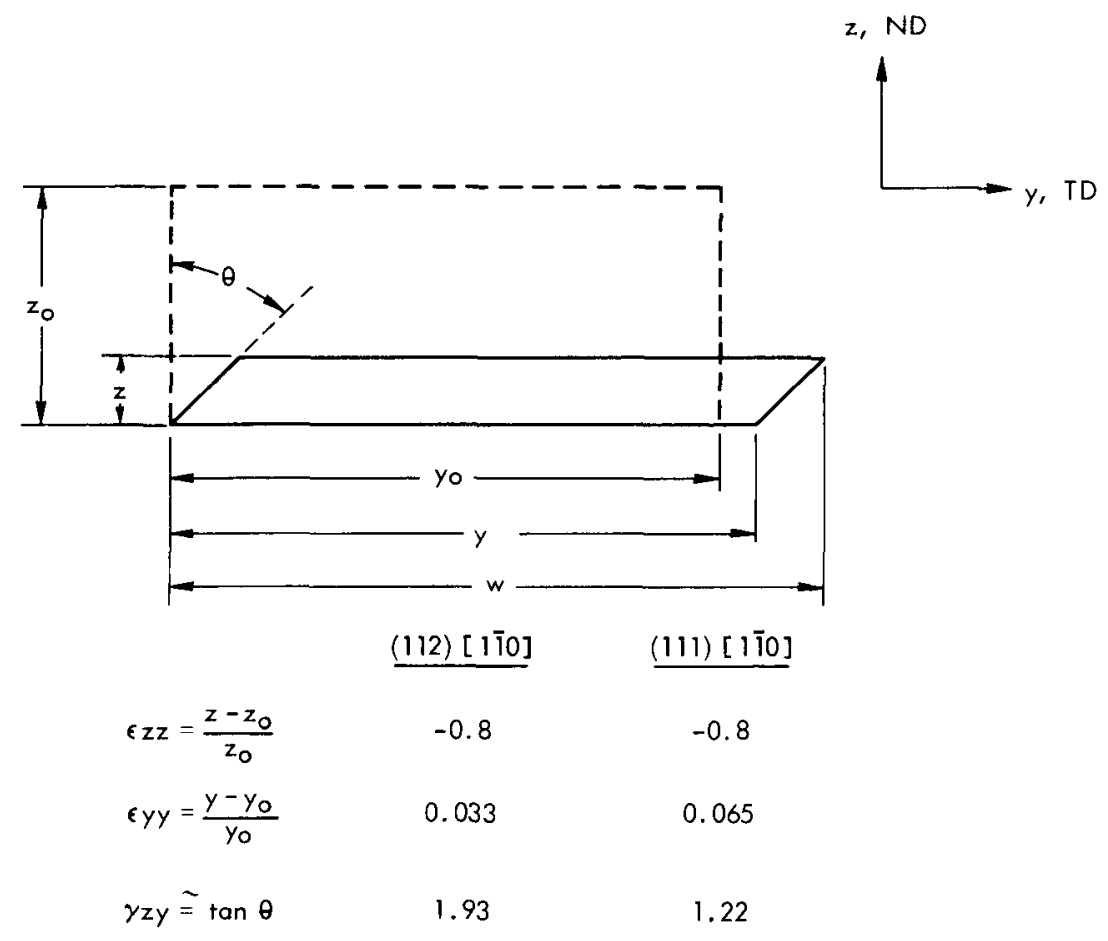

Figure 13. ILLUSTRATION OF THE CROSS-SECTIONAL SHAPE CHANGE OF (112) AND (111) CRYSTALS.

In agreement with the hardness data, the integral breadth of the rolled (112) crystal was larger than the integral breadth of the (001) crystal. The (200) pole figure, shown in Figure 14, shows that the crystal maintained its initial orientation during rolling, with very little spread in orientation. A comparison of Figures 11 and 14 shows that the 0.5 random contour of the (200) pole figure of the (112) crystal subtended a larger solid angle than the same contour of the (001) crystal, which demonstrates that the (112) crystal contained more orientation spread.

TEM examination of the rolled crystal, Figure 15, revealed that the microstructure consisted of very dense tangles of dislocations, with an apparently higher incidence of jogs and loops than was observed in the (001) crystal. No observations of distinct dislocation cell formations were made on any (112) crystal which was only deformed. From a comparison of Figures 12 and 15 it would be concluded that the (112) crystal had a lower overal! dislocation density than the (001). However, this was not felt to be the case, and at least two explanations can be given for this apparent discrepancy. 


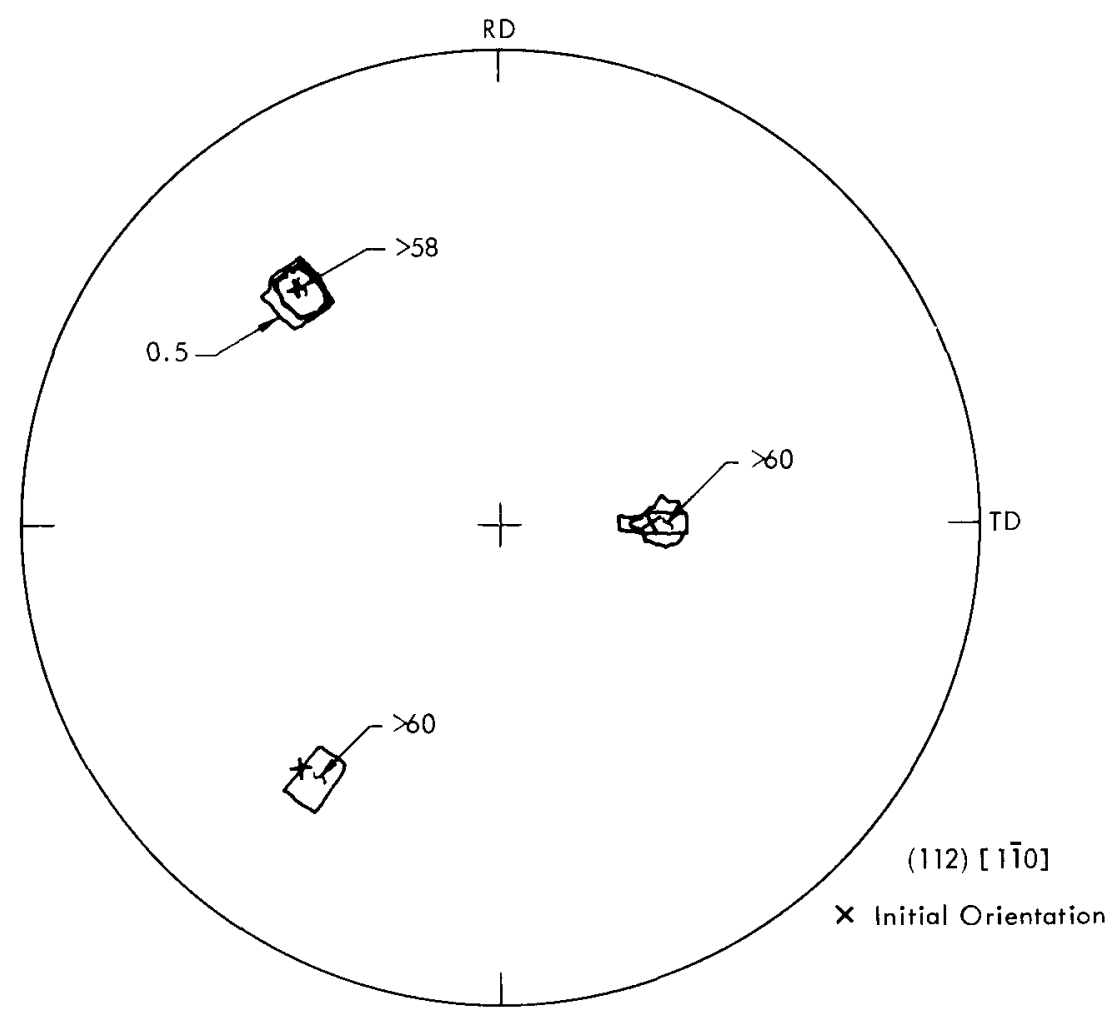

Figure 14. (200) POLE FIGURE OF THE (112)[110] CRYSTAL THAT WAS ROLLED TO 80 PERCENT REDUCTION IN THICKNESS.

First, the (112), (111), and (110) crystals contained increasing amounts of internal strain, as is evident from the integral breadth and hardness data. Scattering of electrons by these lattice imperfections and the high electron absorption of tantalum limited observation of the rolled crystals to areas which were quite thin. Thus, dislocation losses during thinning might have contributed to a lower apparent dislocation density. Second, diffraction conditions in the $\langle 111\rangle$ zones precluded the observation of all possible dislocations simultaneously.

In order to allow for the observation of a microstructure which would be representative of the rolled condition, crystals of the (112) orientation were recovered for four hours at $400^{\circ} \mathrm{C}$. It was felt that, at $400^{\circ} \mathrm{C}$, no major microstructural change would occur, yet some recovery and stress relieving would facilitate specimen thinning and observation of more foil area in electron transmission.

During observation of (112) crystals that were annealed for four hours at $400^{\circ} \mathrm{C}$, slip bands were observed when crystals were tilted to bring the [111] parallel to the foil normal. Figure 16 shows the slip bands and the only observation of a clear tendency for dislocation cell formation in this crystal. Similar areas, Figure 17, observed with an [001] foil normal do not show slip bands. The early stages of cell formation observed in these specimens may have been due to the low-temperature annealing treatment. SAD of the (112) crystal (inset of Figure 16) indicated that the $\{110\}$ planes were rotated five degrees around the zone axis of the diffraction patterns, with no splitting of reflections. Optical examination showed the rolled crystal to be featureless. 


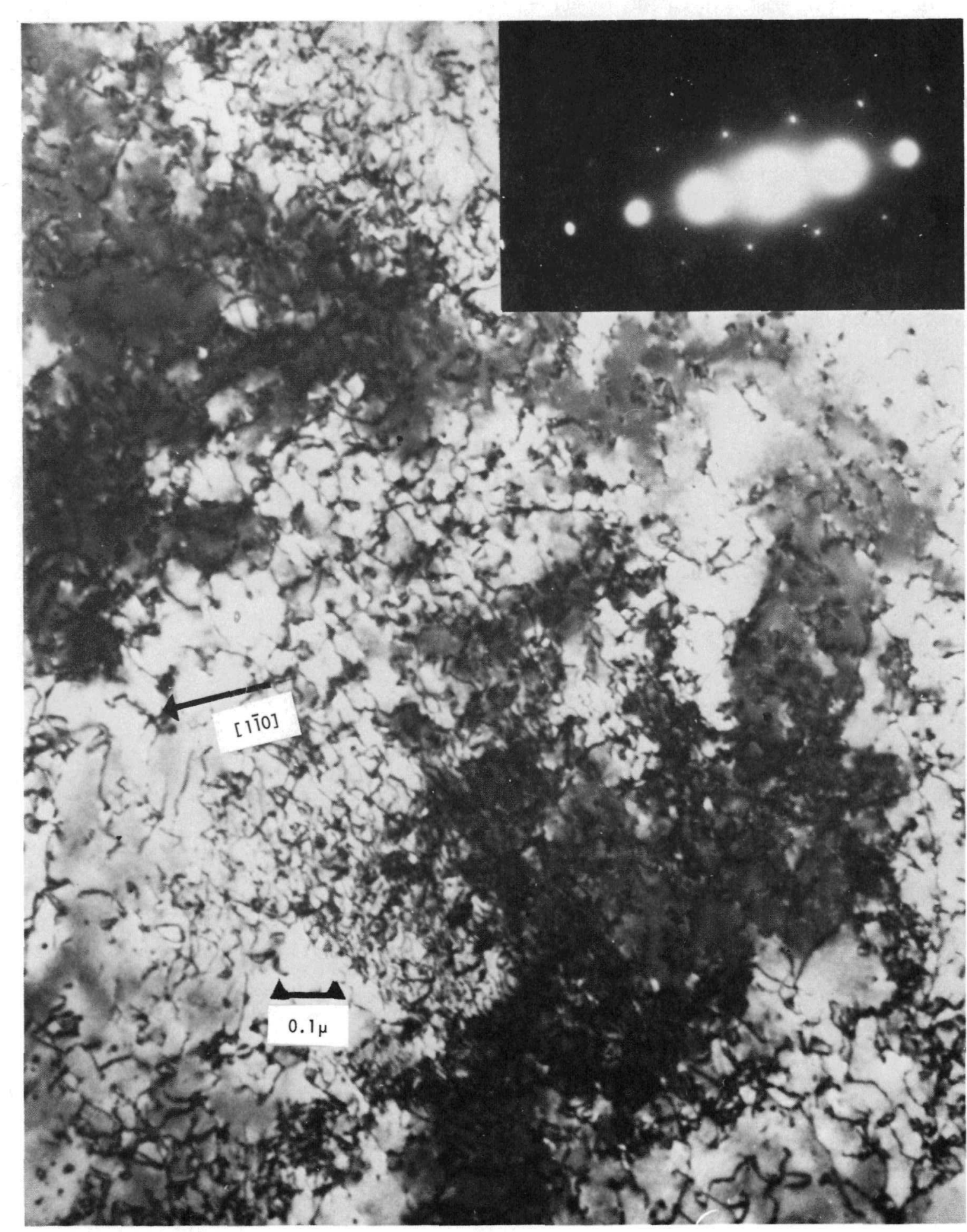

Figure 15. MICROSTRUCTURE OF THE DEFORMED (112) $\mid(1 \overline{1} 0]$ CRYSTAL. $\bar{g}=[1 \overline{1} 0]$; [111] Zonel

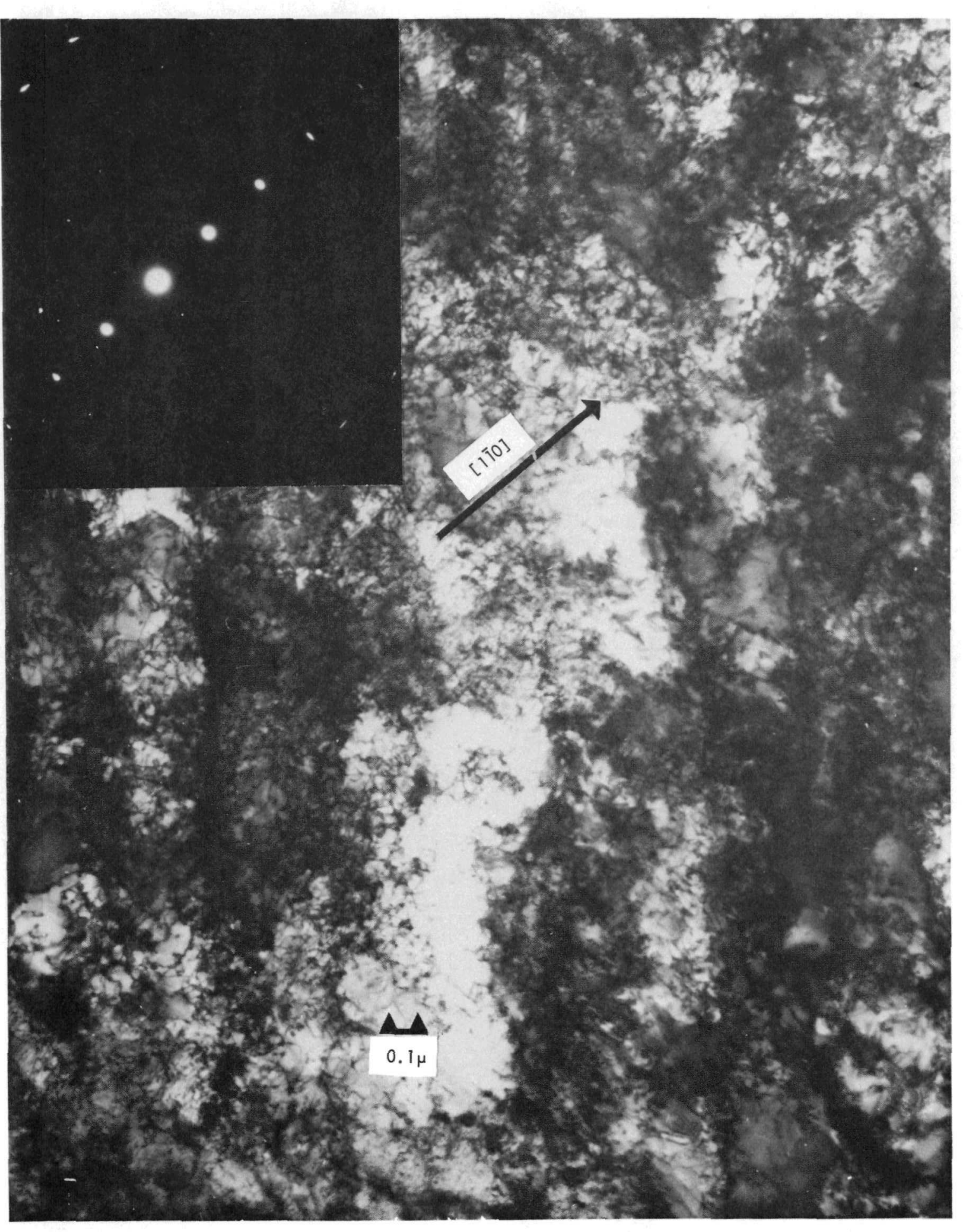

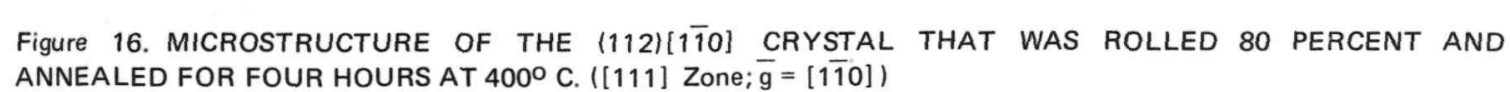

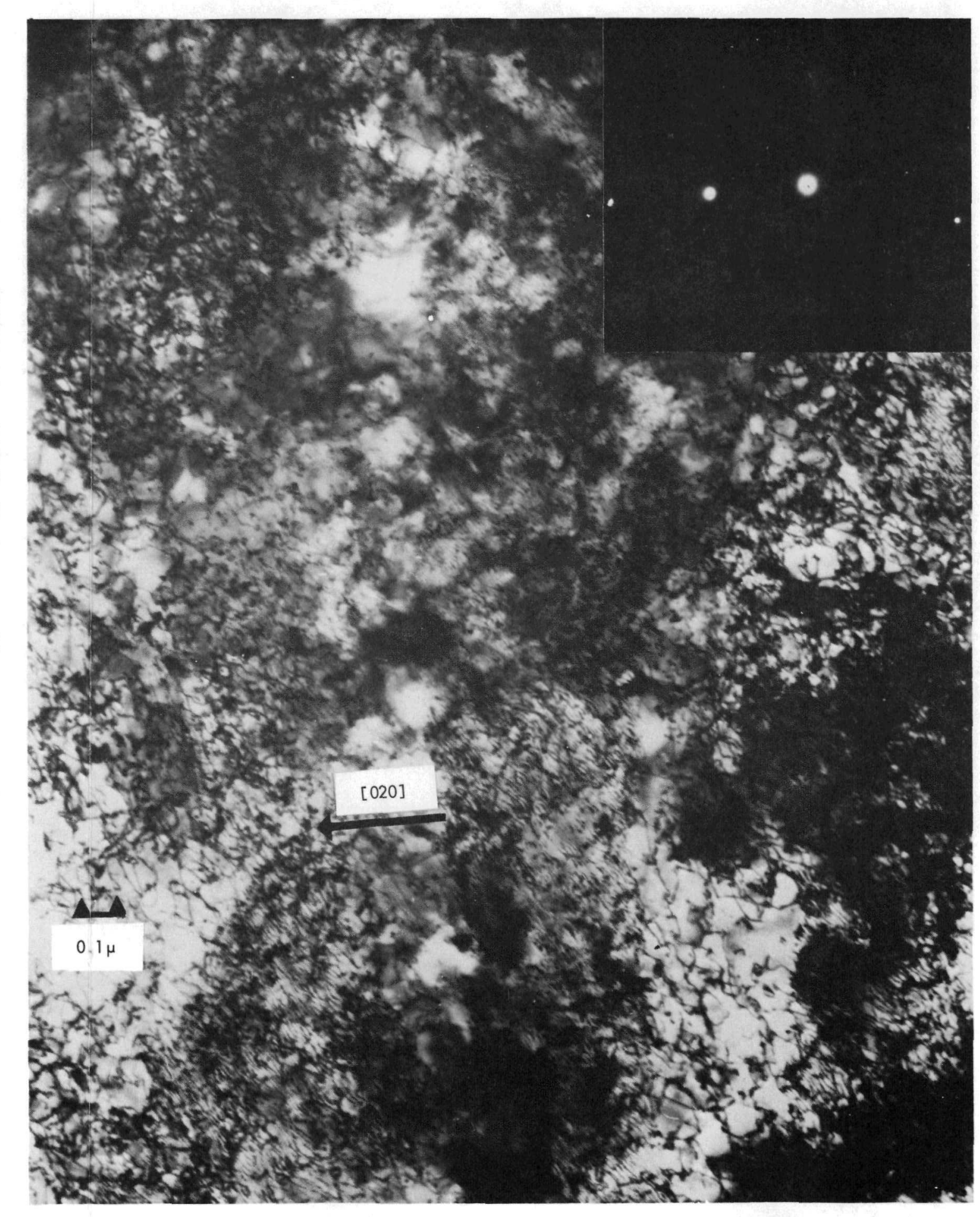

Figure 17. MICROSTRUCTURE OF THE (112)!11010] CRYSTAL THAT WAS ROLLED 80 PERCENT AND 
(111)[110] Crystal - The (111) crystal widened by both transverse shear and normal strains. After correcting for shear offset, the (111) crystal had a normal transverse strain of 0.065 , which is greater than either the (001) or (112) crystals. Up to about $40 \%$ reduction the hardness (Figure 10) of the (111) crystal increased quite rapidly. Subsequent rolling to $80 \%$ reduction increased the hardness to $205 \mathrm{DPH}$, demonstrating a decrease in work hardening as the crystal was strained.

Integral breadth measurements demonstrated (Table 3) that the (111) crystal contained more strain and particle-size broadening than either the (001) or (112) crystal. Additionally, pole figures, such as Figure 18, showed that the orientation spread within the crystal was much greater than for the (001) and (112) crystals. This orientation spread appeared to be related to the fact that the crystal is unstable during rolling; ie, the crystal was rotated about the indicated axis 10 degrees from the original orientation toward the (112) $[1 \overline{1} 0]$.

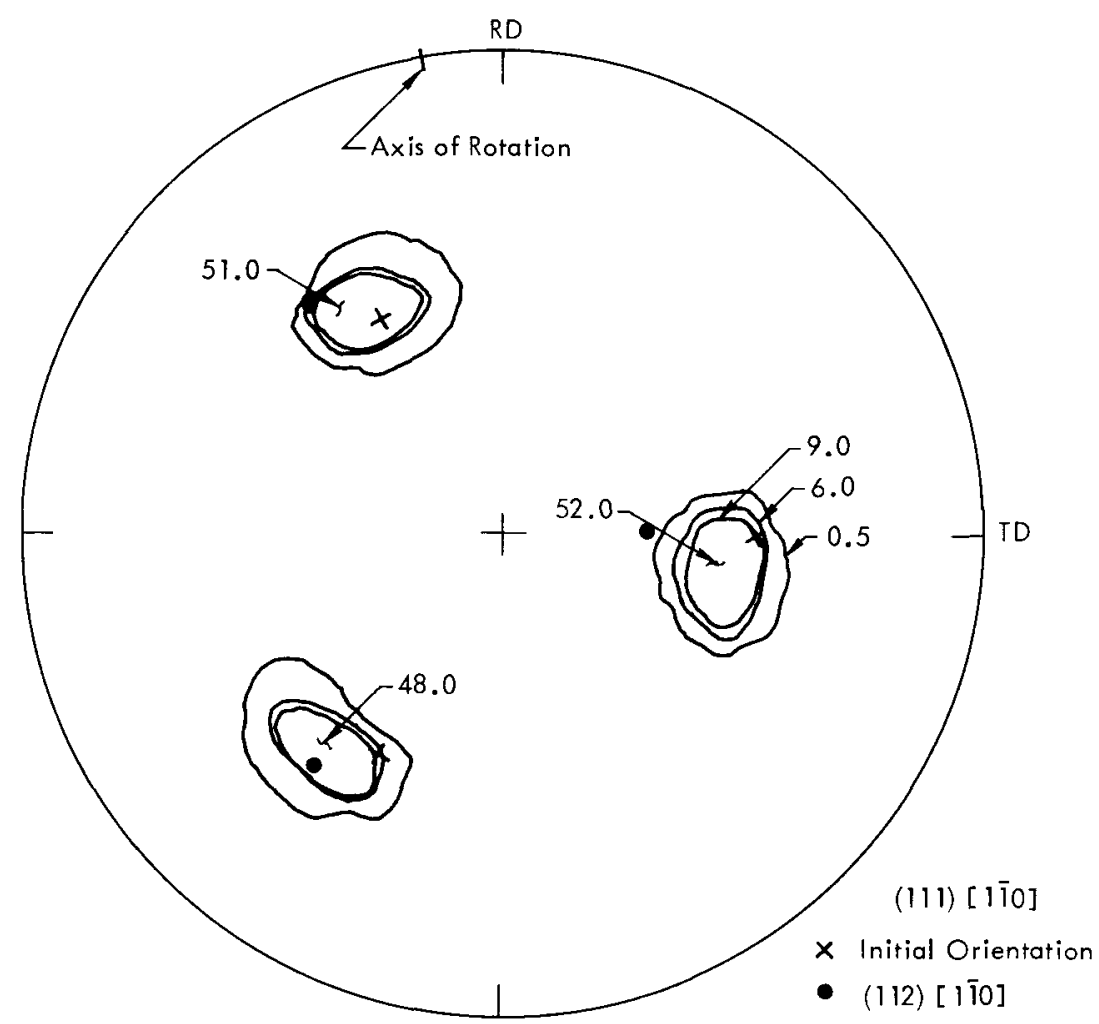

Figure 18. (200) POLE FIGURE OF THE (111)[110] CRYSTAL, INDICATING AN AXIS OF TEN-DEGREE ROTATION.

Examination of a rolled (111) crystal by TEM indicated a very definite dislocation cell structure, as seen in Figure 19. Areas which were obvious heavy concentrations of tangled dislocations surround areas which had a much lower concentration of dislocations. Though a limited number of areas could be examined in the rolled condition, a measurement of the dislocation cell areas was made. Figure 20(a) shows the results of these measurements in the form of a histogram which has been fitted with a normal distribution curve. The number of observations, $N$, the calculated mean value, $\bar{x}$, and the calculated variance, $s^{2}$, are shown 


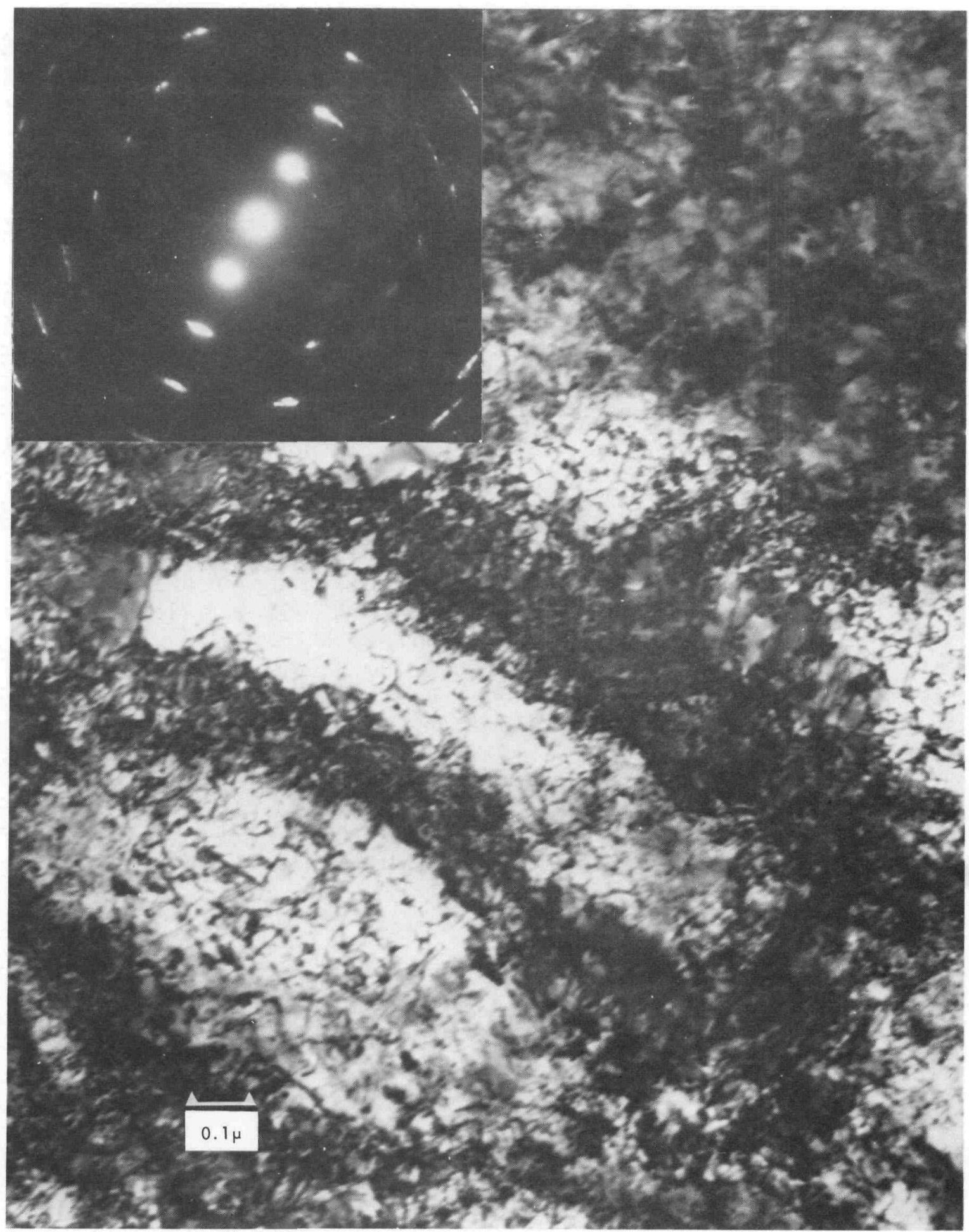

$90,000 x$

Figure 19. MICROSTRUCTURE OF THE (111)[11̄0] CRYSTAL THAT WAS ROLLED TO 80 PERCENT REDUCTION IN THICKNESS. ([112] Zone) 
above the histograms. It is apparent that the data were not normally distributed; and, thus, normal, parametric statistics could not be used to compare the mean values of the two distributions. However, the data could be transformed by taking the natural logarithm and replotting, as indicated in Figure 20 (b). A test of these data indicated that they were normally distributed. The antilog of the mean of this distribution is the geometric mean, $\bar{x} G$, of the real population, which is defined as: $\bar{x}_{G}=\left(x_{1} \cdot x_{2} \cdot x_{3} \ldots x_{n}\right)^{1 / n}$. Because of the relatively small numbers of observations obtained from the rolled crystal, measurements were also made on crystals annealed for four hours at $400^{\circ} \mathrm{C}$, as previously described. Histograms of the cell areas and the natural logarithm of the cell areas are given in Figure 21 , which again shows the normality of the logarithm of the data.

A statistical test of the mean values of the log normal data of Figures 20 and 21 demonstrated that the mean values of the two sets of data were not significantly different at the $95 \%$ confidence level. This test also signified that the arithmetic mean values of the original data were not significantly different at the $95 \%$ confidence level. Thus, a starting-cell area size from the weighted average of the geometric means of the two sets of data of $0.1 \mu \mathrm{m}^{2}$ seems reasonable.

Examination of the microstructure of the crystal that was annealed for four hours at $400^{\circ} \mathrm{C}$ (Figure 22), indicated that a decrease in the internal cell dislocation density has occurred along with sharpening and polygonization of the cell boundaries. A noticeable feature of Figure 22 is an elongation of the cells. Careful analysis of such micrographs revealed that the direction of elongation was transverse to the rolling direction. SAD patterns of the (111) crystal (inset of Figure 19) showed a maximum rotation about the rolling plane normal of 18 - 20 degrees, which agreed quite well with the pole-figure results. Optical examination of the (111) crystal revealed no significant microstructural features.

(110) [110] Crystal - During the course of rolling and annealing a number of crystals of this orientation, it became evident that these crystals were extremely unstable during rolling and deformed in a very unexpected manner. Crystals rolled under what were apparently identical conditions produced widely different final orientations, as determined by a pole-figure analysis. Considerable orientation variation existed within a deformed crystal and often varied from the top to bottom rolling surfaces. It should be explained at this point that "ideal" single-crystal orientations given for rolled (110)[110] crystals were based on peak intensities from the (200), (110), (222), and (112) pole figures. Obviously, in many cases, wide ranges of orientation existed around the "ideal" orientations. In addition, specific crystallographic indices may have been given an orientation, though equivalent indices would have satisfactorily described the orientation. Separate experiments were run on individual crystals to characterize deformation band formation and orientation change during rolling as well as the effects of the rolling conditions on the final orientation. Each of these experiments will be discussed separately. Two crystals were selected and characterized for further recrystallization studies, which will be described in the subsections to follow.

Width, Hardness, and Integral Breadth Measurements - The width of the (110) crystal (Figure 9) increased rapidly to $20 \%$ reduction and then increased less rapidly from 20 to $60 \%$ reduction. From 60 to $80 \%$ reduction, there appeared to be a decrease in the rate of widening. The hardness of the crystal (Figure 10) increased rapidly to $20 \%$ and then increased in a more or less linear manner to $80 \%$ reduction. 


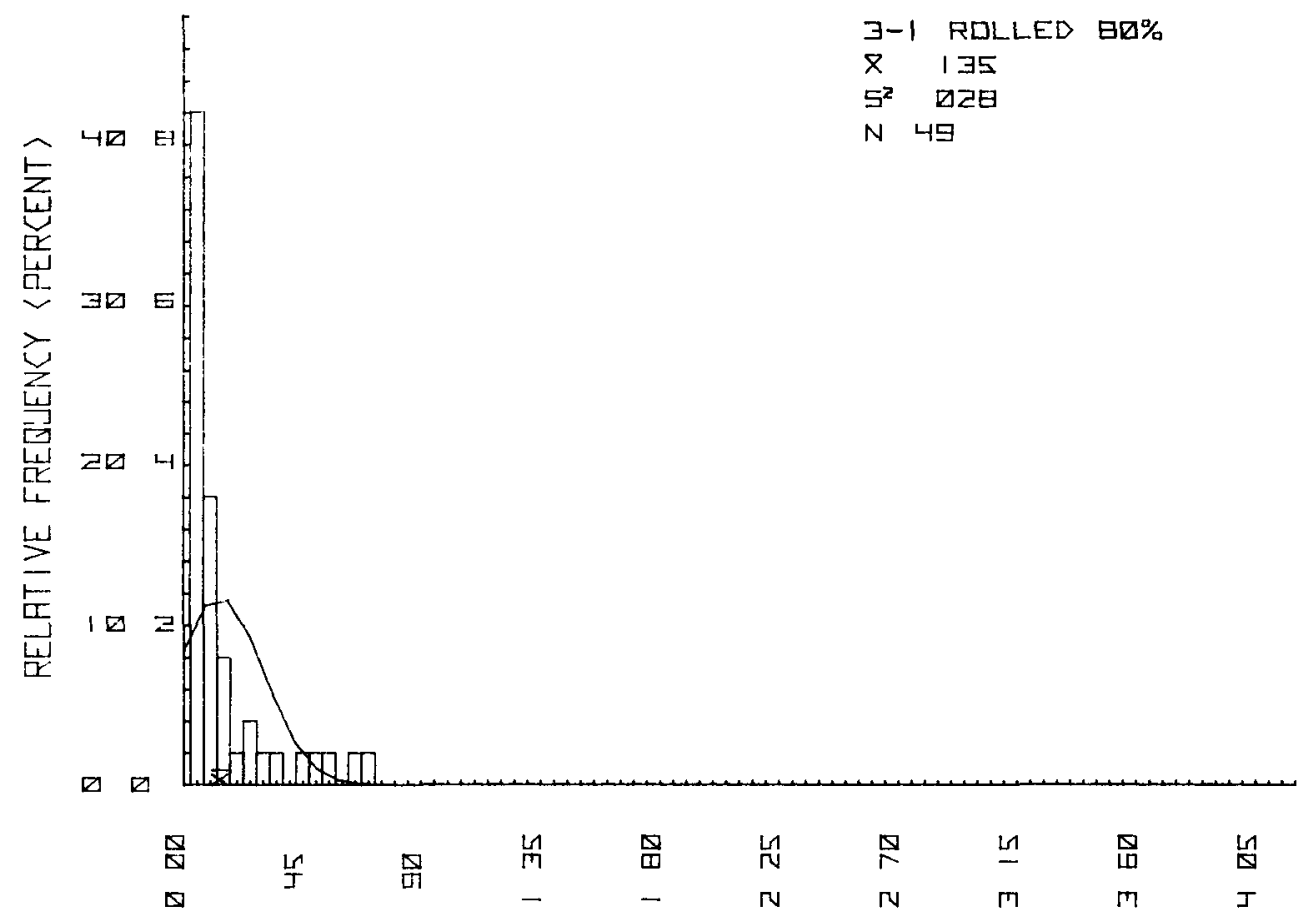

CELL AREA 〈SQURRE MICRDMETERS>

(a) H stogram of the Cell Areo

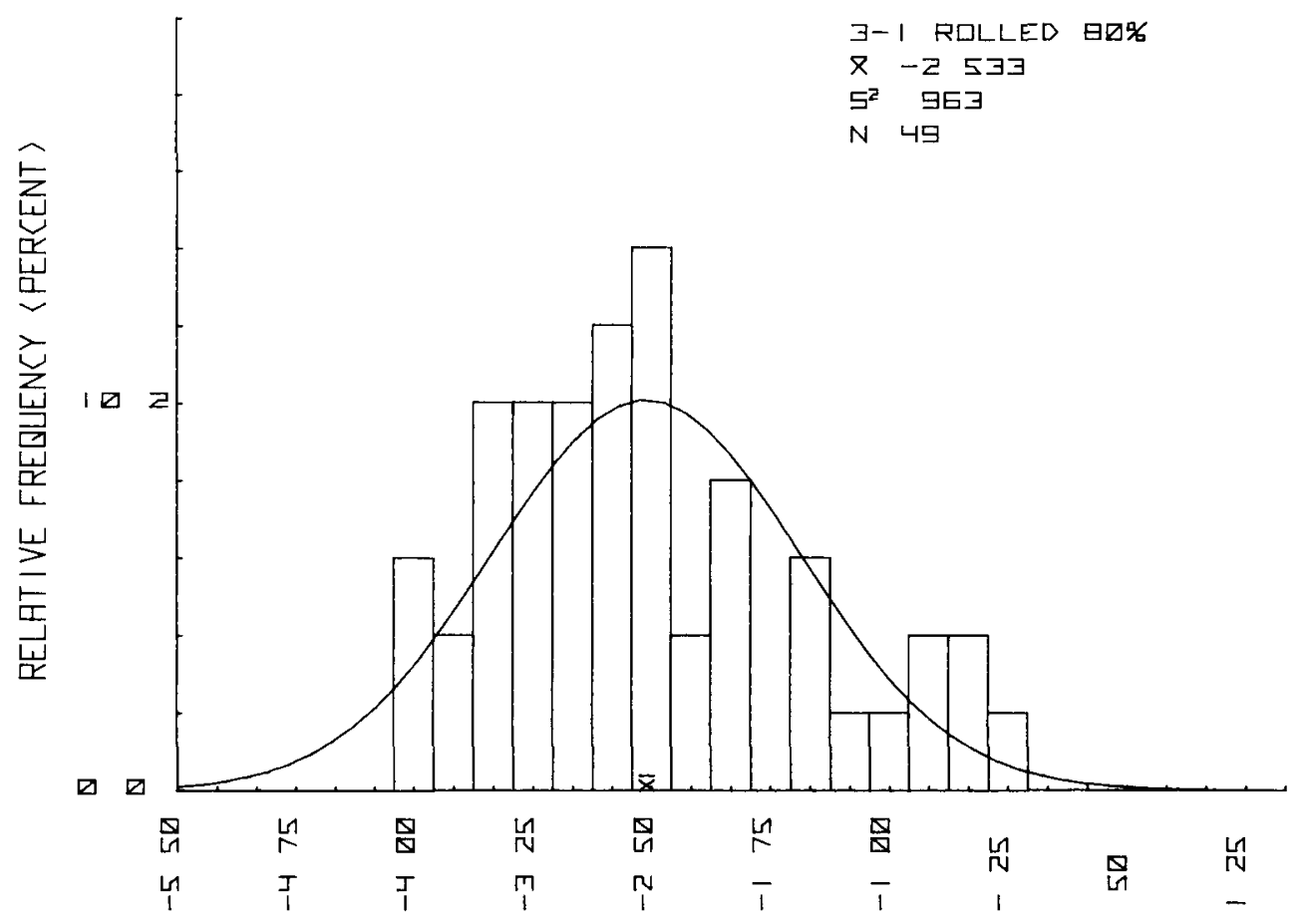

LN CELL FREA >

(b) Histogram of the Natural Logarithm of the Cell Area $\left(\bar{x}_{G} \quad 008 \mathrm{~mm}^{2}\right.$ )

Figure 20. HISTOGRAMS OF THE CELL-AREA MEASUREMENTS FROM THE (111)[1 $\overline{10}]$ CRYSTAL AFTER ROLLING TO AN 80 PERCENT REDUCTION. 


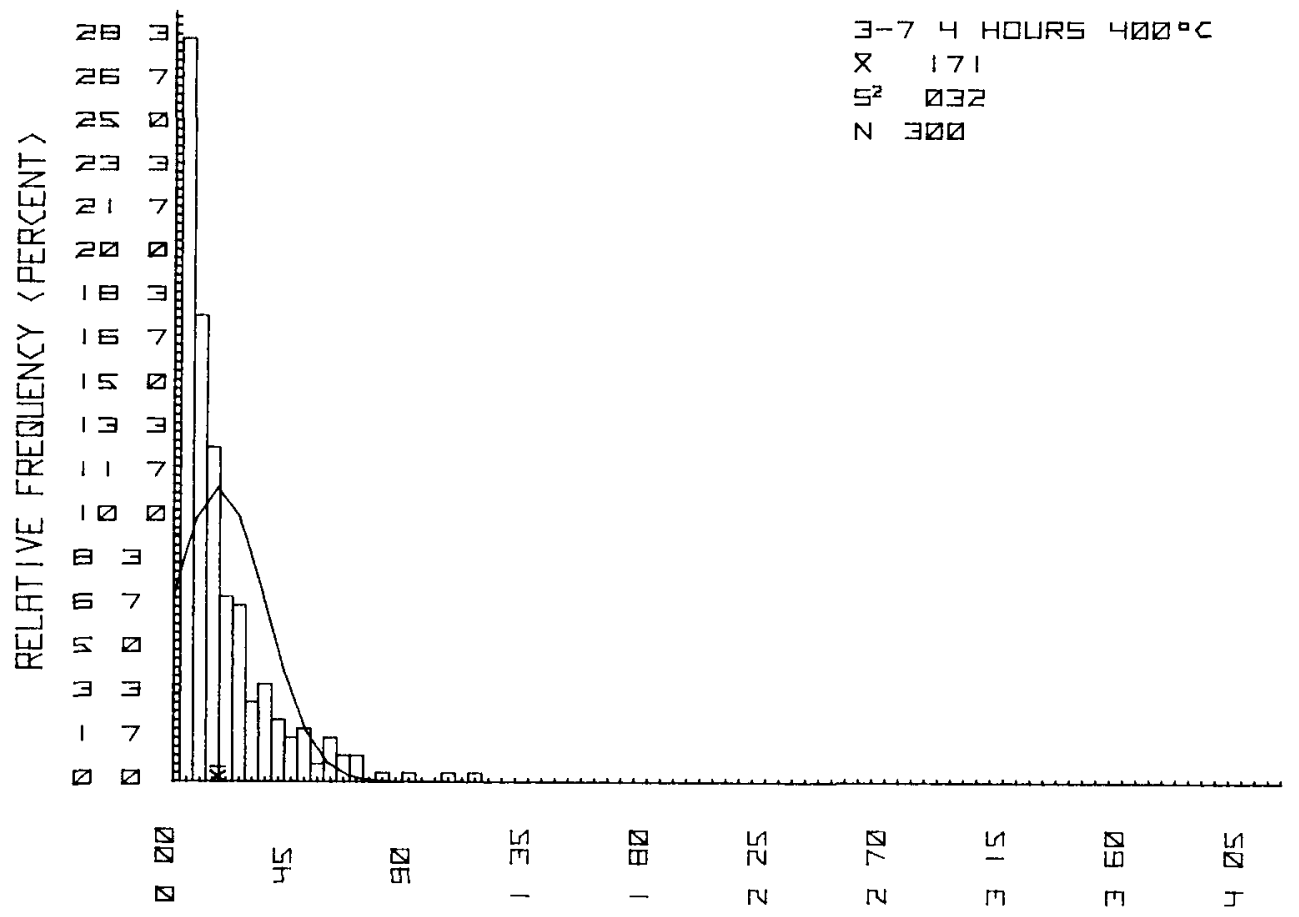

$$
\begin{array}{ll}
\exists-7 & 4 \text { HDURS } 4 \text { HOD } \\
8 & 171
\end{array}
$$$$
\text { ¿ } 2 \exists \exists \text { 列 }
$$$$
\text { I }
$$$$
1 \text { 日 }
$$$$
\text { ¿ } 157
$$

10

E $匚 7$

$5 \square$

$\exists \exists$

17

$\square$

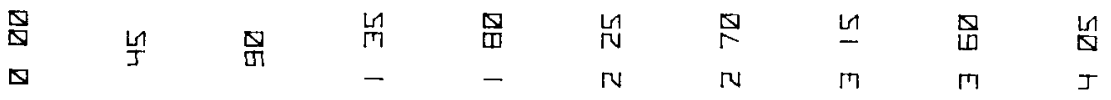

(a) Histogram of the Cell Area

CELL AREA 〈SQUIARE MI CROMETERS >

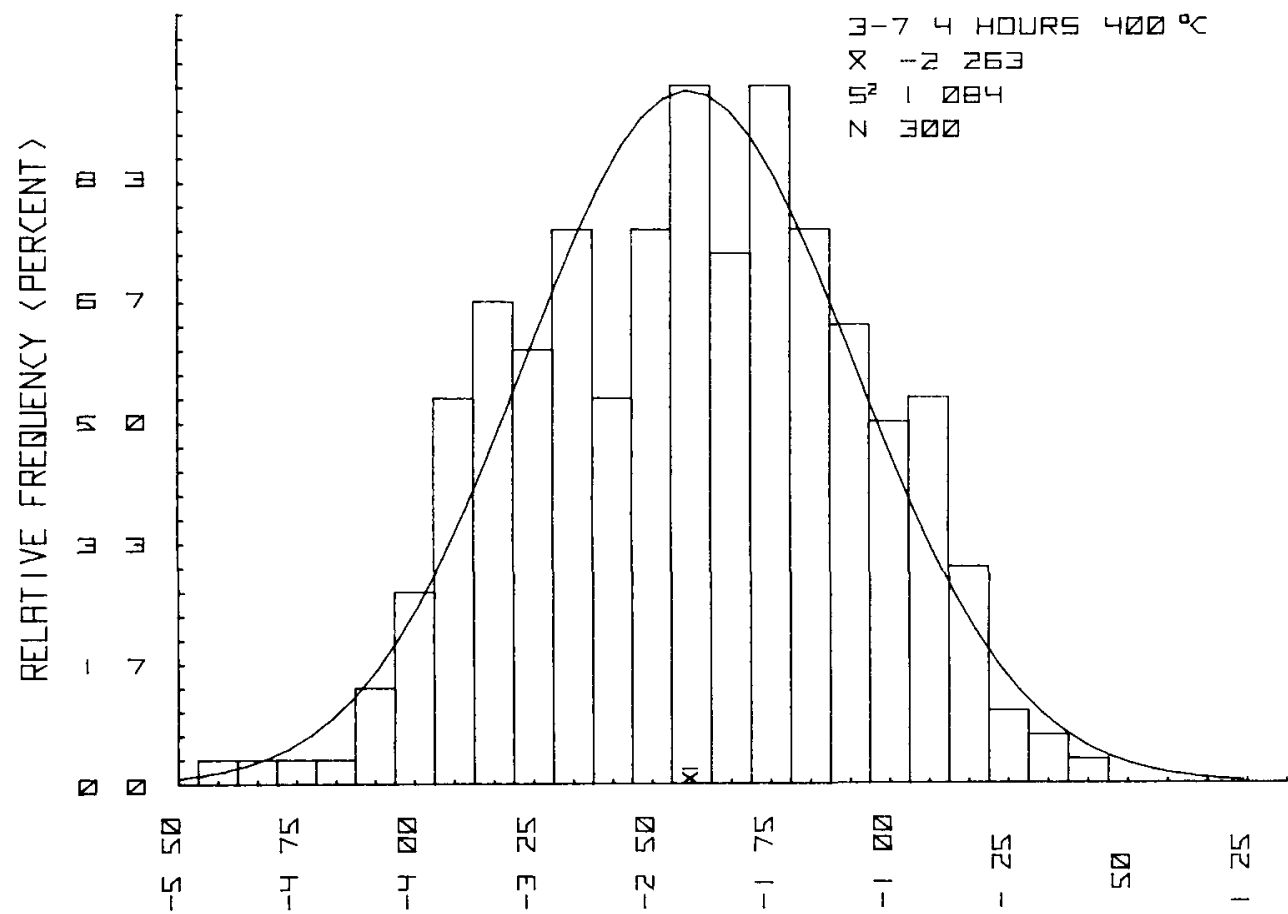

$L N\langle C E L L$ AREA >

(b) Histogram of the Natural Logarithm of the Cell Areo $\left.{ }^{\left({ }_{x}\right.} G \quad 01 \mu \mathrm{m}^{2}\right)$

FIgure 21. HISTOGRAMS OF THE CELL-AREA MEASUREMENTS OF THE (111)[110] CRYSTAL, ROLLED 80 PERCENT AND RECOVERED AFTER FOUR HOURS AT $400^{\circ} \mathrm{C}$. 


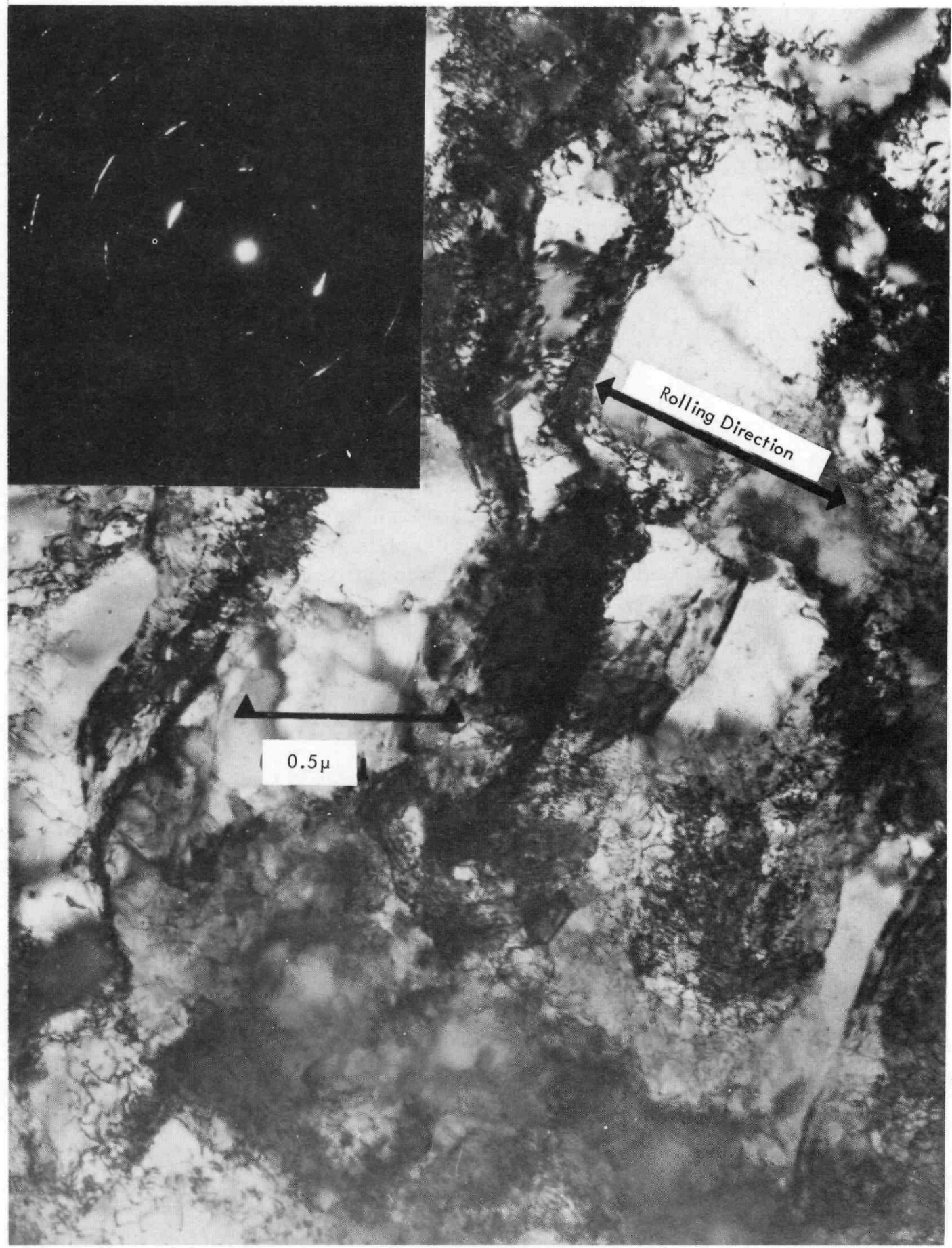

Figure 22. MICROSTRUCTURE OF THE (111) CRYSTAL THAT WAS ROLLED 80 PERCENT AND ANNEALED FOR FOUR HOURS AT $400^{\circ} \mathrm{C}$.

Unlike the other orientations, this crystal showed no decrease in work hardening with increased reduction. One crystal (4-8) reoriented upon rolling such that the $\{111\}$ planes were parallel to the rolling plane. Thus, the integral breadth of the (222) reflection was measured and compared to the same unrolled standard used for 
the (111) crystal. Not only was the (110) crystal widened and strain hardened more than any other orientation, but (as Table 3 indicates) the integral breadth increased more than that of any crystal.

Optical Observations - One crystal (4-10) was rolled incrementally and both top and bottom sections mounted for metallography at 20,40,60, and $80 \%$ reduction. Figure 23 shows both the top and cross sections at each reduction, photographed in polarized light. An examination of the crystal cross sections at all reductions revealed the following features:

1. At $20 \%$ reduction, very sharp deformation bands formed near the crystal edges, and these bands persisted to $80 \%$ reduction.

2. Close inspection of the cross sections revealed some deformation banding in the upper portion of the crystal at $20 \%$.

3. At $40 \%$ reduction, a layering effect in addition to banding appeared to develop in a direction perpendicular to the rolling plane; ie, alternate layers of light and dark contrast with a notable absence of large macroscopic bands in the lower portion of the crystal, which condition persisted to $80 \%$ reduction.

4. At $40 \%$, the individual deformation bands were of alternate contrast, indicating perhaps substantial orientation changes between bands.

Differences in microstructure from top to bottom are believed related to the variation in width strain noted at the edges of the crystal. An edge instability developed at $20 \%$ and continued such that, at $80 \%$ reduction, a "double-barrel" effect developed at the edges, with the bottom surface having greater transverse strain (widening) than the top surface.

The following observations were made on the crystal top surface:

1. At $20 \%$ reduction, the only discernible features were bands near the edges.

2. As straining increased to $40 \%$, a fine structure developed in the top surface which could have been deformation-band boundaries viewed in a different plane.

3. At $60 \%$, these features persisted and appeared to widen.

4. Further straining to $80 \%$ produced a much different structure in the top surface, with definite bands formed nearly parallel to the rolling direction. Transverse within these bands, and more clearly defined in Figure 24, were smaller secondary deformation bands.

5. Secondary banding was mostly restricted to areas near the crystal edges, which perhaps meant that inhomogeneous transverse strains were concentrated near the crystal edges. (58) 

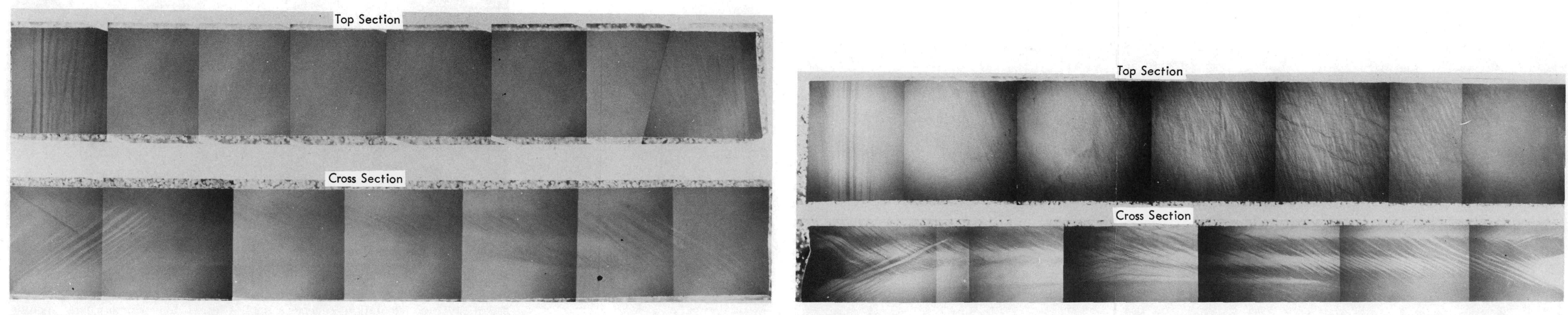

(a) At $20 \%$ Reduction.

(b) At 40\% Reduction.
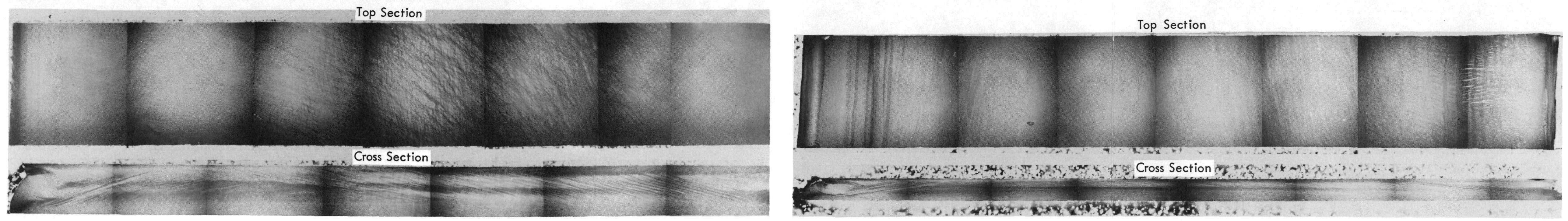

(c) At $60 \%$ Reduction.

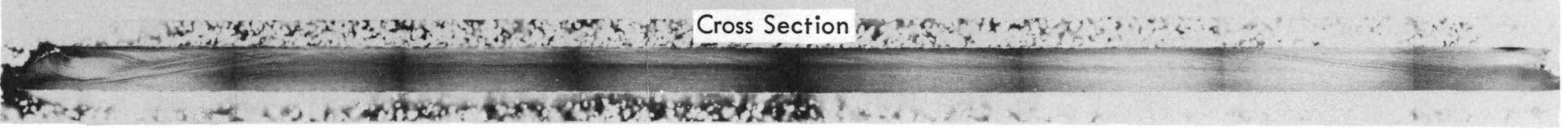

(d) At 80\% Reduction.

Figure 23. OPTICAL MICROSTRUCTURE OF THE TOP AND CROSS SECTIONS OF CRYSTAL 4-10 THAT WERE ROLLED TO FOUR DIFFERENT REDUCTIONS.

(Polarized Light; 14.7X) 


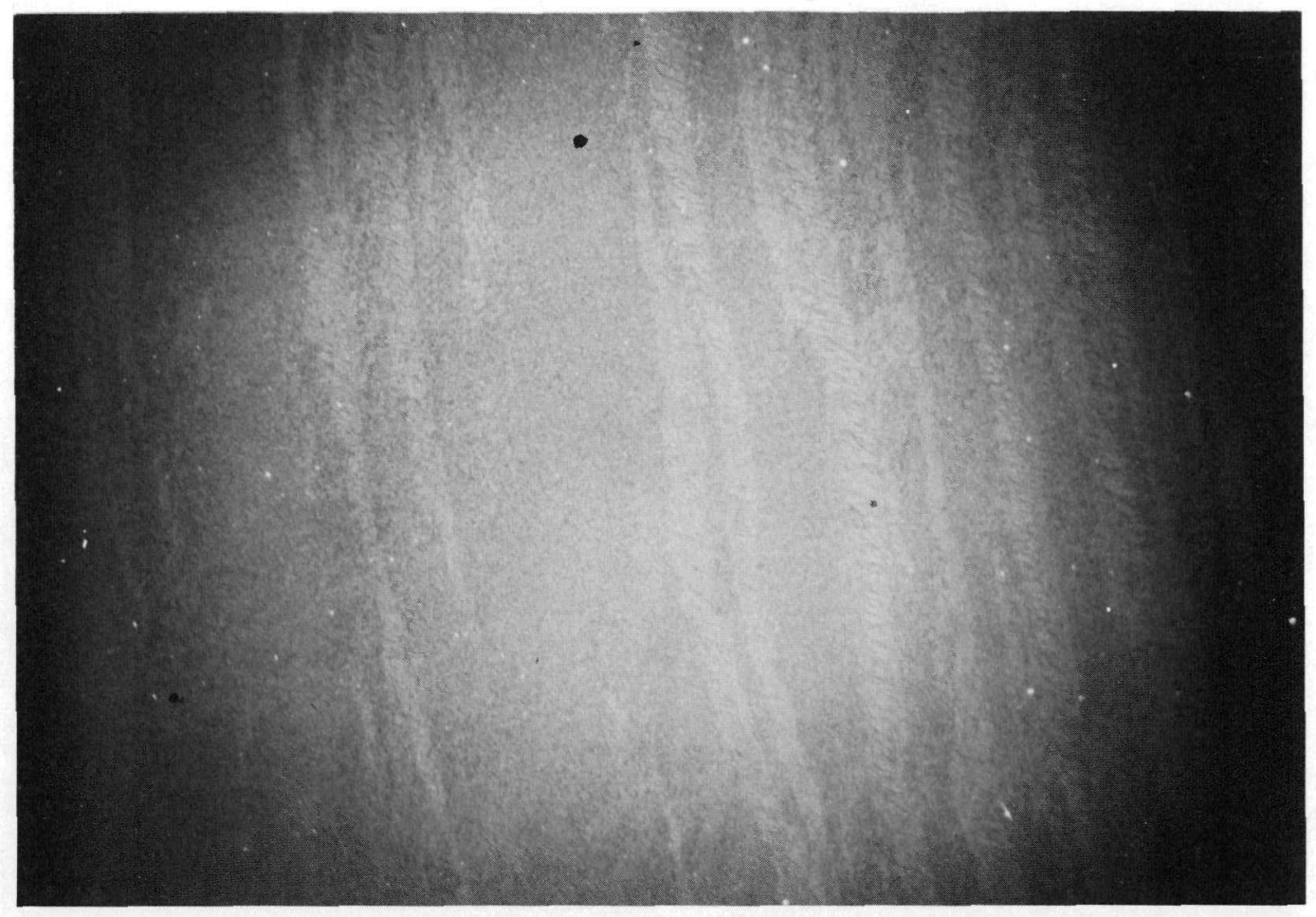

Figure 24. ILLUSTRATION OF DEFORMATION BANDING, AS VIEWED FROM THE TOP SURFACE OF CRYSTAL 4-10 THAT WAS REDUCED 80 PERCENT IN THICKNESS. (Polarized Light; 50X)

Two-surface trace analysis of the crystal strained $20 \%$ was performed, assuming essentially no orientation change-a fact attested to by pole-figure analysis. Macroscopic deformation band boundaries were found to be parallel to the (111) planes. This observation is in agreement with those of Barrett(59) on (110) iron single crystals deformed in uniaxial compression.

The greatest difference in orientation between the top and bottom surfaces of any of the (110)-type crystals was exhibited by Crystal 4-10. Pole figures of the top (narrow) and bottom (wide) surfaces of this crystal are presented in Figure 25. An unusually sharp $\{100\}<010>$-type orientation was evident on the bottom surface. The top surface, on the other hand, consisted of two components-a very smeared (111) [325] component, rotated seven degrees about the rolling direction away from the transverse direction and an (001) [010] component rotated six degrees about the transverse direction (TD) away from the rolling direction (RD).

To determine how such a tremendous orientation change could be accommodated, pole figures of this crystal were taken at various through-the-thickness locations from the bottom surface. Figure 26 shows the texture in various layers of the crystal. At $24 \%$ of the crystal thickness from the bottom, the (200) pole figure showed considerable spread of the central pole and minor indications of other orientations. At 35\% from the bottom, three distinct orientations were present-a (001)[010] orientation, and two symmetrically disposed $\{234\}$ rolling planes with

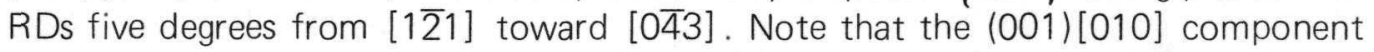
was a similar orientation to that of the bottom surface of the crystal and an 


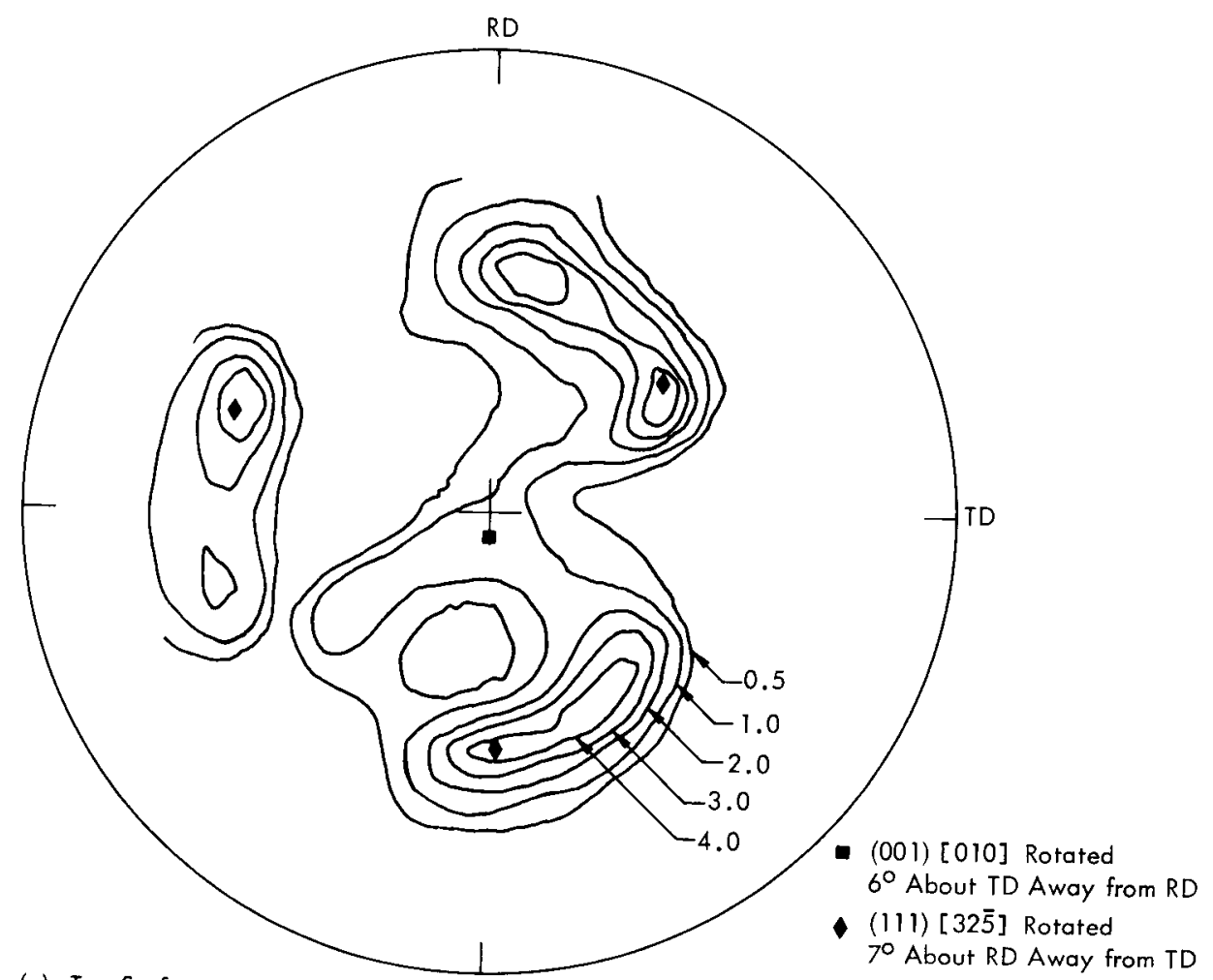

(a) Top Surface.

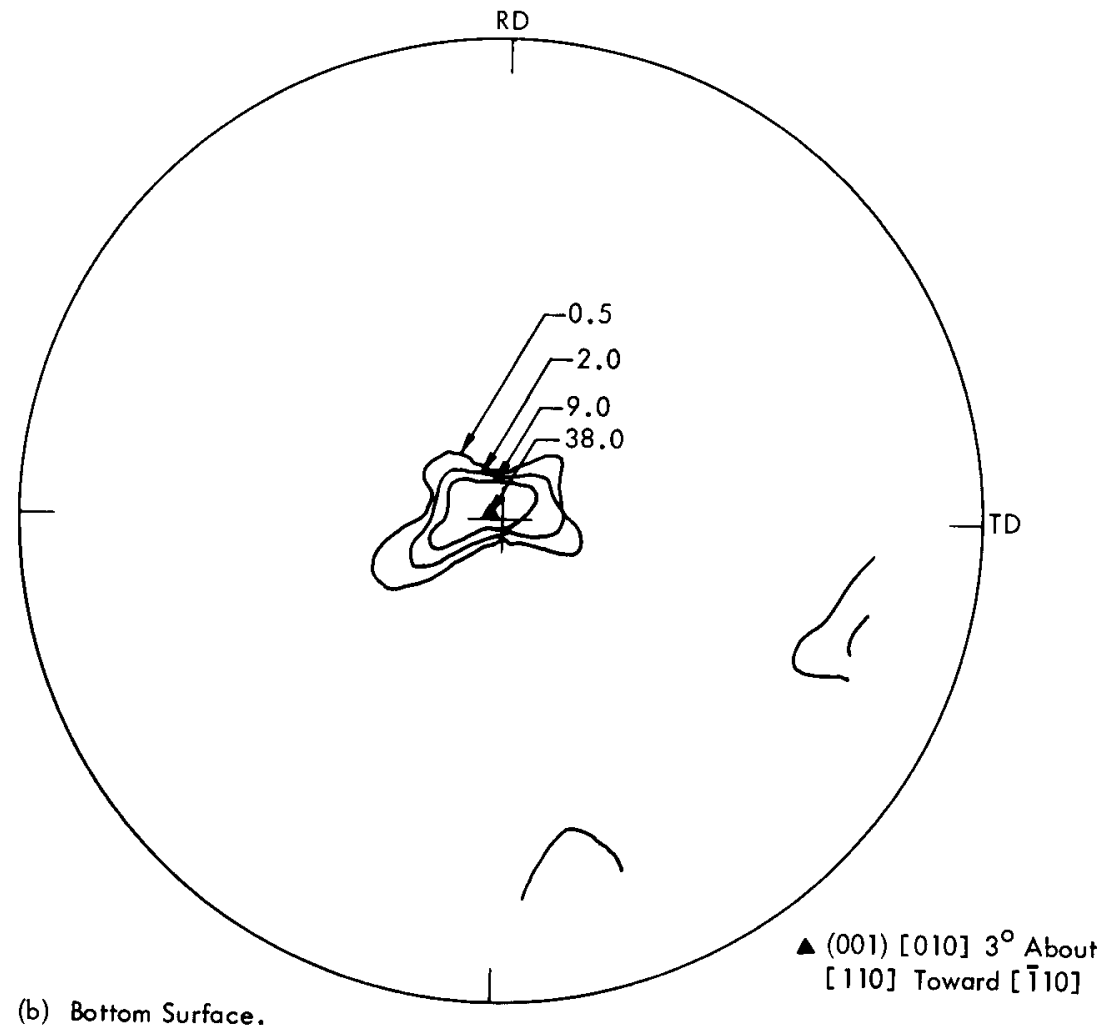

Figure 25. (200) POLE FIGURES OF CRYSTAL 4-10 THAT WAS ROLLED 80 PERCENT. 


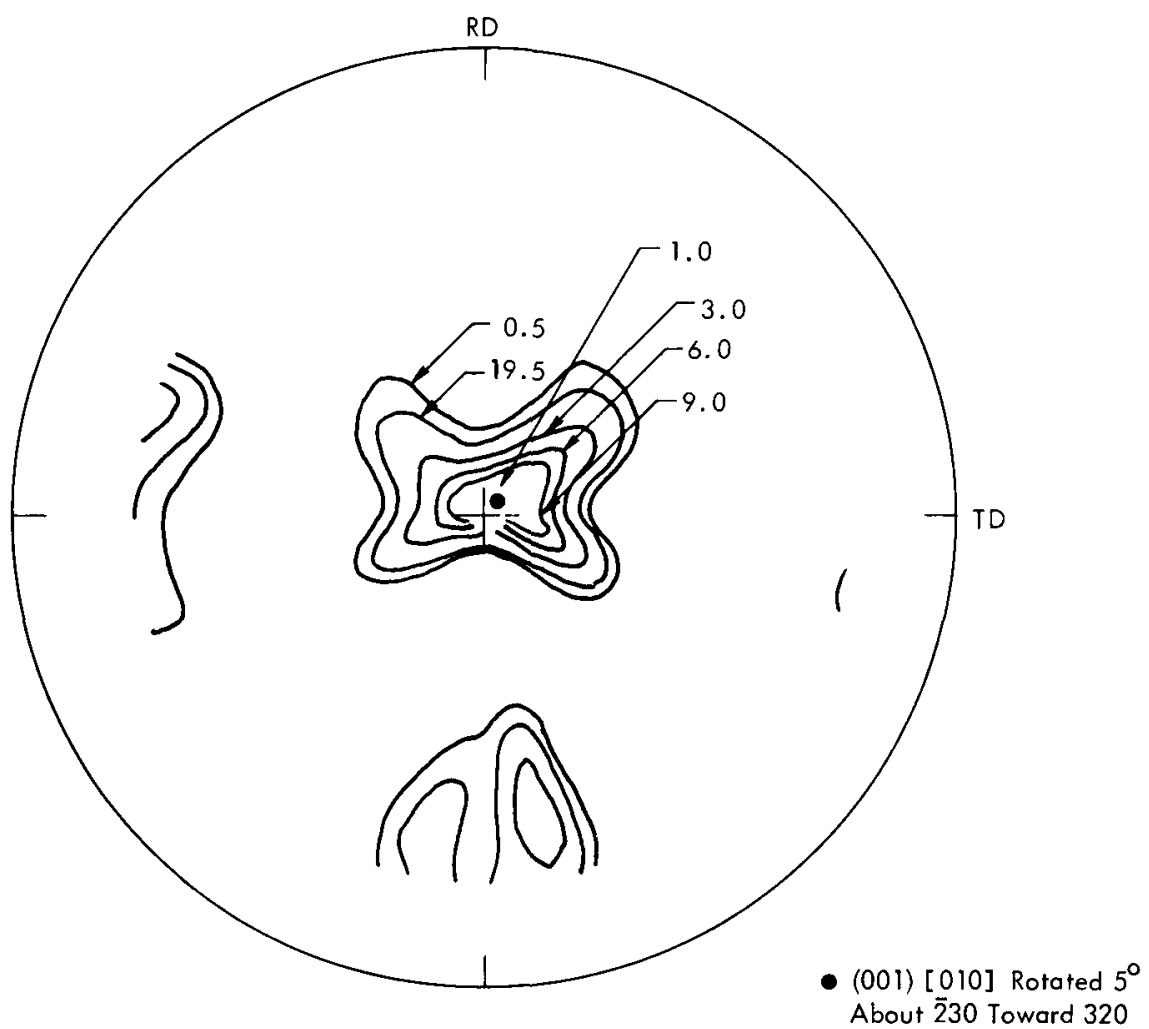

(a) 24 Percent from Bottom.

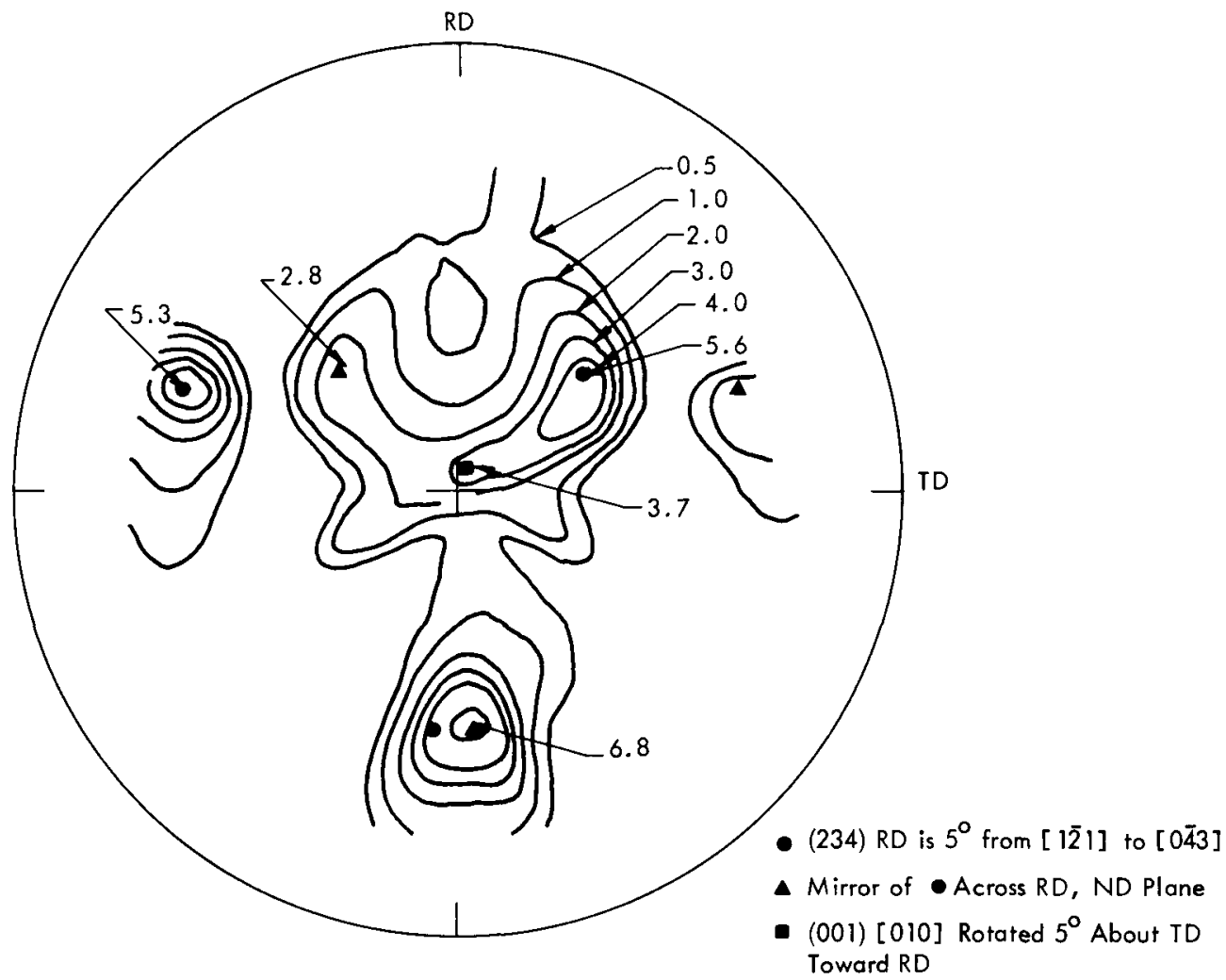

(b) 35 Percent from Bottom.

Figure 26. (200) POLE FIGURES OF CRYSTAL 4-10 AT DISTANCES OF 24 PERCENT $(0.1 \mathrm{~mm})$ AND 35 PERCENT $(0.15 \mathrm{~mm}$ ) OF THICKNESS FROM THE BOTTOM SURFACE. (Original Thickness was $0.43 \mathrm{~mm}$ ) 
orientation also seen in the top surface. Near the specimen mid plane, the orientation very closely approximated that of the top surface, as seen in Figure 27
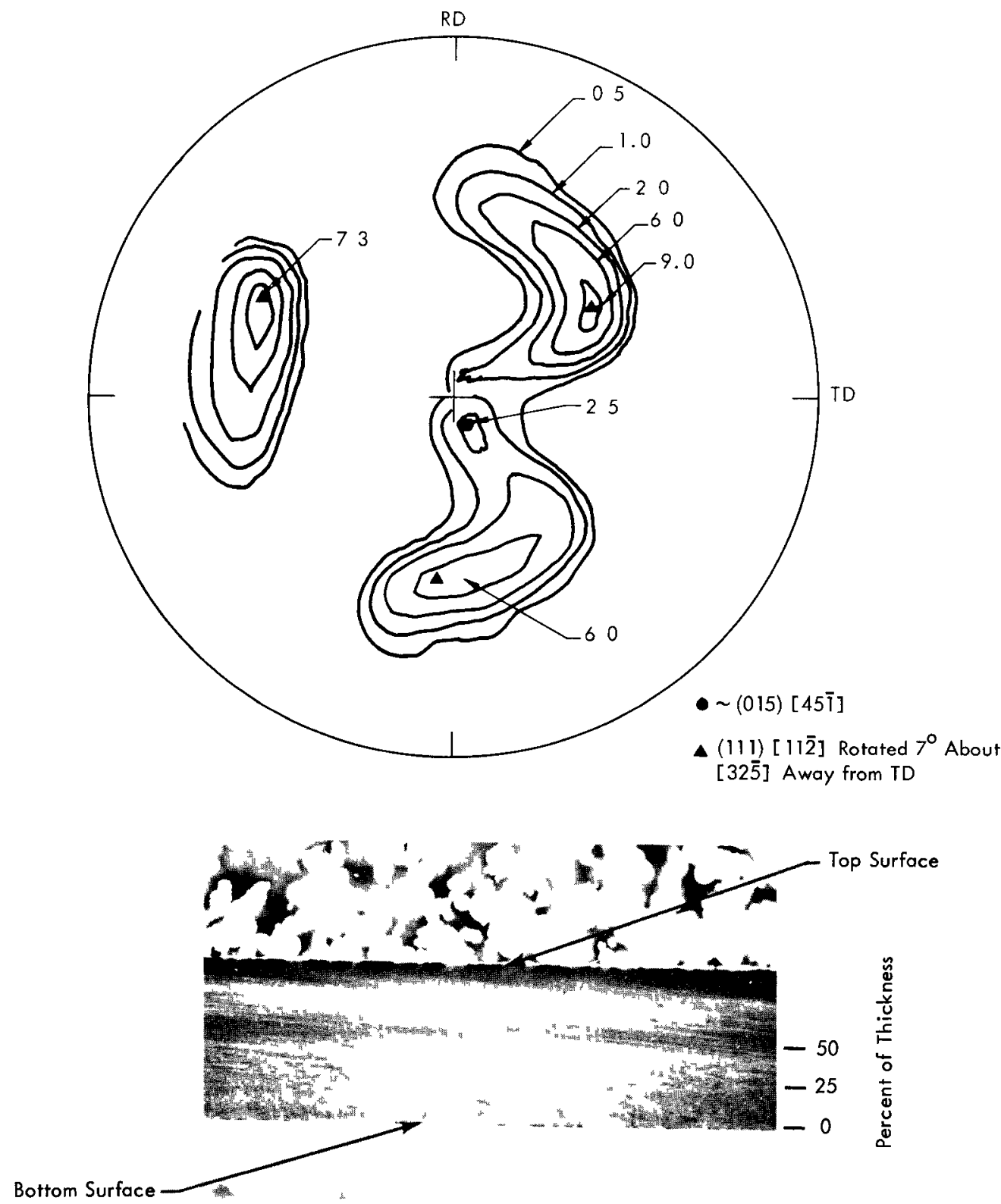

Figure 27 (200) POLE FIGURE OF THE MID PLANE AND CROSS SECTION OF CRYSTAL 4-10 THAT WAS ROLLED 80 PERCENT. (Polarized Light, 50X)

The transition from the duplex texture of Figure 26(b) to that of Figure 27 (a) appeared to coincide with a change in microstructure Note that in Figure $27(\mathrm{~b})$, resolvable deformation bands were present between 25 and $50 \%$, whereas a much finer optically unresolvable structure was present below $25 \%$ to the bottom surface In summary, optically resolvable deformation bands were found to correlate with a multicomponent texture Unresolvable microstructures on the other hand were found to correlate with single-component textures Microstructural layering effects 
through the crystal thickness were found to correspond to textural changes through the crystal thickness. Through-the-thickness textural and microstructural changes were also observed in Crystal $4-8$ and will be discussed in terms of its recrystallization behavior in a later section. In general, the microstructures of Crystal 4-10 were representative of most of the rolled crystals of the (110)[110] orientation.

Orientation Change of (110) Crystals During Rolling - in order to follow orientation changes during the rolling process, one crystal (4-1) was rolled in increments of $20 \%$ thickness reduction, and the (110) pole figures taken. At each step, $0.03 \mathrm{~mm}$ of material was removed from the rolled surfaces and the (110) pole figures obtained. Corrections to the reduction calculations were made for surface removal at each $20 \%$ reduction step. Figure 28 shows that, at $20 \%$ total thickness reduction, the only significant changes which occurred were a transverse spread in the (110) planes, which could be described as a rotation about the rolling direction.

Further rolling to $40 \%$ caused a greater spreading of the (110) poles, with an indication of initial breakup of the crystal into two orientations. At this point, the two orientations could not be clearly identified because there was no suitable separation of peaks other than the central peak. Upon rolling to $67 \%$ reduction, very obvious dual orientations were present in both surfaces, which were symmetric about the rolling direction (Figure 29). One surface contained $\{113\}$ rolling planes while the other contained $\{334\}$ rolling planes. These rolling-plane orientations are approximately 21 degrees apart. Further rolling to $80 \%$ reduction produced the orientation shown in Figure 30. Here the (200) pole figures are presented because they more clearly show the orientations. The bottom surface reoriented to two $\{324\}<312>$-type orientations which were smeared into what could have been a (001)[010] rotated 10 degrees about a $<120>$ axis. At the same time, the top surface reoriented to what appeared to be a strong (111)[110] orientation, but with considerable spread and perhaps a weaker $\{001\}$-type orientation. Once again the bottom surface of Crystal 4-1 was widened more than the top, with a resultant "double-barrel" effect like that of Crystal 4-10. Textures of Figure 30 should be compared to Figures 25(a), 26, and 27.

Effects of the Rolling Conditions - Texture inhomogeneities generated during rolling have been reported both for single and polycrystalline materials. $(60-62)$ As opposed to presently described results, the texture normally varies from surface to center and is symmetrical about the specimen mid plane (ie, the top and bottom surfaces have the same orientation). These results have been interpreted in terms of frictional effects independent of the other rolling variables. Transverse strains generated during rolling were not discussed.

Tarnovskii, et al, $(63)$ have shown for polycrystalline materials that the size of the zone of deformation controls strain inhomogeneity during rolling. Vandermeer and Ogle(62) have further shown how variations in the deformation zone size during rolling can cause texture variations in rolled polycrystalline niobium. The zone of deformation, $\Delta$, has been quantitatively described as the ratio of the mean strip thickness to the roll contact length, or approximately : 

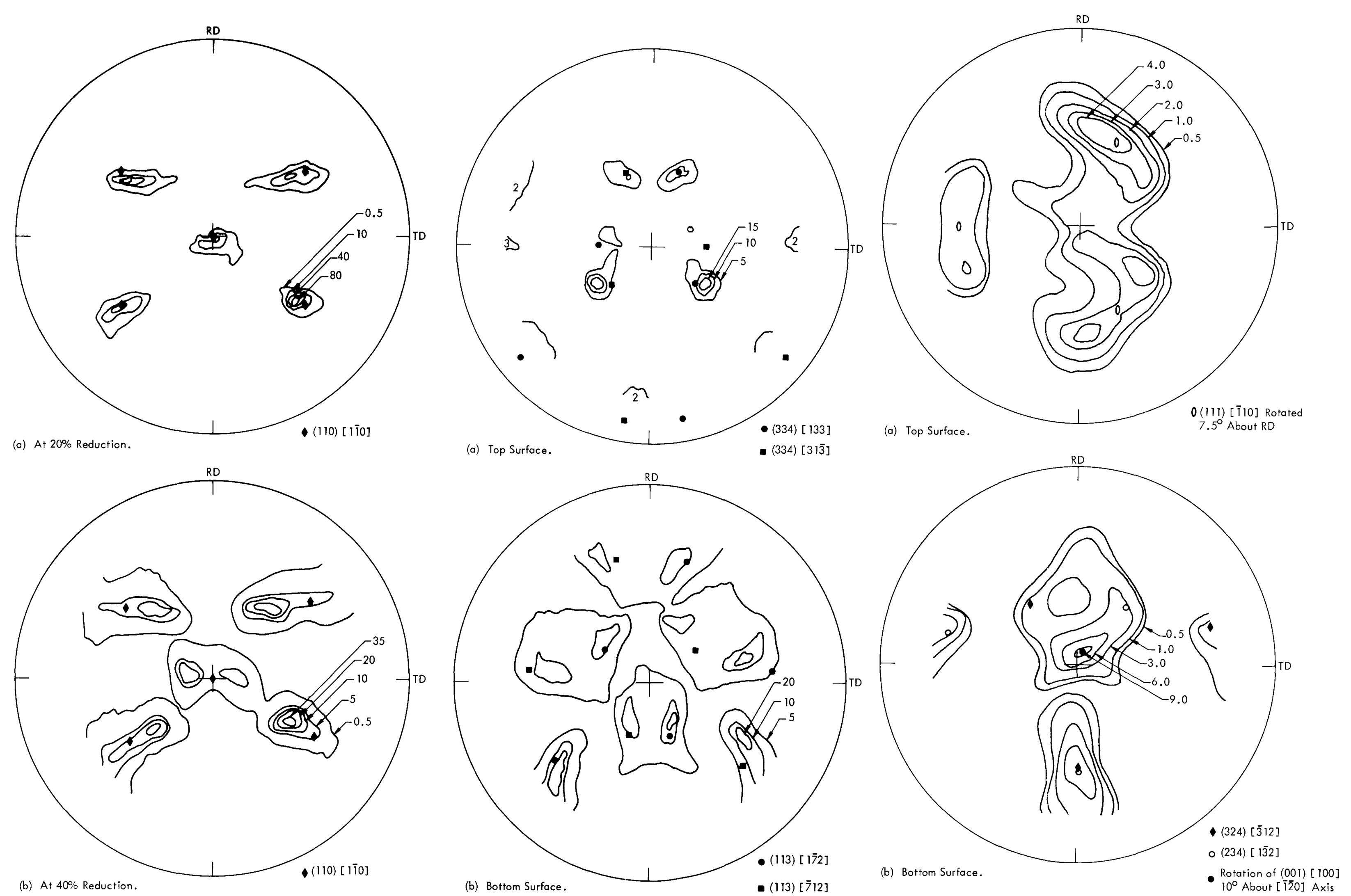

Figure 28. (110) POLE FIGURES OF CRYSTAL 4-1 THAT WAS ROLLED AT Figure 29. (110) POLE FIGURES OF CRYSTAL 4-1 THAT WAS ROLLED Figure 30. (200) POLE FIGURES OF CRYSTAL 4-1 THAT WAS ROLLED 80 67 PERCENT. 


$$
\Delta \simeq h_{0} / 4 \operatorname{Rr}[2-r]
$$

where:

$h_{0} \quad$ represents the initial strip thickness,

$\mathrm{R} \quad$ the roll radius, and

$r$ the fractional-thickness reduction. (This nomenclature is consistent with Backofen $(64)$ and is the reciprocal of the parameter used by Vandermeer and Ogle(65) and Tarnovskii, (63) et al.)

For polycrystalline materials, Tarnovskii, et al, separated the effects of rolling into three categories: $\Delta>1.25$, high-body rolling; $0.67>\Delta>1.25$, moderate-body rolling; $\Delta>0.67$, thin-body rolling. During high-body rolling, edges showed a "double-barrel" formation, and strain was quite inhomogeneous (Figure 31). As $\Delta$

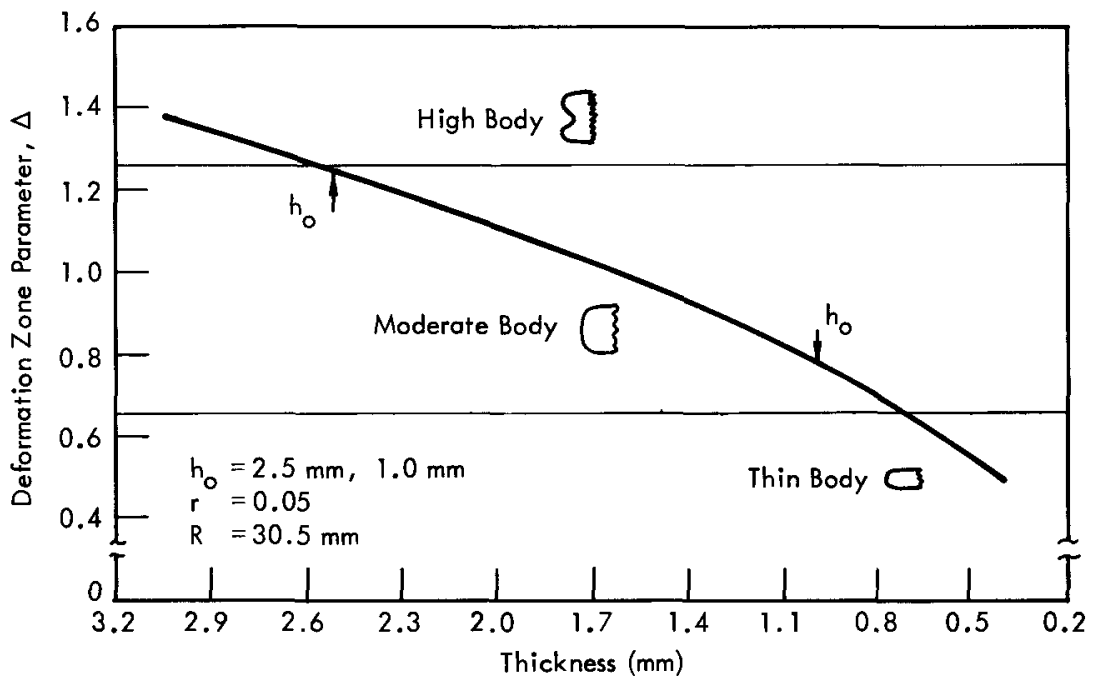

Figure 31. DEFORMATION-ZONE PARAMETER AS A FUNCTION OF THE CRYSTAL THICKNESS.

was decreased, both transverse and thickness strains became more homogeneous. Lowering the coefficient of friction between rolls and the workpiece (lubrication) had an effect similar to lowering the deformation zone size; ie, straining became more homogeneous.

The four sets of rolling conditions given in Table 4 were selected to study their effects on reorientation and transverse straining of (110) crystals. The deformation-zone parameter was controlled by varying the starting thickness, $h_{0}$, as indicated in Figure 31. The thicknesses were selected such that two crystals could be rolled almost completely under moderate-body conditions, while the other two would be rolled into the thin-body region. Roll radius $(30.5 \mathrm{~mm})$ and fractional reduction per pass $(0.05)$ were kept constant during rolling to a final thickness 
reduction of $80 \%$ When necessary, a lower coefficient of friction was obtaıned by liberally applyıng a mineral on to the crystal and rolls

All of the (110) crystals discussed prior to this section were rolled, using an initial deformation zone parameter of 125 and dry rolls $A n$ additional crystal (4-8) was rolled to $80 \%$ reduction using the same conditions, that is $\Delta_{\mathbf{i}}=125$ and dry rolls Figure 32 shows the optical microstructure of the cross section of this crystal Note that the top surface widened $69 \%$ while the

Table 4

ROLLING CONDITIONS FOR THE EXPERIMENT

\begin{tabular}{lll}
\hline & $\begin{array}{c}\text { Friction } \\
\text { Conditions }\end{array}$ & $\begin{array}{c}\text { Crystal } \\
\text { Identıfıcatıon }\end{array}$ \\
\hline 125 & Dry Rolls & 4841410 \\
125 & Mıneral Oıl & 411 \\
& Lubricant & \\
079 & Dry Rolls & 413 \\
079 & Mineral Oıl & 412 \\
& Lubricant & \\
\hline
\end{tabular}
bottom surface widened $118 \%$

Thus, a gradient of transverse strain existed from the top to bottom surface Every (110) crystal rolled under these conditions exhibited more transverse strain in one surface than in the opposite surface Note that, in the central portion of the crystal, there was a change in the appearance of deformation bands from the top to bottom surface From the top to slightly below the mid thickness, deformation band boundaries were sharp and the bands themselves were quite large Upon moving toward the bottom surface, the deformation bands became indıstınguishable

Pole figures from the top (narrow) and bottom (wide) surfaces of Crystal 4-8 are presented in Figure 33 Essentially three components were present in the top (narrow) surface-two $\{111\}<110>$, which were symmetric with respect to the rolling direction, and an approximately $\{001\}<010>$ component Three orientations were also present in the bottom (wide) surface-two $\{235\}<142>$ components, which are also symmetric with respect to the rolling direction, and a possible (001)[010] component Due to the spread in orientation, identification of an (001)[010] component in the bottom surface was quite difficult and, therefore, its existence was questionable In order to determine the extent of orientation variation through the thickness of this crystal, the upper half was etched and pole figures taken at increments through the thickness (200) pole figures of the mid thickness are indicated in Figure 34 Agaın, three components were present-two orientations very close to $\{111\}<2 T \bar{T}$, which were symmetric about the rolling direction, and an orientation close to (001)[010]

A second crystal (4-11) was rolled under exactly the same conditions as the previous crystal except that mineral oll was applied to the rolls and crystal A cross section of this crystal is seen in Figure 35 Note that the edges of this crystal have a "double-barrel" appearance that is indicative of equal transverse strains in the upper and lower portions of the crystal (The small up turn in the lower left photo is due to bending during handling) Transverse strain (widening) in this crystal was $86 \%$ for both surfaces, which was between the 69 and $118 \%$ strains of the dry-rolled crystal Deformation-band boundaries were not quite as sharp as the upper portion of the 


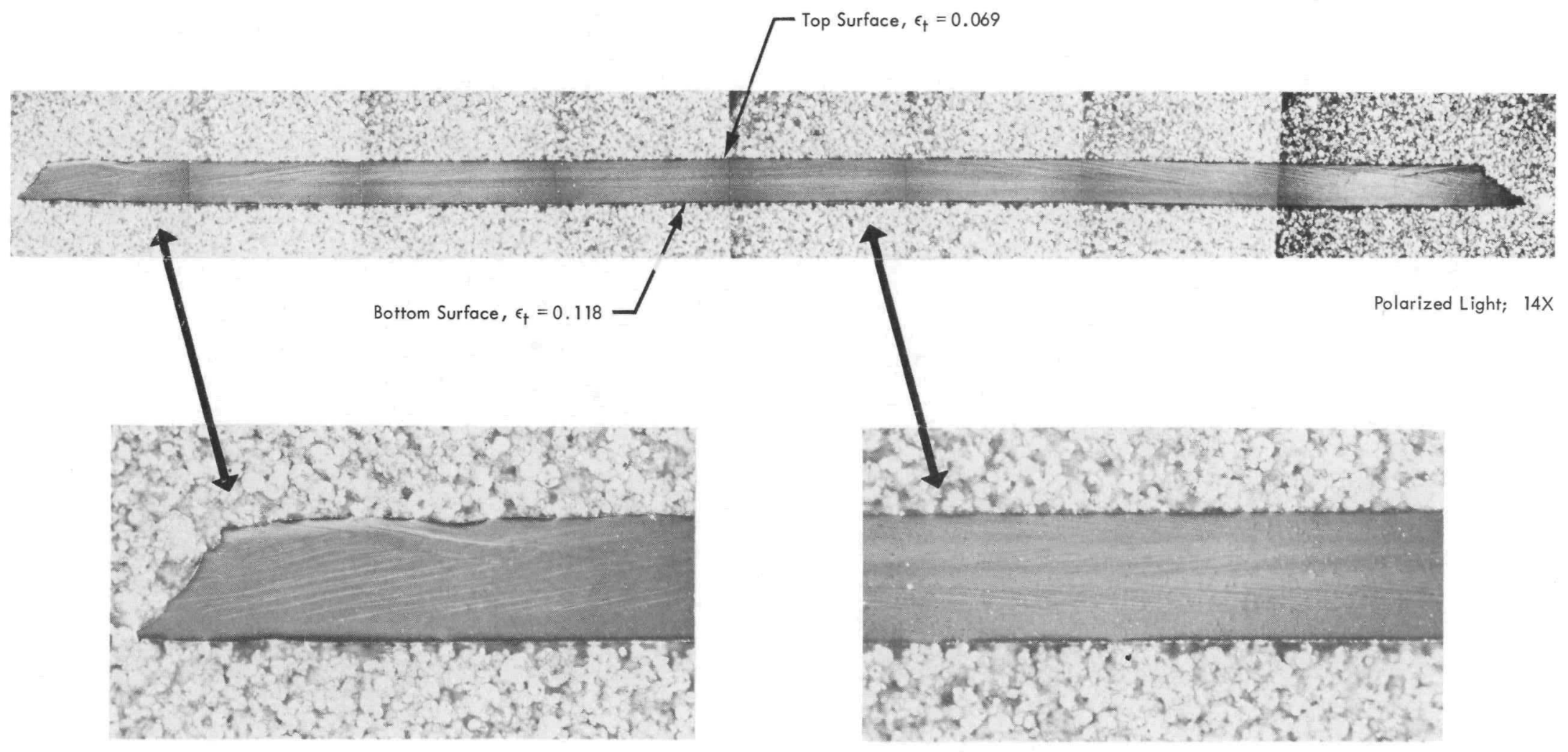

Polarized Light; $46.7 \mathrm{X}$

Polarized Light; $46.7 \mathrm{X}$

Figure 32. CROSS SECTION OF (110) [1 $1 \overline{10}]$ CRYSTAL 4-8 THAT WAS ROLLED 80 PERCENT. $\left(\Delta_{\mathrm{i}}=1.25\right.$, Dry) 


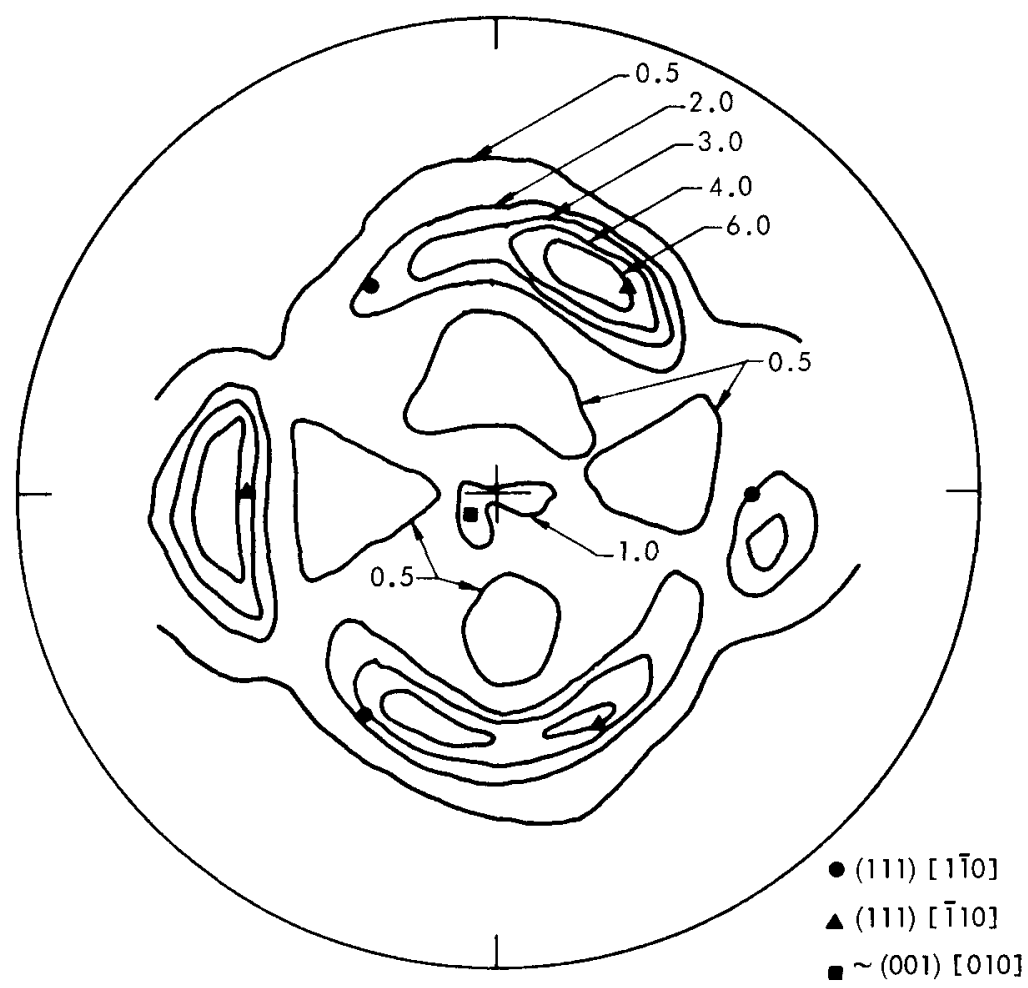

(a) Top Surface.

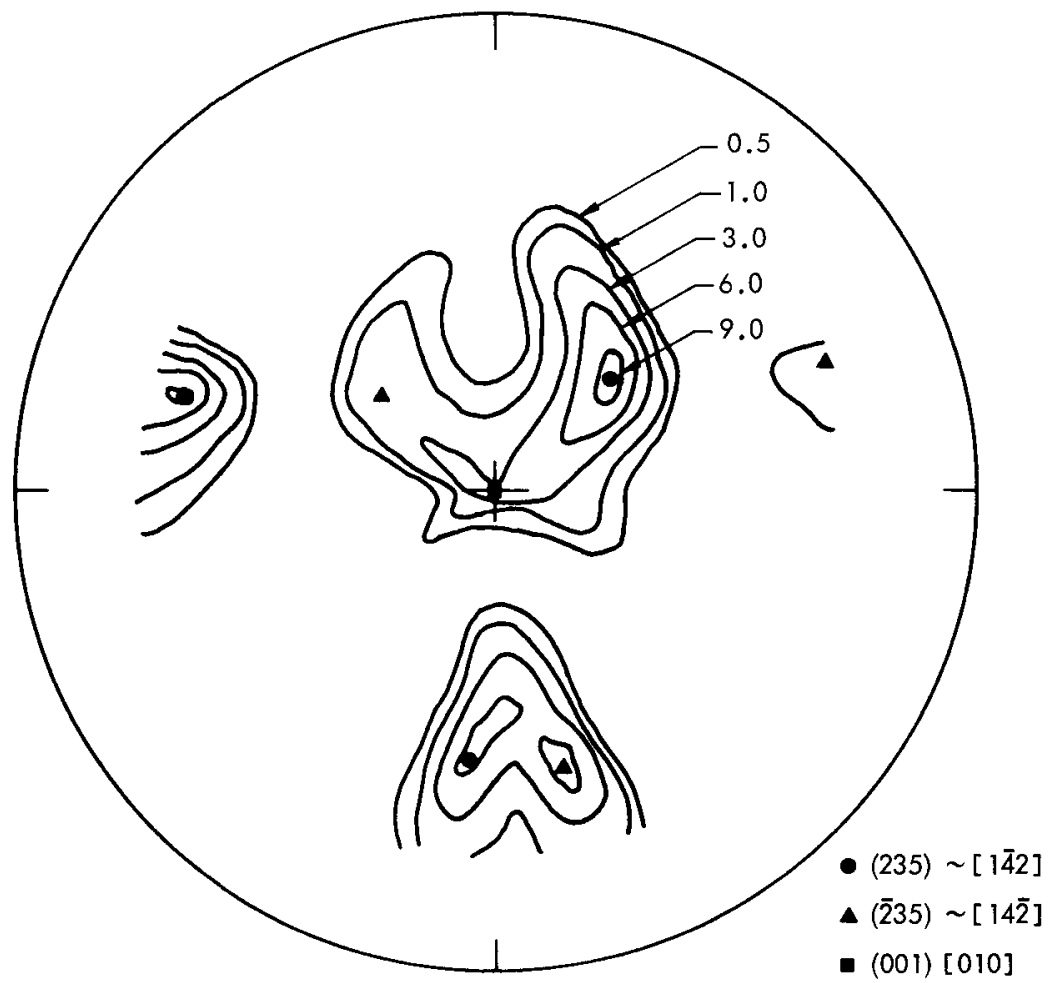

(b) Bottom Surface.

Figure 33. (200) POLE FIGURES OF CRYSTAL 4-8 THAT WAS ROLLED 80 PERCENT. $\left(\Delta_{\mathrm{i}}=1.25\right.$, Dry $)$ 


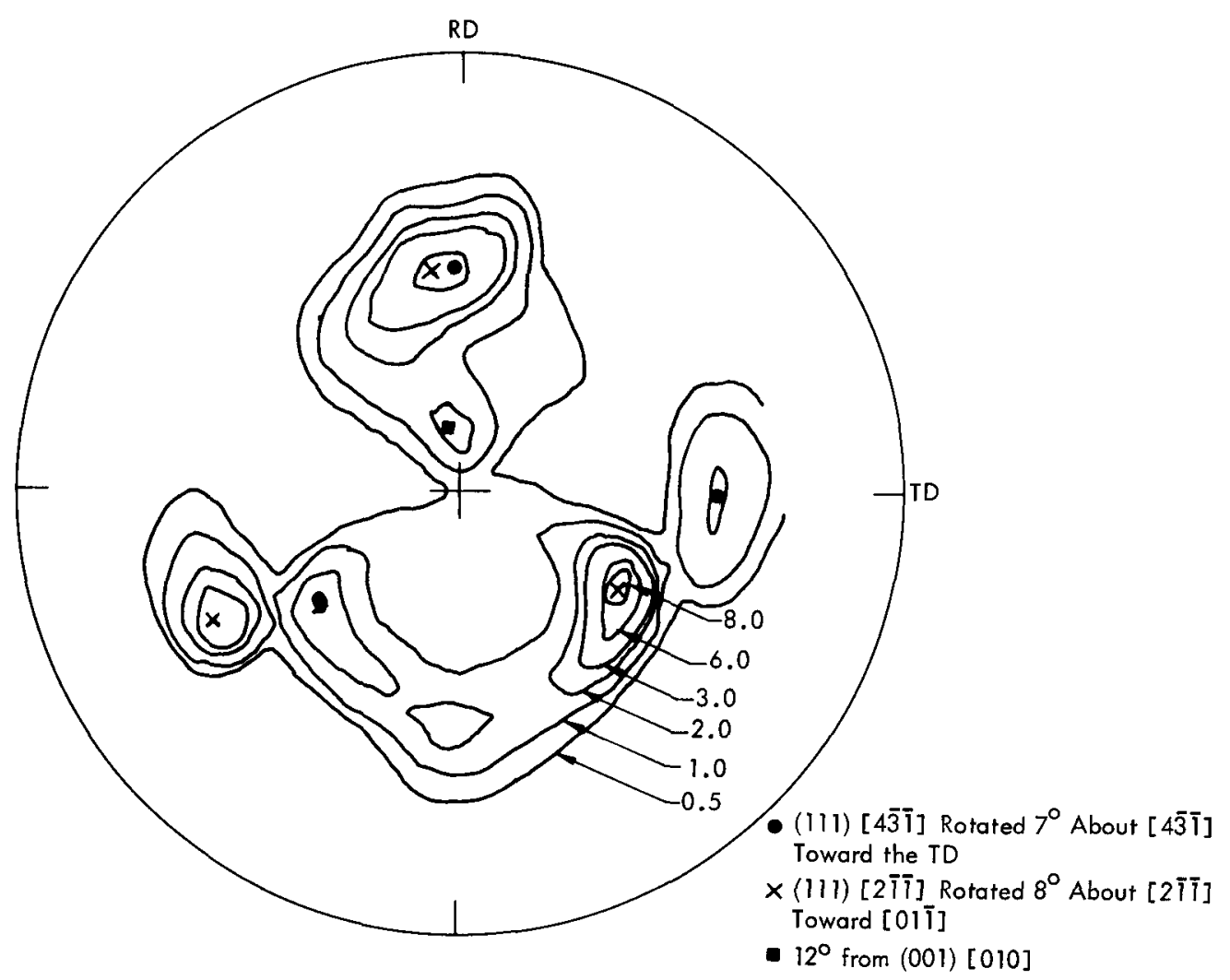

Figure 34. (200) POLE FIGURE OF CRYSTAL 4-8 NEAR THE MID THICKNESS, ILLUSTRATING THREE COMPONENTS OF TEXTURE.

dry-rolled crystal, but were symmetrical with respect to the crystal mid plane. In addition, there was no ill-defined, optically unresolvable region observed in this crystal.

A view of the (200) pole figures of Crystal 4-11 are given in Figure 36. The major features of the two pole figures were essentially the same, indicating that both surfaces were of the same orientation. Again, three components were present in each surface-the major component had a rolling plane close to $\{111\}$, with a rolling direction almost halfway between $<110\rangle$ and $<112\rangle$. A minor component was nearly symmetrically related to the major component by a 180-degree rotation about the rolling direction, and was too weak to be properly identified in the top surface. A third component was an approximately $\{001\}<010>$ which, in the top surface, was rotated 16 degrees about the transverse direction. In the bottom surface it was rotated 10 degrees in the opposite direction.

A lower-deformation zone parameter of 0.79 and high friction conditions (dry rolls) produced the microstructure of Crystal 4-13, seen in Figure 37. Note that even under conditions which would normally produce homogeneous straining (ie, $\Delta_{i}=0.79$ ), the edges showed a rather dramatic "double-barrel" effect, with transverse strains being symmetric about the crystal mid thickness. Deformation bands in the center section of the crystal were less distinct, but appeared to be 


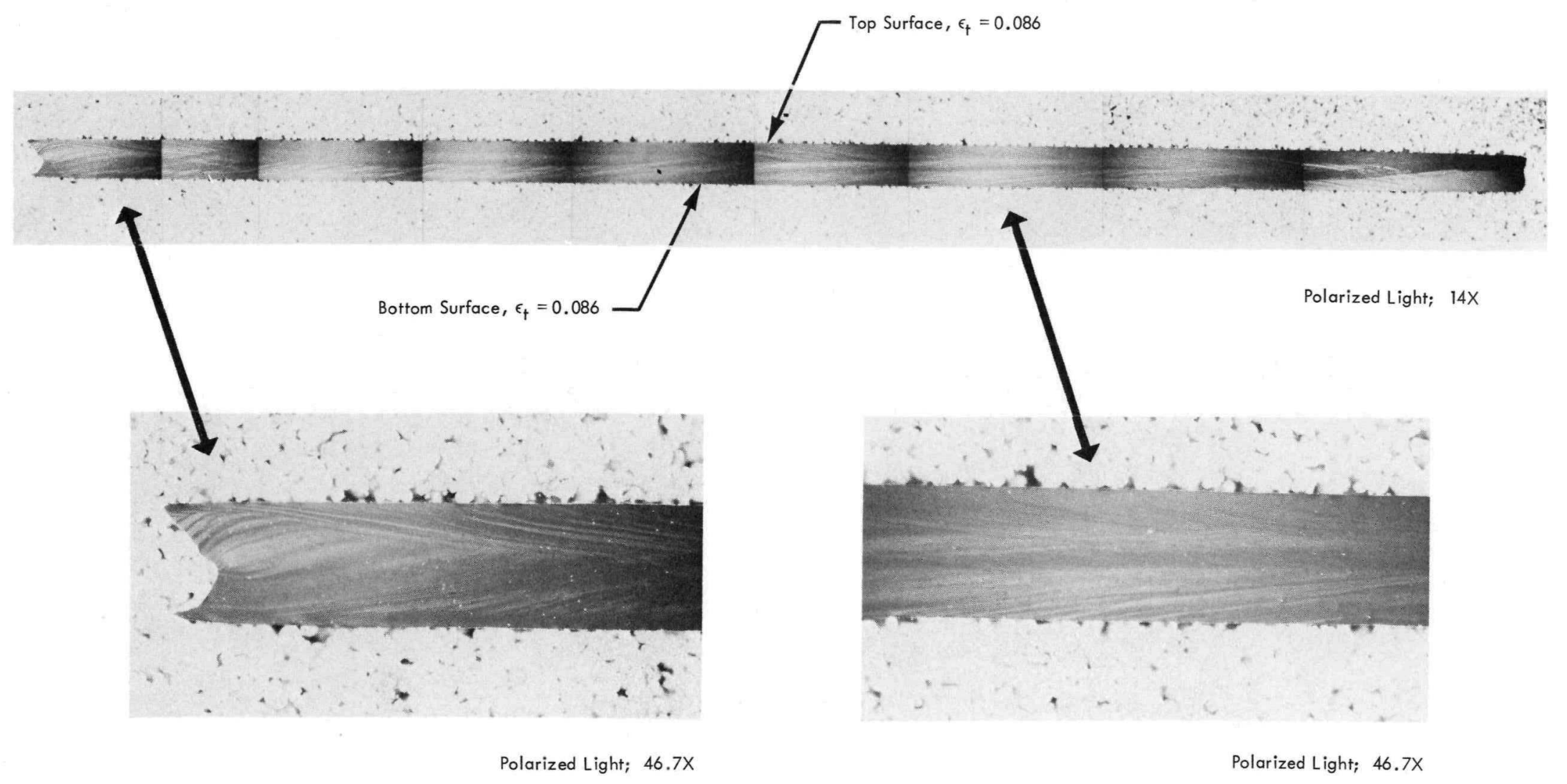

Figure 35. CROSS SECTION OF (110) [110] CRYSTAL 4-11 THAT WAS ROLLED 80 PERCENT. $\left(\Delta_{\mathrm{i}}=1.25\right.$, Mineral Oil) 


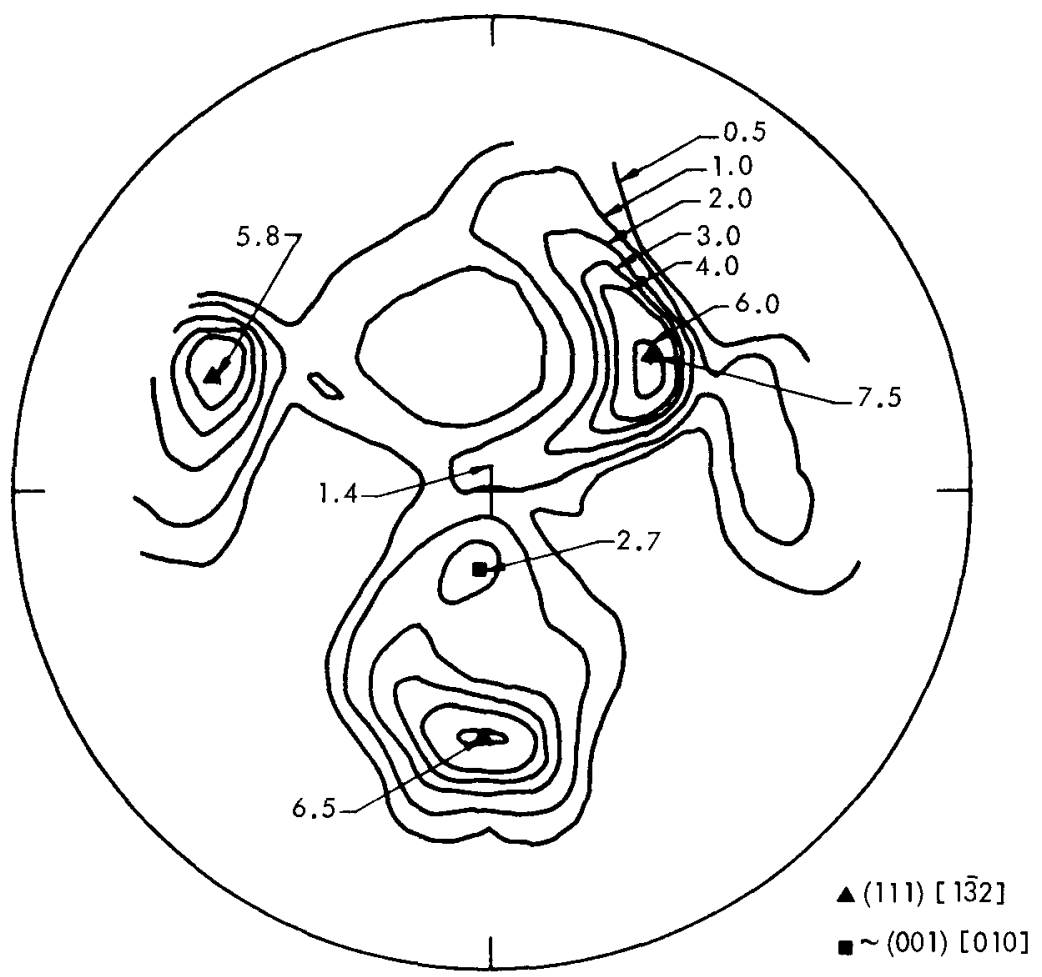

(a) Top Surface.

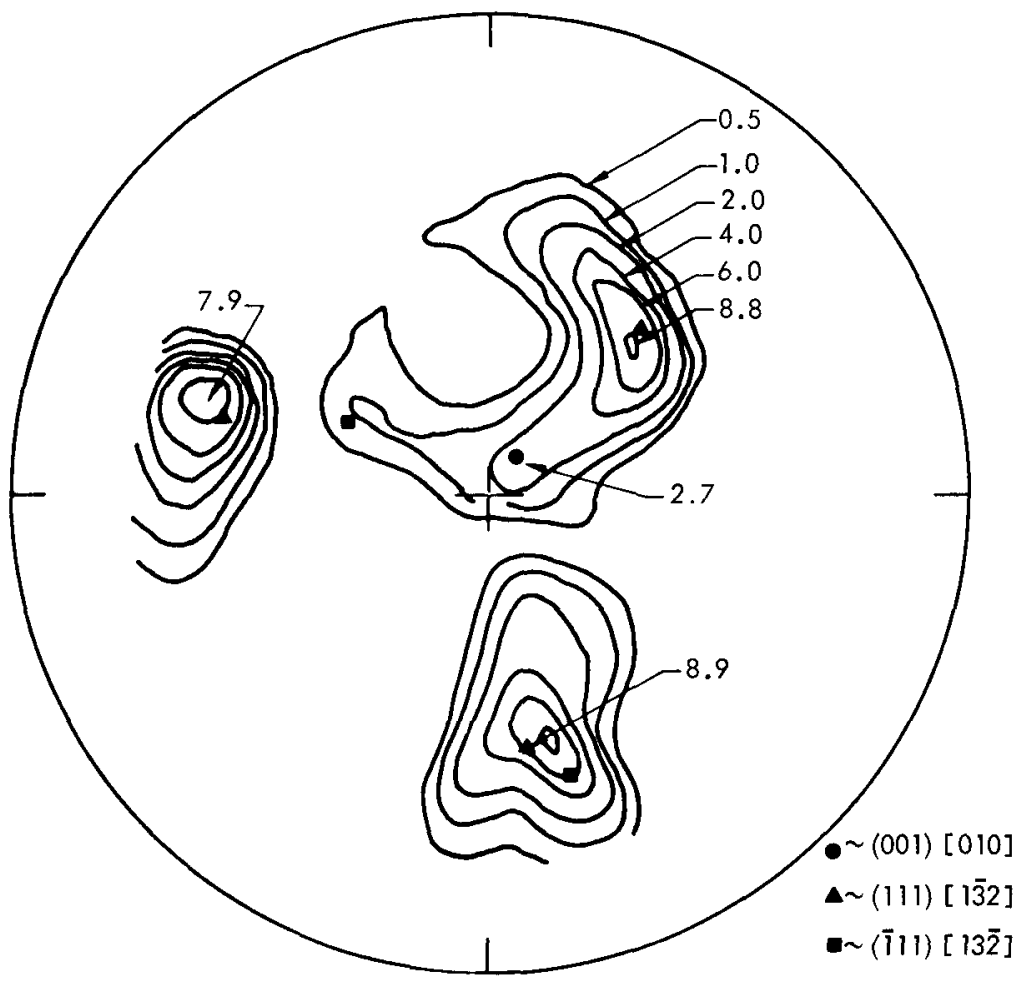

(b) Bottom Surface.

Figure 36. (200) POLE FIGURES OF THE TOP AND BOTTOM SURFACES OF CRYSTAL 4-1 1 THAT WAS ROLLED 80 PERCENT. $\left(\Delta_{\mathrm{i}}=1.25\right.$, Mineral Oil) 


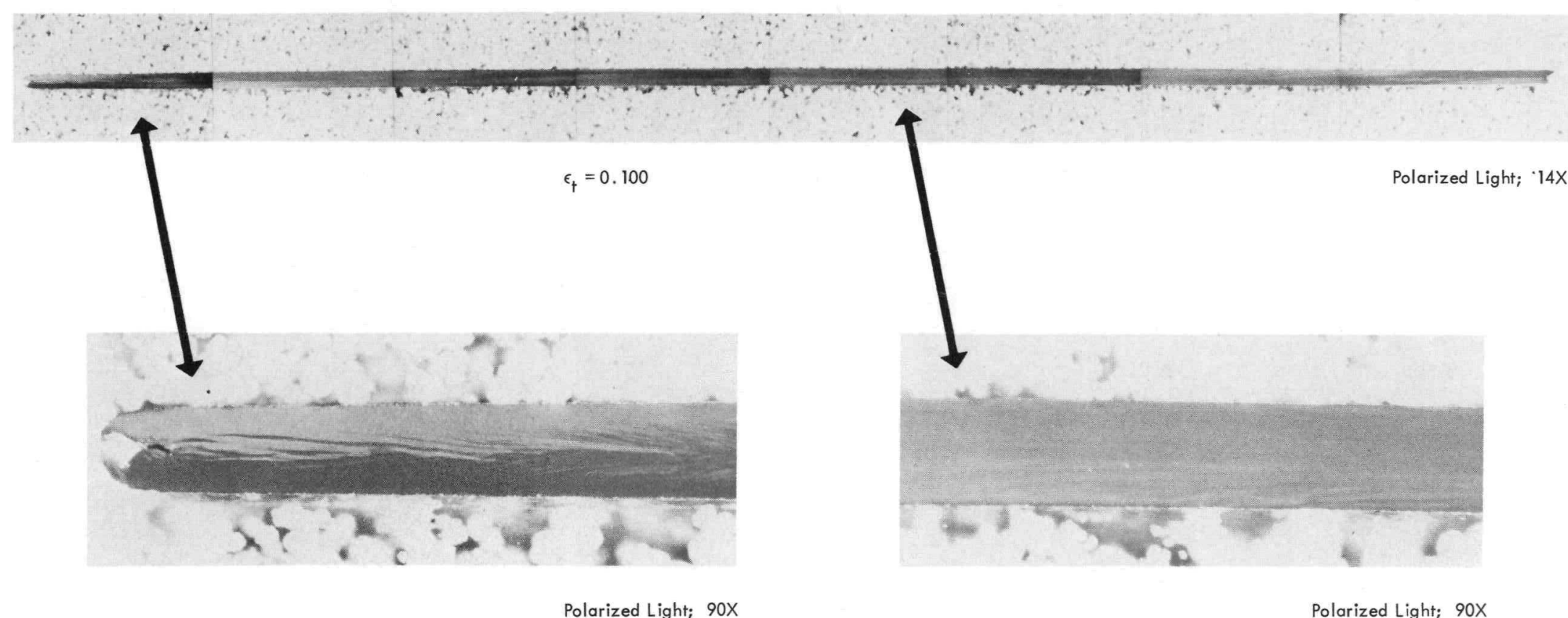

Figure 37. CROSS SECTION OF (110) [1 $1 \overline{1} 0]$ CRYSTAL 4-13 THAT WAS ROLLED 80 PERCENT. $\left(\triangle_{i}=0.79\right.$, Dry) 
symmetric about the specimen mid plane This crystal had a transverse straın of $100 \%$

Pole figures of the top and bottom surfaces of Crystal 4-13 are given in Figure 38 Three orientations were again present in each surface-two were essentially $\{111\}$ $<112>$ type, which were symmetric about the rolling direction, the third was again an $\{001\}<010\rangle$, which had been rotated about the transverse direction seven to ten degrees Though one $\{111\}<\overline{1} 12>$ component was stronger in one surface than the other, the main features of the pole figures were the same

A fourth crystal (4-12) was rolled under the same conditions as the previous crystal, except that lubricant was added Figure 39 shows the optical microstructure of this crystal Once, again, note that, under the most homogeneous of rolling conditions, a "double barrel" effect occurred at the crystal edges Total transverse strain for this crystal was $157 \%$, which demonstrated that it widened more than any other crystal Deformation banding in this crystal was poorly defined, but appeared to be symmetric about the specimen mid plane

Reorientation of Crystal 4-12 is illustrated by the pole figures of Figure 40 These pole figures were somewhat different from these previously discussed in that they contained only two orientations in each surface These orientations were a single $\{111\}<\overline{1} 12>$ component and a $\{001\}<010>$, both rather intense and well defined Superposition of these two pole figures produced the pole figures for the previously described crystal, ie, the orientations present in the top and bottom surfaces of this crystal were present simultaneously in both surfaces of Crystal 413

A summary of the results of this section is given in Table 5 Under moderate body, high friction conditions, an instability existed which produced a transverse strain gradient through the crystal thickness This condition did not develop under thin-body conditions or low friction in searching for an explanation for this behavior, the rollıng-mıll roll diameters and indıvidual speeds were measured and compared No significant differences were found Thus, the instability was apparently due to a difference in friction conditions (perhaps surface finısh) between the rolls Under dry, moderate-body conditions, the narrow surface maıntaıned a $<1 \overline{1} 0>$ rollıng directıon, possıbly because of the transverse constraint from high friction forces The lowering of frictional forces, with $\Delta=125$, allowed both surfaces to widen equally, while the $\langle 1 \overline{1} 0\rangle$ direction moved away from the rollıng direction such that a crystallographic direction between $\langle 1 \overline{10}\rangle$ and $\langle 1 \overline{1} 2\rangle$ alıgned with the rollıng direction

More transverse straınıng occurred under high-frıctıon, thın-body condıtıons, and the $<1 \overline{1} 2\rangle$ became parallel to the rolling direction Lower frictional conditions under thin-body rollıng allowed the crystal to widen more, yet maıntain the same orientations Thus, more homogeneous rollıng conditions, Ie, low $\Delta$, with or without lubricant, allowed more widening In addition, a "double-barrel" effect due to nonuniform transverse straıns was observed at the edges of all crystals 


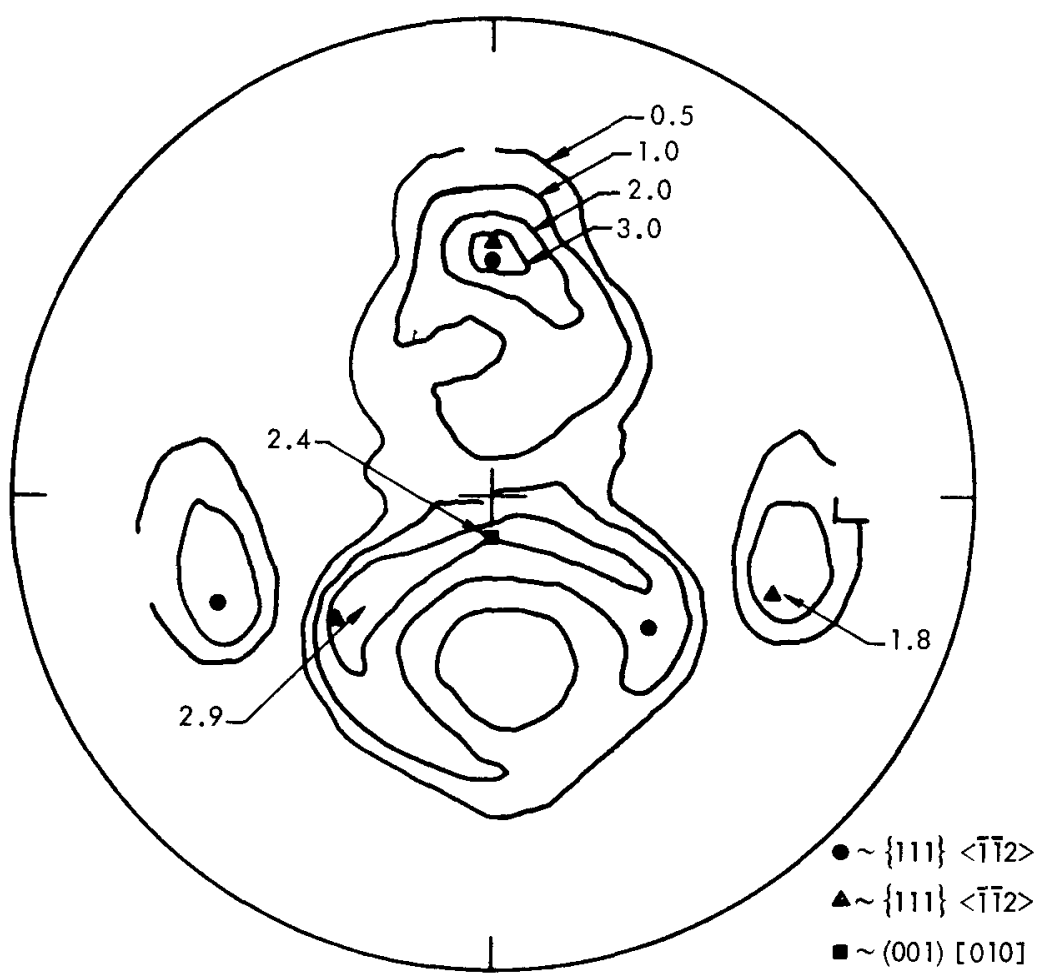

(a) Top Surface.

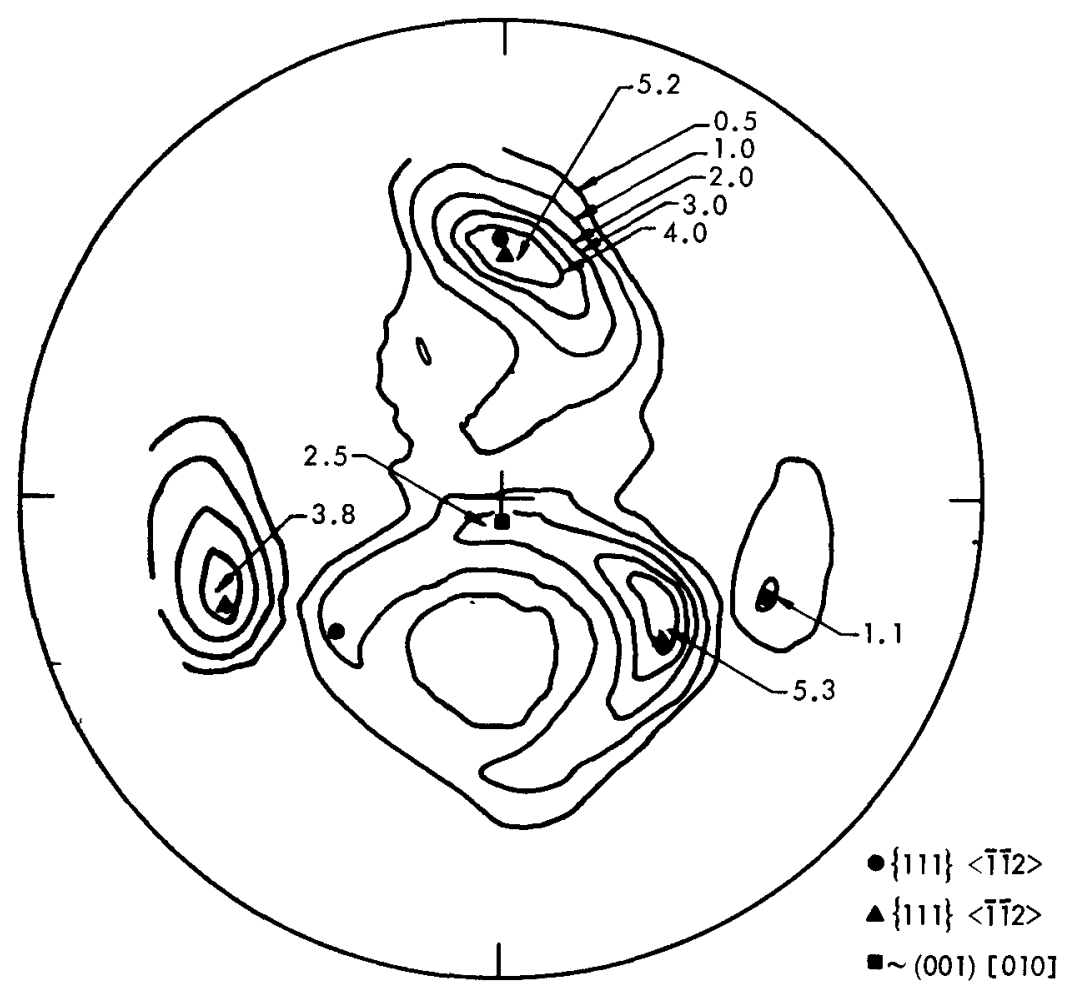

(b) Bottom Surface.

Figure 38. (200) POLE FIGURES OF THE SURFACES OF CRYSTAL 4-13. $\left(\Delta_{\mathrm{i}}=0.79\right.$, Dry $)$ 


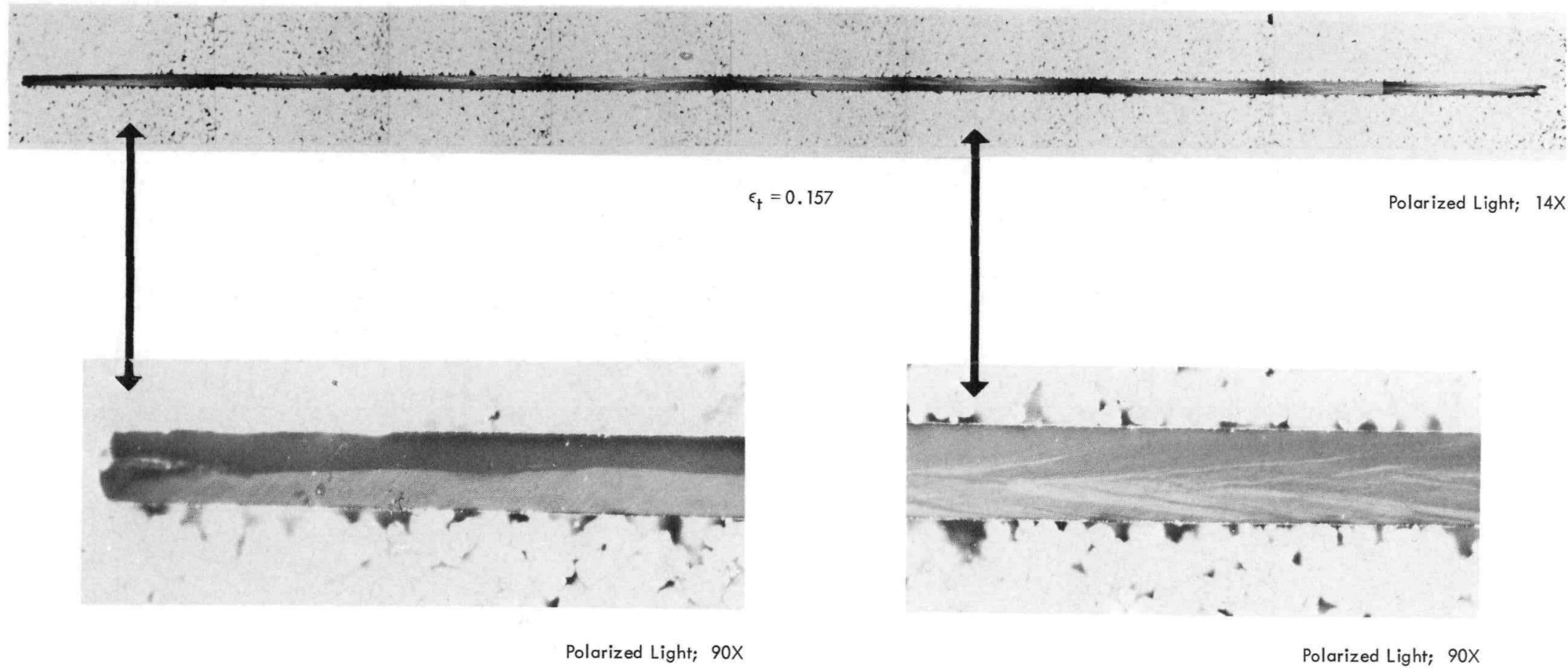

Figure 39. CROSS SECTION OF (110) [1 $1 \overline{1} 0]$ CRYSTAL 4-12 THAT WAS ROLLED 80 PERCENT. ( $\Delta_{\mathrm{i}}=0.79$, Mineral Oil) 


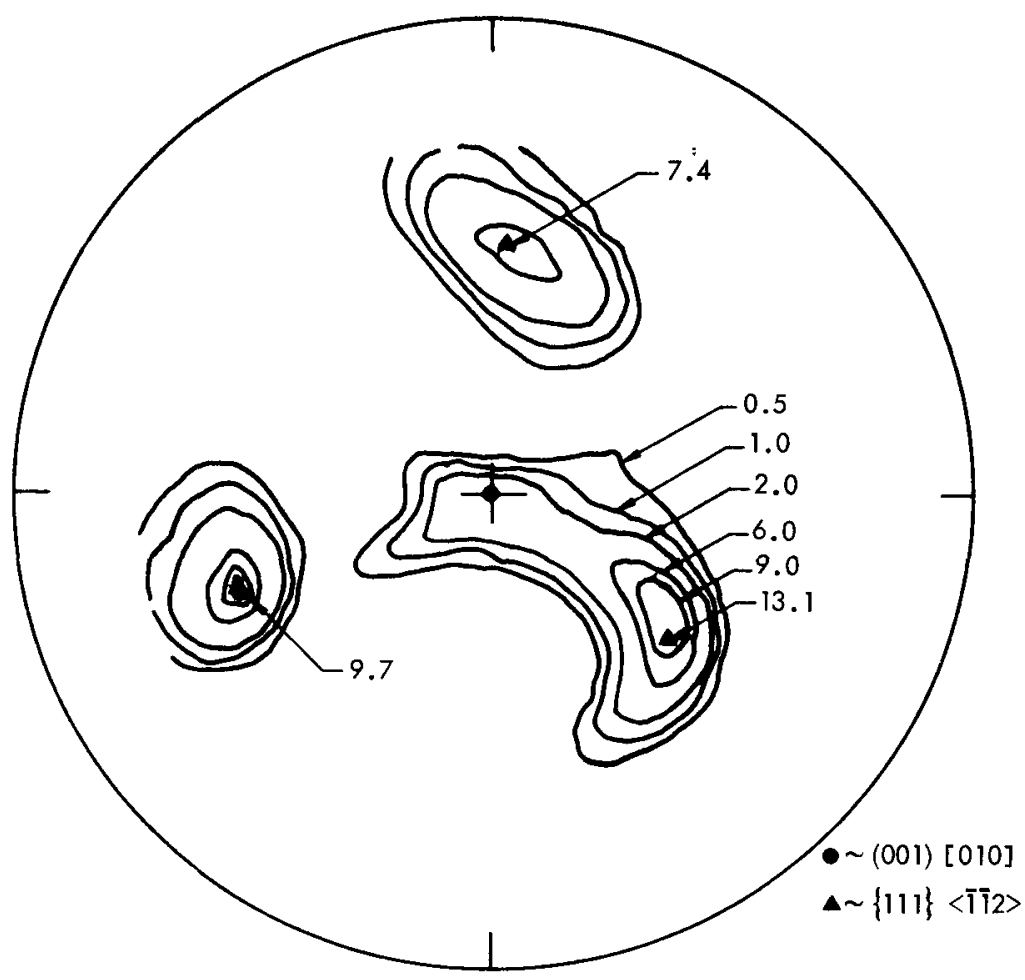

(a) Top Surface.

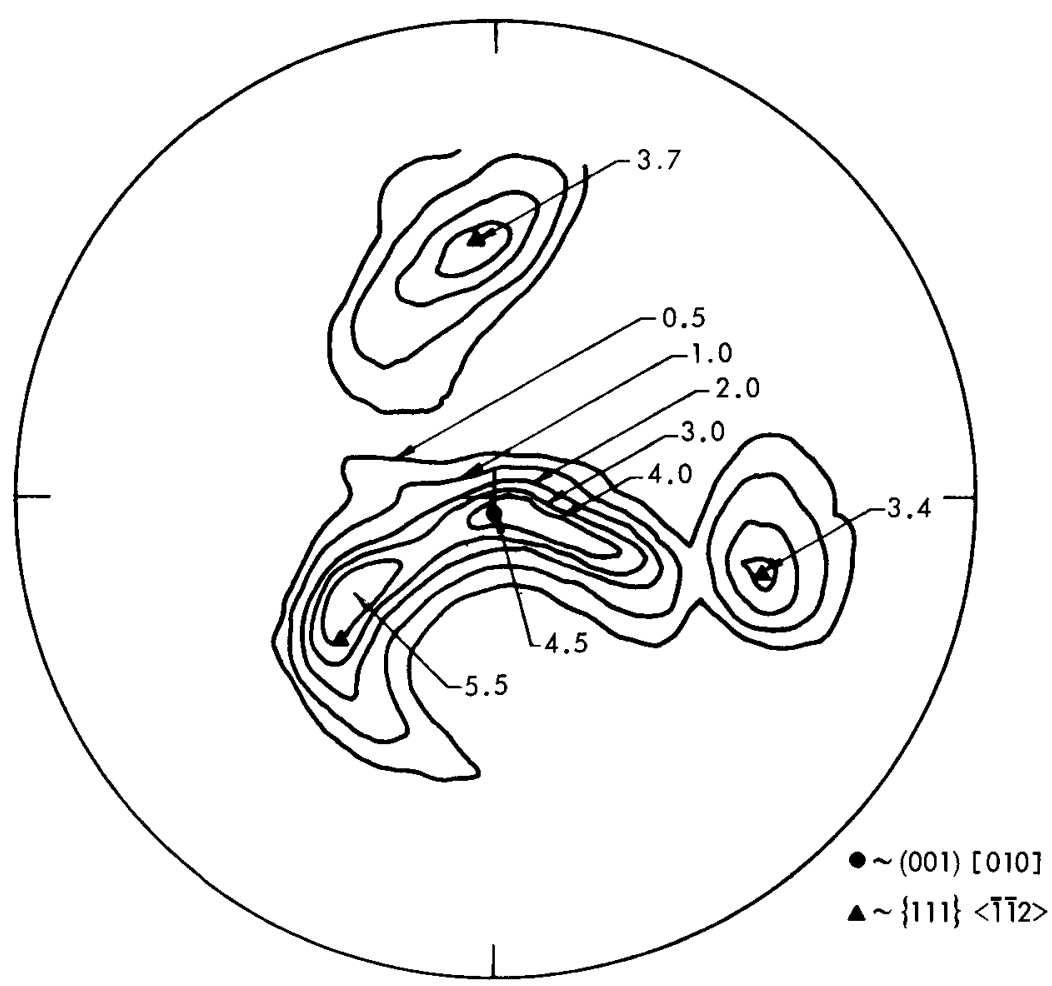

(b) Bottom Surface.

Figure 40. (200) POLE FIGURES OF THE SURFACES OF CRYSTAL 4-12. $\left(\Delta_{i}=0.79\right.$, Mineral Oil) 
Table 5

SUMMARY OF ROLLING RESULTS

\begin{tabular}{|c|c|c|}
\hline $\begin{array}{l}\text { Rolling } \\
\text { Conditions }\end{array}$ & $\begin{array}{c}\text { Transverse } \\
\text { Width Strain, } \epsilon \mathrm{t}\end{array}$ & Orientations \\
\hline$\Delta_{1}=125$, Dry & 0069 Top & Dual $\{111\}<1 \overline{10}>$. \\
\hline (moderate body) & 0118 Bottom & $\begin{array}{l}\text { Dual }\{235\}<1 \overline{42>} \\
\text { Possible }\{001\}<010>\end{array}$ \\
\hline & 0086 & $\begin{array}{l}\text { Dual }\{111\} \text { RD between } \\
\langle 1 \overline{12}\rangle \text { and }\langle 1 \overline{10}\rangle\end{array}$ \\
\hline (moderate body) & & $\{001\}<010>$ \\
\hline $\begin{array}{l}\Delta_{1}=079, \text { Dry } \\
\text { (thin body) }\end{array}$ & 0100 & $\underset{\{001\}}{\text { Dual }} \tilde{\{}\{111\}<1 \overline{12}>$ \\
\hline $\begin{array}{l}\Delta_{1}=079,011 \\
\text { (thin body) }\end{array}$ & 0157 & $\begin{array}{l}\text { Single } \sim\{111\}<1 \overline{12}>\text {, } \\
\{001\}<010>\end{array}$ \\
\hline
\end{tabular}

Selection of Crystals for Annealing Experiment - Two rolled crystals (4-8 and 4-11), described in the prior section, were selected from the (110)[110] orientation group for the annealıng experıments Crystal 4-11 was selected because it was a thicker crystal which exhibited symmetric transverse strain, symmetric deformation banding, and approximately the same orientation on both surfaces of the crystal Crystal 4-8, on the other hand, was characteristıc of those crystals which exhıbited nonsymmetric transverse straıns, nonsymmetric deformation bandıng, and surfaces of differing orientation These annoyıng differences in preferred orientation and the nature of deformation banding from one surface to the other of Crystal 4-8 were put to advantage to determıne what role these effects play in possıble differences in recrystallization behavior At the same time, they were also to be compared to the more symmetric behavior of Crystal 4-11

Transmission Electron Microscopy - Microscopy of the deformed (110) crystals was quite difficult due to their highly straıned condition However, a limited examination of Crystal 4-3 was successful The surface texture of this crystal was very similar to that of the top surface of Crystal 4-10, Figure 25(a) Although this crystal was to have been annealed and its recrystallization behavior subsequently characterızed, oxygen contamınation durıng annealıng of these specımens precluded its being used Nevertheless, these TEM results are felt to be representative of the deformed condition of all (110) crystals rolled under sımılar conditions Figure 41 shows a typical area of the rolled crystal, while the inset shows the selected-area diffraction pattern from thıs field Note that the crystal had a definıte cell structure, with a very high dislocation density in the individual cells Diffraction patterns from several areas revealed that the rolling plane was approxımately (111), in agreement with the pole-figure data Also, considerable misorientation existed with arcs of Intensity extending 22 - 24 degrees, with several satellıte spots present These smaller spots were most likely due to spıkıng of intensity from very thın misoriented regions, and some orientations were present that were more than simple rotations around the normal direction A comparison of the diffraction patterns of Figure 41 with Figures 19 and 22 revealed that the amount of misorientation withın a limited 


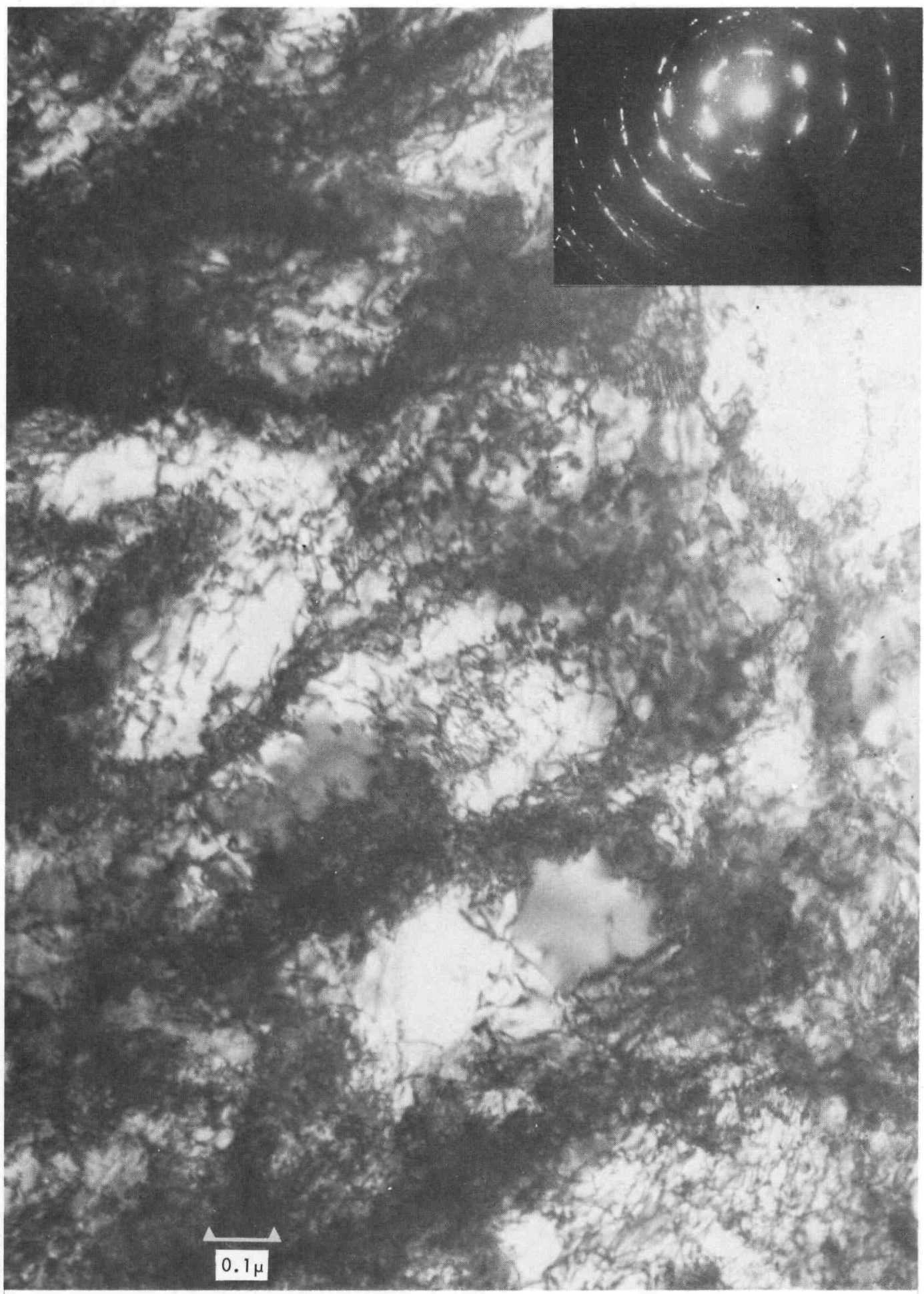

Figure 41. MICROSTRUCTURE OF CRYSTAL 4-3 THAT WAS ROLLED 80 PERCENT.

field of the (110) crystal was greater than in the (111) crystal, though the deformed crystals both had essentially (111) rolling planes. Figure 42 shows the results of 


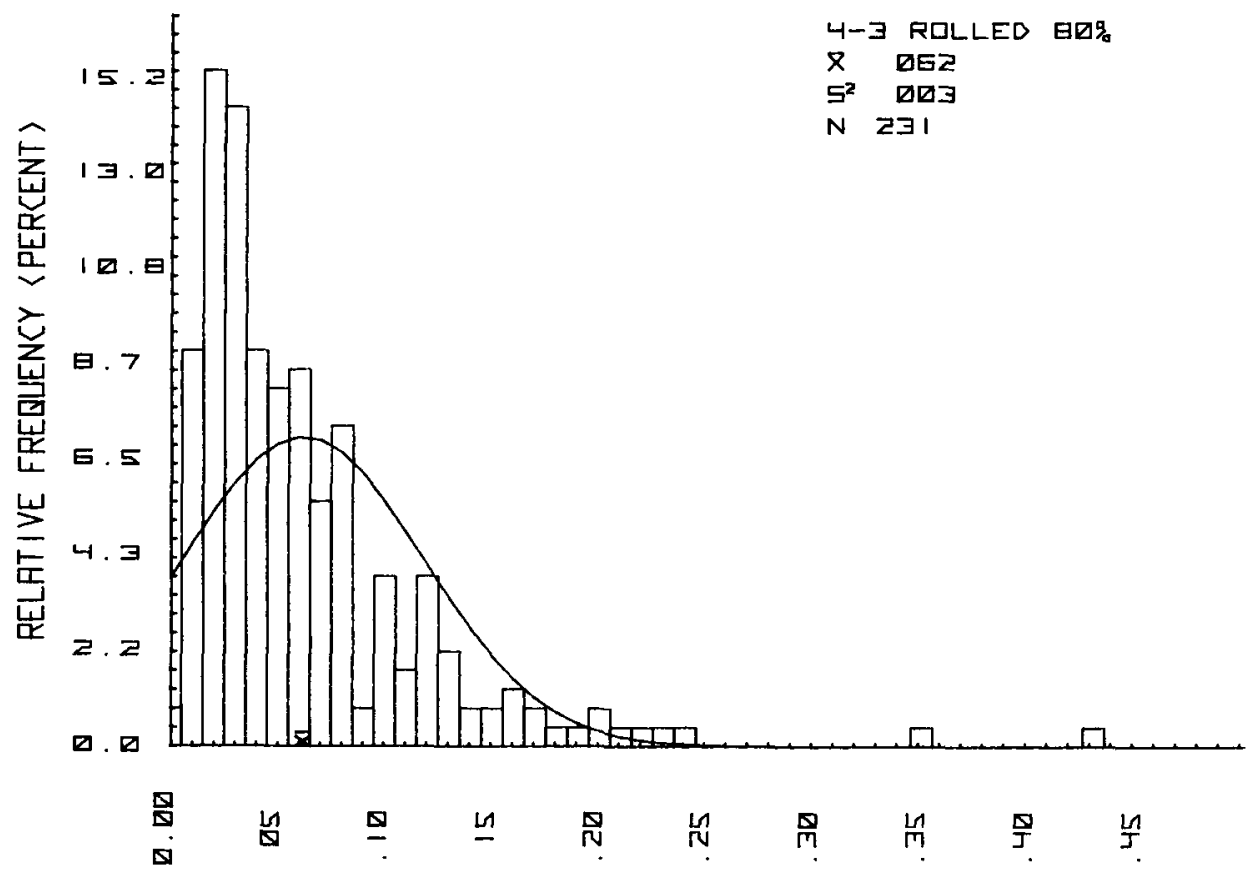

CELL FREA 〈SQUARE MICRUMETERS〉.

(o) Histogrom of the Cell Areo

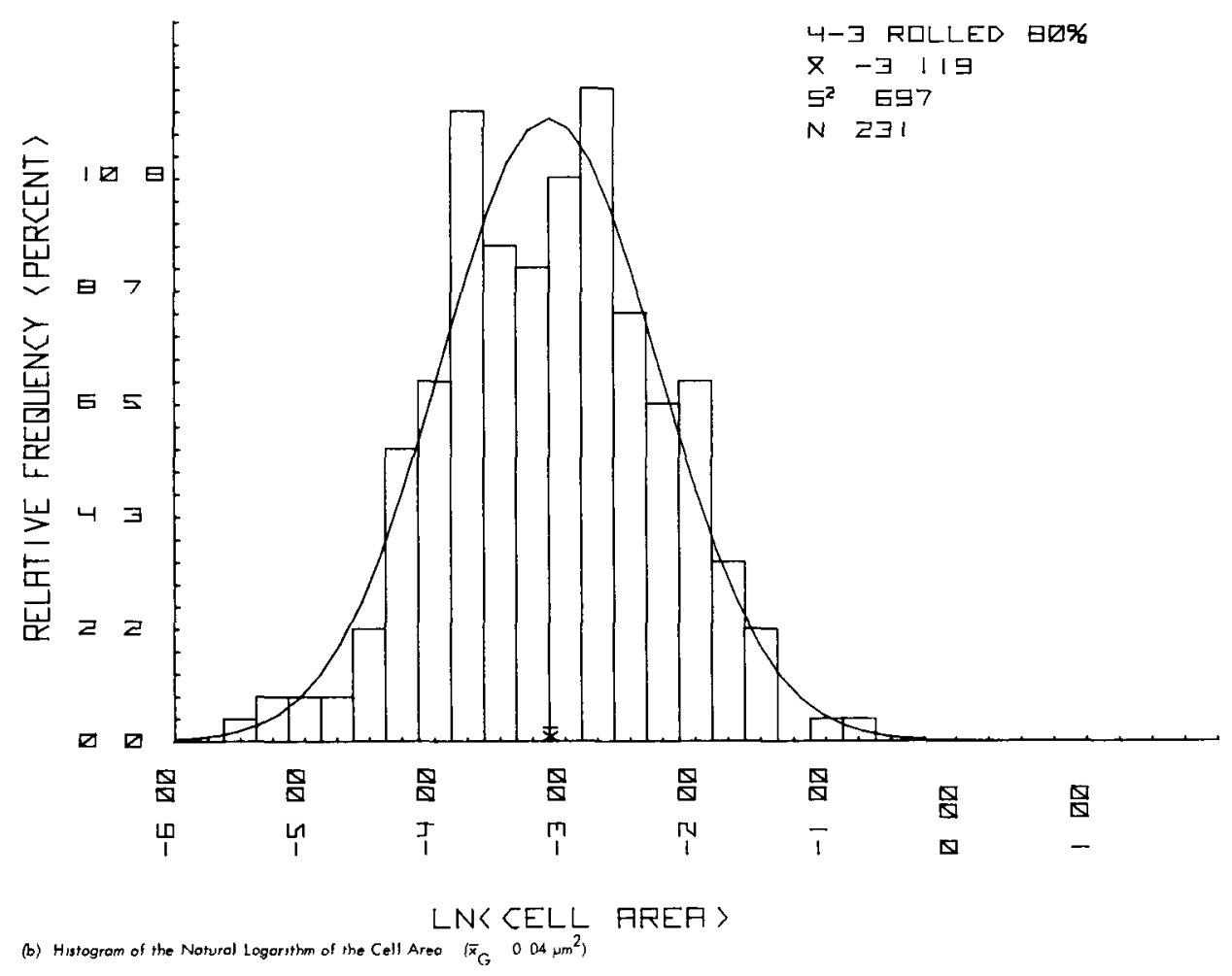

Figure 42. HISTOGRAMS OF THE CELL AREA AND THE NATURAL LOGARITHM ICELL AREA) FOR CRYSTAL 4-3 THAT WAS ROLLED 80 PERCENT. 
cell-area measurements on Crystal 4-3 which clearly demonstrate that the cell size of the (110) crystal is smaller than that of the (111) crystal (Figures 20 and 21). Average cell area of the $(110)$ crystal is $0.062 \mu \mathrm{m}^{2}$, whereas the cell area of the (111) crystal is $0.14-0.17 \mu \mathrm{m}^{2}-$ a factor of nearly three times. Because of limited observations in the rolled condition, another (110) crystal picked at random from the many that were deformed was annealed for four hours at $400^{\circ} \mathrm{C}$, as described previously for other crystals. Though microscopy was somewhat easier to perform on the recovered material, significant differences in the cell area were found, as noted in Figure 43 which shows the results of cell-area measurements on the recovered crystal. Statistical tests of the transformed data indicate that the means of these distributions are significantly different at the $95 \%$ confidence level. Unlike the (111) crystal, significant structural changes appear to be taking place under moderate annealing conditions. Though a major portion of the cell-size differences could have been due to errors in marking the cells of the deformed crystal, some growth appears to have resulted from the annealing treatment. Data from the recovered crystal could not, therefore, be used to indicate the condition of the deformed crystal.

\section{Effects of Annealing}

For convenience, the word "crystal" may be used in this and later sections when referring to a material that is obviously polycrystalline. The implication will be that the material started as a single crystal.

Times and temperatures for the annealing treatments were selected to best characterize the wide variation in recrystallization behavior among the various orientations. Because of the small size of the starting crystals, and the many different tools used to study them, only a limited number of specimens could be annealed from any one crystal. Where possible, direct comparison of the annealing response between two orientations was made. In addition to observing the initial stages of recrystallization, an effort was also made to select at least one set of conditions that would produce complete recrystallization of a crystal.

Figures 44 and 45 show the fractional residual integral breadth and microhardness of all orientations versus the logarithm of the annealing time. The fraction residual property remaining was defined as:

$$
\text { Fraction Unrecovered }=\frac{P_{O}-P_{\text {std }}}{P_{\text {rolled }}-P_{\text {std }}} .
$$

where $P_{0}, P_{\text {std }}$, and $P_{\text {rolled }}$ refer to the property of a recovered crystal, an unrolled crystal standard, and the crystal rolled to $80 \%$ reduction, respectively. Using these variables, a comparison of all orientations can be made on the same scale. Two temperatures were used where sufficient data were taken so that isothermal comparisons could be made for different orientations (600 and $800^{\circ} \mathrm{C}$ ). Dislocation-cell-area measurements on crystals annealed at these temperatures, as well as others, are given in Table 6 . Data in the form of histograms for all of the cell-area measurements may be found in Appendix B. 


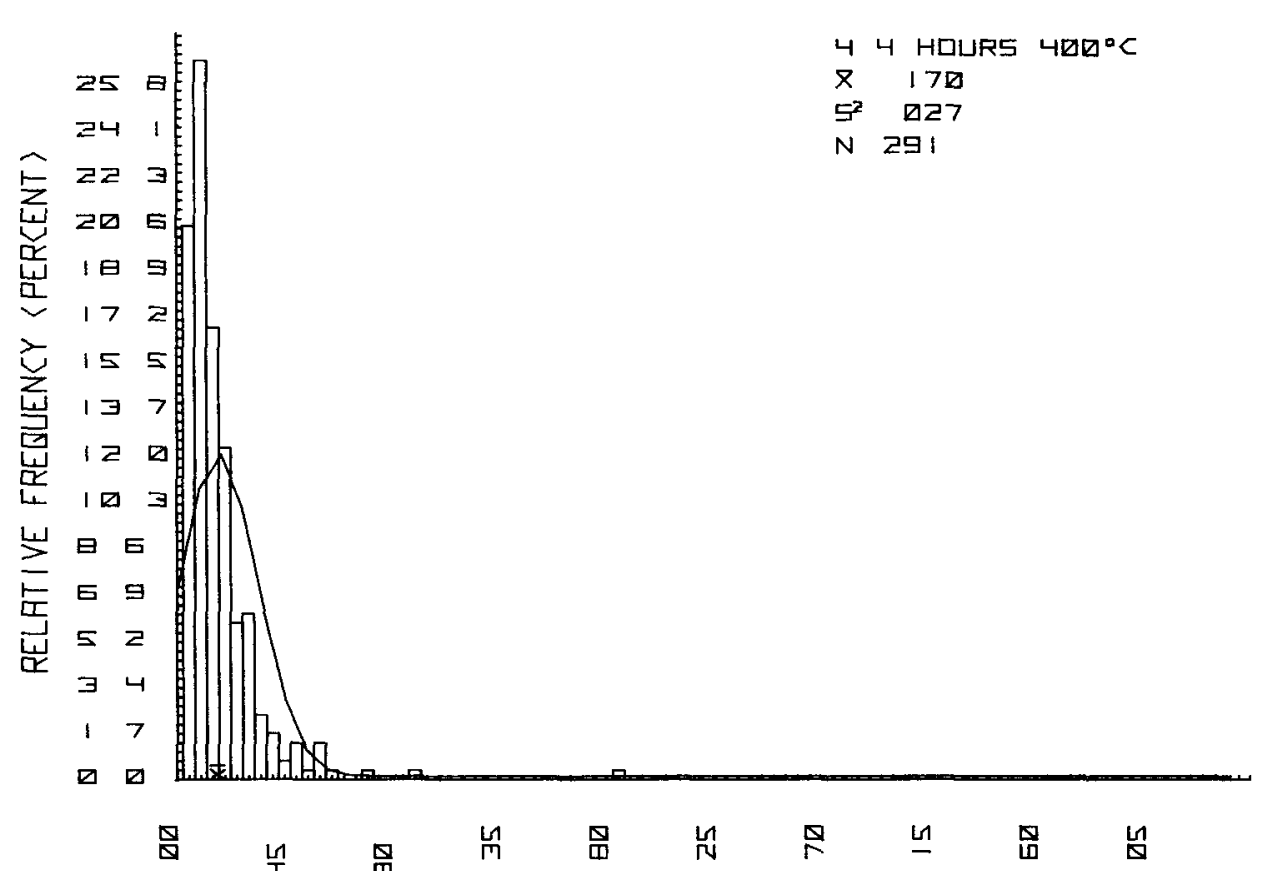

CELL FREA 〈SQUHRE MI CRDMETERS〉

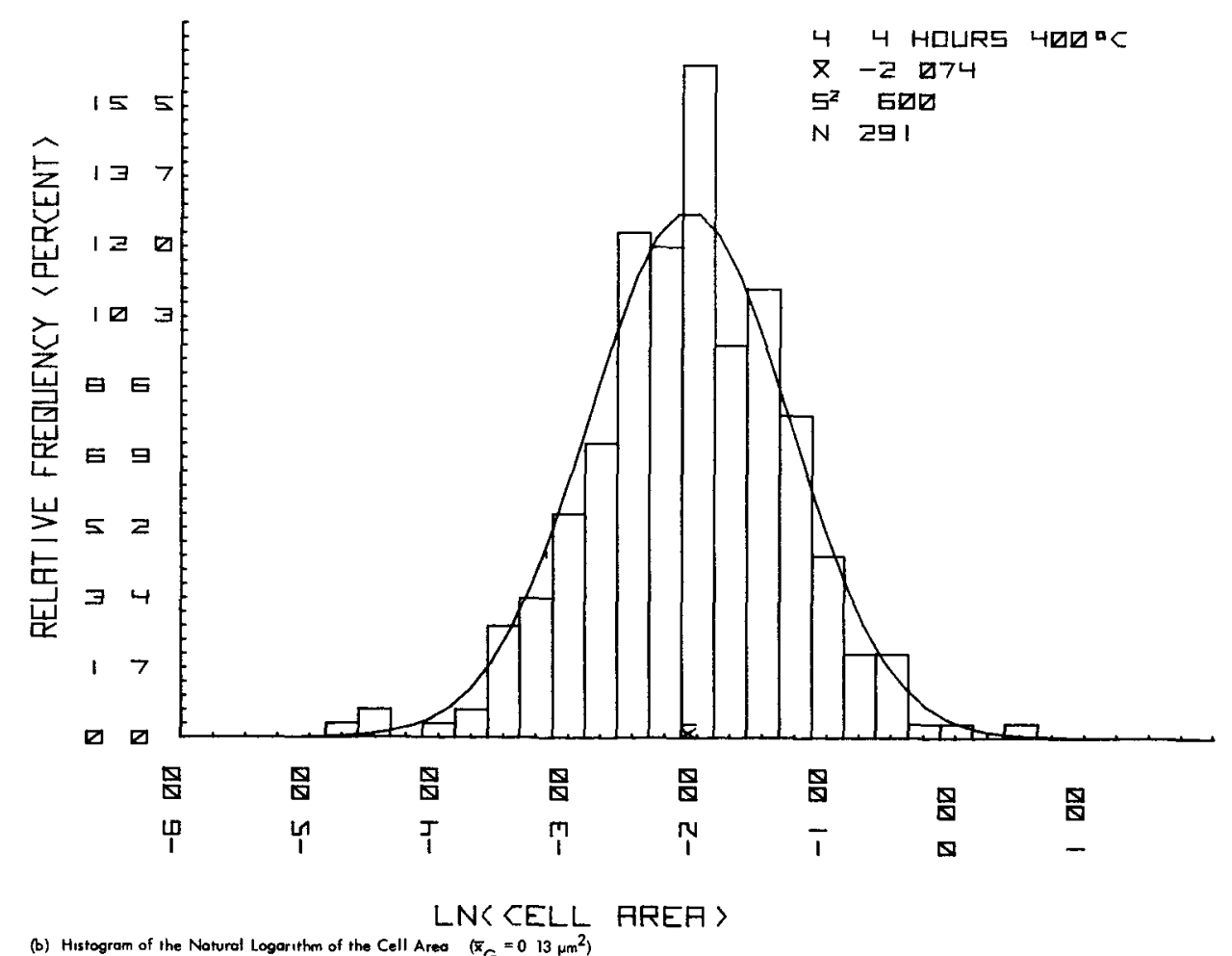

Figure 43. HISTOGRAMS OF THE CELL-AREA MEASUREMENTS OF THE $(1101[1170]$
CHYSTAL THAT WAS ROLLED 80 PERCENT AND ANNEALED FOR FOUR HOUPS AT CRYSTAL THAT WAS ROLLED 80 PERCENT AND ANNEALED FOR FOUR HOURS AT
$400^{\circ} \mathrm{C}$.
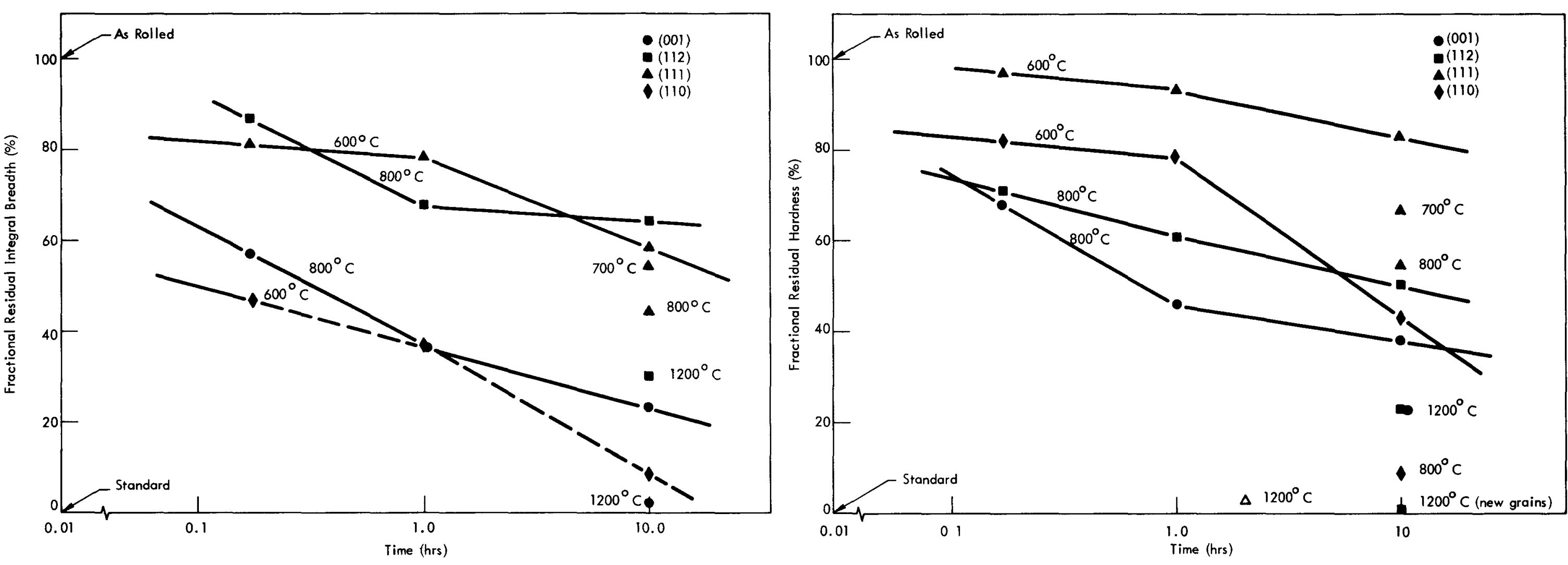

Figure 44. FRACTIONAL RESIDUAL INTEGRAL BREADTH AS A FUNCTION OF THE LOGARITHM OF THE Figure 45. FRACTIONAL RESIDUAL MICROHARDNESS AS A FUNCTION OF THE LOGARITHM OF THE

Table 6

DISLOCATION-CELL-AREA MEASUREMENTS

\begin{tabular}{cccccc}
\multicolumn{6}{c}{ DISLOCATION-CELL-AREA MEASUREMENTS } \\
ON ANNEALE CRYSTALS
\end{tabular}


(001)[1T0] Crystal - When properly handled, (001)[1T0] crystals did not recrystallize even after annealing for ten hours at $1400^{\circ} \mathrm{C}$-the highest temperature possible in this experiment. Thus, annealing of this orientation was accomplished only through recovery processes. Grains did nucleate, however, in crystals which had been scratched during preparation. Scratching may have activated additional slip systems which apparently caused a much greater misorientation on a local scale than that noted here. Artificial nucleation of new grains has been reported previously for the (001)[110] crystal. (66) The results obtained on the (001) crystal were in essential agreement with those of $\mathrm{Hu}^{(15)}$ and others $(67,68)$ who have noted a reluctance of this orientation to recrystallize.

The hardness and integral breadth of the (001) crystal (Figures 44 and 45) recovered rather rapidly between 0.17 and one hour, and then more slowly up to ten hours. These observations suggested a possible change in the recovery mechanism. In ten hours at $800^{\circ} \mathrm{C}$, the (001) crystal recovered more of its hardness and integral bread th than either the (112) or (111) crystals. In ten hours at $1200^{\circ} \mathrm{C}$, the (001) crystal completely recovered its integral breadth, yet retained $23 \%$ of its original hardness.

The integral breadth and hardness are believed to be related to the change in microstructure of the crystal during annealing. Transmission electron micrographs of the crystal annealed at 800 and $1200^{\circ} \mathrm{C}$ are presented in Figure 46. Dislocation densities measured from these micrographs and others are given in Table 7. A rather dramatic decrease in the dislocation density occurred from the rolled condition in 0.17 hour at $800^{\circ} \mathrm{C}$, as is evident in the microstructure of Figure 46(a). A rather high density of small loops (marked with As) was present after 0.17 hour. This rapid decrease in dislocation density from the rolled condition corresponded to the initial rapid recovery of hardness and integral breadth of Figures 45 and 46.

Upon further annealing for one hour at $800^{\circ} \mathrm{C}$, the dislocation density continued to decrease and dislocation reactions (marked with arrows) were observed in the microstructure, Figure 46(b). Additional annealing for ten hours reduced the dislocation density slightly, and more dislocation nodes (arrows) become apparent in the microstructure, Figure 46(c). The small decrease in dislocation density from one to ten hours corresponded to the apparent decrease in the recovery rate of the hardness and integral breadth (Figures 44 and 45 ).

Increasing the annealing temperature to $12000 \mathrm{C}$ resulted in a further decrease in the dislocation density with essentially all dislocations present in networks, Figure 46(d). Some dislocations were out of contrast in Figure 46(d). Under the diffraction conditions used $(\bar{g}=\langle 200\rangle)$, all a/2 $<111>$-type dislocations should have been in contrast. On the other hand, only one third of all possible a $<100>$ dislocations would have been in contrast under the same diffraction conditions. Therefore, these networks were believed to consist of hexagonal arrays of a $\langle 100\rangle$ dislocations which have been reported in body-centered cubic materials by several investigators. $(8,69,70)$ Analysis of single-crystal electron diffraction patterns indicated less than one degree of misorientation across these boundaries. Thus, subgrains, when they did form in this crystal, were very large by comparison with the other crystals and only slightly misoriented, suggesting that the crystal was attempting to return to its initial state by recovery processes only. 


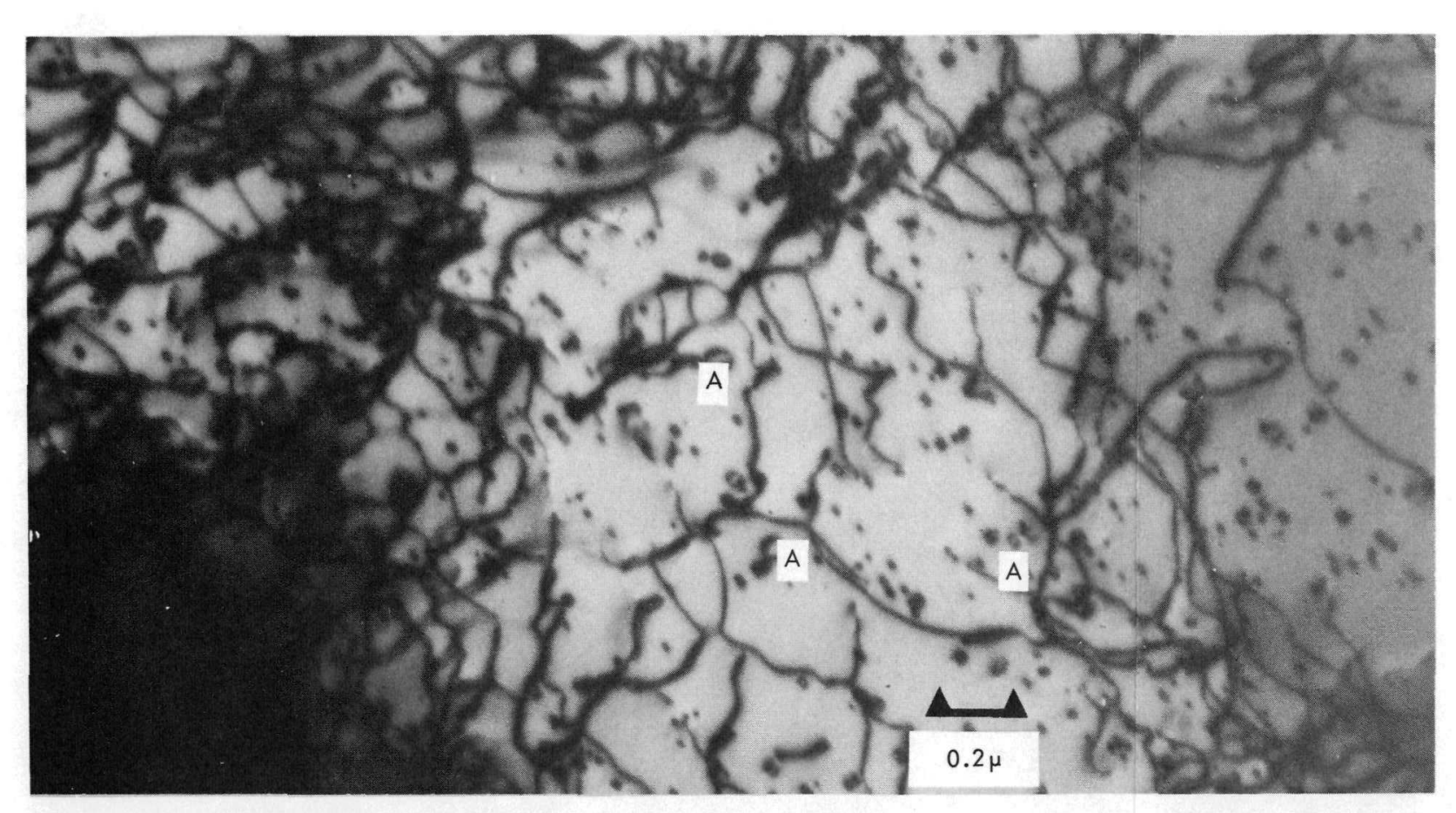

(a) For 0.17 Hour at $8000^{\circ} \mathrm{C}$.

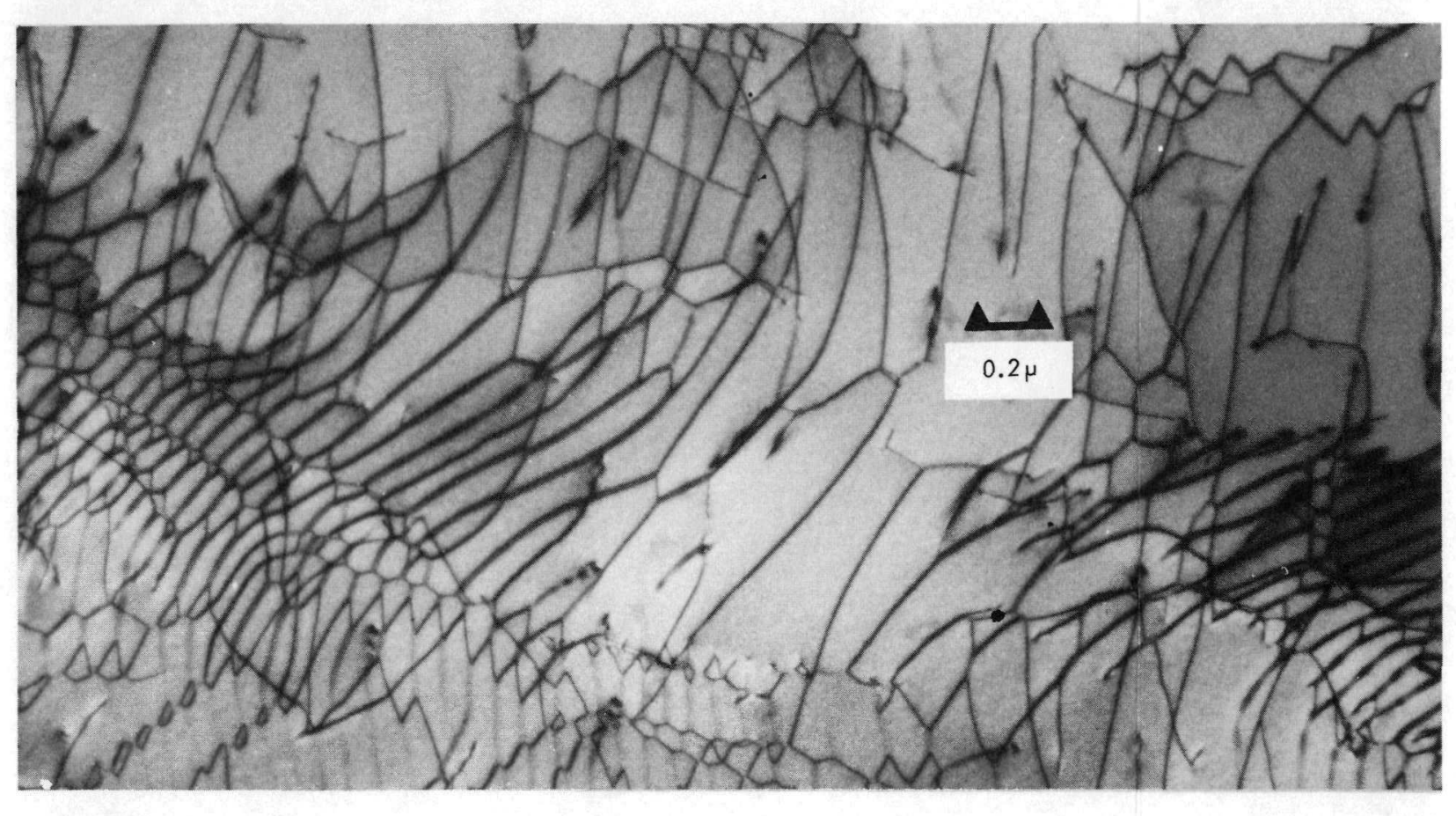
(c) For 10 Hours at $8000^{\circ} \mathrm{C}$

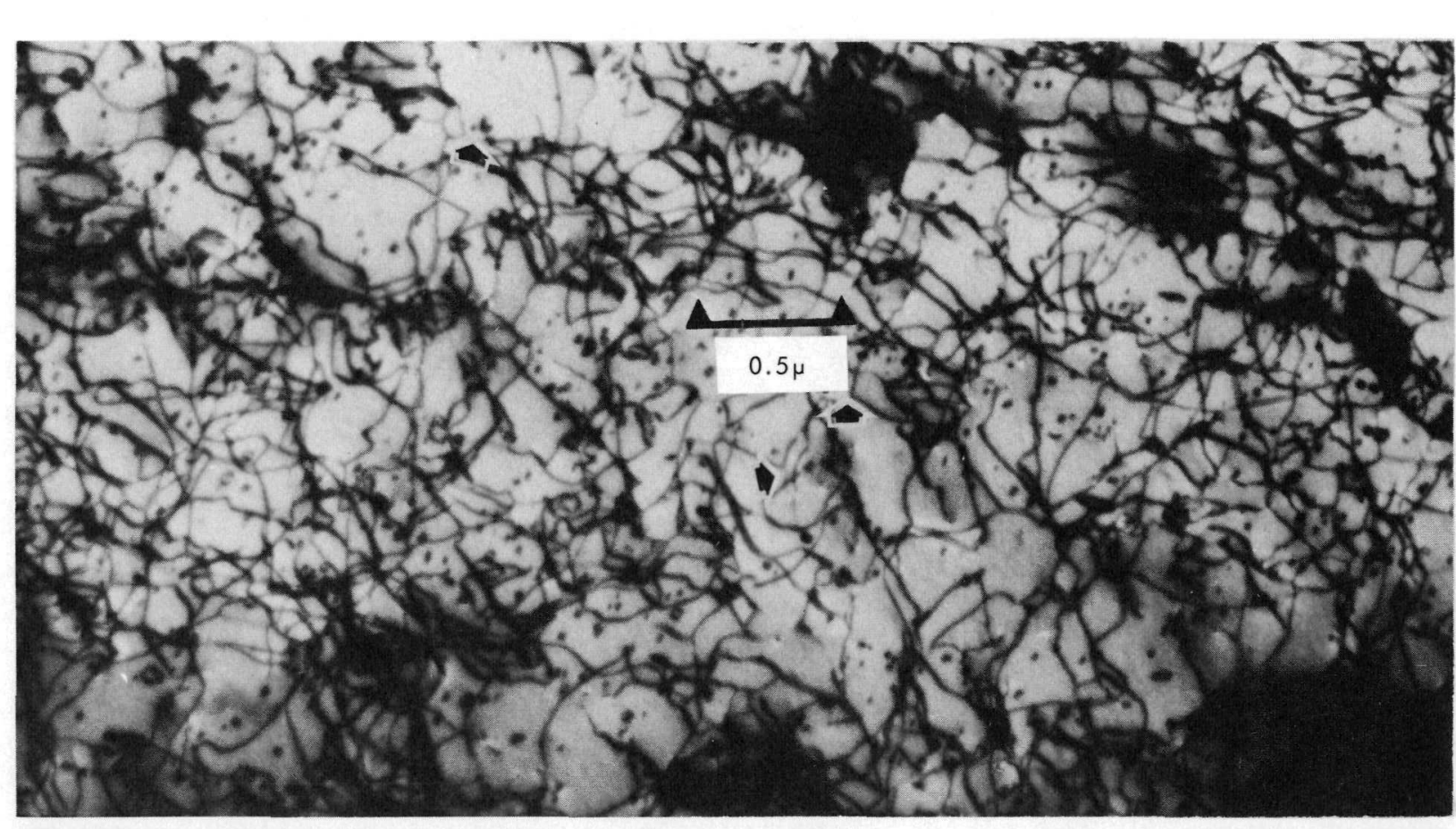

(b) For 1.0 Hour at $800{ }^{\circ} \mathrm{C}$

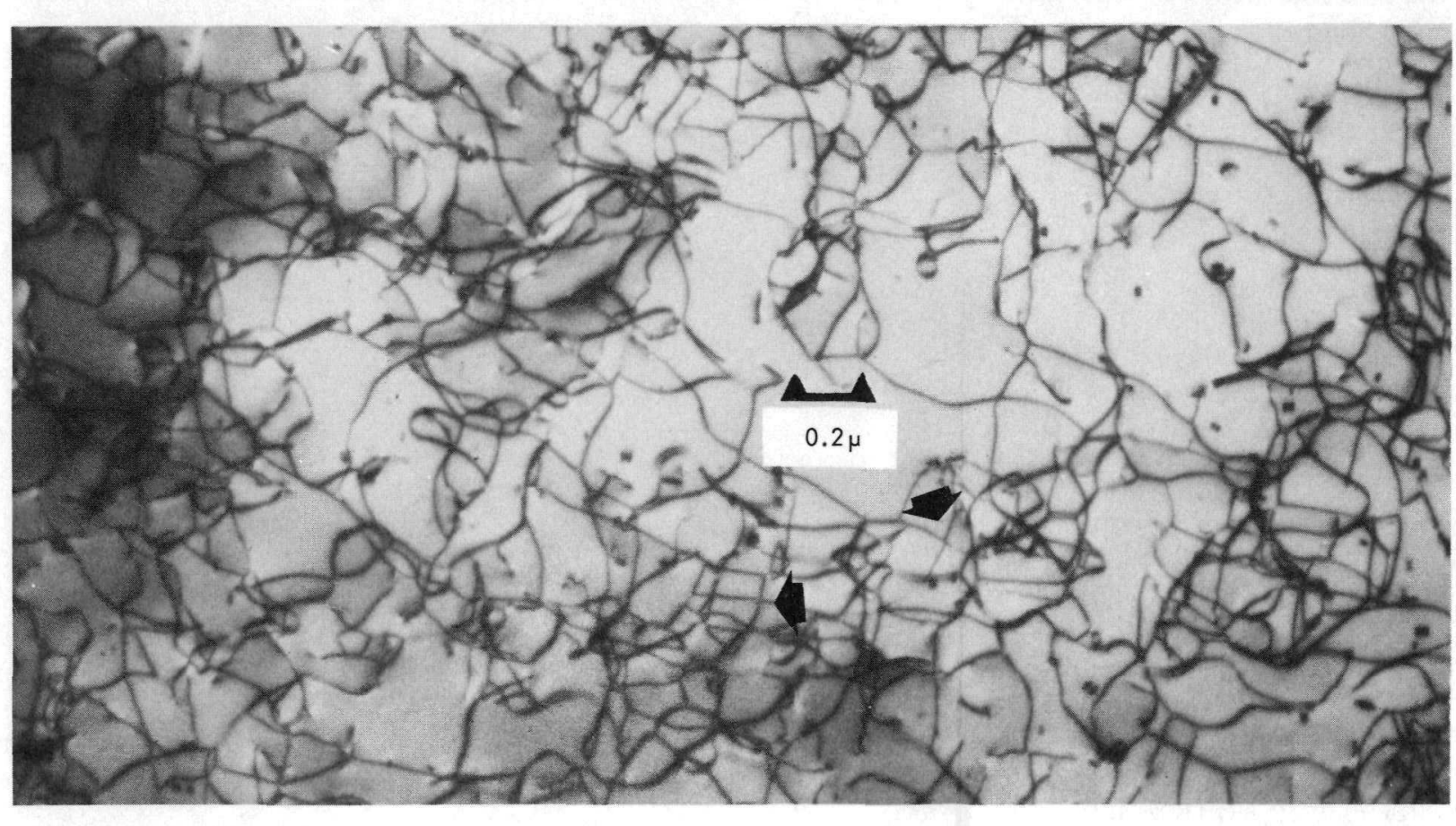

(d) For 10 Hours at $1200^{\circ} \mathrm{C}$.
Table 7

MEASURED DISLOCATION DENSITIES FOR

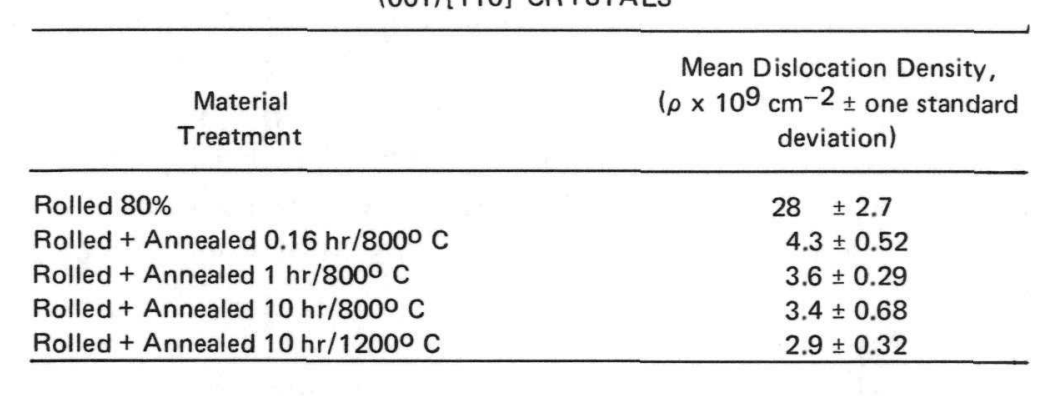


(112) [1T0] Crystal - The (112) crystal was observed to be somewhat less reluctant to recrystallize than was the (001) crystal. Annealing of this crystal for 10 hours at $12000^{\circ} \mathrm{C}$ resulted in partial recrystallization and the creation of a few large grains (Figure 47),

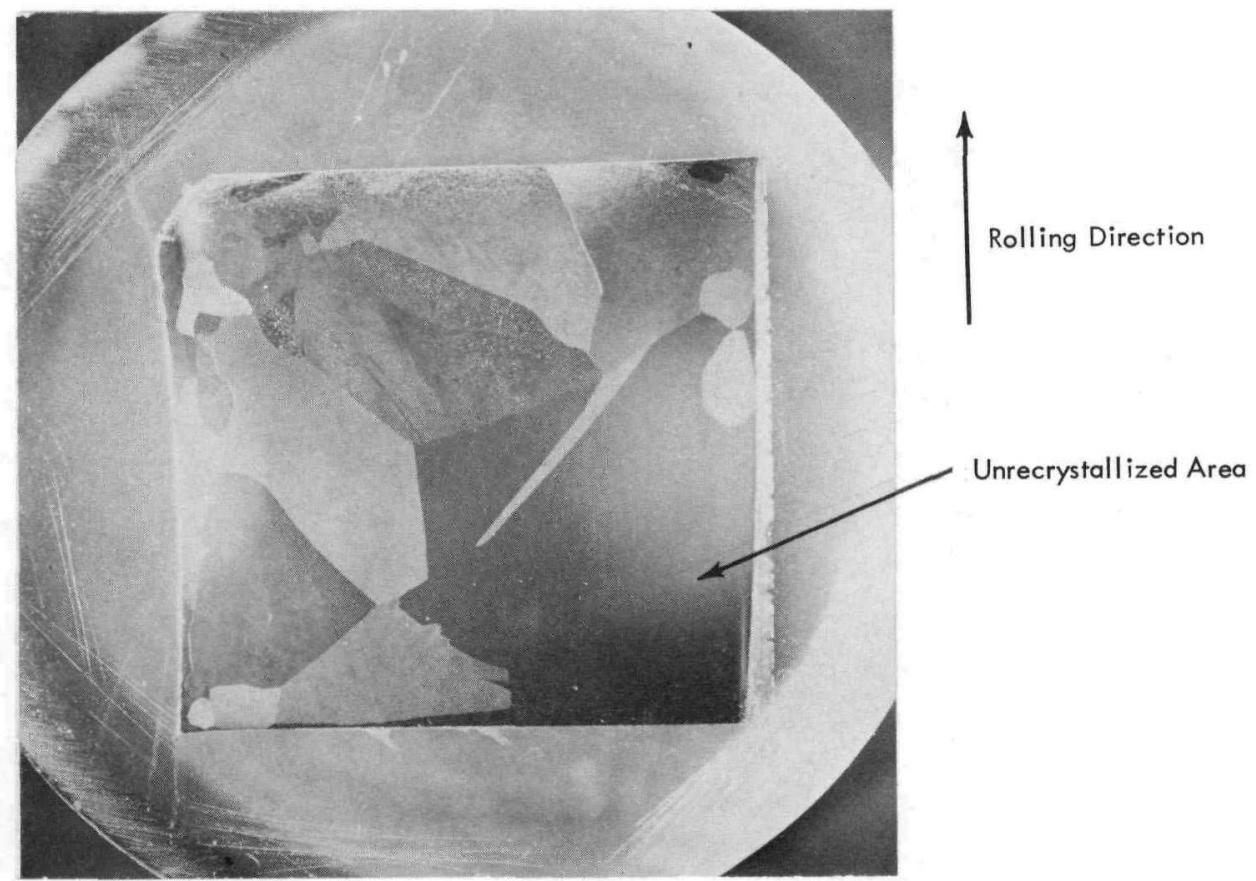

Figure 47. PORTION OF THE (112)[110] CRYSTAL THAT WAS ANNEALED FOR TEN HOURS AT $1200^{\circ} \mathrm{C}$. (Note the Uncrystallized Area; Bright Field Illumination; 5X)

possibly indicative of artificial nucleation. During isothermal annealing at $800^{\circ} \mathrm{C}$, the (112) crystal recovered slightly less of its hardness and substantially less of its integral breadth than the (001) crystal. The hardness of new grains formed upon annealing for ten hours at $1200^{\circ} \mathrm{C}$ was approximately the same as the unrolled starting crystal (Figure 45). The hardness of the unrecrystallized region of the crystal recovered to the same point as the (001) crystal annealed under the same conditions of time and temperature. Integral breadth of the unrecrystallized portion of the (112) crystal recovered less than the (001) crystal.

Dissimilarities in properties of the (001) and (112) crystals were most likely due to differences in microstructure. Annealing of the (112) crystal for 0.17 hour at $800^{\circ} \mathrm{C}$ produced the microstructure shown in Figure 48. A comparison with the rolled microstructures of Figures 15 through 17 shows that dislocations polygonized to form very broad, low-angle grain boundaries surrounding areas of much lower dislocation density. Many low-angle tilt/twist boundaries can be seen with evidence of stable hexagonal networks beginning to develop. Alternate contrast from subgrain to adjacent subgrain indicates a more or less random rotational misorientation with a possible net zero rotation over a range of subgrains. The geometric mean cell area of the recovered crystal was found to be $0.41 \mu \mathrm{m}^{2}$, Table 6 .

A typical diffraction pattern from an area, such as seen in Figure 48, is shown in Figure 49. Analysis of the pattern revealed that the foil normal was at least seven degrees and possibly 
further from the [111] zone axis. Pole figures of the crystal showed an approximate [112] crystal normal which is 19.5 degrees from the [111]. Thus, considering the errors possible in both measurements, the electron and $\mathrm{X}$-ray diffraction results are in reasonable

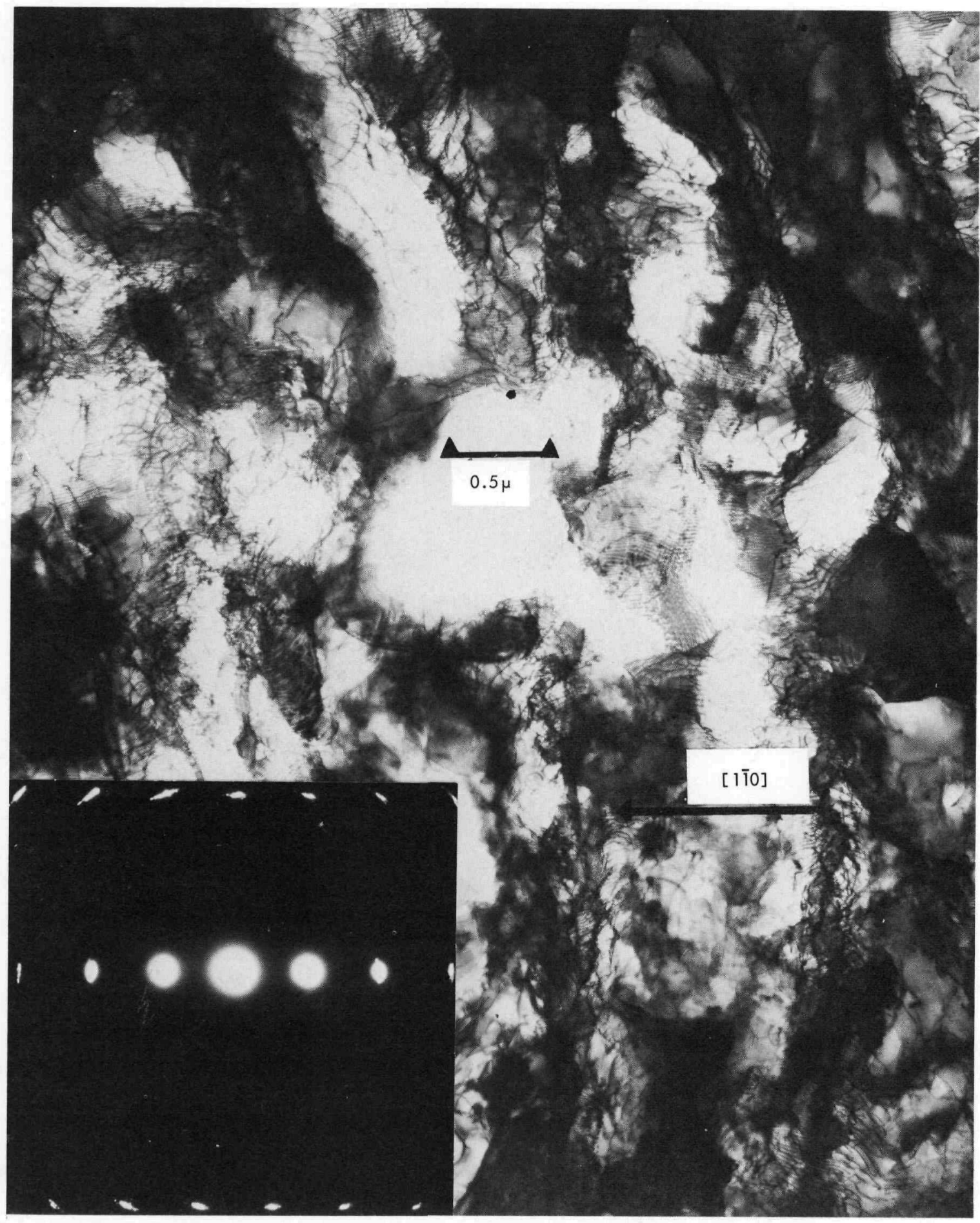

Figure 48. MICROSTRUCTURE OF THE (112)[110] CRYSTAL THAT WAS ROLLED AND ANNEALED FOR 0.17 HOUR AT $800^{\circ} \mathrm{C} . \overline{\mathrm{lg}}=[1 \overline{1} 0], \sim[111]$ Zone $)$ 
agreement. Rotation about the foil normal is a measure of maximum misorientation of the field of view and was approximately four degrees for the $\{110\}$ planes.

A higher-magnification micrograph of a large subgrain is shown in Figure 50. SAD patterns from the enclosed area indicated a rotation of two degrees around the specimen normal. The lack of contrast across the boundary substantiates the fact that there was little orientation difference between the two subgrains. (c) The misorientation between these subgrains was felt to be representative of the maximum misorientation between subgrains after annealing for 0.17 hour at $8000 \mathrm{C}$. Note that the boundary running from the top to bottom of the large subgrain appeared to be dissolving. Boundary disappearacce such as this has been interpreted by Hu. (15) Guthrie, ${ }^{(11)}$ and many others as evidence of coalescence of two subgrains.

Continued annealing at $800^{\circ} \mathrm{C}$ increased the geometric average subgrain size of the crystal (Table 6) and reduced the internal-dislocation density of the subgrains. Increasing the temperature to $1200^{\circ} \mathrm{C}$ resulted in a very large subgrain size in the unrecrystallized region of the crystal, as seen in Figure 51. The diffraction pattern (inset) was taken from the entire field of view. Though nearly 20 specimens were examined, no individual subgrain with a high-angle boundary was ever found that could be identified as a recrystallization nucleus.

As previously shown in Figure 47, recrystallization of the (112) crystal was approximately $60-70 \%$ complete after ten hours at $1200^{\circ} \mathrm{C}$, with an average grain diameter of approximately $2.0 \mathrm{~mm}$. Annealing at $1000^{\circ} \mathrm{C}$ for ten hours resulted in an approximately $10 \%$ recrystallization, as noted in Figure 52 . The elongated nature of the two larger grains (light in the photomicrograph), suggested that grain-boundary migration was easier in some directions than in others. Widely scattered, isolated grains such as these demonstrated the difficulty of nucleation in this crystal.

In order to determine the orientation relationship between the new grains and the matrix, back-reflection Laue photographs of seven grains of a crystal annealed for ten hours at $1200^{\circ} \mathrm{C}$ were taken and analyzed. Rotation axes, yielding the smallest angle of misorientation between the new grains and matrix, were determined and plotted in the stereographic triangle presented in Figure 53. Many investigators have established a definite crystallographic relationship between the deformed matrix and recrystallized

(c) A very fine contrast effect, consisting of parallel lines spaced $59 \AA$ apart, was noted in the subgrain boundary. These could have been either dislocations of a simple tilt boundary or a rotation Moire' fringe pattern. The equation giving the dislocation spacing of a simple tilt boundary is $D=b /(2 \sin \theta / 2)$, where $b$ represents the Burger's vector of the dislocations and $\theta$ the tilt angle. Using an $a / 2<111>$ Burger's vector and a tilt angle of 2 degrees, a dislocation spacing of $82 \AA$ was calculated for tantalum. The equation giving the spacing of rotation Moire' fringes is $D=d /(2 \sin a / 2)$, where $d$ represents the interplanar spacing of the planes making up the grating and $a$ is the angle of rotation. Using the interplanar spacing for $\{110\}$ planes, which were oriented for strong diffraction, a fringe spacing of $67 \AA$ was calculated. Thus, it appeared that the contrast effect was due to rotation Moire' fringes rather than periodically spaced dislocations. 


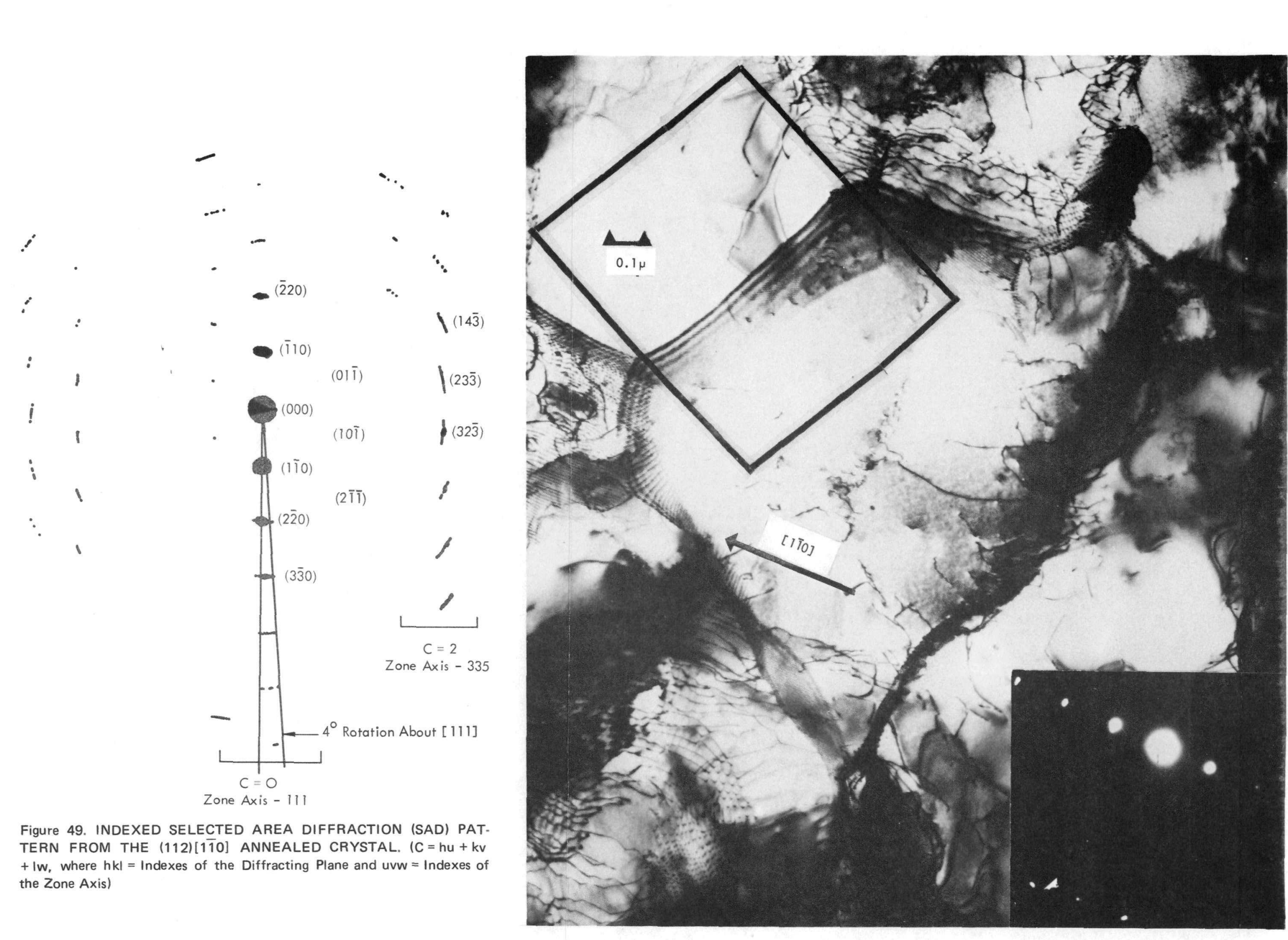

Figure 50. MICROSTRUCTURE OF THE (112)[110] CRYSTAL THAT WAS ANNEALED FOR 0.17 HOUR AT

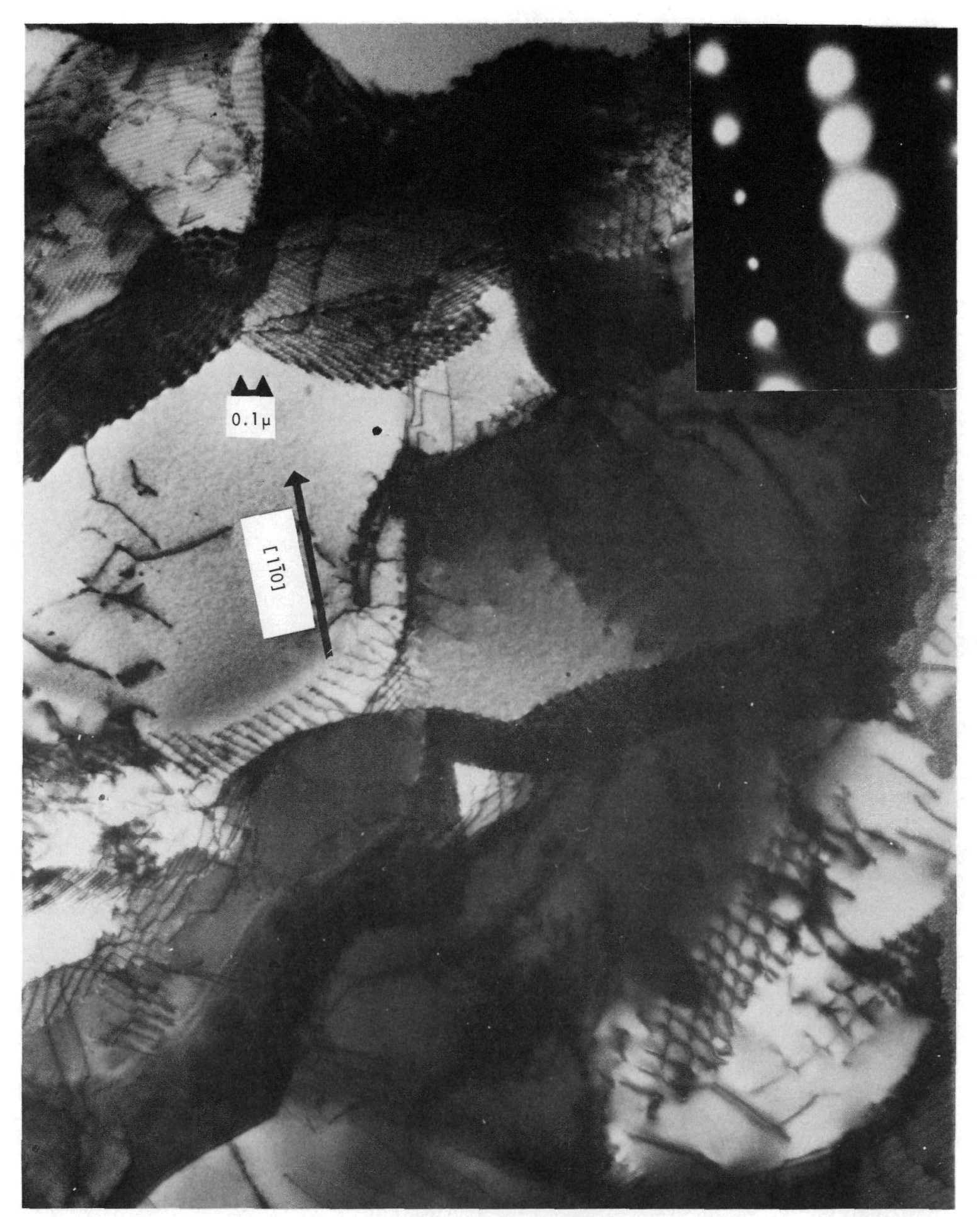

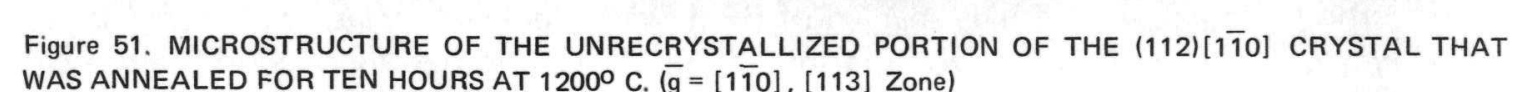


grains, $(23,38,66,71$ - 74) which were equivalent to a coincident site or to higher-order twin relationships discussed by Kronberg and Wilson. (75) Based on the present small amount of data, no such clear crystallographic relation existed between the deformed matrix and new grains for the (112)[110] crystal. These results agreed with Taoka, et al, (72) who found that some recrystallization textures, particularly that of a (112)[110] iron-silicon crystal, could not be described by simple rotation relations. Thus, recrystallization could have been the result of inadvertent artificial nucleation.

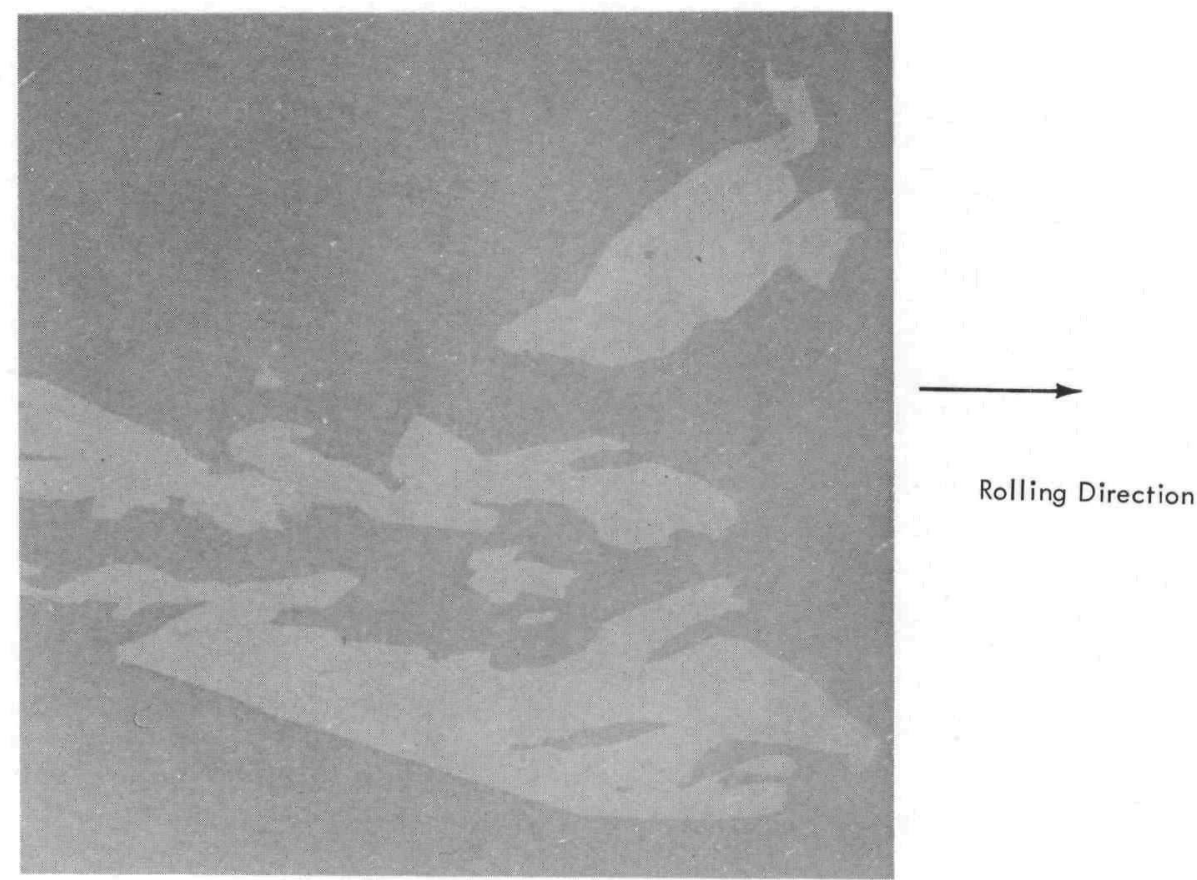

Figure 52. NEW GRAINS OF A (112)[110] CRYSTAL THAT WAS ROLLED AND ANNEALED FOR TEN HOURS AT $1000^{\circ} \mathrm{C}$. (Polarized Light; $50 \mathrm{X}$ )

(111)[110] Crystal - Some variability was noted in the recrystallization behavior of (111) crystals which was believed to be due to not presenting the crystals perpendicularly to the rolling-mill rolls. In addition, some variability was noted in recrystallization behavior from the edge to the center of the crystals, which was perhaps indiçative of inhomogeneous transverse straining. Thus, all data in the annealing phase of this work were taken from the central portion of the crystals. Isothermal annealing of the (111) orientation was performed at $6000 \mathrm{C}$ for comparison with the (110) crystal. In addition, ten-hour anneals were performed at 700 and $8000 \mathrm{C}$ for comparison with the (001) and (112) crystals. Recrystallization and recovery were found to occur in the (111) crystal simultaneously, and property measurements were therefore made on both structures at the same time. Recrystallization was found to be complete in two hours at $1200^{\circ} \mathrm{C}$.

Hardness of the (111) crystal recovered less at $600^{\circ} \mathrm{C}$ than did the (110) crystal at this temperature. In ten hours at $800^{\circ} \mathrm{C}$, the crystal partially recrystallized and its hardness decreased to that of the recovered (112) crystal annealed under the same conditions. 
Upon full recrystallization, the (111) hardness approached that of the unrolled crystal.

Integral breadth measurements also demonstrated that the (111) crystal recovered less than the (110) crystal when annealed at $600^{\circ} \mathrm{C}$. A change in the recovery rate of the integral breadth appeared to occur between one and ten hours at $600^{\circ} \mathrm{C}$, coinciding with a slight break in the hardness data. The integral breadth of the (111) crystal recovered more than that of the (112) when both were annealed for ten hours at $800^{\circ} \mathrm{C}$. However, ten hours at $800^{\circ} \mathrm{C}$ failed to recover the integral breadth to that of the (110) crystal annealed for ten hours at only $600^{\circ} \mathrm{C}$.

The electron microstructure of the (111) crystal that was annealed for 0.17 hour at $600^{\circ} \mathrm{C}$ is presented in Figure 54. Cell-area measurements revealed that the geometric mean cell area of the annealed crystal was unchanged from that of the rolled crystal. A high concentration of dislocations was present in the cell interiors, while cell boundaries remained diffuse and poorly defined. Dislocation interaction and formation of regular

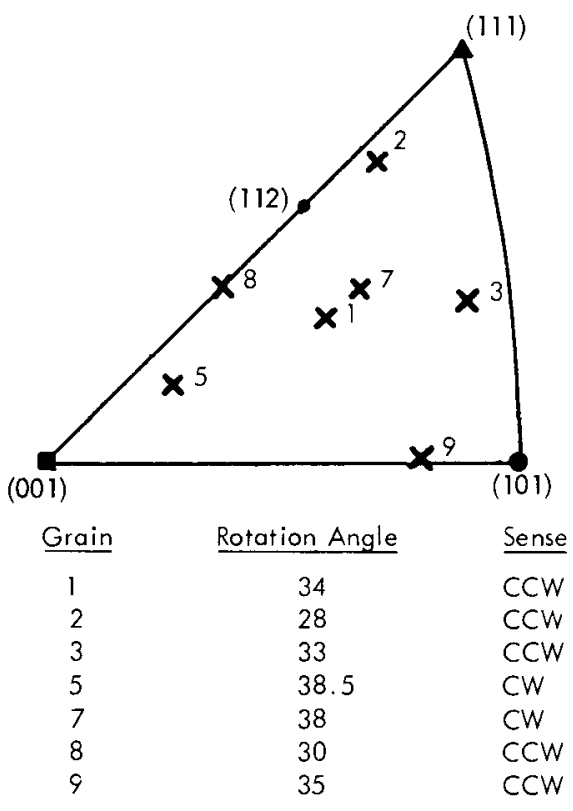

Figure 53. ROTATION AXES OF SEVEN GRAINS OF THE (112)[110] CRYSTAL THAT WAS ANNEALED FOR TEN HOURS AT $1200^{\circ} \mathrm{C}$, PLOTTED IN A STANDARD STEREOGRAPHIC TRIANGLE. (Rotation will Bring the Grain into the Matrix Orientation) arrays could be seen in some areas. Cells were found to be elongated in a direction transverse to the rolling direction. This pattern is contrary to the cell elongation parallel to the rolling direction reported by $\mathrm{Hu}(15)$ and Guthrie. (11) Selected-area electron diffraction of the area (inset of Figure 54) indicated a maximum rotation of the $\{110\}$ planes of $18-21$ degrees about the (111) zone axis. Maximum misorientation measured across some large subgrains was six to eight degrees of rotation. Alternate contrast across subgrains implied that the rotation between subgrains may also alternate in a more or less random manner, and perhaps cancel out over a distance of several subgrains.

Of the several specimens examined which had been annealed for 0.17 hour at $600^{\circ} \mathrm{C}$, one contained a cell which was much different in contrast than the surrounding area (Figure 55). In addition, the dislocation density of this cell was much lower than that of the cells surrounding it. The more regular shape of the boundaries implied that this was a subgrain which would soon become a recrystallization nucleus. The top inset shows a selected-area pattern from the subgrain, while the bottom inset shows a pattern encompassing the entire area. While determination of the exact orientation relationship between the subgrain and surrounding area was not tenable, it appears that the subgrain was within the overall spread of orientation in the area. 


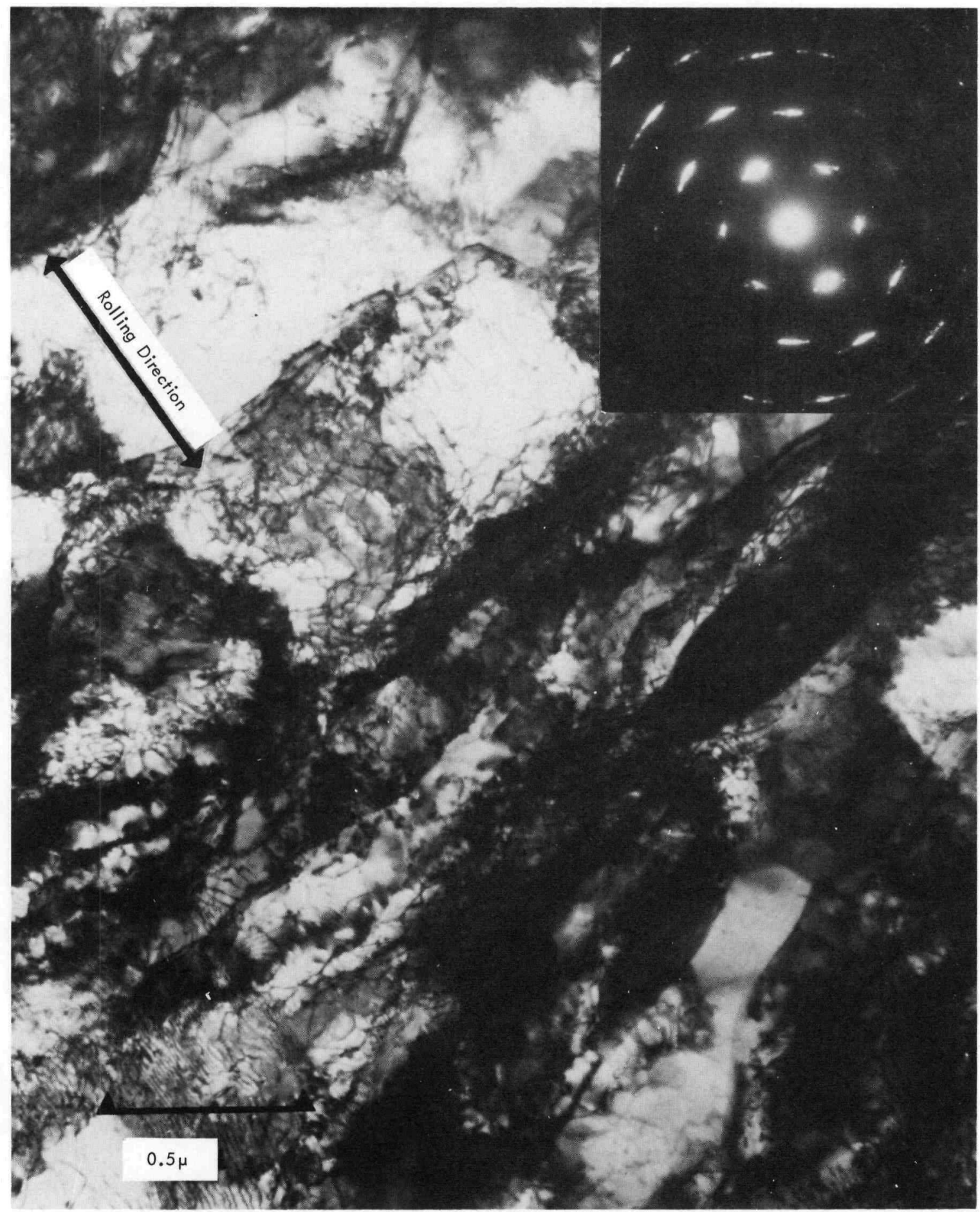

Figure 54. MICROSTRUCTURE OF THE (111)[110] CRYSTAL THAT WAS ANNEALED FOR 0.17 HOUR AT $600^{\circ}$ C. ([111] Zone Axis)

Upon increasing the annealing time to 1.6 hour at $600^{\circ} \mathrm{C}$, the geometric-mean cell area increased (Table 6). Dislocation-cell boundaries became more distinct, while dislocation concentrations within cells continued to decrease, as seen in Figure 56. 


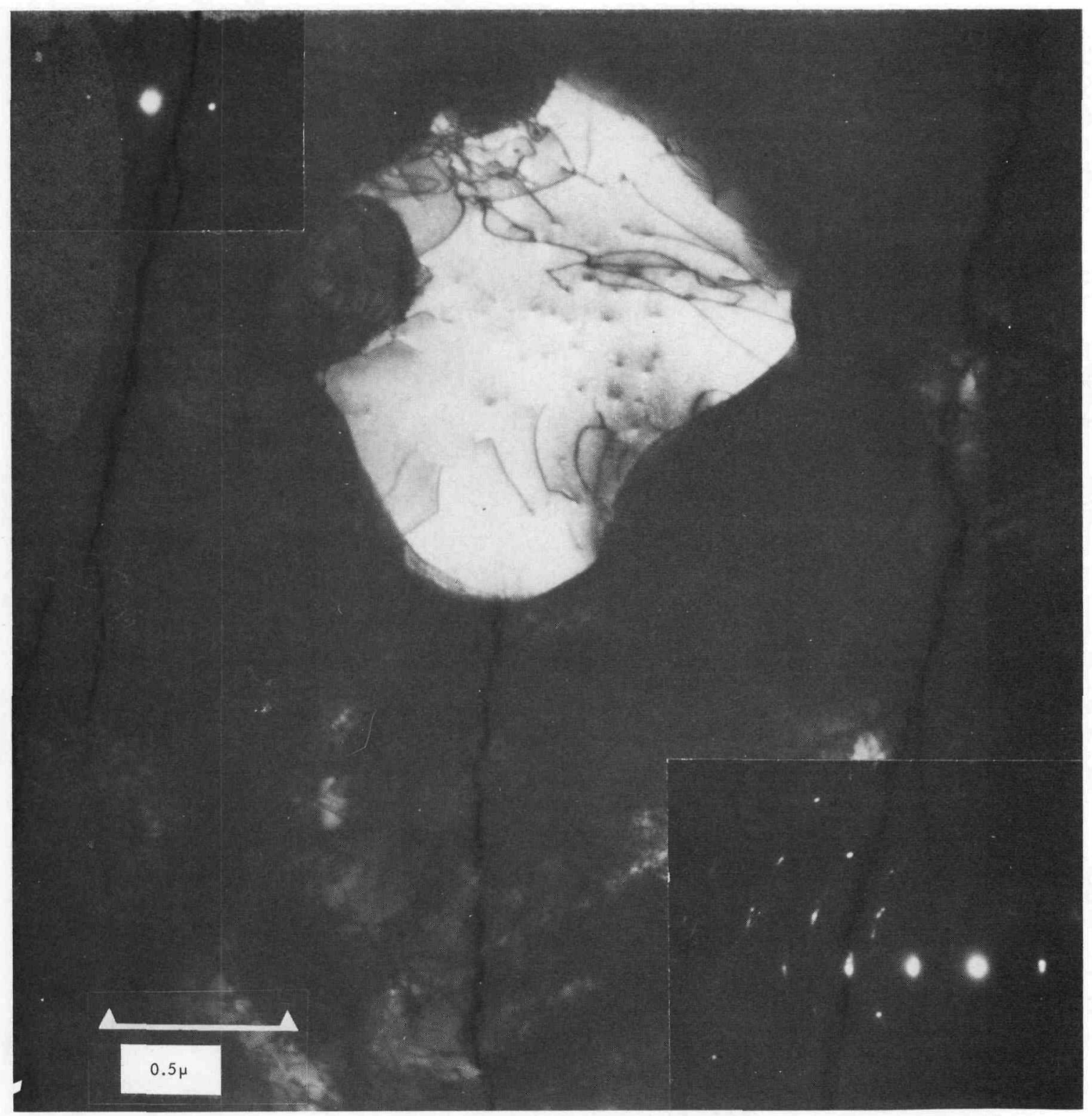

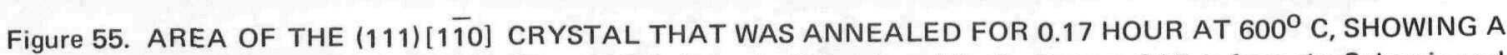
RAPIDLY RECOVERING SUBGRAIN. (Top SAD is from the Subgrain, while the Bottom SAD is from the Subgrain and Surrounding Area)

Further annealing for ten hours caused an apparent decrease in the geometric-mean cell areas. However, this decrease was not real, but was believed to be due to the uncertainties of measurement and specimen inhomogeneity. In effect, very little cell growth or change in microstructure occurred for the (111) crystal annealed at $600^{\circ} \mathrm{C}$, as illustrated by Figure 57.

An increase in the annealing temperature to $700^{\circ} \mathrm{C}$ produced a rather dramatic increase in cell area, with several large subgrains being present, Figure 58. Comparison with Figure 57 shows that considerable recovery occurred from $600^{\circ} \mathrm{C}$. Boundaries marked with arrows in Figure 58 were transverse to the rolling direction and appeared to be stable dislocation 


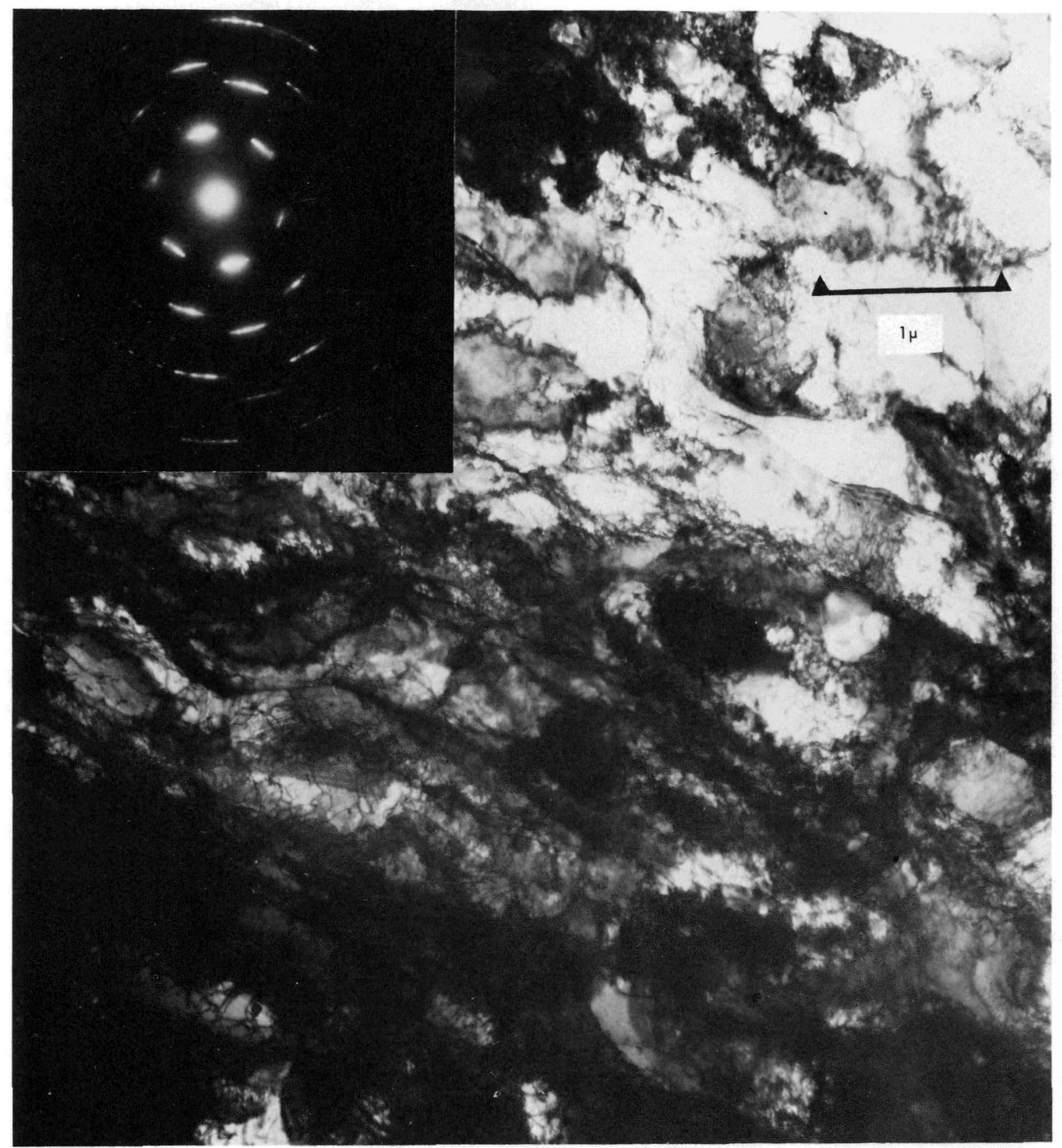

Figure 56. MICROSTRUCTURE OF THE (111)[1ํㅣ CRYSTAL THAT WAS ANNEALED FOR ONE HOUR AT $600^{\circ}$ C. ([111] Zone)

networks. These boundaries ran continuously through the crystal and varied in width and inclination to the foil surface. They were, therefore, on planes whose zone axis was in the transverse direction. A higher magnification of the large subgrain is provided in Figure 59. Surrounding subgrains were in various stages of recovery, with many appearing to have essentially no dislocations in contrast. It is not difficult to imagine that this subgrain might be a recrystallization nucleus that grew into the surrounding subgrains on all sides. Though some dislocations were out of contrast in the nucleus, a row of dislocations marked by an arrow appeared to be the remnants of a previous boundary which was disappearing. Additional boundaries (arrows) in surrounding subgrains also appeared to be dissolving. 


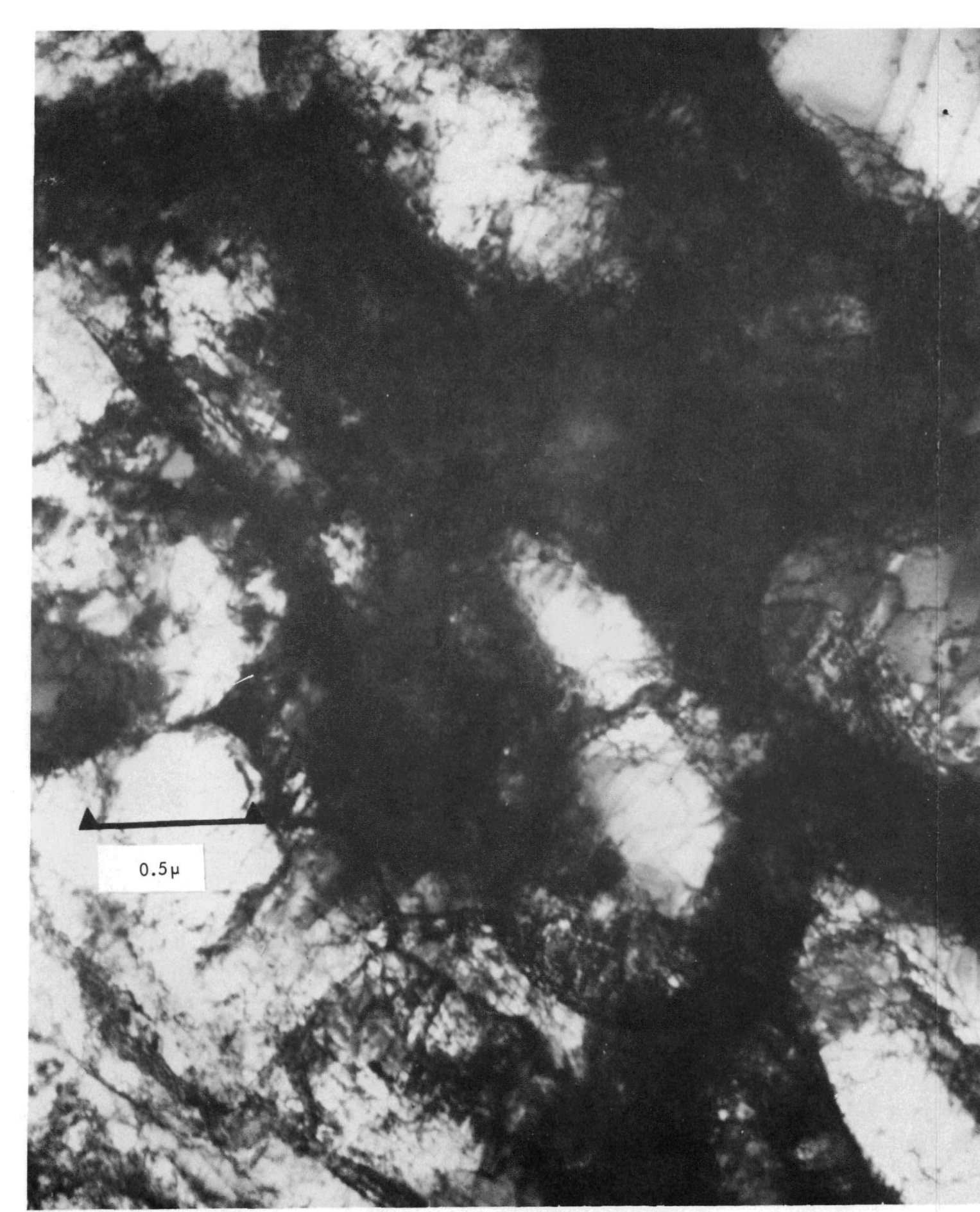

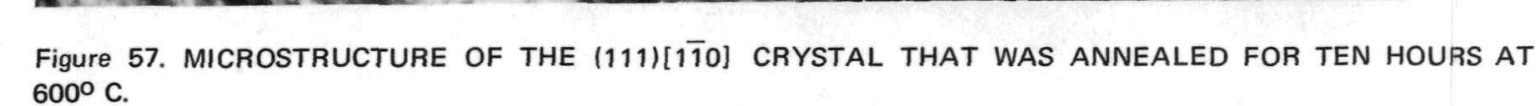
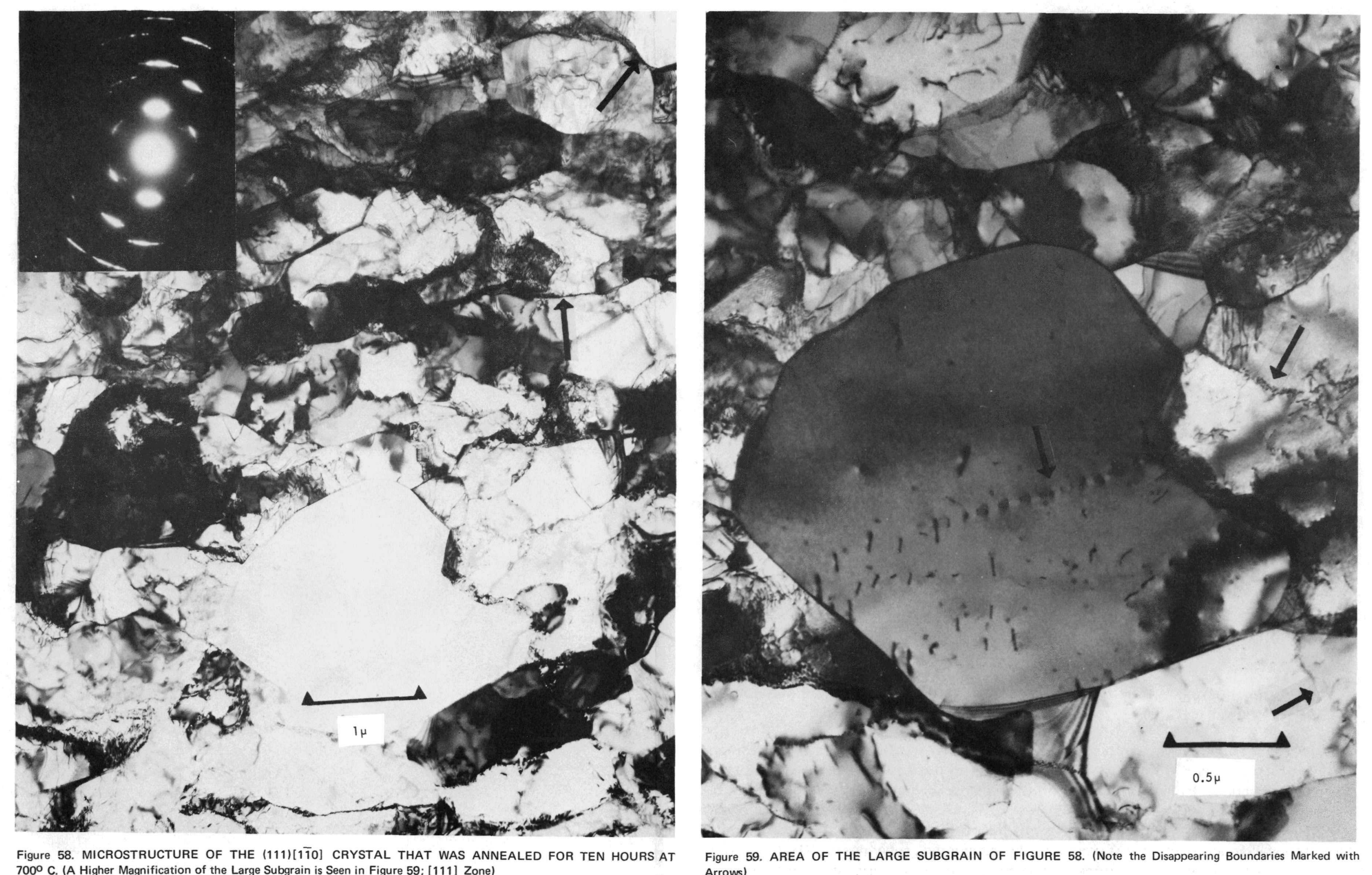
Results of SAD from this nucleus and the surrounding area gave essentially the same conclusion as that in Figure 55; ie, the nucleus was only slightly misoriented with respect to its surrounding subgrains.

Increasing the annealing conditions to $8000 \mathrm{C}$ for 10 hours produced the partially recrystallized structure shown in Figure 60 . The following features were noted in this structure: the unrecrystallized matrix was the gray areas marked with ms; recrystallized grains appeared as both lighter and darker areas marked by the shorter arrows. Some of these recrystallized grains had serrated boundaries on one side, and individual serrations were elongated approximately in the transverse direction. A typical transmission electron microstructure from the crystal is seen in Figure 61. Though the rolling direction relative to the microstructure of Figure 61 was not known, a $\langle 110\rangle$ direction was indicated by a double arrow as the probable rolling direction. SAD from Areas 1, 2, and 3 indicated that all regions had a (111) plane approximately parallel to the specimen rolling plane. Areas 1 and 2 of Figure 61 still contained dislocations, whereas Area 3 was essentially dislocation free. The boundary separating Areas 1 and 2 was a low-angle boundary which caused a relative rotation about the $\langle 111\rangle$ zone axis of one degree. Thus, Areas 1 and 2 appear to be the recovered matrix which now contains enormous elongated subgrains with boundaries which were probably perpendicular to the rolling direction. These boundaries were believed to be the same as the serrated boundaries mentioned in Figure 60, and appeared to be stable, low-angle grain boundaries consisting of hexagonal dislocation networks. Area 3 is related [by a 16-degree rotation about the (111) zone axis] to Area 1, which indicated that the two regions were separated by a high-angle grain boundary. The electron transmission microstructure of Figure 61 was believed to be from an area marked with short arrows in Figure 60(a). A schematic of the recrystallizing grain and surrounding subgrains is presented in Figure 62. The large subgrains are Areas 1 and 2, while the recrystallized grain is Area 3. Large-angle serrated boundaries, such as that represented schematically in Figure 62, appear to be "pinned" by the lower-angle boundaries until such time as they are absorbed. On the other hand, the smooth, high-angle grain boundaries appeared to be more mobile. When recrystallization was complete [Figure $61(\mathrm{~b})$ ], the grains had all acquired a more equiaxed structure. The average grain diameter of this specimen was then $0.23 \mathrm{~mm}$.

A (200) pole figure of the fully recrystallized crystal is shown in Figure 63, with the rolled texture superimposed. An analysis of the (110), (222), and (200) pole figures indicated that the recrystallized texture had essentially two components. One component can be described as a seven-degree rotation of a (111) [253] component about the rolling direction toward the transverse direction, while the other component is a nine-degree rotation of the (111) [235] component about the RD toward the TD. These components were related to the peak positions of the rolled texture by rotations about the axes indicated in Figure 63, which were both very close to the rolling plane normal and within seven degrees of $\langle 111\rangle$. Rotations of 23 and 24 degrees brought the rolled orientation into coincidence with the recrystallized orientations. Taoka, et al, 23 reported that the deformation texture of a (111) [1 10] iron-silicon crystal was essentially the same as the rolled texture of the present tantalum crystal. On the other hand, they reported that the recrystallized texture of the iron-silicon crystal contained both $\{110\}<112>$ and $\{410\}<145>$ components. These components were not found in the present study on recrystallized tantalum and, thus, the two results are in disagreement. Using TEM, Stiegler, et al, (39) found recrystallized grains in rolled (111) [150] niobium single crystals which were related to the deformed matrix by a 20 - 30-degree rotation of about $\langle 111\rangle$. Stiegler's results agree very well with those of the 


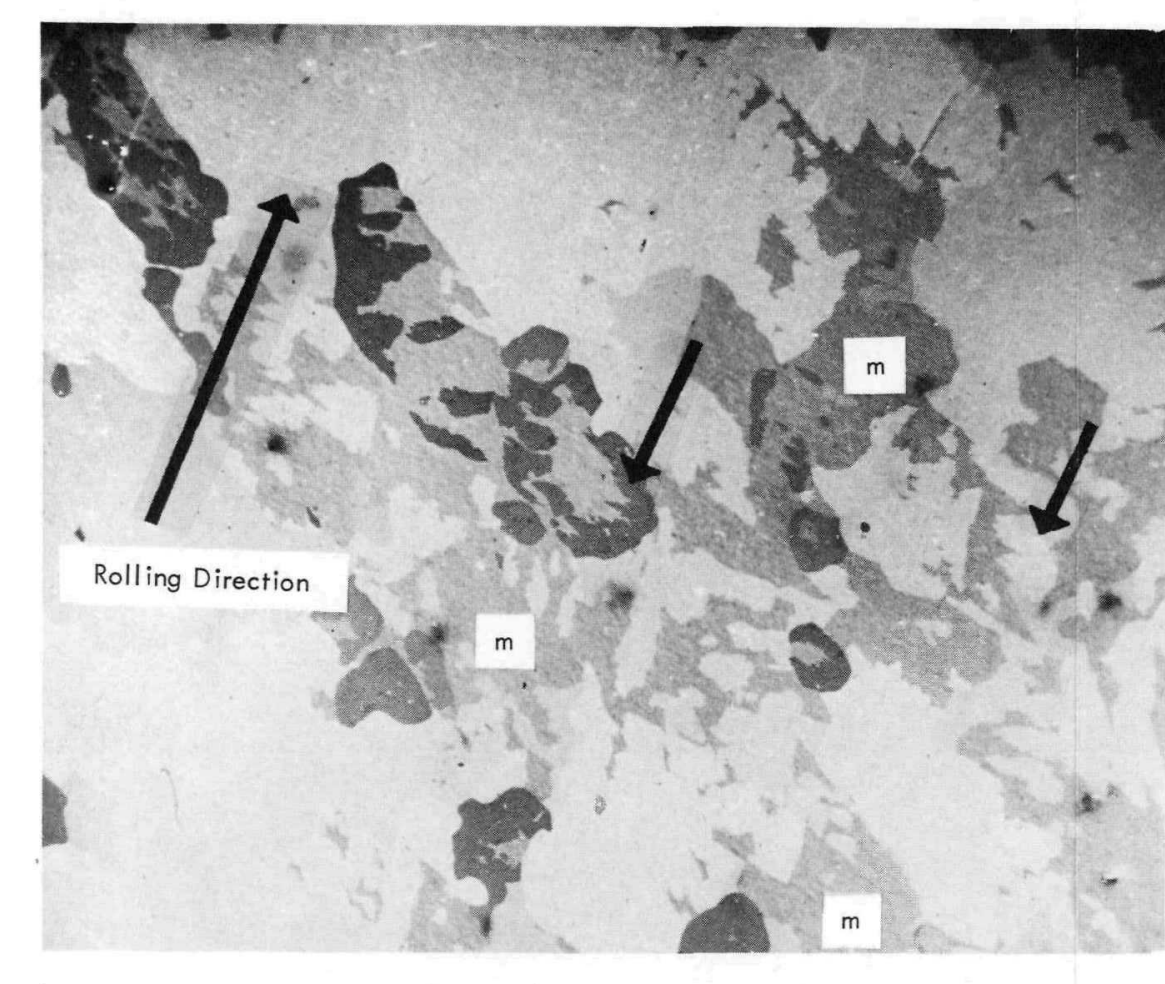

(a) Annealed for Ten Hours at $800^{\circ} \mathrm{C}$.

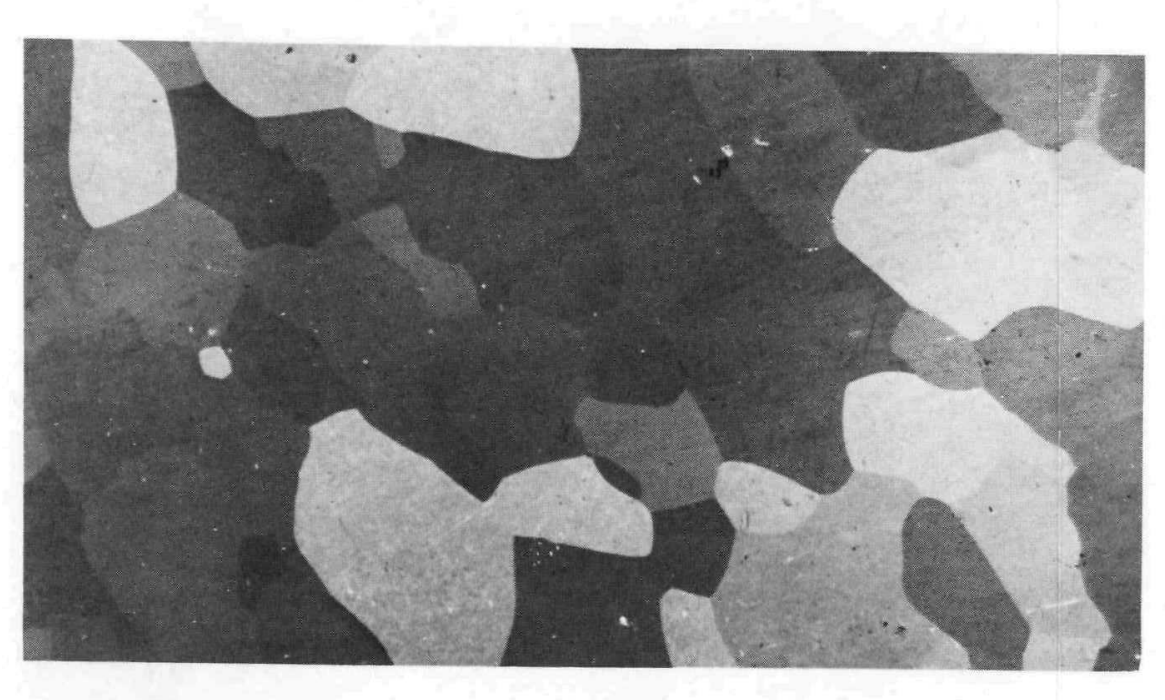

(b) Annealed for Two Hours at $12000^{\circ} \mathrm{C}$.

Figure 60. OPTICAL MICROGRAPHS OF THE (111)[110] CRYSTAL THAT WAS ROLLED 80 PERCENT AND ANEALED FOR TEN HOURS AT $800^{\circ}$ C AND FOR TWO
HOURS AT $1200^{\circ} \mathrm{C}$. (Polarized Light; $\sim 75 \mathrm{X}$ )

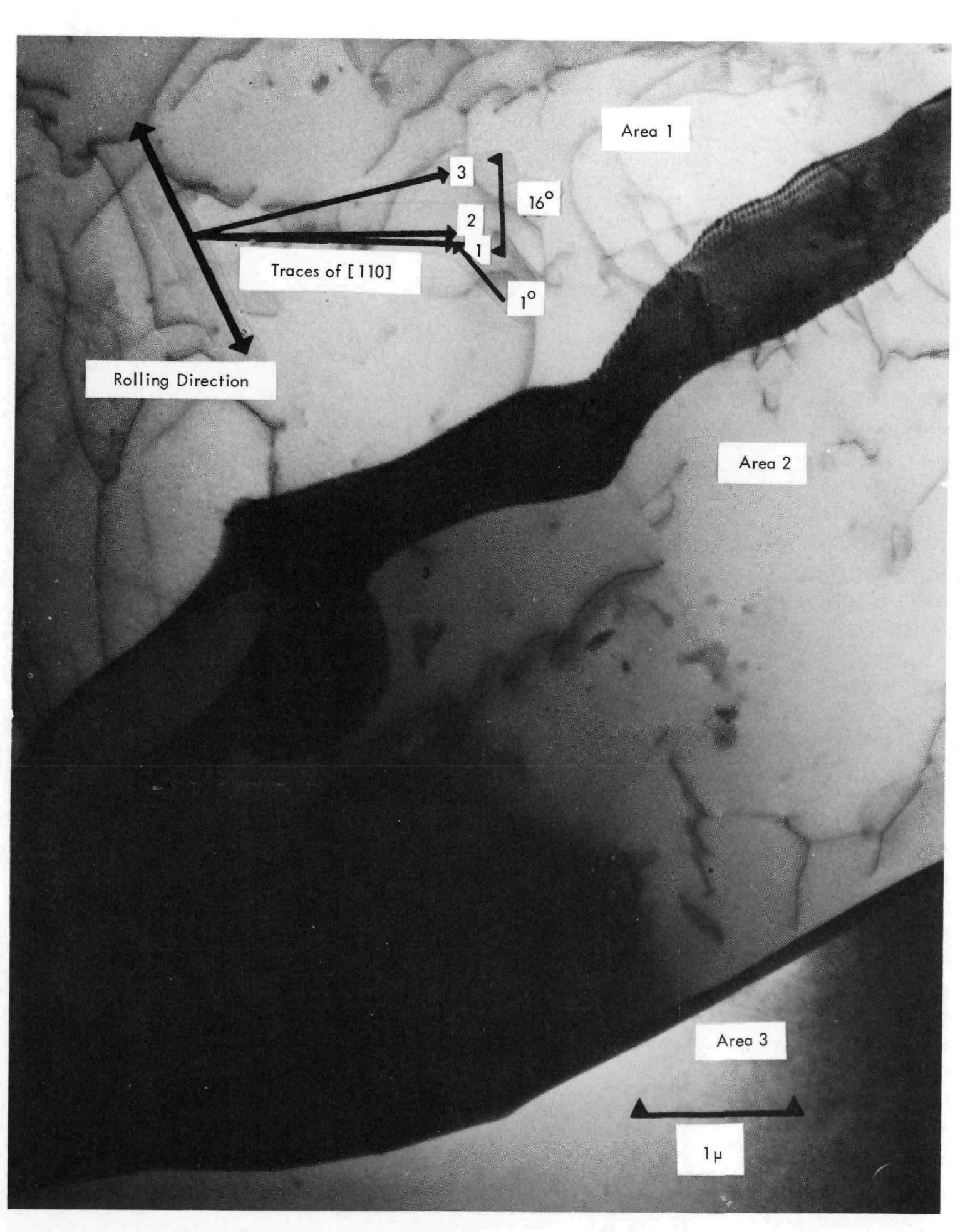

Figure 61. MICROSTRUCTURE OF THE (111)[1170] CRYSTAL THAT WAS ANNEALED FOR TEN HOURS AT
$800^{\circ}$ C. IA Possible Rolling Direction is Indicated by the Double-Ended Arrow; [1111] Zone)

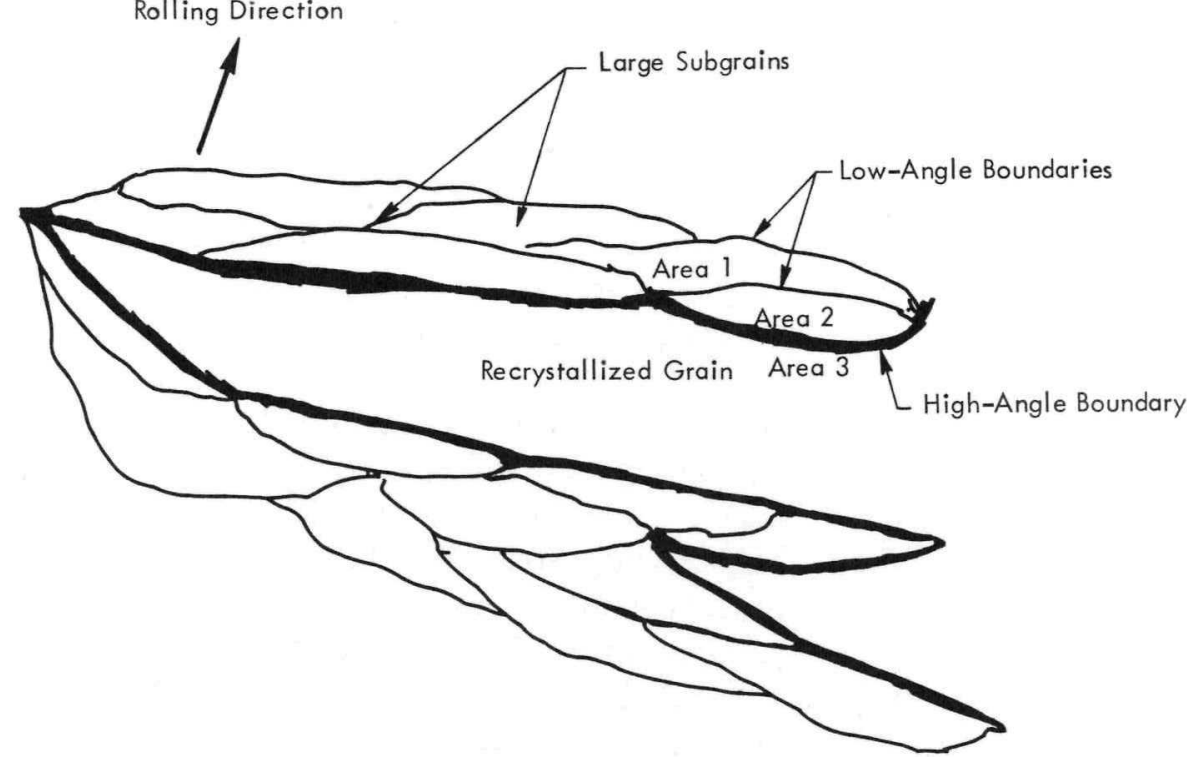

Figure 62. SERRATED GRAIN BOUNDARY OF FIGURES 60(a) AND 61.

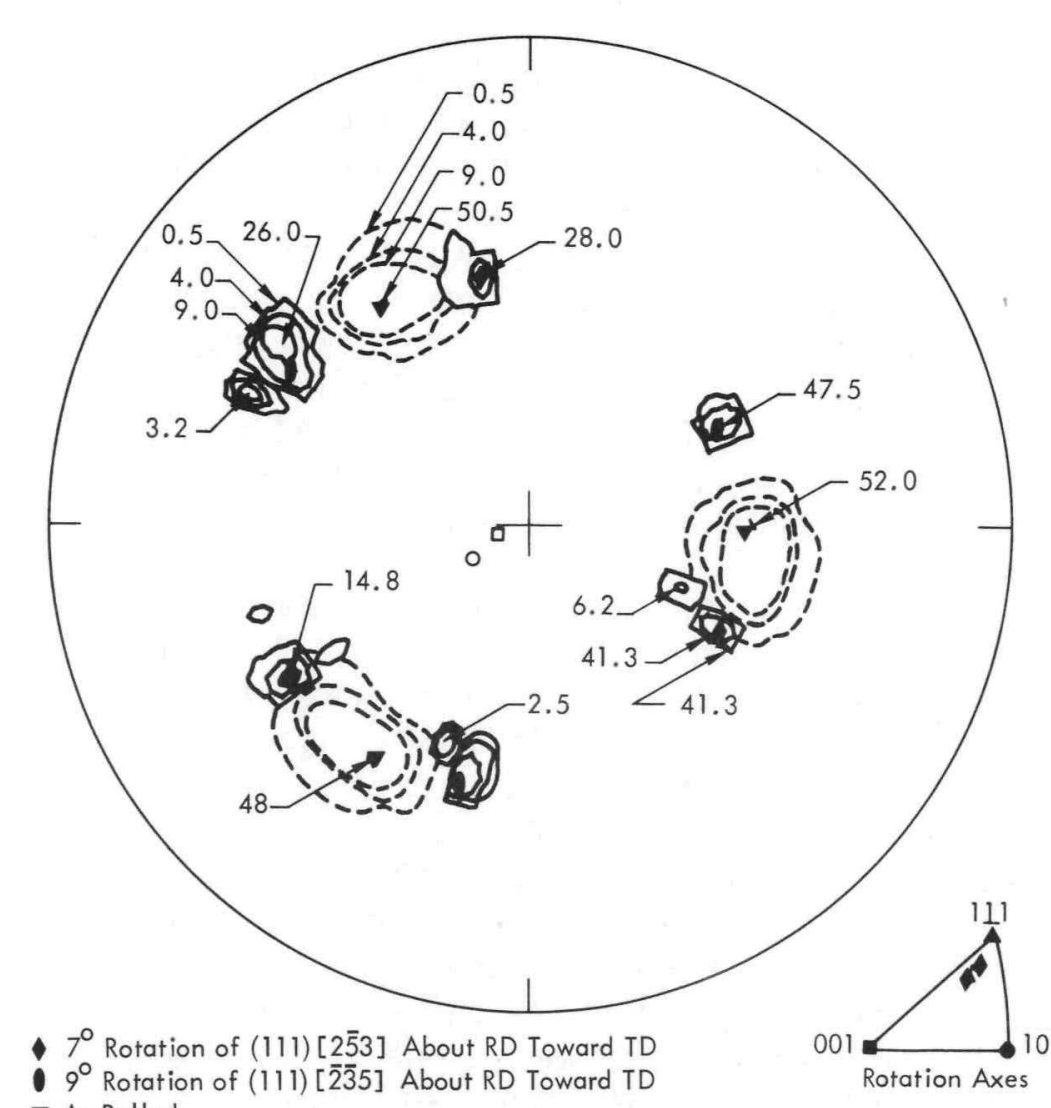

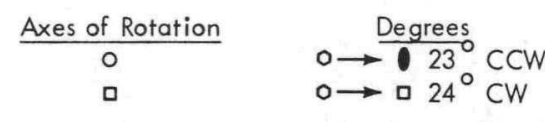

Figure 63. (200) POLE FIGURE OF THE (111)[110] CRYSTAL THAT WAS
ANNEALED FOR TWO HOURS AT $1200^{\circ} \mathrm{C}$. (Dotted Lines are the Rolled Texture) 
present experiment. Thus, the discrepancy between the results on tantalum and those on iron-silicon may have been due to the difficulty in assigning indices to the very diffuse textures noted by Taoka, et al.

(110) [1T0] Crystal - The (110) crystals were isothermally annealed at $600^{\circ} \mathrm{C}$ for comparison with the (111) crystal. An additional ten-hour anneal at $800^{\circ} \mathrm{C}$ was utilized to compare the recrystallization behavior with all of the other orientations as well. Recrystallization of the deformed (110) crystals occurred at low temperatures and resulted in very small grains being formed. The recrystallization behavior was found to depend on the nature of the deformation bands produced during rolling.

As discussed in a prior section, two crystals (4-8 and 4-11) of this orientation were selected for recrystallization studies. Crystal 4-8 contained a gradation of texture from the top surface to the bottom surface, with a "double-barrel" formation at the edges. In addition, transverse strains were asymmetric with respect to the specimen mid plane, with the top surface undergoing less transverse strain than the bottom surface. Accompanying the texture and width changes was an apparent change in the macroscopic banding from the top surface to the bottom. Crystal 4-11 also showed a "double-barrel" edge effect; but, in contrast to Crystal 4-8, was symmetric about the specimen mid plane. Orientations from the top and bottom surfaces of Crystal 4-11 were very similar, with no apparent change in the deformation banding pattern through the crystal thickness. Most of the annealing study was performed on Crystal 4-8.

Hardness and integral-breadth measurements on the narrow, or (111)-oriented, surface of Crystal 4-8 are presented in Figures 44 and 45. The (110) crystal recovered more of its hardness in 0.17 hour at $600^{\circ} \mathrm{C}$ than the (111) crystal annealed under the same conditions. Recovery from 0.17 hour to one hour was very slow. The slope of the hardness plot in this region appears to be the same for both the (111) and (110) crystals. From one to ten hours, a very sharp drop in hardness occurred due to the onset of recrystallization. Annealing for ten hours at $800^{\circ} \mathrm{C}$ decreased the residual hardness to $9 \%$. Note that the (111) crystal when annealed for 10 hours at $800^{\circ} \mathrm{C}$ only partially recrystallized (55\% residual hardness), while the (112) and (001) crystals were only recovered to 50 and $38 \%$ residual hardness, respectively.

Additional hardness data on Crystals 4-8 and 4-11 is shown in Figure 64. These results were obtained by placing the long axis of a Knoop indenter parallel to the transverse direction and making indentions at fixed intervals through the thickness. The abscissa indicates the relative position of the indention from one surface. Values close to the top and bottom surfaces were discarded. From the rolled data in Figure 64 it is apparent that, in the as-rolled condition, a hardness gradient existed through the thickness of Crystal 4-8, while Crystal 4-11 showed a reasonably constant hardness. As Crystal 4-8 was annealed at successively longer times at $6000^{\circ} \mathrm{C}$, the hardness at first leveled out at 0.17 hour, signifying that initial recovery of the specimen occurred more rapidly in the upper part of the crystal. Further annealing for one hour led to additional recovery, which lowered the overall hardness. From one to ten hours, a reversal in hardness occurred because recrystallization had taken place in the top surface, but not in the bottom [Figures 64 and 65(a)]. Crystal 4-11, when annealed for ten hours at $600^{\circ} \mathrm{C}$, showed a very uniform hardness due to a more homogeneous recrystallization through the crystal thickness. The variation in 

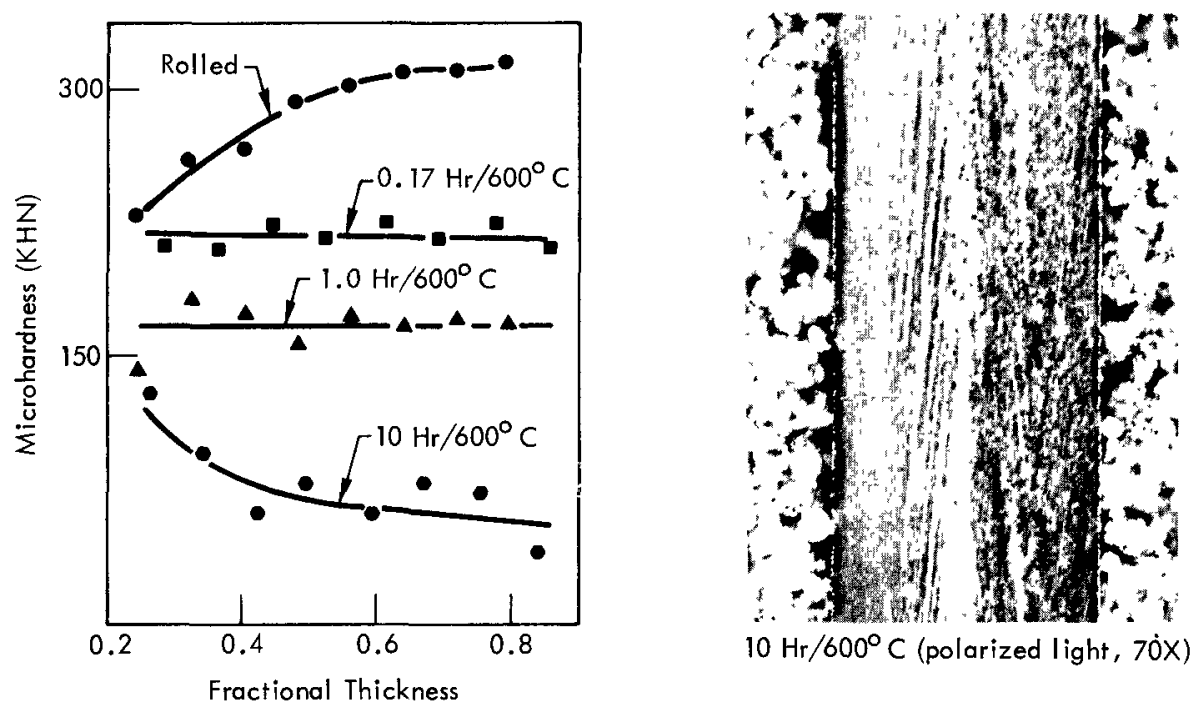

$10 \mathrm{Hr} / 600^{\circ} \mathrm{C}$ (polarized light, $70 \mathrm{X}$ )

(a) $\Delta_{i}=1.25$, Dry.

$\stackrel{T D D}{T D}^{-N D}$
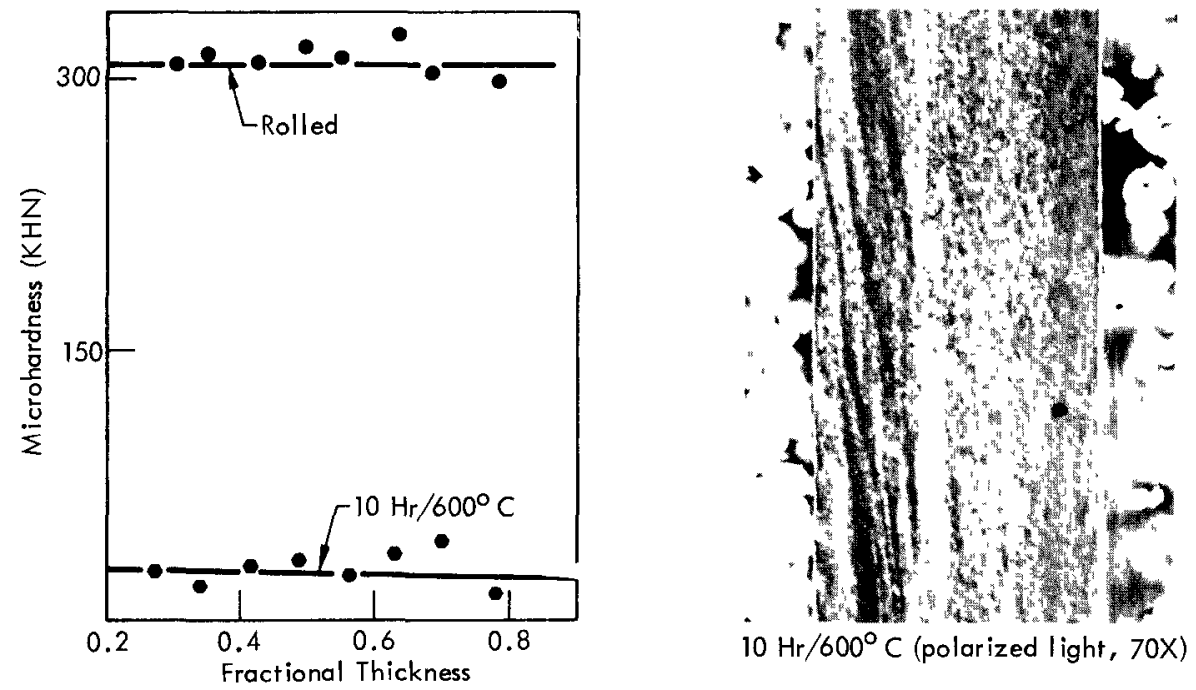

(b) $\Delta_{\mathbf{i}}=1.25$, Lubricant.

Figure 64. CROSS-SECTIONAL MICROHARDNESS AND MICROSTRUCTURE OF $(110)[1 \overline{10}]$ CRYSTALS THAT WERE ANNEALED AT $600^{\circ} \mathrm{C}$.

recrystallization behavior noted for Crystal 4-8 was believed related to the difference in deformation bands through the thickness. Annealing Crystal 4.8 at $800^{\circ} \mathrm{C}$ resulted in grain growth of the upper portion of the crystal, while recrystallization occurred in the lower portion. Optically, it appeared that, after ten hours at $600{ }^{\circ} \mathrm{C}$, recrystallization was complete in the upper surface of Crystal 4-8, and the drop in hardness of the upper portion (Figure 44) from 600 to $800^{\circ} \mathrm{C}$ appeared due to the observed grain growth. Figure 65(b) at $100 \mathrm{X}$ should be compared with Figure $60(\mathrm{a})$ at $75 \mathrm{X}$ to obtain an appreciation of the difference in recrystallization potential between the (111) and (110) crystals. 

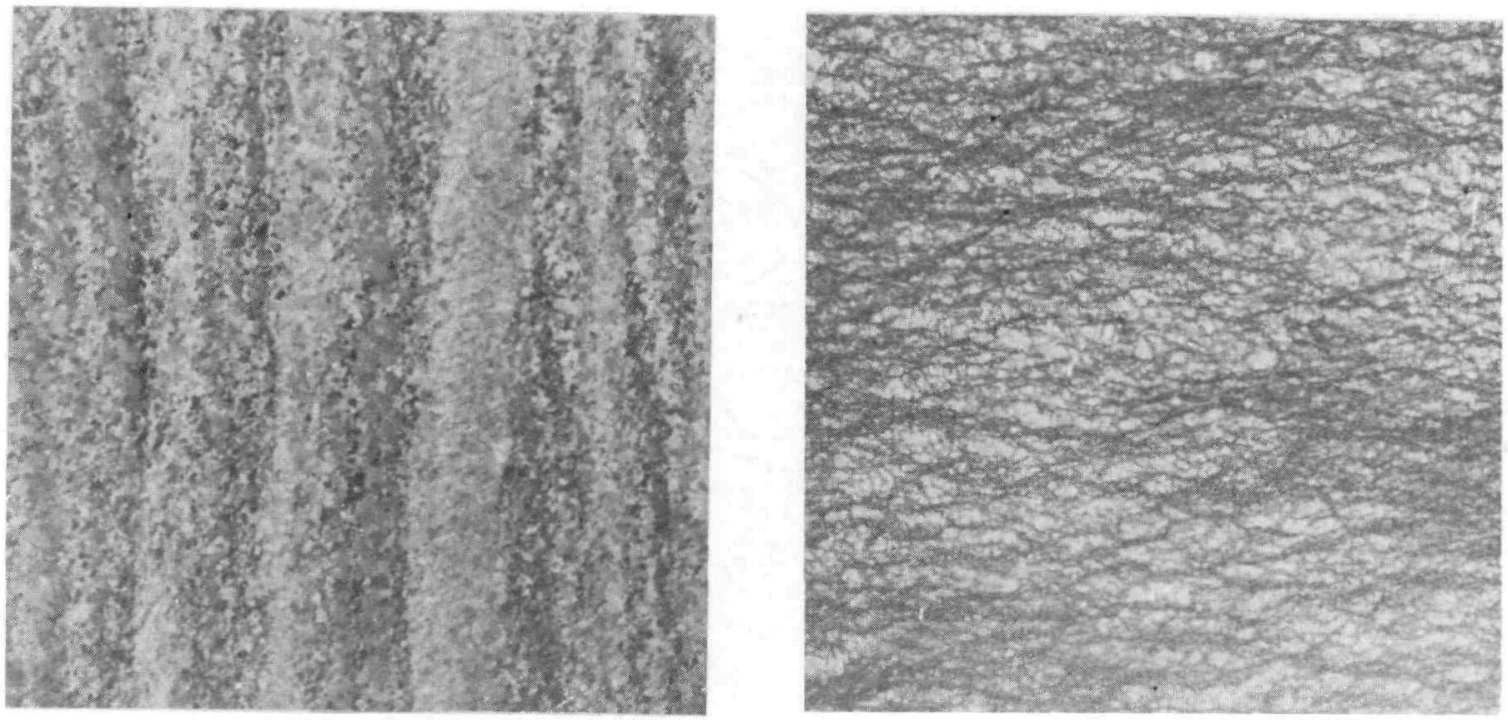

Top

(a) Annealed for Ten Hours at $600^{\circ} \mathrm{C}$.

Bottom

$\stackrel{R D}{\longrightarrow T D}$

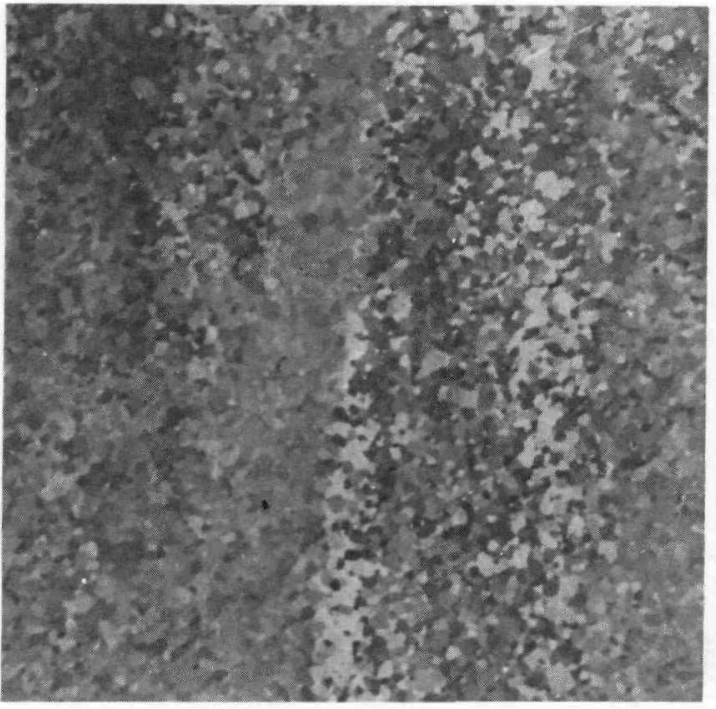

Top

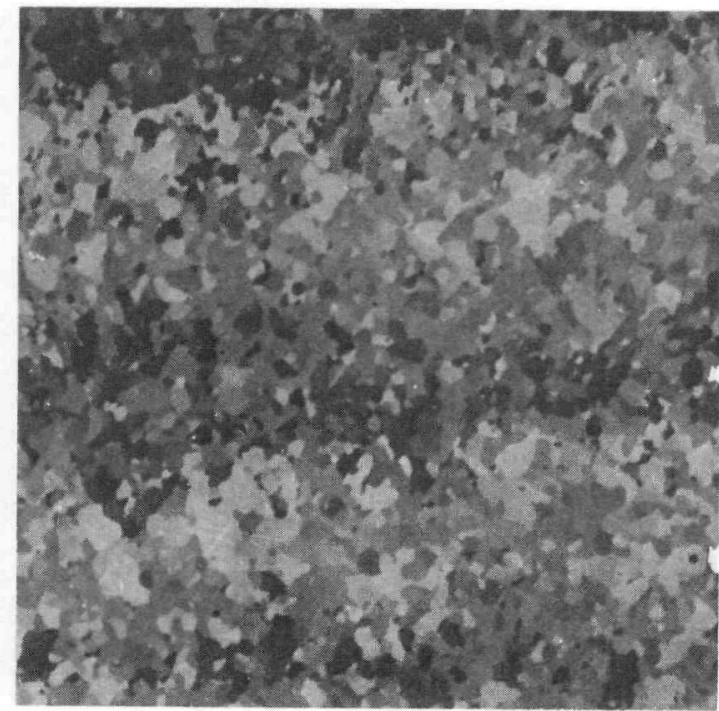

Bottom

Figure 65. OPTICAL MICROSTRUCTURES OF THE TOP AND BOTTOM SURFACES OF CRYSTAL 4-8 THAT WAS ANNEALED FOR TEN HOURS AT 600 AND $800^{\circ}$ C. (Polarized Light; 100X)

Upon annealing at $600^{\circ} \mathrm{C}$ for ten hours, the textures of both surfaces of Crystals 4-8 and 4-11 remained essentially identical to the rolled textures, as illustrated by Figure 66. A comparison with Figure 36 shows that only very minor changes have occurred in the texture of Crystal 4-11. Similar observations were made for the textures of Crystal 4-8. Annealing Crystal $4-8$ for ten hours at $800^{\circ} \mathrm{C}$ produced the texture shown in Figure 67. Though this pole figure was taken from a small piece of the crystal, it still showed that the (111) and (001) components of the rolled texture were present after significant grain growth. Peak positions in the rolled texture were maintained after annealing. The conclusion is that during primary recrystallization, no texture change occurs in this crystal. 


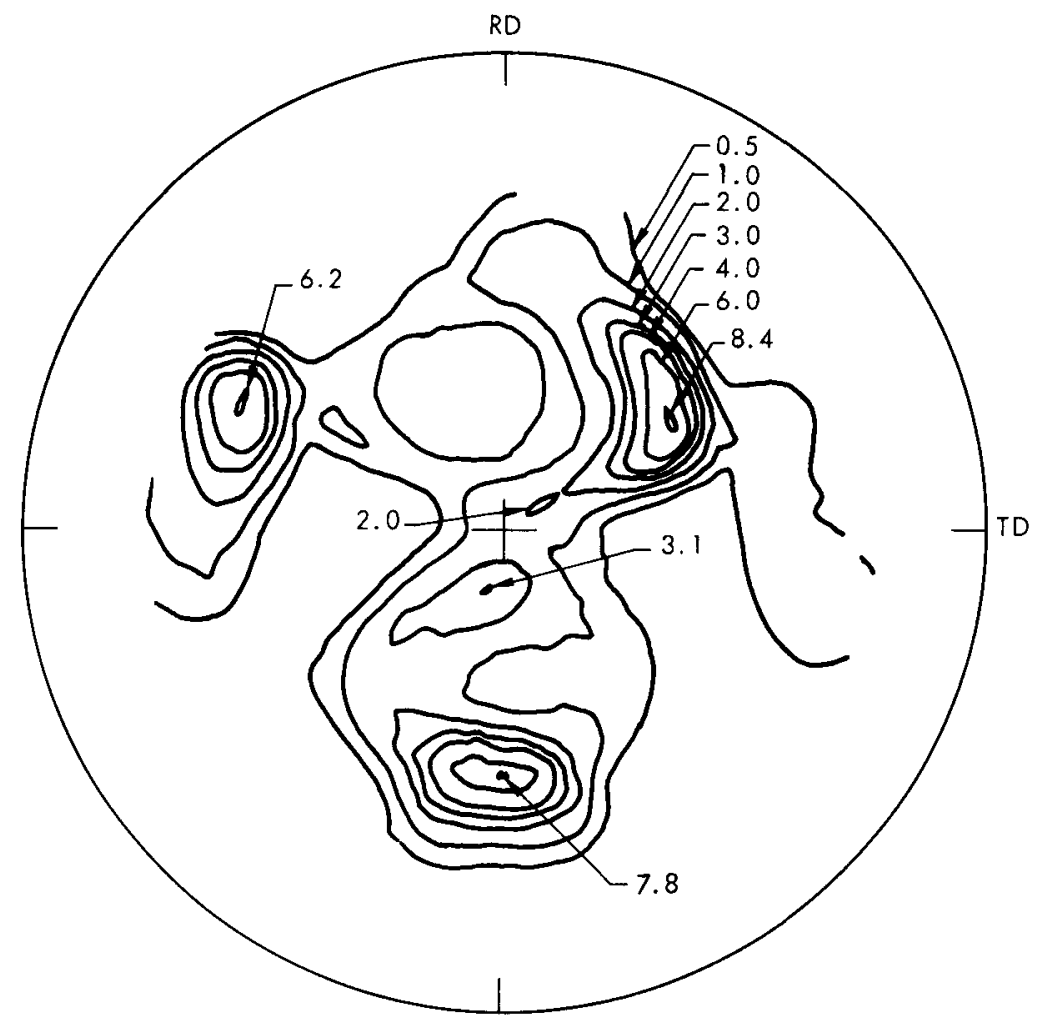

(a) Top Surface.

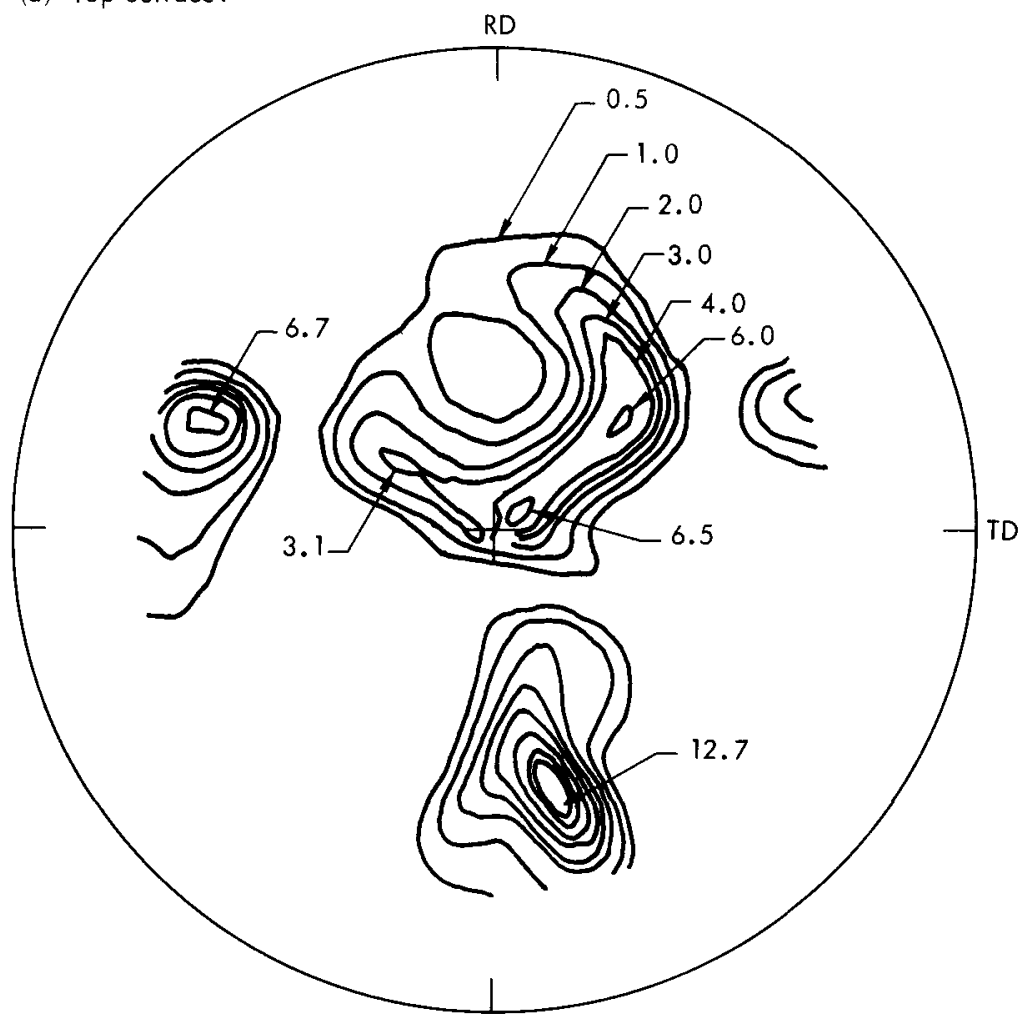

(b) Bottom Surface.

Figure 66. (200) POLE FIGURES OF CRYSTAL 4-11 THAT WAS ROLLED 80 PERCENT AND ANNEALED FOR TEN HOURS AT $600^{\circ} \mathrm{C}$. (Compare to the Rolled Pole Figures of Figure 36) 


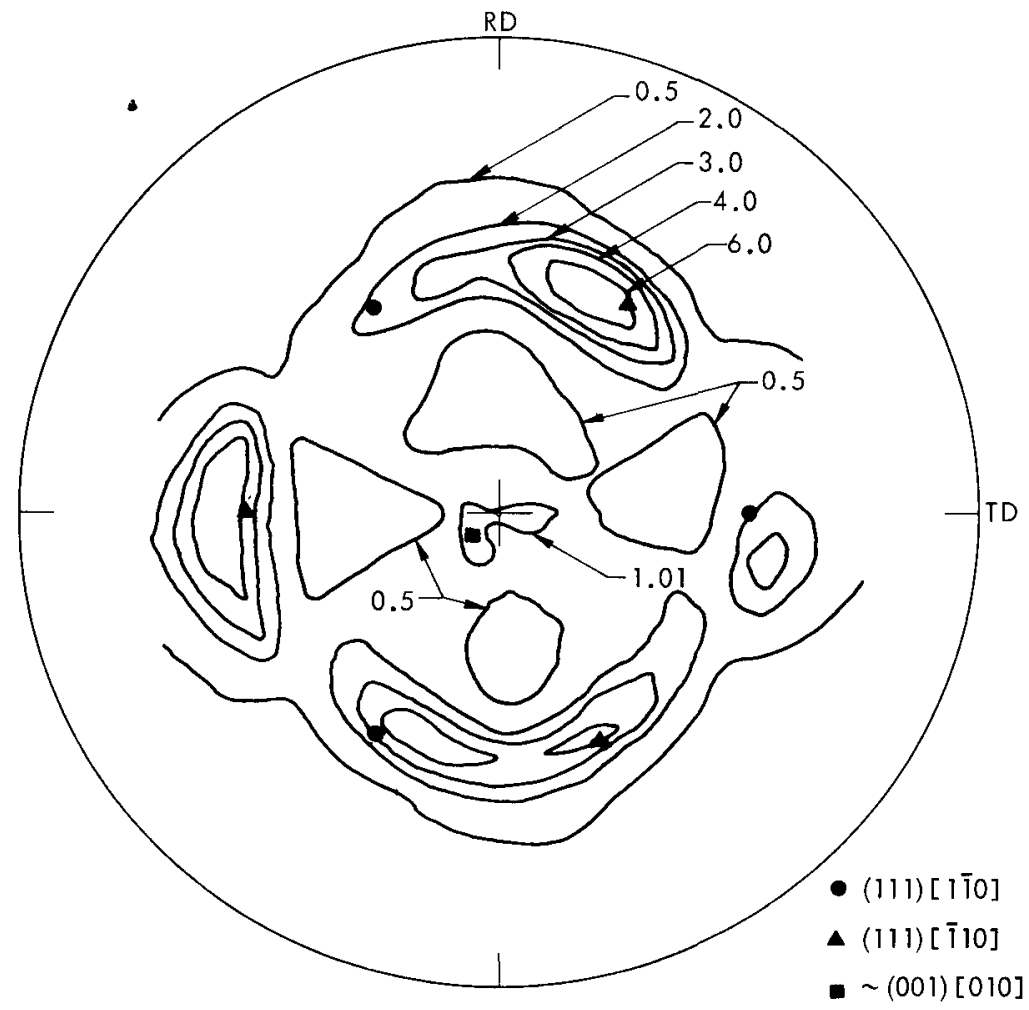

(a) Rolled $80 \%$.

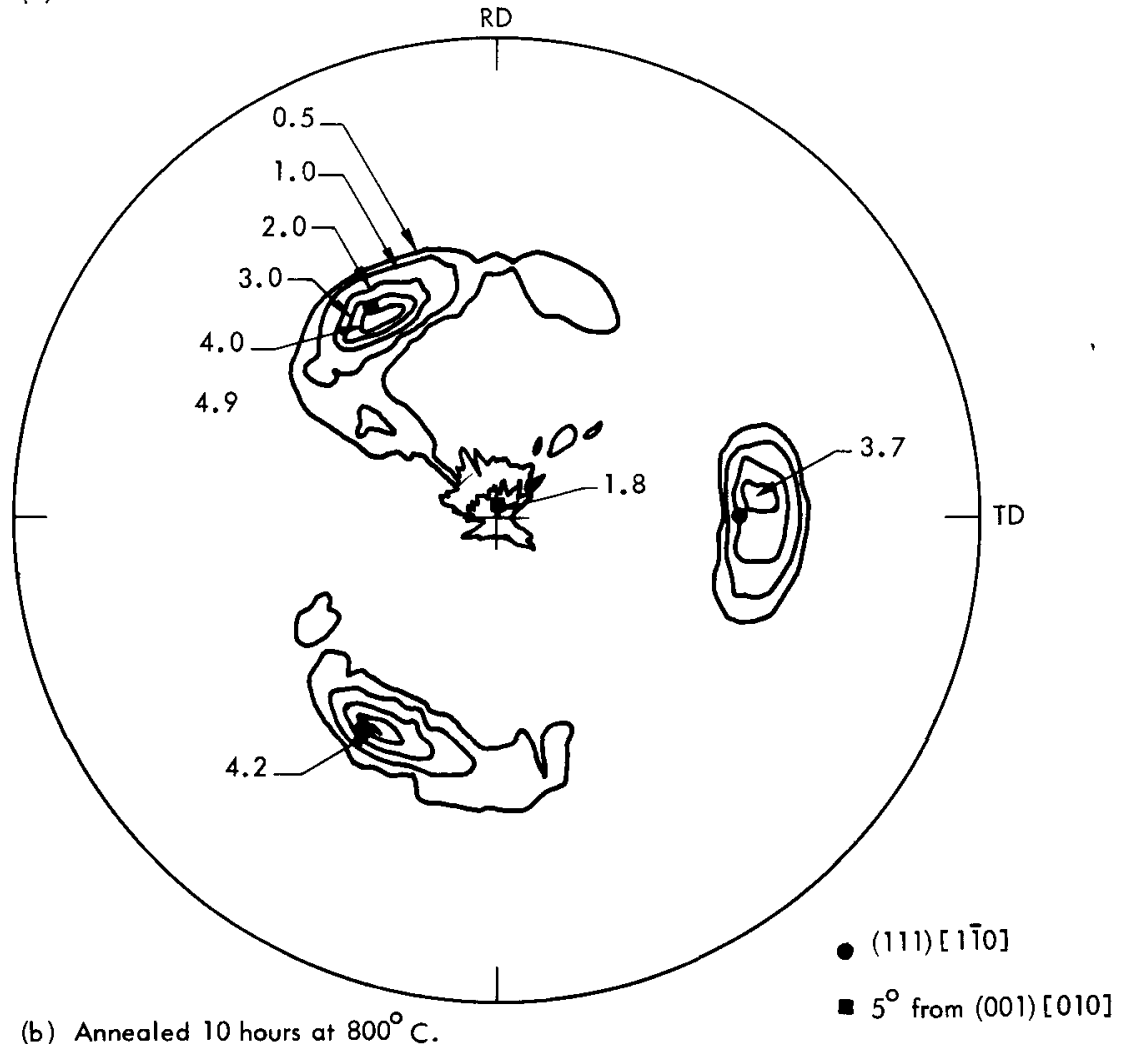

(b) Annealed 10 hours at $800^{\circ} \mathrm{C}$.

Figure 67. (200) POLE FIGURES FROM THE TOP SURFACE OF CRYSTAL 4-8 THAT WAS ROLLED 80 PERCENT AND ANNEALED FOR TEN HOURS AT $800^{\circ} \mathrm{C}$. 
TEM was performed on Crystal 4-8 that was annealed for $0.17,1.0$, and 10 hours at $600^{\circ} \mathrm{C}$, and Crystal 4-11 annealed for ten hours at $600^{\circ} \mathrm{C}$. Microstructures were examined for the mid plane (mid thickness) of Crystals 4-8 and 4-11, except where noted. Annealing for 0.17 hour at $600^{\circ} \mathrm{C}$ produced the cell structure shown in Figure 68. Considerable recovery occurred, with a decrease in the internal dislocation density of the cells. Dislocation networks (arrows) were evident in many areas of the structure. In a few instances, areas of elongated cells were noted; however, these areas were very rare. Cell-area measurements of this structure were very difficult, and areas which were not clearly identified as cells were neglected. A rather large increase in the cell area from the rolled condition resulted from the 0.17 hour, $600^{\circ} \mathrm{C}$ anneal (Table 6). This increase in cell size accompanied by a decrease in internal dislocation density was believed responsible for the rapid drop in hardness and integral breadth of Crystal 4-8 that was annealed for 0.17 hour at $600^{\circ} \mathrm{C}$. The geometric-mean cell area of the (111) crystal, annealed for 0.17 hour at $600^{\circ} \mathrm{C}$, suggested that little cell growth occurred in the (111) crystal when compared to the (110) crystal, given the same anneal. Lack of cell growth and a higher dislocation density accounted for the very slight recovery of the (111) crystal.

Increasing the annealing time from 0.17 to 1.0 hour at $600^{\circ} \mathrm{C}$ resulted in a much lower dislocation density and perhaps a slight increase in the mean cell size. Though the geometric-mean cell area was essentially the same as for the 0.17-hour anneal, a comparison of the actual distributions shows that many larger subgrains were present. The observation of large cells was a result of being able to examine a larger portion of the crystal due to a reduction in dislocation density and improvement in the sample-preparation technique. Essentially three types of areas were found in the microstructure of Crystal 4-8 that was annealed for one hour at $600^{\circ} \mathrm{C}$. Figure 69 shows an area which contains rather large subgrains with diffuse, poorly defined boundaries. SAD from this area (inset) indicated that it had a (001) plane parallel to the foil surface, with a nine to ten-degree spread, corresponding to rotations about the normal. A comparison with the pole figures from the mid thickness of the foil (Figure 34) revealed that this region would correspond to the orientation marked with a square, which is close to a $\{001\}<010\rangle$. The rolling direction was not identified in the transmission microscope. A second type of microstructure is noted in Figure 70 and also contained large, diffuse dislocation cells. SAD from this area showed that it had a (111) plane parallel to the foil, with an orientation spread corresponding to a rotation of $15-17$ degrees about the specimen normal. This orientation may be identified with either of the peaks marked with xs in the pole figure of Figure 34, or those marked with solid dots, which are both nearly $(111)$ rolling planes. Most areas examined in this and other crystals of this orientation were of the (111) regions which contained smaller subgrains than are indicated in Figure 70 (see Figure 68). A third type of microstructure, illustrated by Figure 71, contained much smaller cells with well-defined boundaries, and diffraction patterns (inset) from this region showed multiple orientations present. This region was found, by diffraction analysis, to be a transition between the (001) and (111)-oriented areas. While recovery in the (001) (Figure 69) and (111) (Figure 70) regions of the crystal appeared to be advanced to the same stage, dislocation densities within cells in this transition region seemed lower, suggesting a more advanced stage of recovery. Observations from this region of the crystal were quite limited because such areas were thought to compose a small volume fraction of the total crystal. However, the finding of (001) and (111) orientations was consistent with the pole figures. 


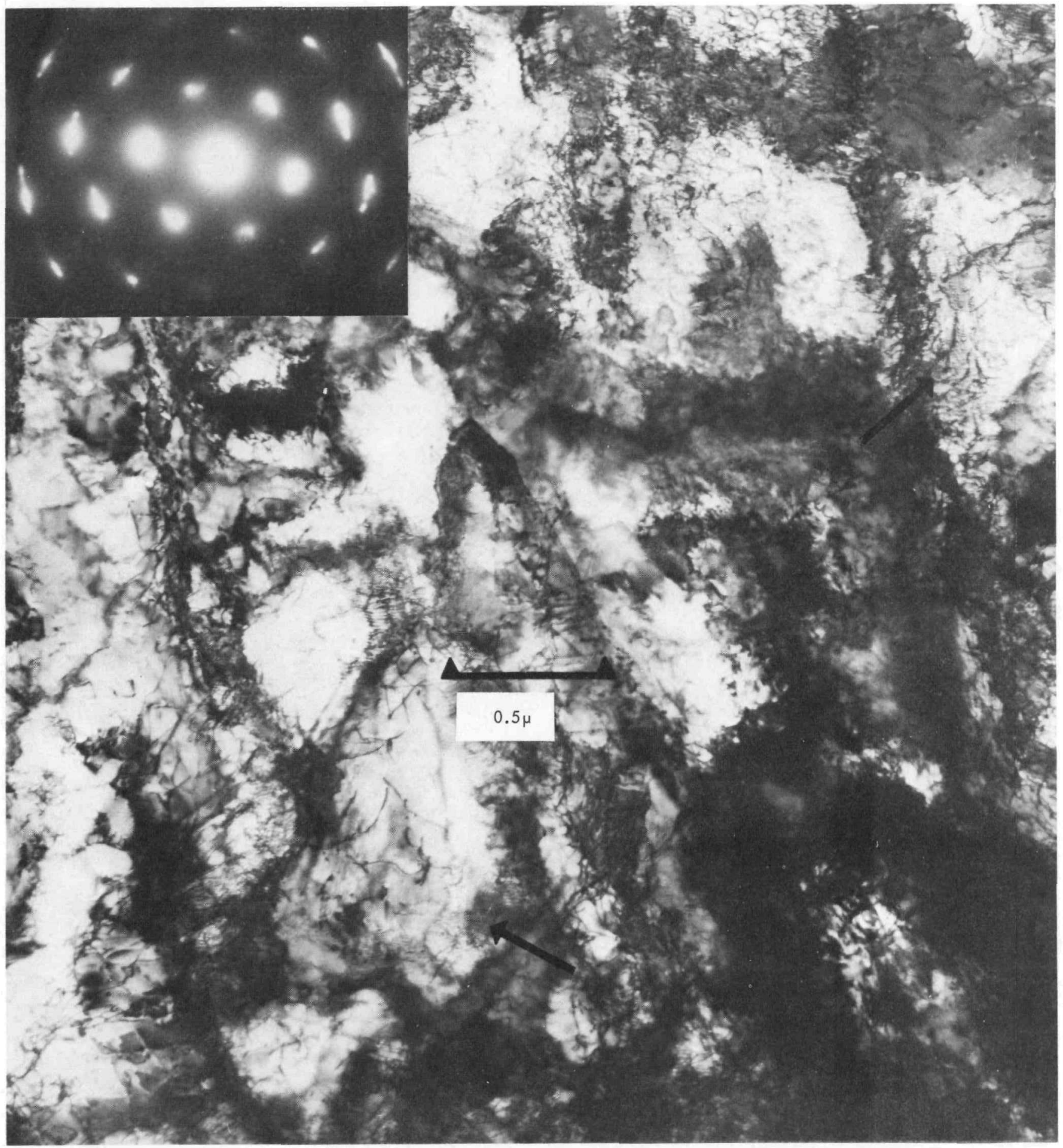

Figure 68. MICROSTRUCTURE OF CRYSTAL 4-8 THAT WAS ANNEALED FOR 0.17 HOURS AT $600^{\circ} \mathrm{C}$. (Note Areas of the Dislocation (1)

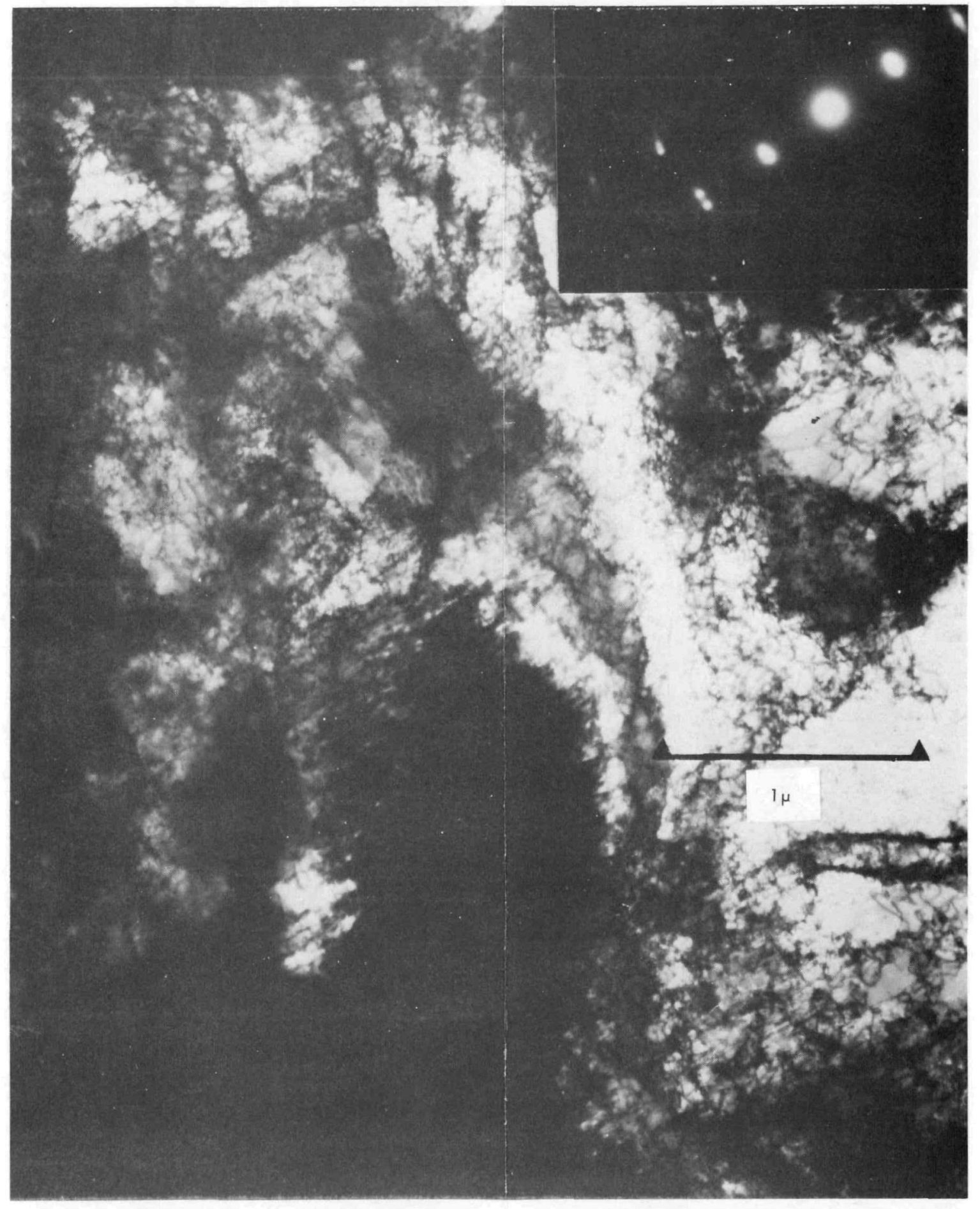

Figure 69. MICROSTRUCTURE OF CRYSTAL 4.8 THAT WAS ANNEALED FOR ONE HOUR AT $600^{\circ} \mathrm{C}$. (Area Contains Rather Large, Poorly Defined Cells; [001] Zone Axis] 


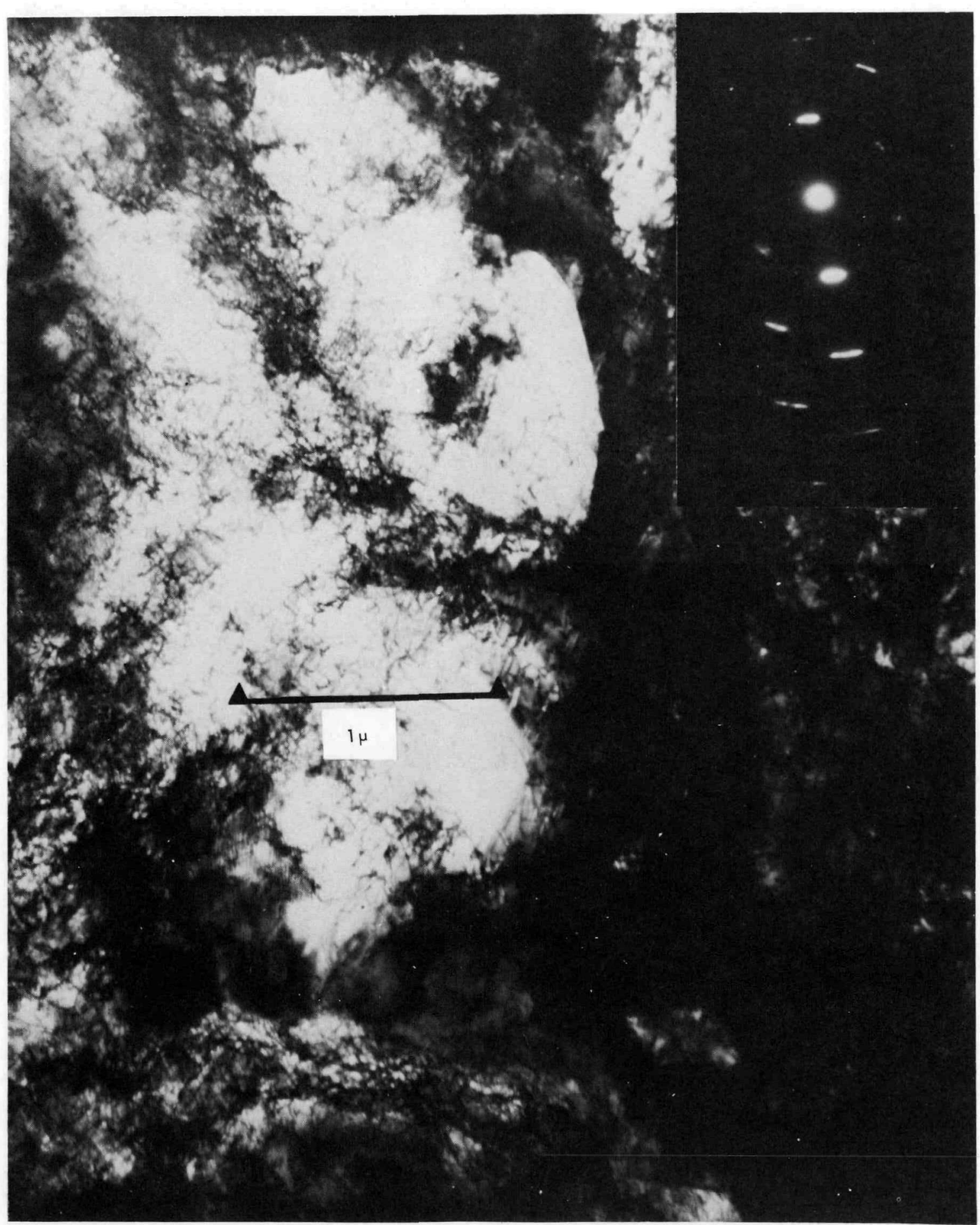

Figure 70. MICROSTRUCTURE OF CRYSTAL 4-8 THAT WAS ANNEALED FOR ONE HOUR AT $600^{\circ} \mathrm{C}$. (Note Large,

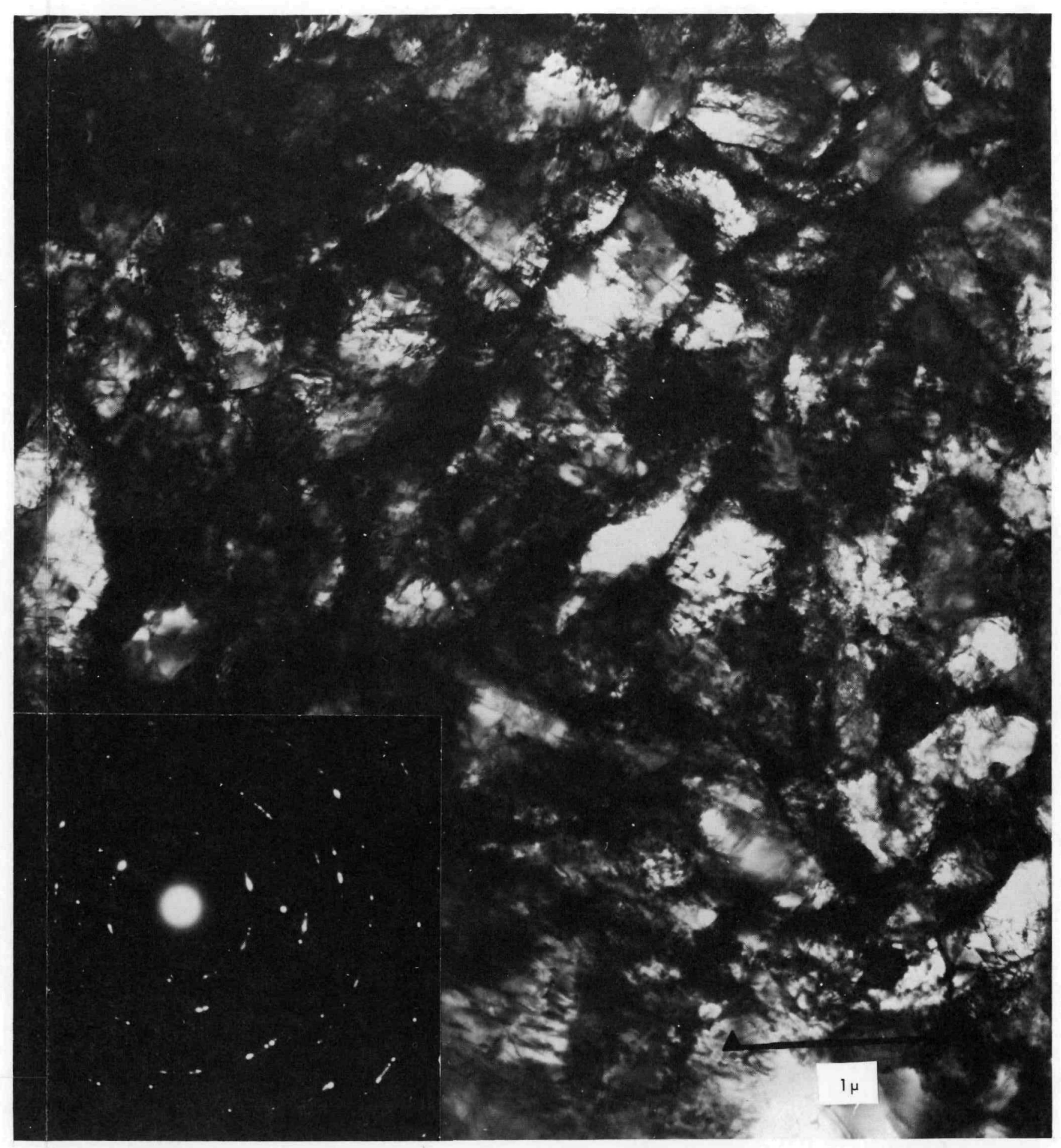

Figure 71. MICROSTRUCTURE OF CRYSTAL 4-8 THAT WAS ANNEALED FOR ONE HOUR AT $600^{\circ} \mathrm{C}$, SHOWING THE REGION WITH SMALLCELLS (Unidentifiable Zone Axisl 
Annealing of Crystal 4-8 for ten hours at $600^{\circ} \mathrm{C}$ resulted in recrystallization being fairly advanced in the crystal mid thickness. Therefore, an intermediate anneal was performed for four hours at $6000^{\circ} \mathrm{C}$ in an attempt to define the early stages of recrystallization. One specimen of the crystal near the top surface could be examined, and Figure 72 shows the microstructure of this region. Recrystallization had already begun, and a very large subgrain is shown which presumably was in the process of advancing into the surrounding region. Subgrains near the advancing boundary were in various stages of recovery, with some essentially unrecovered, while others had a very low dislocation density. A small subgrain (shown by the arrow) appeared to be in the process of being absorbed by the advancing boundary. SAD from the unrecovered region (lower inset) indicated that it had a (111) plane parallel to the foil surface, with misoriented regions of up to 16 degrees rotation about the foil normal. These regions are similar in orientation and structure to previously described regions. Diffraction from the recrystallization nucleus (top inset) showed that it was tilted approximately four to six degrees from the $\langle 111\rangle$. Thus, a nearly (111)-oriented subgrain was growing into a similarly oriented region. It is felt it would continue to do so until a new grain was formed whose orientation had been a member of the orientation spread of the deformed crystal. These observations are consistent with the texture results which showed no texture change upon recrystallization.

A second specimen of Crystal 4-8, annealed for four hours at $600^{\circ} \mathrm{C}$, was examined at the mid thickness, and a representative microstructure is shown in Figure 73 . No recrystallization was evident in the mid thickness of the specimen, yet recovery was quite advanced, as evidenced by the low internal-dislocation density of the cells. Diffraction indicated that this region was oriented with a (111) plane parallel to the rolling plane and a maximum rotation of eight degrees misorientation about the zone axis. The microstructure of this region was very similar to that of the (111) [110] crystal. Partial recrystallization of the top surface, with no recrystallization at the mid thickness in four hours at $6000^{\circ} \mathrm{C}$, is consistent with the previously described hardness results.

Specimens from the mid thickness of the crystal were examined after annealing for ten hours at $600^{\circ} \mathrm{C}$. Recrystallization was estimated to be $70.80 \%$ complete. An example of a nearly completely recrystallized region is given in Figure 74 . The horizontal boundary in the lower portion of the micrograph contained trapped subgrains which were apparently dissolving their boundaries and reorienting. The small region above the boundary (arrow) was an isolated subgrain within the recrystallized grain. Examples of partially recrystallized regions are shown in Figures 75 and 76 . Note that the large recrystallized area of Figure 75 has boundaries which conform to the subgrain boundaries of the region in which they are growing. This relationship would imply that a moving, higher-angle boundary possibly sweeps through a subgrain and is halted momentarily when it reaches the position of the opposite subgrain boundary. Because the diffraction pattern was similar to that of Figure 71, the area of unrecrystallized subgrains of Figure 75 was assumed to be a transition region between (001) and (111), as discussed before. Thus, a (111)-oriented grain was growing into a transition region. In Figure 76, the grain in the lower left had a (113) plane parallel to the foil surface and, again, appeared to be growing into a transition region. The $\langle 113\rangle$ is 25.2 degrees from a $\langle 001\rangle$ and 29.5 degrees from $a\langle 111\rangle$, which indicated that this grain may have nucleated from the edge of a transition region and was growing into the remaining transition area. Some subgrains, such as the one shown by an arrow in Figure 75 , were apparently resistant to 


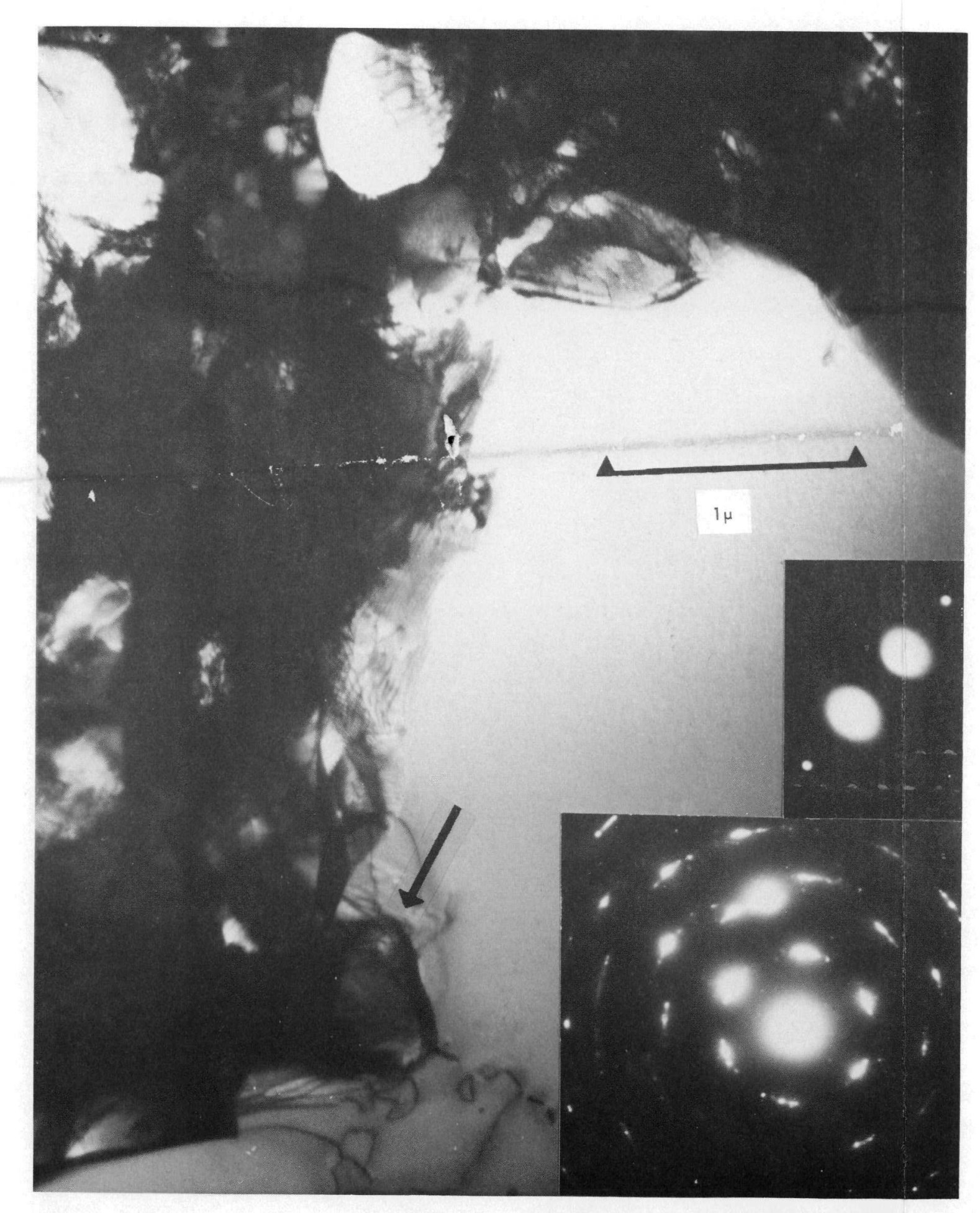

Figure 72. MICROSTRUCTURE OF CRYSTAL 4.8 THAT WAS AN
from Near the Top Surface of the Crystal, as Illustrated in Figure 64)

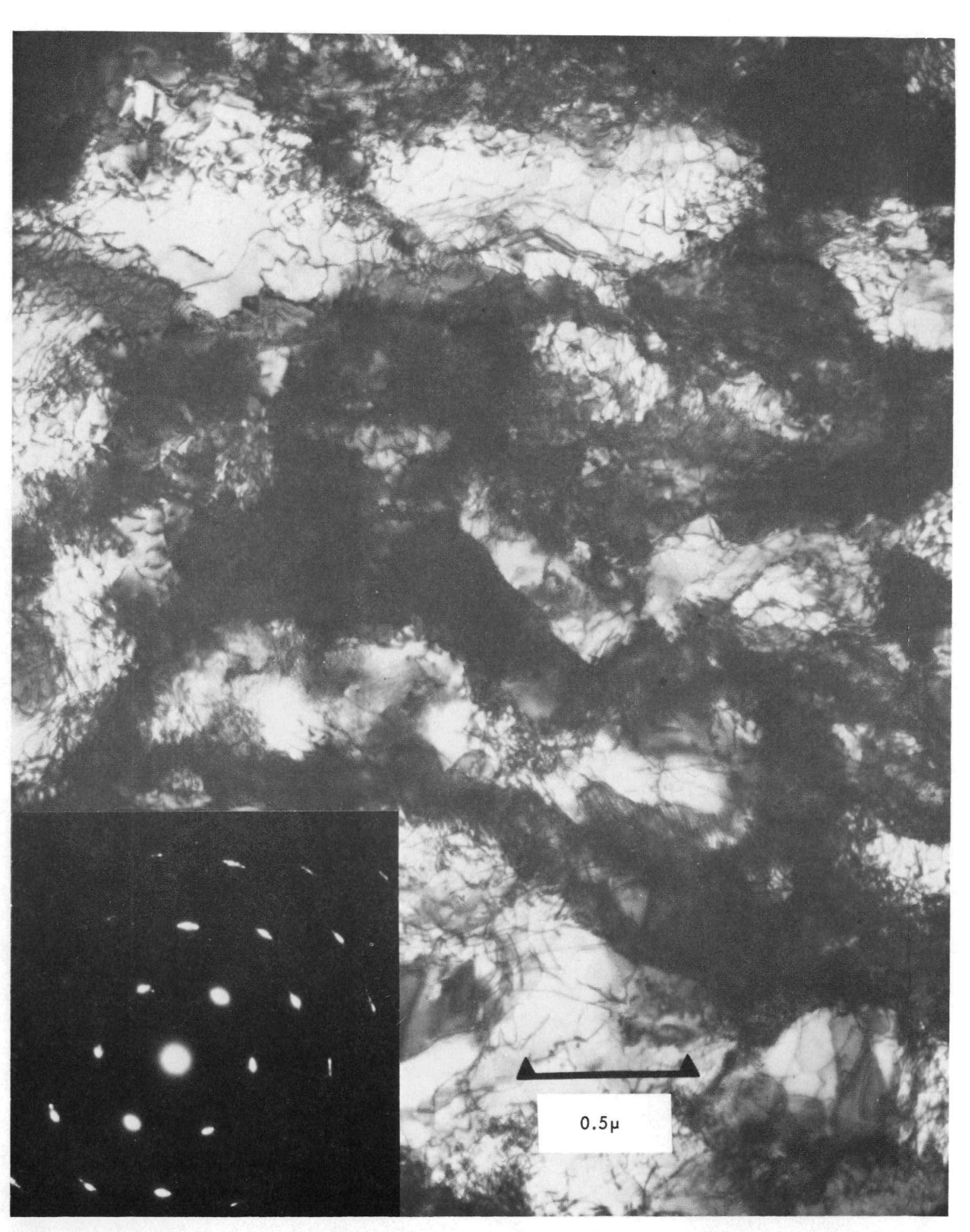

Figure 73. MICROSTRUCTURE OF CRYSTAL 4.8 THAT
is from the Mid Thickness of the Crystal; [111] Zone Axis

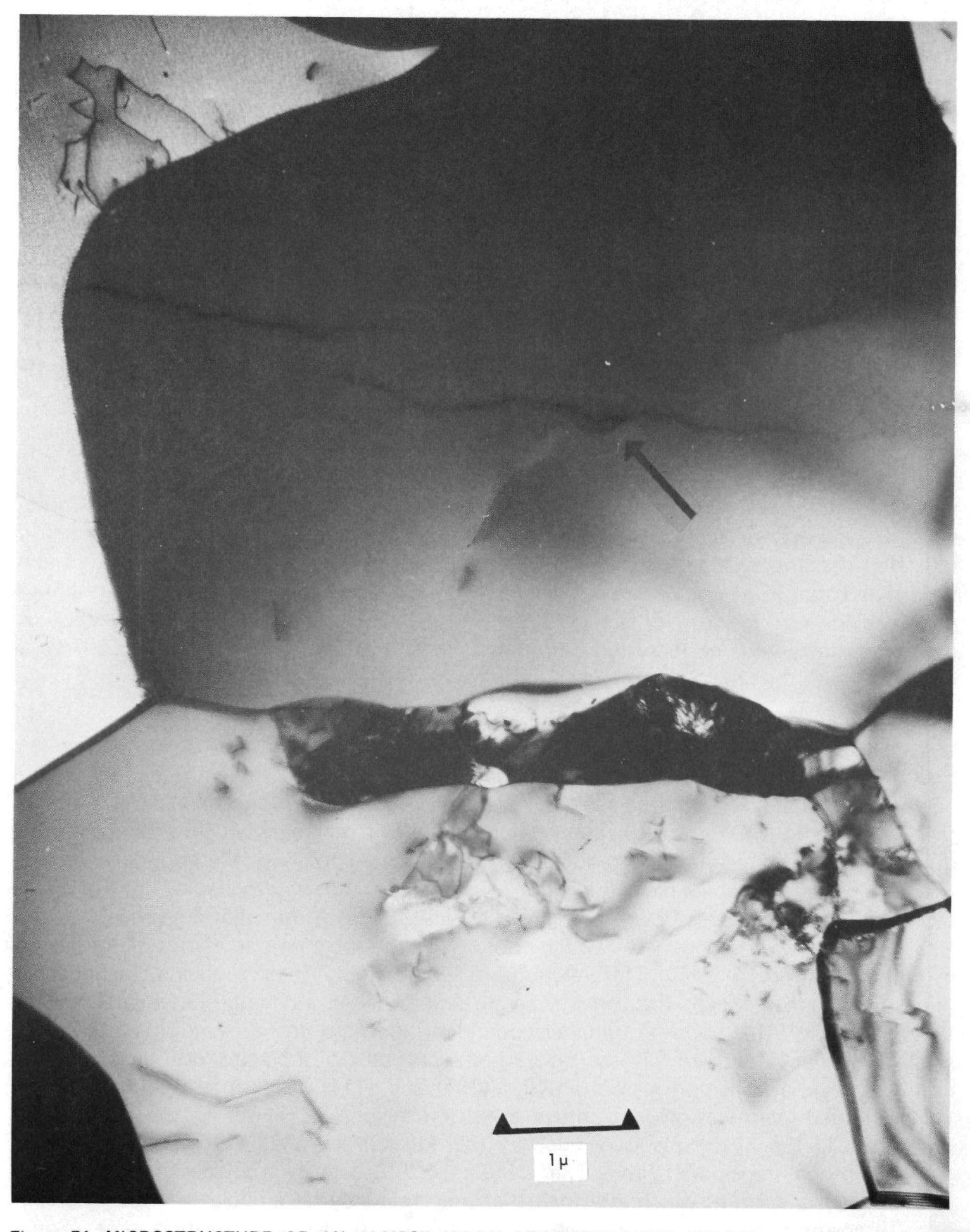

Figure 74 . Mi.
SUGGRAINS. 


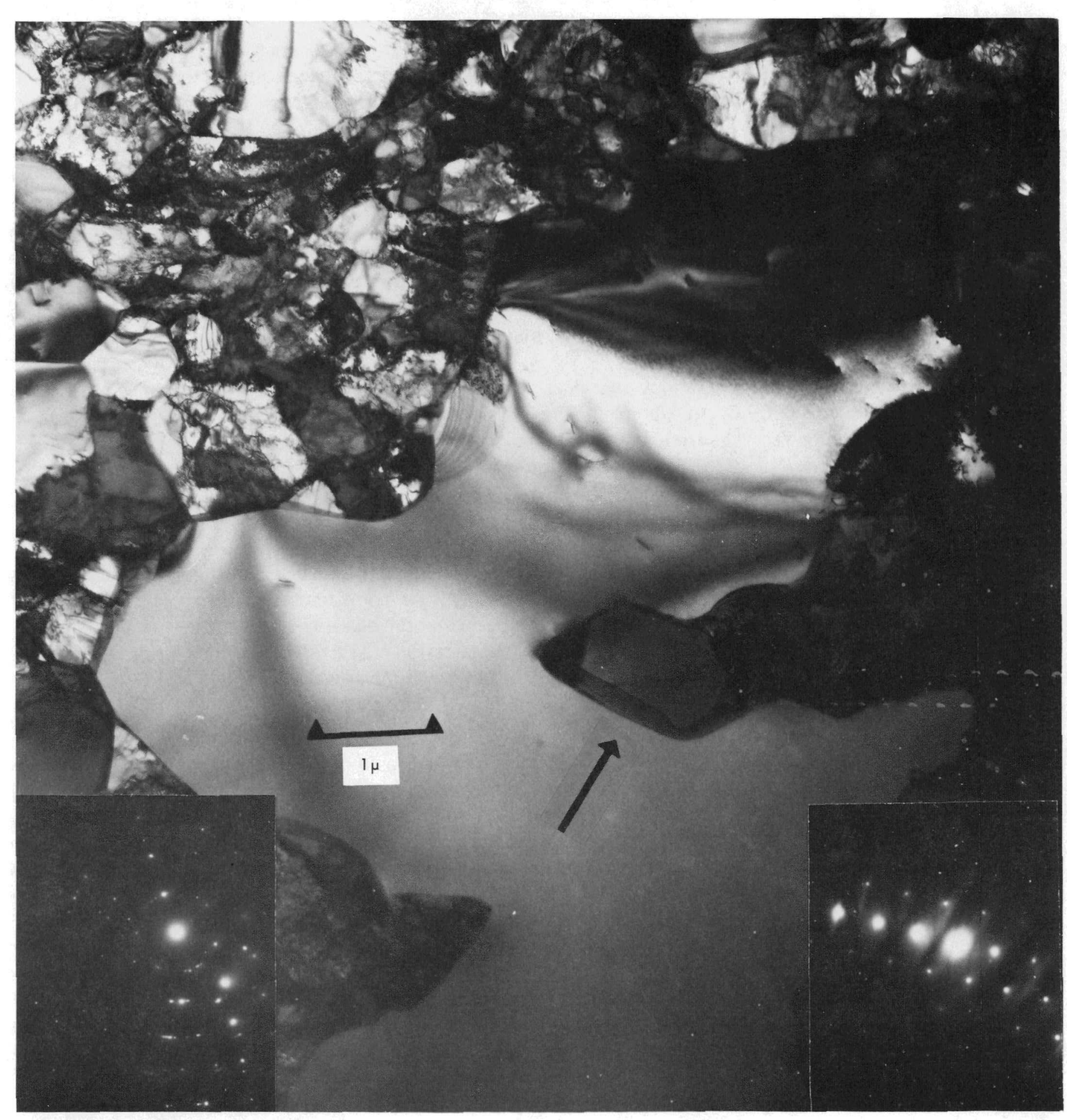

Figure 75. MICROSTRUCTURE OF THE MID THICKNESS OF CRYSTAL 4-8 THAT WAS ANNEALED FOR TEN HOURS AT $6000^{\circ} \mathrm{C}$ while the Pattern on the Right is from a Recrystallized Grain)

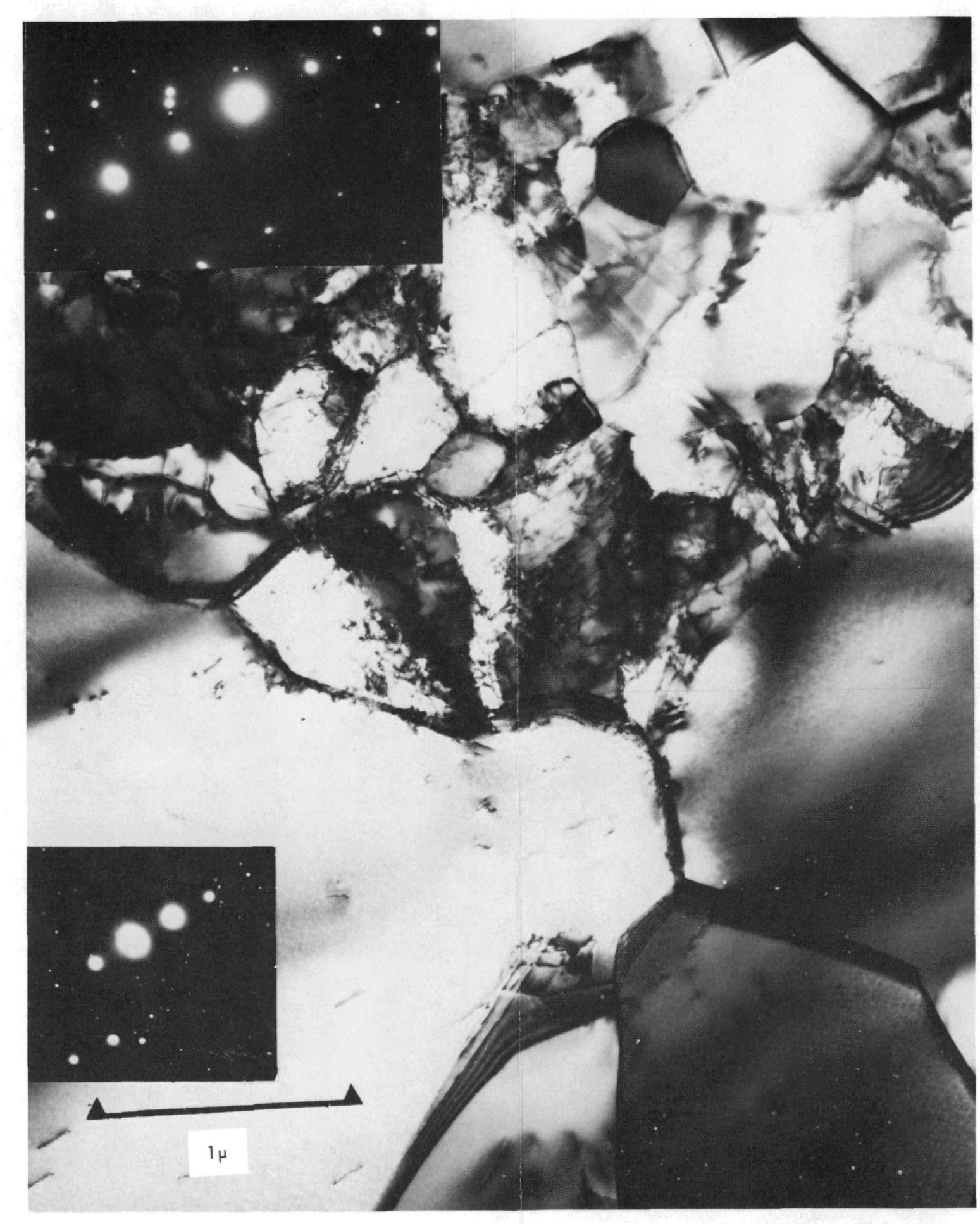

Figure 76. MICROSTRUCTURE OF CRYSTAL 4.8 THAT WAS ANNEALED FOR TEN HOURS AT $600^{\circ} \mathrm{C}$ ILLUSTRATING THE PARTIALLY RECRYSTALLIZED CONDITION. (Top Pattern is from the Subgrain Region, while

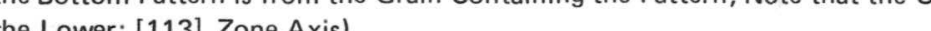


movement of the high-angle boundary and could possibly have become isolated, like the subgrain in Figure 74. Most recrystallized grains of the crystal were found to have (111) planes parallel to the foil surface, in agreement with the texture results.

Cell-area measurements (Table 6) were made on unrecrystallized regions of the micrographs, such as in Figures 75 and 76. The geometric-mean cell area had increased while the distribution was obviously shifted to larger cell areas. A striking similarity existed between the cell-area distributions of the (111) crystal that was annealed for ten hours at $700^{\circ} \mathrm{C}$ and Crystal 4-8 that was annealed for ten hours at $600^{\circ} \mathrm{C}$ (Appendix B). An obvious change in the subgrain growth rate occurred in the (110) crystal between one and ten hours at $600^{\circ} \mathrm{C}$. Subgrain growth in the (110) crystal was more rapid than in the (111) crystal between one and ten hours at $600^{\circ} \mathrm{C}$. A $100^{\circ} \mathrm{C}$ increase in temperature was necessary to produce subgrains in the (111) crystal that were comparable in size to those of the (110) crystal. However, even at $700^{\circ} \mathrm{C}$ the (111) crystal contained an extremely small number of isolated recrystallization nuclei. Thus, the subgrain growth rate appeared to be much higher in the (110) crystal than in the (111) crystal.

Transmission microscopy was also performed on Crystal 4-11 that was annealed for ten hours at $600^{\circ} \mathrm{C}$. An example of the microstructure is presented in Figure 77, which shows a partially recrystallized region. The microstructure is very similar to that of Crystal 4-8 (Figures 75 and 76 ). Recrystallization is estimated to be 80 to $90 \%$ complete.

\section{DISCUSSION OF RESULTS}

In this section, a review of the rolling results will first be given and the important features discussed. The reorientation observations will be compared to theoretical predictions of crystal stability, and a model of the deformation banding observed in the (110) [1T0] crystal will be offered. Finally, the recrystallization characteristics will be discussed in terms of how they relate to the deformation structure of the crystals.

A summary of the rolling results is given in Table 8 . In general, the further removed an orientation was from (001) [110] the less stable was the orientation during rolling. Though the (001) and (112) crystals both maintained their original orientations, only the (001) crystal approached plane-strain deformation during rolling. It appeared that the (112) crystal had to undergo transverse shear strain in addition to approximately plane strain in order to maintain its initial orientation. In view of this observation, it is questionable whether the (112) crystal would be stable if there was enough transverse constraint to force plane-strain deformation. Support for such a prediction comes from Wonsiewicz and Chin (76) who have shown that transverse constraints applied to normally stable copper single crystals during uniaxial compression lead to reorientation and inhomgeneous slip. The (111) crystal, on the other hand, reoriented toward a single (112) orientation, which implied that the (112) orientation was a more stable orientation. Obviously, the (110) orientation was extremely unstable and reoriented into multiple orientations, which were greatly different from the original orientation.

The stability of crystals used in this experiment can be compared with theoretical predictions of body-centered-cubic, single-crystal reorientation during deformation. Crystal reorientation and stability have been treated theoretically by several investigators in past 


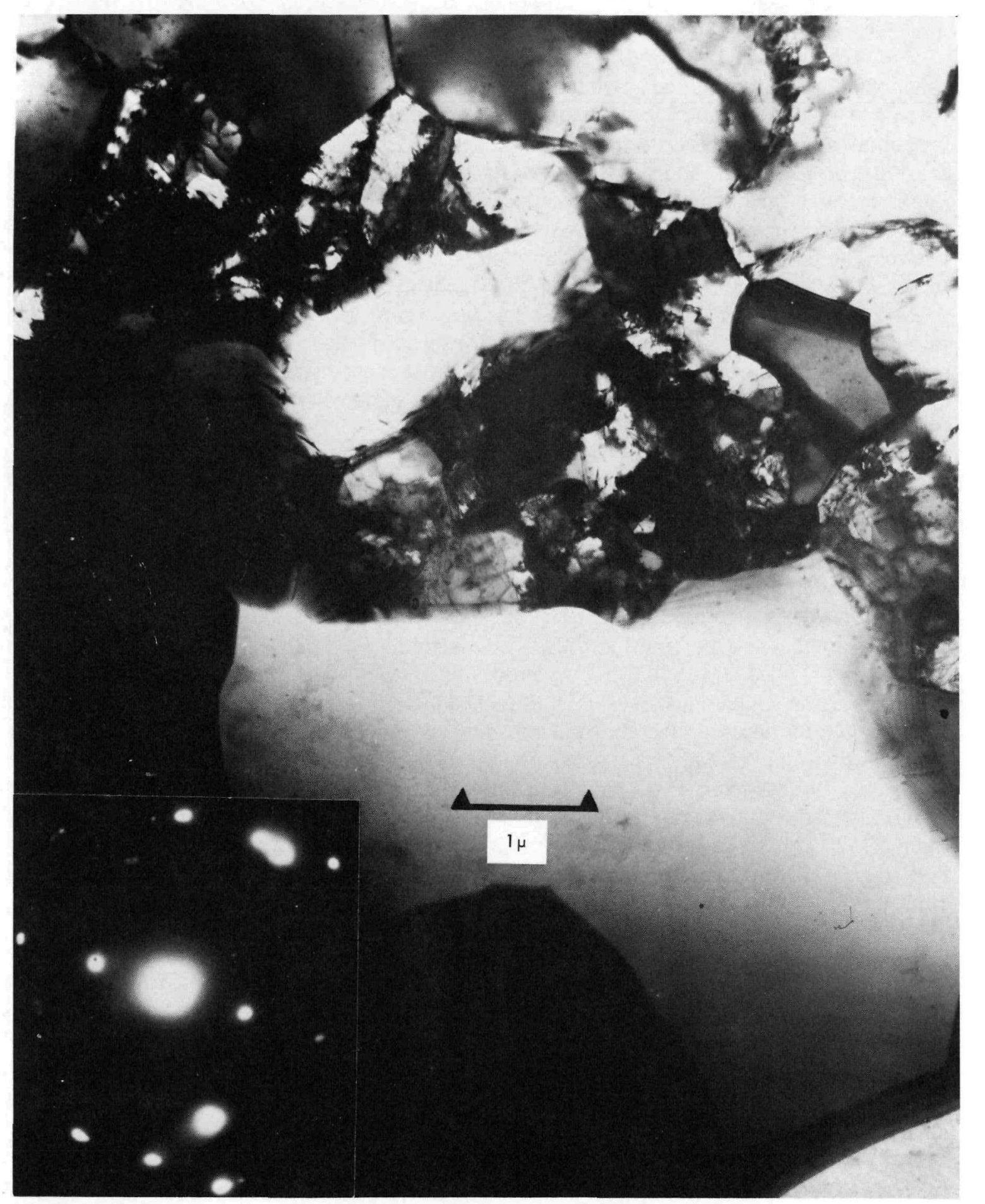

Table 8

SUMMARY OF ROLLING RESULTS

\begin{tabular}{|c|c|c|c|c|c|}
\hline $\begin{array}{c}\text { Original } \\
\text { Orientation }\end{array}$ & $\begin{array}{c}\text { Final } \\
\text { Orientation }\end{array}$ & $\begin{array}{c}\text { Transverse } \\
\text { Strains }\end{array}$ & $\begin{array}{c}\text { Hardness } \\
\text { Increase }(1) \\
(\%)\end{array}$ & $\begin{array}{c}\text { Line- } \\
\text { Broadening } \\
\text { Increase } 11) \\
(\%)\end{array}$ & $\begin{array}{l}\text { Microstructural } \\
\text { Features }\end{array}$ \\
\hline$(001)[1 \overline{1} 0]$ & $(001)[1 \overline{1} 0]$ & Normal, 0.015 & 69.0 & 20.0 & $\begin{array}{l}\text { Dense, uniform } \\
\text { dislocation } \\
\text { tangles, loops. }\end{array}$ \\
\hline (112) [1 $1 \overline{1} 0]$ & $(112)[1 \overline{1} 0]$ & $\begin{array}{l}\text { Normal, } 0.033 \\
\text { Shear, } 1.93\end{array}$ & 100.0 & 21.0 & $\begin{array}{l}\text { Dense dislocation } \\
\text { tangles, loops. }\end{array}$ \\
\hline (111) $[1 \overline{1} 0]$ & $\begin{array}{l}\text { Rotated } 10^{\circ} \text { Toward } \\
(112)[1 \overline{10}]\end{array}$ & $\begin{array}{l}\text { Normal, } 0.065 \\
\text { Shear, } 1.22\end{array}$ & 159.0 & 105.0 & $\begin{array}{l}\text { Cell structure } \\
\text { elongated } \\
\text { transverse to the } \\
\text { rolling direction. }\end{array}$ \\
\hline$(110)[1 \overline{1} 0]$ & $\begin{array}{l}\{111\}<1 \overline{10}>\text { to } \\
<112>\text { plus } \sim\{001\} \\
<010>\end{array}$ & $\begin{array}{l}\text { Normal, } 0.069- \\
0.157 \\
\text { Double-Barrel } \\
\text { Edges }\end{array}$ & 285.0 & $160.0^{(2)}$ & $\begin{array}{l}\text { Deformation bands } \\
\text { observed opti- } \\
\text { cally. Large cell } \\
\text { structure in bands; } \\
\text { small cell struct- } \\
\text { ure between bands. }\end{array}$ \\
\hline
\end{tabular}

(1) Percent increase relative to the unrolled standard.

2) Relative to the $\{111\}$ standard. 
years. $(22,77,78)$ Only recently, however, has anyone attempted to predict when deformation banding might occur. Dillamore and coworkers $(21,24,79-81)$ have calculated the stability of selected body-centered-cubic crystal orientations to rolling deformation. The results of their calculations for crystals having a [110] rolling direction (crystals used in this study) are given in Figure 78. These calculations were made by assuming that the Taylor theory of plasticity holds; ie, that the crystal will undergo the imposed shape change with a minimum amount of shear on the active slip planes. Slip planes were taken to be those for pencil glide in body-centered-cubic metals, $\{h k l\}<111\rangle$. Two types of deformation were considered: (1) a situation with plane strain only $(\epsilon \mathrm{ND}=-\epsilon \mathrm{RD}$, and $\epsilon \mathrm{RD}=0)$, and (2) a case allowing some transverse spreading $(\epsilon T D / \epsilon N D=-0.1)$ where $T D, N D$, and RD refer to the transverse, normal, and rolling directions, respectively. For an arbitrary shape change, there are five independent components of strain when referred to crystal axes; for body-centered-cubic pencil glide, there are eight independent parameters from which the five may be chosen. The shear magnitudes along the four $\langle 111\rangle$ directions provide half of these, while the angular inclinations of the slip planes to some arbitrary zero provide the other four. Since all of these variables have a continuous range of variation, it is possible, for some crystal orientations, to use optimization procedures to give a unique solution for crystal rotation corresponding to Taylor's minimum-shear hypothesis. On the other hand, consideration of slip on the $\{110\}<111>$ systems alone will not lead to a unique solution to crystal rotation in many instances. $(82)$

The upper graph in Figure 78 gives the Taylor factor, $M$, for each of the orientations; the lower one gives the rotation rate about the rolling direction, $\mathrm{d} \phi / \mathrm{d} \epsilon$, for a unit normal strain, $\mathrm{d} \epsilon$. The solid line of the lower graph is for assumed plane-strain deformation, while the dashed line is for assumed lateral spreading. Arrows indicate the direction of rotation of a particular orientation, while convergence of the arrows indicates a stable orientation. An orientation which has a zero rotation rate, but which would tend to reorient if moved slightly from its zero position, is called "metastable". For plane-strain deformation, both the (001) [1T0] and (110) [1T0] orientations should be metastable according to this theory. If some widening is allowed, the (001) [1T0] orientation is stabilized (because the rotation is now negative and the ordinate acts as a mirror plane), while the (110) [1 10 ] remains metastable. Dillamore predicts that deformation banding would occur for metastable orientations. Thus, for plane-strain deformation, the theory predicts that the (001)[1 $\overline{10}$ ] and (110) [1 $\overline{1} 0$ ] would form deformation bands, with reorientation toward the stable (112) [1 $\overline{1} 0]$ orientation. Under lateral widening conditions, the theory would predict that the (001) [1T0] and an orientation close to the (112) [1T0] would be stable, while the (110) [1 $\overline{10}$ ] orientation would form deformation bands and reorient toward (112) [1 $\overline{1} 0]$.

Results of this experiment indicate that the (001) [1T0] is quite a stable orientation which does not form deformation bands. A slight amount of lateral widening (1.5\%) was observed in this crystal. Thus, it would seem, qualitatively at least, that the predicted stability of this crystal with lateral widening was confirmed experimentally. However, the amount of widening necessary to stabilize this orientation was not clearly stated in Dillamore's theory. The dashed line of the diagram in Figure 78 is for $8.0 \%$ lateral widening when applied to the present experiment $(\epsilon N D=-0.8)$. If a very slight amount of widening is not sufficient for theoretical stability, then deformation banding would still be expected to occur. Deformation banding of the (001) [1 $\overrightarrow{10}$ ] seems highly unlikely even if transverse straining is suppressed completely. Therefore, the theory, as applied to plane-strain deformation, should be viewed with some reservation. 


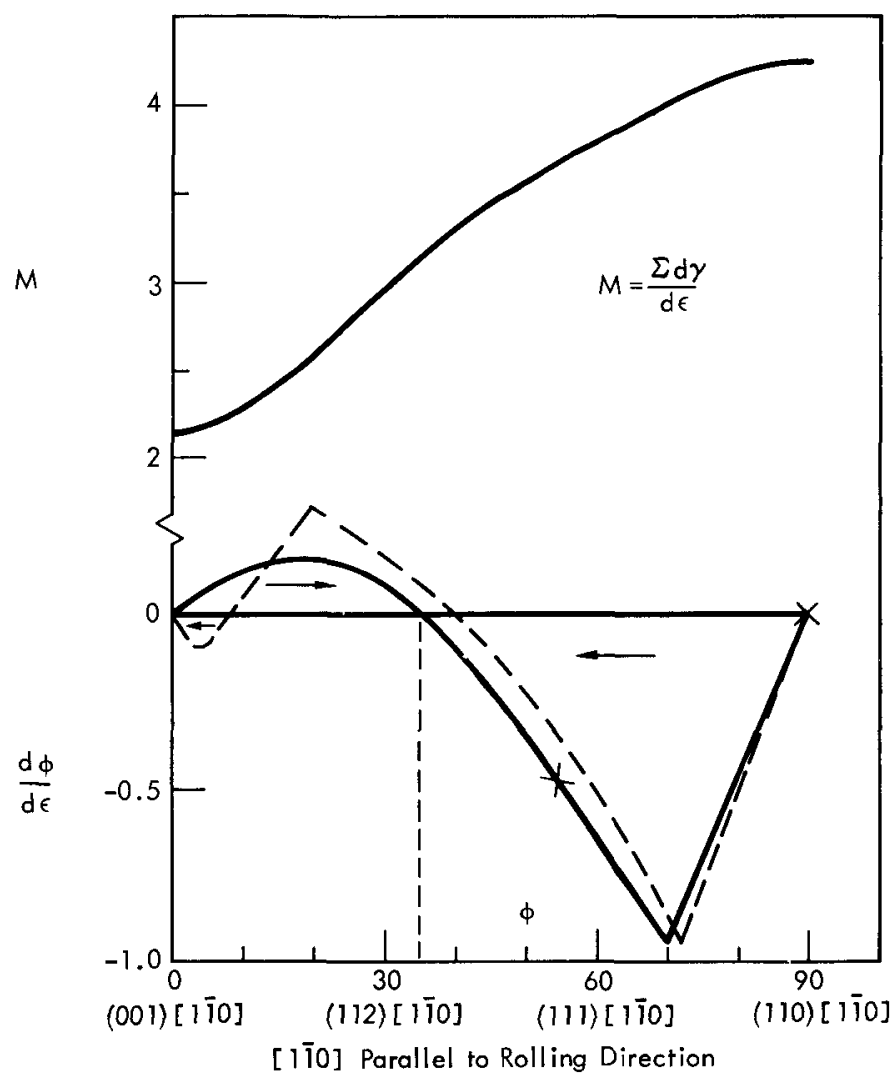

Figure 78. TAYLOR FACTOR AND ROTATION RATE AROUND THE ROLLING DIRECTION FOR ORIENTATIONS WITH A [110] ROLLING DIRECTION. (Solid Line in the Lower Diagram is for Plane Strain, while the Dashed Line Assumes Lateral Widening with $\epsilon$ TD/ $\epsilon N D=-0.1 ; \epsilon N D=-0.8$ for this Experiment)

The (112) [1T0] crystal was also observed to be stable after undergoing both transverse normal and shear strains. Dillamore's theory predicts that this orientation would be stable under either plane strain or slight lateral widening. However, as previously mentioned, it is possible that this orientation would not be stable or strain homogeneously if transverse straining were suppressed.

Theory also predicts that under either straining condition, the (111) [1 $\overline{1} 0$ ] orientation would reorient toward the (112) [1T0]. Experimentally, the (111) [1T0] was seen to reorient toward the (112) [110], in agreement with the theory. However, the crystal underwent more complex straining than was examined theoretically. Both transverse normal strains (lateral widening) and transverse shear strains were observed. Once, again, the question arises as to whether the crystal would reorient toward (112) [110] if transverse straining were suppressed.

Due to the symmetry of the bottom diagram of Figure 78, a properly oriented (110) [1T0] crystal would have an equal probability of reorienting to the stable (112)[1T0] and $(11 \overline{2})[1 \overline{10}]$ positions (not shown on diagram). Implications of the theory are that deformation bands with alternate orientations of $(112)[1 \overline{10}]$ and $(1 \overline{1})$ [1 $\overline{1} 0]$ would be formed in the (110) [1T0] crystal. Pole-figure and TEM analyses of rolled (110) [1T0] 


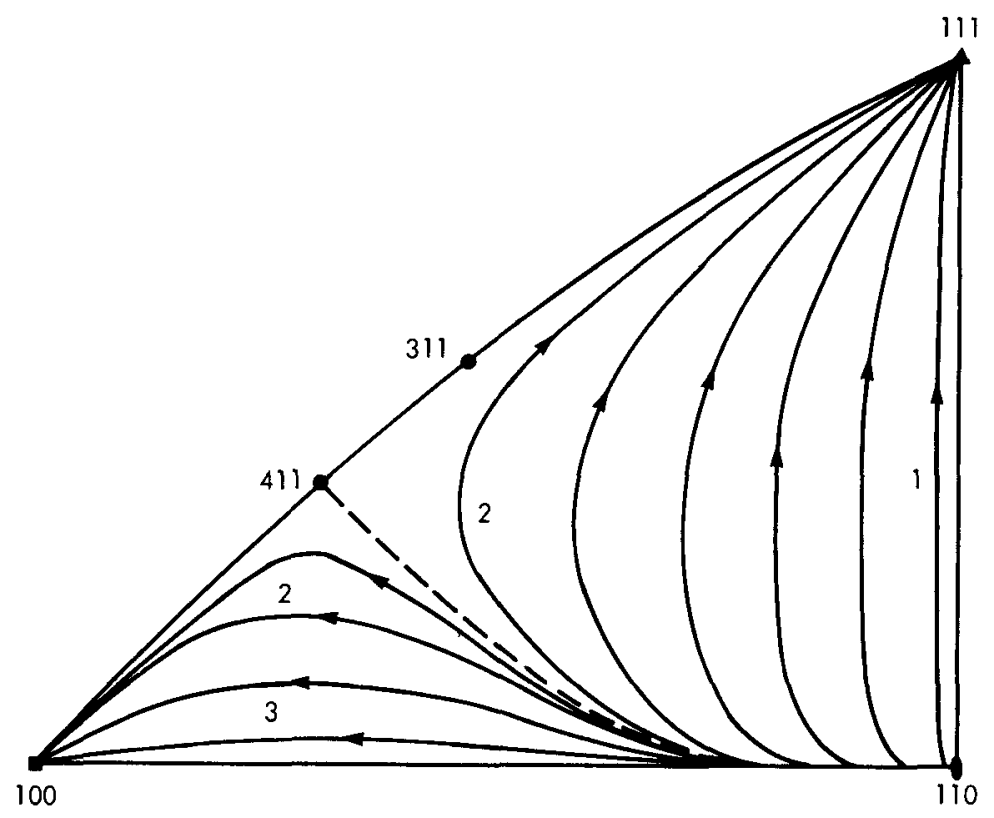

FIgure 79. PATH OF SLIP ROTATIONS FOR THE COMPRESSION OF BODY-CENTERED-CUBIC METALS DEFORMING BY PENCIL GLIDE. (After Dillamore and Katoh $(81)$ )

crystals used in the present study consistently showed both $\{111\}$ and $\{001\}$ rolling planes present simultaneously. These results are in agreement with those of other workers on other body-centered-cubic materials, as reported in Table 9 . Blanks in this table indicate that the data were not published. Note that many investigators report identification of a $\{111\}$ rolling plane, and Mochalov, (17) in fact, noted both $\{111\}<110>$ and $\{001\}<100>$ orientation present simultaneously in rolled molybdenum crystals. Dual $\{111\}$ orientations symmetrically related about the rolling direction were observed in all but one crystal (4-12) of the present study. Rolling directions of these components were $<110>$ under moderate-body conditions and moved to $<112>$ under thin-body conditions. An orientation close to $\{001\}<100>$ was observed under all rolling conditions. One of the observed orientations, $\{111\}\langle 1 \overline{10}\rangle$, would have been expected from the theoretically predicted reorientation of the $(110)[1 \overline{10}]$ toward the stable $\{112\}<1 \overline{10}>$. However, neither the $\{111\}<112>$ nor the $\{001\}<100>$ were predicted theoretically for plane strain or slight transverse spreading.

Some rolled crystals had transverse strains of up to $15 \%$. While still a far cry from the $40 \%$ necessary to be able to describe the strain state in rolling as one of axisymmetric compression $(\epsilon T D=\epsilon R D)$, it was thought that a better understanding of the evolution of an $\{001\}$ rolling plane could be gained by examination of crystal reorientation during axisymmetric compression. Shown in Figure 79 are the reorientation paths calculated for the axisymmetric compression of body-centered-cubic single crystals deforming by pencil glide. (81) Note that a crystal oriented with its compression plane initially parallel to (110) could reorient toward (111) or (100). Thus, it would be conceivable for different regions of a (110) crystal to rotate to both (111) and (100) orientations, giving rise to multiple texture components. Regions of the crystal might tend initially toward (411) along lines marked " 2 " or they might reorient in a more direct manner along lines " 1 " and " 3 ". Pole figures taken of crystals rolled $67 \%$ in this experiment indicated that multiple $\{113\}$ rolling-plane 
orientations; ie, near the (114), were present, thus lending further experimental support to the proposed reorientations.

Table 9

SUMMARY OF PRIOR WORK ON (110) [1 $1 \overline{10}]$ CRYSTALS

\begin{tabular}{|c|c|c|c|c|c|c|c|}
\hline \multirow[b]{2}{*}{ Material } & \multirow[b]{2}{*}{$\begin{array}{c}\text { Final } \\
\text { Orientation }\end{array}$} & \multicolumn{6}{|c|}{ Rolling Conditions } \\
\hline & & $\begin{array}{l}\text { Starting } \\
\text { Thickness } \\
\text { (mm) }\end{array}$ & $\begin{array}{l}\text { Roll } \\
\text { Radius } \\
(\mathrm{mm})\end{array}$ & $\begin{array}{c}\text { Initial } \\
\Delta\end{array}$ & $\begin{array}{c}\text { Rolling } \\
\text { Temperature } \\
\text { (O C) }\end{array}$ & $\begin{array}{l}\text { Total } \\
\text { Reduction } \\
(\%)\end{array}$ & Lubricant \\
\hline $\mathrm{Fe}-3 \% \mathrm{Si}(83)$ & $(111)[0 \overline{1} 1]$ & 0.5 & 20 & 0.69 & $\mathrm{RT}$ & 85 & \\
\hline $\mathrm{Fe}-3 \% \mathrm{Si}(22)$ & $\begin{array}{l}(110)[1 \overline{10}] \text { Rotated } \\
10^{\circ} \text { around the Rolling } \\
\text { Direction }+ \text { Minor } \\
(221)[0 \overline{11}]\end{array}$ & $0.6-1.0$ & 75 & 0.21 & $\mathrm{RT}$ & 71 & Rape Oil \\
\hline $\mathrm{Fe}-3 \% \mathrm{Si}(71)$ & $(110)[1 \overline{10}]$ & 0.8 & & & $\mathrm{RT}$ & 66 & \\
\hline Mo(84) & Not Given & & $\begin{array}{l}\text { No } \\
\text { Rolling } \\
\text { Data }\end{array}$ & & & 70 & \\
\hline Mo(65) & $\begin{array}{l}\text { TEM Showed (111) } \\
\text { and (100) Rolling } \\
\text { Planes }\end{array}$ & 1.0 & & & RT & 80 & \\
\hline Mo(85) & $\begin{array}{l}\text { Crystals Ruptured } \\
\text { after } 20 \% \text { Reduction }\end{array}$ & 2.0 & & & RT & 20 & \\
\hline $\mathrm{Mo}(17)$ & $\begin{array}{l}\text { Strong }(111)[1 \overline{10}] \\
+(111)[\overline{110}] ; \\
\text { Weak }(001)[100]\end{array}$ & & & & & $80-96$ & \\
\hline$w(16)$ & $\begin{array}{l}\text { Identified as } \\
\text { Complex }\end{array}$ & 6.0 & 76 & 0.84 & 1000 & 50 & None \\
\hline
\end{tabular}

A further extension of the reorientations of Figure 79 can be seen in Figure 80. Here the reorientations due to the full-crystal symmetry have been included. First, consider the initial (110) rolling plane indicated by the [110] normal direction. As the crystal begins to reorient, it breaks into two adjacent regions-one which reorients to a (111) rolling plane and one which reorients to an (010) rolling plane, as previously described. It is obvious from the symmetry of the crystal that another set of orientations is equally likely-the (11T) and (010) rolling planes. From this reorientation, two $\{111\}$ and one $(010)$ rolling planes would be expected-a situation observed in this experiment. Further symmetry considerations allow an alternative set of orientations; ie, (11T), (111), and (100) rolling planes. Following the indicated reorientations of Figure 80, the rolling direction of the region having a (010) rolling plane moves to [100] while the region having a (111) rolling plane maintains a [1T0] rolling direction under moderate body conditions, and moves toward a [2/1] under thin-body conditions.

The reorientations just described account for all of the pole figure observations on the (110) class of crystals except for the crystal rolled under thin-body conditions with lubricant (Crystal 4-12), which showed only single $\{111\}$ and $\{001\}$ rolling planes simultaneously. Though it is possible that this was strictly an effect of lower friction conditions, a more likely explanation is that the crystal normal was oriented sufficiently off the ideal orientation, as indicated by the star on the diagram. The symmetry of such an orientation would be destroyed and single $\{111\}$ and $\{001\}$ rolling planes might be expected. 
Whereas reorientation of the (110) [1T0] crystal can be more easily understood in terms of the strain state of axisymmetric compression rather than plane strain, the true response of the crystal perhaps lies somewhere between these two extremes. Though (110) [1 10 ] crystal reorientation is not completely described by the theoretical treatment of plane strain, the observed orientations, $\{111\}$ $\langle\overline{112}\rangle$ and (001) [100], are predicted by Dillamore to be stable with respect to rotations about the rolling and transverse directions. Experimentally, in iron-silicon, the (001) [100] crystal has been observed to produce deformation bands. (15) However, additional experimental work has shown that some niobium crystals of this orientation are stable during rolling. (86) Body-centeredcubic crystals of the $\{111\}$

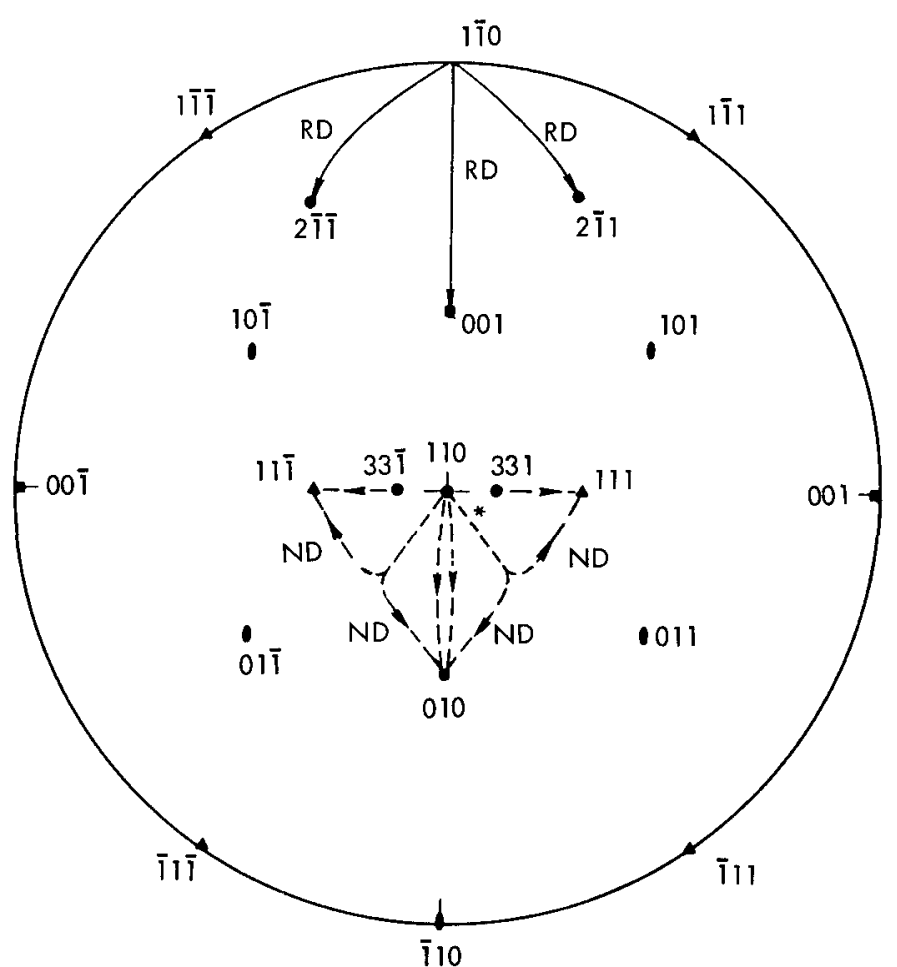

Figure 80. (110) STANDARD PROJECTION, SHOWING (110)[1 $1 \overline{10}]$ CRYSTAL REORIENTATION. (Arrows Indicate the Direction of Reorientation) $\langle\overline{112}\rangle$ orientation have been shown to be stable during rolling by several investigators. $(1,72)$

A model of deformation banding for the (110) [1 10$]$ crystal will be offered, based on observations of this experiment. Figure 81 shows the model and a micrograph of a rolled crystal viewed in the same orientation. Alternate bands with $\{001\}$ and $\{111\}$ are consistent with both the $X$-ray and TEM findings. The transition band corresponds to the region of equiaxed cell structure shown in Figure 71, and lies between the $\{001\}$ and $\{111\}$-oriented regions. A set of electron diffraction patterns, from a region depicted by Figure 81, is given in Figure 82. This series of patterns was made by scanning the diffraction aperture across these regions while maintaining a fixed specimen geometry. The top pattern was from an $\{001\}$-oriented region, while the bottom pattern was from an $\{111\}$. oriented region. Though the rolling direction relative to the patterns was not known, the $\{001\}$ region had a $<001>$ direction nearly parallel to a $<112>$ direction in the $\{111\}$ region, which coincides with the pole-figure results. This similarity suggests that the probable rolling direction was that indicated in the figure.

The center pattern was from a region that is proposed to lie within some sort of transition band. It was indexed as having a $\{331\}$ plane parallel to the plane of the foil. This result may seem confusing until viewed in light of the crystal reorientation discussed in Figures 79 and 80 . In Figure 80, the $\{331\}$ orientation was shown to lie between the (110) and (111). Several further implications stem from this observation. First, this crystal may have reoriented by following Path 1 in Figure 79. If so, then all rolling-plane orientations 

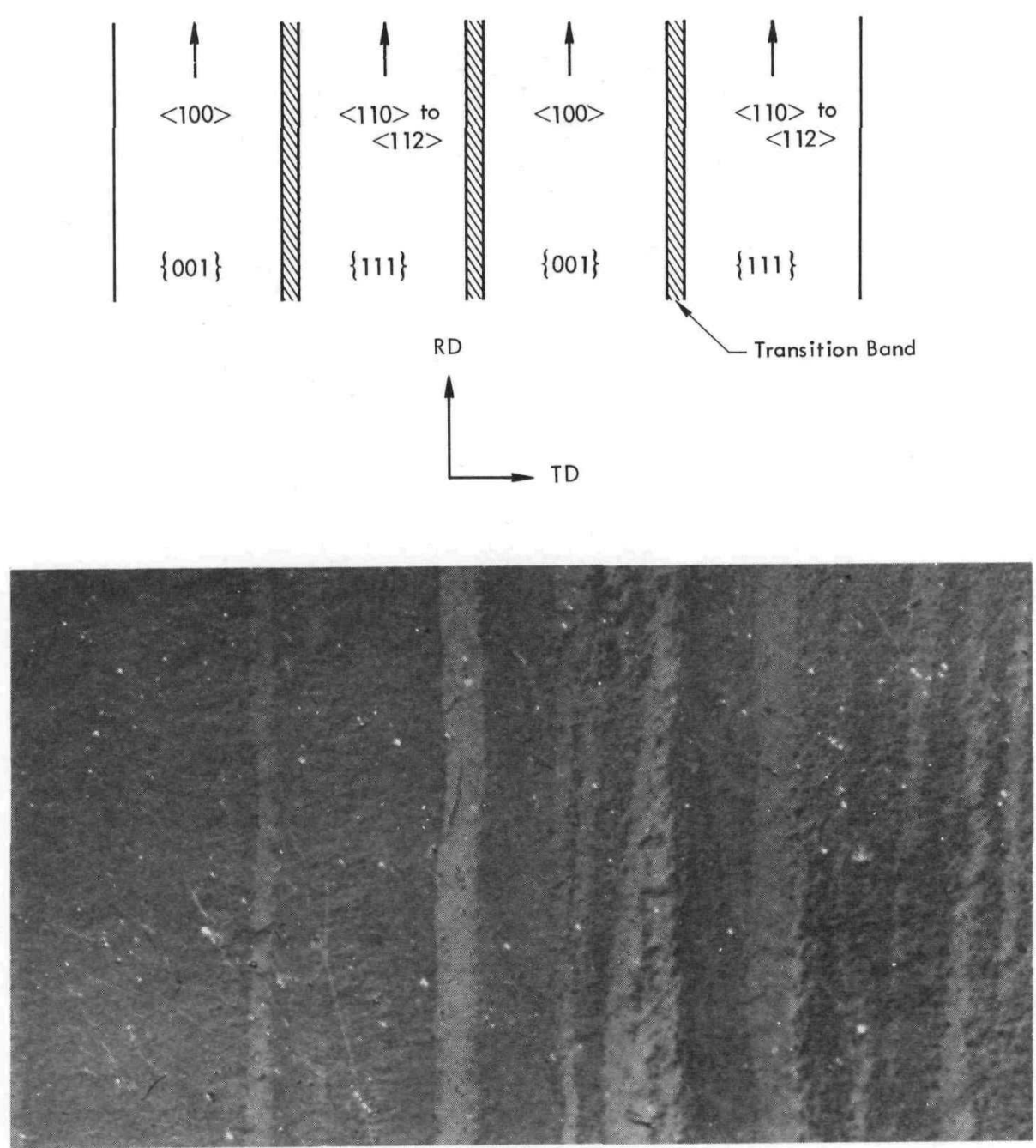

Figure 81. PROPOSED DEFORMATION BANDING AND MICROGRAPH OF CRYSTAL 4-11, VIEWED PARALLEL TO THE NORMAL DIRECTION.

between (110) and (111) may also have been present in the transition band. There was also an equal likelihood that orientations ranging from (110) to (010) were present in the transition band. A further implication is that a fragment (perhaps only one subgrain) of the original orientation was present in the transition region.

The model of Figure 81 indicates that the rolling direction of the $\{111\}$-oriented region varies from $\langle 110\rangle$ to $\langle 112\rangle$. This result is consistent with the effects of lubricant and deformation-zone size, as summarized in Table 5. It appears that when widening was suppressed, the [1T0] remained parallel to the rolling direction. As the transverse strain of the crystal increased, the $\langle\overline{112}\rangle$ tended to align with the rolling direction. Under higher frictional conditions, there may have been enough transverse constraint to prevent widening and maintain the [1T0] parallel to the rolling direction. When transverse frictional forces were lowered (ie, by lubrication), widening and crystal realignment occurred. These frictional effects were observed in the case of moderate body deformation, but not under thin-body deformation. The reason for this behavior is not known at the present time. 
In summary, the experimentally observed deformation behavior of the (001) [1T0], (112) [1T0], and (111) [1 $\overline{10}]$ crystals is in partial agreement with Dillamore's treatment of the Taylor theory of crystal plasticity as it is applied to plane-strain deformation. Reorientation of the (110) [1 T0] crystal, however, can be better understood in terms of the Taylor theory as it is applied to axisymmetric strain. Deformation banding in the (110) crystal can be represented by a model which is consistent with $X$-ray, optical microscopy, and TEM results.

As the crystal orientations became more unstable, the hardness, integral breadth, and texture spread also increased. The macroscopic orientation spread observed in the pole figures was, to a great extent, observed on a microscale by electron diffraction. A notable exception was the (110) crystal, where both (111) and (100) orientations were observed simultaneously by $\mathrm{X}$-ray diffraction, yet singularly by electron diffraction. These differences were, of course, due to the formation of quite large deformation bands (Figure 81).
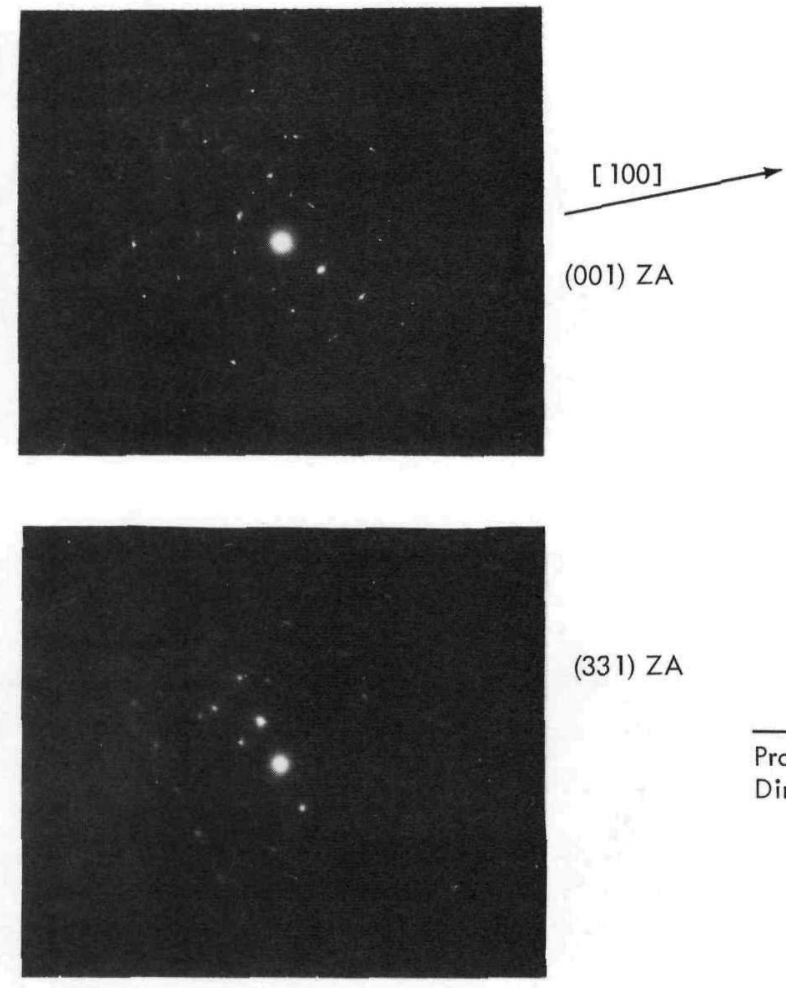

(331) ZA

Probable Rolling Direction

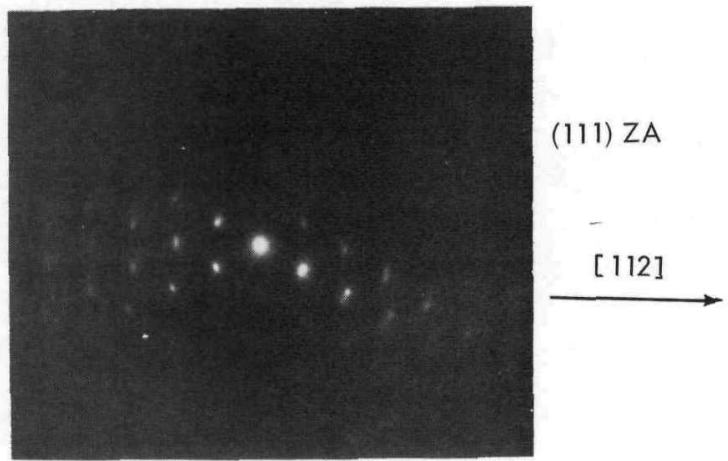

Figure 82. SELECTED-AREA ELECTRON DIFFRACTION PATTERNS FROM A REGION REPRESENTED BY FIGURE 81. (Top and Bottom Patterns are from Deformation Bands; the Center Pattern is from the Transition Region)

A dislocation cell structure was observed in the deformed (111) and (110) crystals, as opposed to the more uniform microstructure of the (001) and (112) crystals. Formation of a cell structure appeared to correlate well with an increased orientation spread, as measured by pole-figure analysis, as well as an increase in both hardness and integral breadth.

Differences in the dislocation substructure have been experimentally observed in both body-centered-cubic polycrystalline metals and single crystals initially oriented for single slip. $(1,2,11,12,69,87)$ In general it has been observed that dislocation cells will form at higher temperatures, lower strain rates, and lower alloy contents. At lower temperatures, higher strain rates, and higher alloying additions, dislocation cell formation is suppressed 
and a more uniform dislocation substructure emerges. These observations have been interpreted in terms of the lattice friction stress encountered by a dislocation. (87) At lower temperatures, higher strain rates, and higher alloy additions, lattice friction stress is believed to be high and screw dislocation mobility is greatly reduced. Thus, straining is mainly due to the motion of edge dislocations while cross slip and tangling (which lead to cell formation) are less prevalent.

In the present experiment, body-centered-cubic crystals of uniform composition were rolled at the same temperature and strain rate. Thus, orientation was the only variable giving rise to different deformation substructures. At present, there has been no comprehensive study of the development of dislocation substructure in single crystals oriented for multiple slip. Indeed, there is considerable variation in the interpretation of results on body-centeredcubic single crystals initially oriented for single slip. (87) At present it is not possible to describe the evolution of microstructure from dislocation theory. In the words of Hirth and Lothe (88)"... there is an enormous gap between the theory developed for the interaction between a few simple geometry dislocations and a description of macroscopic deformation". Though a complete description of the dislocation substructure in terms of dislocation theory is not possible, some generalizations based on simplifying assumptions do seem in order. $\mathrm{Li}(89)$ has theoretically considered the possible interactions of dislocations in the body-centered-cubic lattice to form tangles with long-range stress fields and stress-free dislocation networks. He considered the interactions of dislocations gliding on $\{110\}$, $\{112\}$ and $\{123\}$ slip planes, with dislocations initially lying on $\{110\},\{112\}$, and $\{123\}$ planes. By allowing for all such possible interactions, Li calculated that 18 different stress-free dislocation networks and 124 different tangles with long-range stress fields could possibly form in the body-centered-cubic lattice. In the (001) and (112) crystals rolled in this experiment, there was very little lattice curvature or misorientation produced during deformation. Therefore, it may be that the majority of dislocation reactions in these crystals resulted in stress-free dislocation networks. This condition would also account for the small amount of work hardening observed in these crystals. On the other hand, initial dislocation reactions in the (111) and (110) crystals may have created tangles which resulted in increased work hardening and the creation of cells. As these crystals reoriented, additional slip systems may have been activated, increasing further the probability of tangling, increased lattice curvature, and work hardening. The puzzling transverse elongation of cells in the (111) crystal may, in fact, be due to the operation of additional slip systems during the latter stages of straining. Initial straining could have created boundaries lying parallel to the transverse direction. Later operation of additional systems could have generated boundaries parallel to the rolling direction, creating the impression of cell elongation. Although little can quantitatively be said about the dislocation structures observed, the types of dislocations produced during straining and their distributions are of paramount importance to the recovery and recrystallization processes.

Intuitively, the wide variation and spread in orientation and microstructure observed in the rolled crystals would expect to lead to a variation in the annealing behavior. Differences in recrystallization behavior were, in fact, observed, and are summarized in Table 10. Under the experimental conditions evaluated, only two of the deformed crystals were found to fully recrystallize. The (001) crystal, which had the smallest hardness and integral breadth increase and a uniform dislocation distribution, did not recrystallize. Essentially, it returned to its initial state, with perhaps a smaller-than-original subgrain size, by recovery processes. A 
Table 10

SUMMARY OF THE ANNEALING RESULTS

\begin{tabular}{|c|c|c|c|c|c|c|}
\hline \multirow[b]{2}{*}{ Orientation } & \multicolumn{4}{|c|}{ Crystal Action } & \multirow{2}{*}{$\begin{array}{l}\text { Orientation of the } \\
\text { New Grains } \\
\text { Relative to the } \\
\text { Matrix }\end{array}$} & \multirow{2}{*}{$\begin{array}{c}\text { Average } \\
\text { Diameter } \\
\text { of the New } \\
\text { Grains } \\
(\mathrm{mm})\end{array}$} \\
\hline & $600^{(1)}$ & $800^{(1)}$ & $1000^{(1)}$ & $1200^{(1)}$ & & \\
\hline$(001)[1 \overline{10}]$ & & Recovery & Recovery & Recovery & & \\
\hline$(112)[1 \overline{10}]$ & & Recovery & $\begin{array}{l}\text { Partial } \\
\text { Recrystallization }\end{array}$ & $\begin{array}{l}\text { Partıal }(2) \\
\text { Recrystallızation }\end{array}$ & Random & $\begin{array}{l}1200^{\circ} \mathrm{C} \text { for } \\
\text { Ten hours } \\
\sim 20\end{array}$ \\
\hline$(111)[1 \overline{10}]$ & Recovery & $\begin{array}{l}\text { Partial } \\
\text { Recrystallızation }\end{array}$ & & $\begin{array}{l}\sim \text { Full } \\
\text { Recrystallizatıon }\end{array}$ & $\begin{array}{l}2324 \text { degree } \\
\text { rotation about } \\
<111\rangle\end{array}$ & $\begin{array}{l}1200^{\circ} \mathrm{C} \text { for } \\
\text { two hours } \\
023\end{array}$ \\
\hline$(110)[1 \overline{10}]$ & $\begin{array}{l}\sim \text { Full } \\
\text { Recrystallızatıon }\end{array}$ & $\begin{array}{l}\text { Grain } \\
\text { Growth }\end{array}$ & & & $\begin{array}{l}\text { Same as deformed } \\
\text { crystal }\end{array}$ & $\begin{array}{l}600^{\circ} \mathrm{C} \text { for } \\
\text { ten hours }(3) \\
<001\end{array}$ \\
\hline
\end{tabular}

(1) Temperature for the 10-hour anneal $\left({ }^{\circ} \mathrm{C}\right)$

(2) Artificially nucleated

(3) Annealing conditions to produce grain size 
somewhat higher dislocation density was observed in the (112) crystal, which was probably responsible for the slightly higher hardness increase of Table 8. Upon annealing, the crystal formed only a very few large graıns, of approxımately $2 \mathrm{~mm}$ in diameter, which were randomly oriented with respect to the matrix. There is reason to believe that these graıns may have been artificially nucleated. The as-rolled (111) crystal showed a much greater spread in orientation than either the (001) or (112), and completely recrystallized into a material with a grain diameter of $0.23 \mathrm{~mm}$. In this instance, the orientation of the new grains was related by a $23-24$ degree rotation about a common $<111>$ direction (also the specimen normal) of the deformed crystal. The smallest grain size $(<0.01 \mathrm{~mm})$ was observed for the (110) crystal which had the largest hardness and integral breadth increase, greatest spread in orientation, and multiple orientations (deformation bands). There was no texture change on recrystallization, indicating that recrystallized grains were of the same orientations as the subgrains found in the deformed crystal.

As an aid to understanding the factors influencing the formation of a recrystallized graın in these crystals, reference will be made to the classical concept of a recrystallization nucleus. In the section on LITERATURE SURVEY it was shown that a nucleus would be capable of growing when it exceeds a radius given by $r_{C}=2 \gamma / \Delta G$. In this instance, $\gamma$ is the specific free energy of the boundary between the nucleus and surrounding structure and $\Delta \mathrm{G}$ is the difference in free energy per unit volume between the nucleus and surrounding structure $A$ single dislocation cell could conceivably serve as a recrystallization nucleus However, the very broad, diffuse boundaries of dislocation cells are not considered to be mobile. Though the dislocation-cell boundary is not mobile, the specific dislocations which comprise the boundary will determıne, to a great extent, the rate of polygonization and subsequent mobility of the boundary. Thus, the polygonized boundary of a dislocation cell (or perhaps more appropriately at this point, a subgraın) could be taken as the boundary referred to in the equation. The exact point at which a subgraın attaıns a sufficiently mobıle boundary and grows into a recrystallized graın is difficult to establısh. A very lımıted knowledge of the energy and mobility of low-to-medium-angle grain boundaries is presently available. It has been generally accepted that very low angle boundaries (ie, less than one to two degrees misorientation) are quite mobile. $(1,90)$ Also, much higher angle boundaries $>20-25$ degrees) have also been shown to have rather high mobility. (15) Very little is known about the mobılity of boundaries between misorientations of two to twenty degrees (here called medium-angle boundaries). More recent work of Viswanathan and Bauer, discussed in the section on LITERATURE SURVEY, has shown that the nature of a medium-angle boundary may determıne whether or not it has a reasonably high mobılıty. Indeed, it seems reasonable to expect that medium-angle boundaries, like high-angle boundarıes, would have anıstropic mobilities.

Assuming that a boundary surrounding a nucleus has sufficient mobility, a driving force must exist to cause migration. This driving force is provided by the difference in stored energy between the nucleus and surrounding area. Thus, a subgrain which is to serve as a nucleus must recover and lower its volume free energy more quickly than adjacent regions, in addition to being surrounded by a boundary of high mobility. Within a deformed crystal, large variations in lattice curvature, as manifested by variations in dislocation density and dislocation cell misorientations, would be expected to produce energetically favorable sites for nucleation. Subgraıns with high dislocation densities and high 
misoreintations relative to adjacent subgrains would be expected to recover more quickly and become nuclei.

Interpreting the results from the $(110)$ crystal in terms of the previous discussion leads to the following hypothesis for a mechanism of recrystallization which will be applicable to all of the crystals: Nucleation of recrystallization occurs by the migration of polygonized subgrain boundaries which originally existed in the deformed structure as dislocation cell boundaries. Subgrain boundaries migrate and consume adjacent subgrains with a net increase in the boundary angle. Eventually, the region is surrounded, at least partially, by a high-angle grain boundary and thus becomes a viable recrystallizing grain whose boundary continues to migrate until it impinges upon an adjacent recrystallizing grain. The emerging grains thus have orientations originally present in the deformed crystal.

This hypothesis, it seems, would require some necessary conditions for recrystallization to effectively take place. First, dislocations must form cells or at least cell boundaries during deformation. Second, substantial lattice curvature, manifested as a spread of orientation over reasonably small regions, must exist.

The results obtained on each crystal will now be examined in the light of this hypothesis. As was previously stated, pole figures of rolled and recrystallized (110) crystals are virtually identical. Electron microscopy of the (110) crystals clearly shows that subgrains within the deformation bands grow to consume surrounding subgrains. This action results in the texture of the deformed crystal being retained after recrystallization.

Observations of the early stages of recrystallization of the (111) crystal indicate that subgrains not greatly misoriented from their neighbors recover, grow, and consume adjacent subgrains (Figures 55 and 58). An analysis of the pole figures (Figure 63) shows that the recrystallized grains could have grown from subgrains with an orientation contained in the deformed crystal; ie, there is enough spread in orientation to account for nuclei originating from the tails of pole figure peaks. Though some of the recrystallized peaks are not touching the 0.5 random contour, a further increase in sensitivity of measuring the deformed pole figure (for example, 0.1 random) would surely have encompassed all the recrystallized regions of the pole figure. As further support for the idea of orientations in the tails of the pole peaks contributing to the recrystallized texture, the number of subgrains needed to produce the final grain size of the (111) crystal can be examined. The geometric mean cell area of the rolled crystal is $0.08 \mu \mathrm{m}^{2}$, while the average grain diameter of the (111) crystal is $0.23 \mathrm{~mm}$. Assuming both the cell and grain to be spherical, the ratio of cell volume to grain volume is found to be $2.7 \times 10^{-9}$. In other words, only approximately three dislocation cells in a billion must survive the recovery and recrystallization processes to produce the observed texture. Even allowing for considerable calculational errors, it is quite conceivable that dislocation cells whose orientations are not represented by the pole figures could grow to form the observed texture of the recrystallized crystal. A further observation which supports the concept of subgrain boundary migration is the observation of serrated boundaries, as illustrated by Figures 60 and 61 . Here, it is interpreted that the migrating boundary has absorbed some subgrains and is in the process of absorbing others. Similar observations have been made on serrated grain boundaries of high-purity aluminum. (91) The orientation relationship of a 23 - 24-degree rotation about a common $\langle 111\rangle$ axis of the deformed (111) crystal and new grains is very close to higher-order twin relationships. (2) $A$ 
coincidence of one lattice site in thirteen may be obtained by a clockwise rotation of 27.8 degrees about a $\langle 111>$ axis. A coincidence of one in seven may also be obtained by a counterclockwise rotation of 21.8 degrees about $\langle 111\rangle$. Such boundaries have been found to have rather high mobility by many investigators. $(1,15,91)$ Thus, the final recrystallization texture of the (111) crystal appears to result from subgrain nuclei whose boundaries eventually attain this special orientation; and, because of their high mobility, grow to consume surrounding subgrains.

Results obtained on the (112) crystal at first glance might seem contradictory to the hypothesis in that none of the recrystallized grains could reasonably have grown from a subgrain of the deformed crystal. However, several observations indicate that the grains formed in the (112) crystal are not representative of this crystal's natural recrystallization behavior, but are the result of spurious inadvertent artificial nucleation. Of the few grains observed, most extended to the edges of the crystal, which have undoubtedly undergone rather more severe and complex deformation than the bulk. Differently oriented subgrains artificially nucleated from the edge of the crystal could have grown into the deformed crystal. The lack of an orientation relationship between the nucleated grains and deformed crystal gave reason to suspect this to be the case, since most investigators have found quite definite crystallographic relationships between the deformed matrix and the naturally recrystallizing grains. $(1,15,92)$ Furthermore, no region which could have been identified as a nucleus was ever found in the approximately 20 specimens of this crystal examined by transmission microscopy. In view of the difficulty of preventing artificially nucleated grains in the (001) crystal, it is also conceivable that many if not all of the grains observed in the (112) crystal were artificially nucleated. Because of the slightly greater lattice curvature of the (112) crystal, artificial nucleation of grains might be expected to be easier in the (112) crystal than in the (001) crystal.

Ignoring, then, the artificial nucleation that occurred, it is concluded that both the (112) crystal and (001) crystal find it virtually impossible to form recrystallization nuclei; a fact that can be understood in the framework of the hypothesis, when the deformation and recovery characteristics of these crystals are examined. The deformation of these crystals by rolling produced no clearly identifiable cell boundaries, but a more or less uniform dislocation distribution. Even upon recovery annealing, little fragmentation occurred, and cell walls were difficult to form, especially in the (001) crystal. Dislocations in deformed and recovered regions did rearrange themselves into subgrains, but these were misoriented from each other only very slightly less than one degree in the (001) crystal and a maximum of two degrees in the (112) crystal. No high-angle boundaries were produced because the growth of one subgrain, by whatever mechanism, would result in its boundaries achieving only a slightly increased misorientation with respect to neighboring subgrains.

In conclusion, the data obtained on the crystals used in this experiment support the hypothesis that nucleation occurs by growth of subgrains formed from polygonized dislocation cells. The aforementioned hypothesis is quite similar to the "preformed-nucleus" concept discussed earlier. $(1,33,93,94)$

In the preceding discussion, the recrystallization behavior of the various crystals has been considered in a somewhat general manner. However, because of the remarkable influence of deformation banding on the recrystallization behavior of the $(110)$ crystal, results obtained 
in the $(110)$ crystal will be more fully discussed. Shown in Figure 83 is a top view of Crystal 4-11 that was annealed for 10 hours at $600^{\circ} \mathrm{C}$. This crystal is from a similar region of the rolled crystal presented in Figure 81 . Within a given deformation band, several new grains have apparently been formed. (The metallographic polarized-light technique used in this

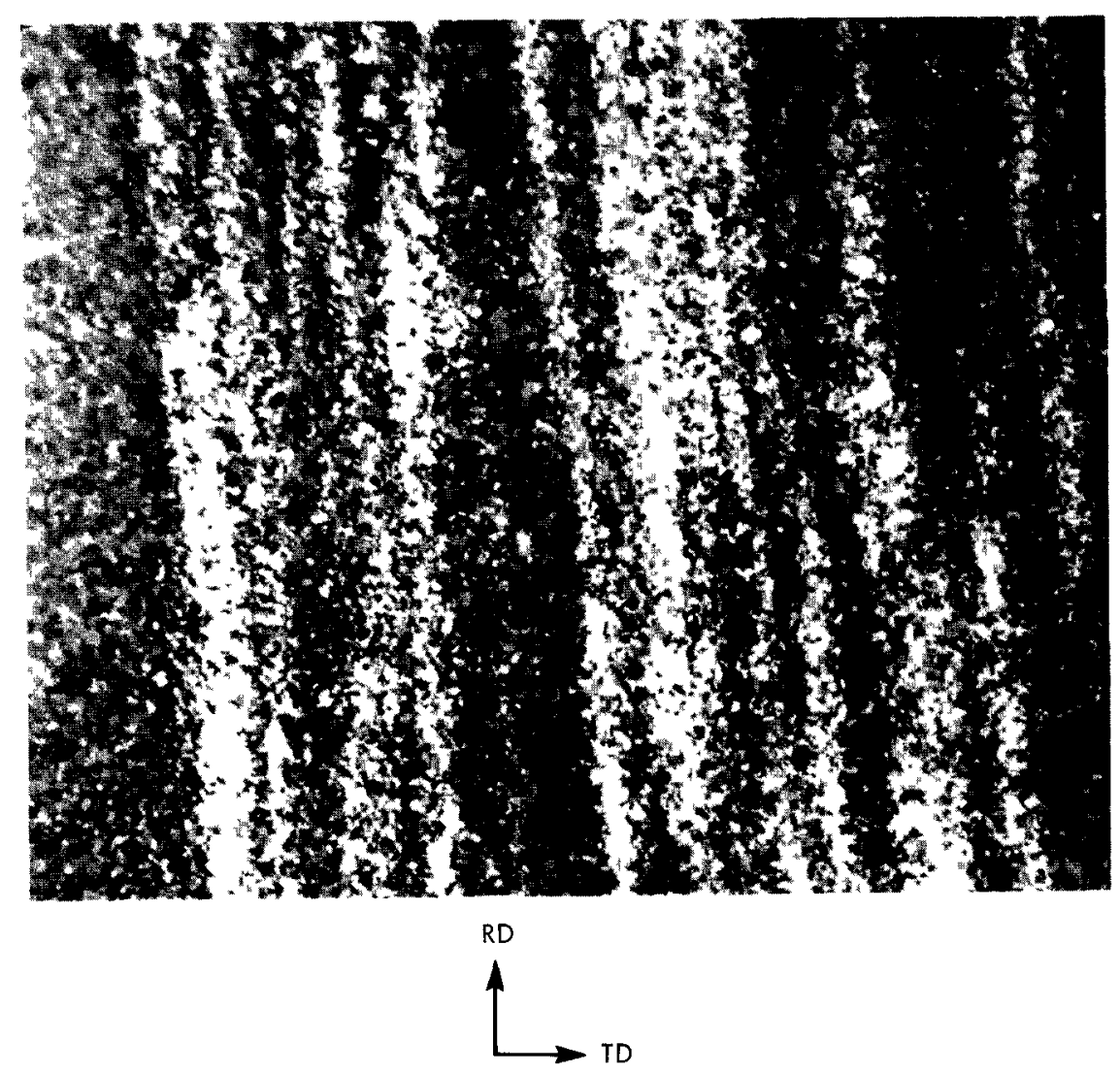

Figure 83. MICROGRAPH OF CRYSTAL 4-11 THAT WAS ROLLED 80 PERCENT AND ANNEALED FOR TEN HOURS AT $600^{\circ} \mathrm{C}$. (View is Parallel to the Normal Direction; Compare this with the View of Figure 81; Polarızed Light; 100X)

study may have been sensitive enough to distinguish grains which were not at this stage greatly misoriented from each other; ie, their boundaries may be medium angle rather than high angle.) Because the new grains are of the same orientation as the parent bands, contrast differences between bands can still be seen as they existed in the deformed crystal. The texture, TEM, and optical results suggest several important points. Grains are nucleated within the bands and grow to consume the transition region which appears to recover more slowly. Nucleation of several grains can occur because the lattice curvature across a band is quite large and accounts for the large orientation spread of the pole figures (see Figure 36). In addition, the structure within a band varies from a fairly homogeneous dislocation distribution to quite sharp dislocation cell structures. The more heterogeneous structure of bands within the (110) crystal allows for regions to become more energetically favorable for nucleation, as discussed previously.

Interpretation of the role of deformation bands in recrystallization in the present experiment is in stark contrast to the results on (001) [100]-oriented iron-silicon single 
crystals described by $\mathrm{Hu}$. Observation of alternate bands of $\{001\}$ and $\{111\}$-oriented regions separated by a transition region are similar to those of $\mathrm{Hu} .15)$ The $\{001\}$ and $\{111\}$-oriented areas would be equivalent to the matrix bands described by Hu, while the region of mixed orientations correspond to Hu's transition or microbands. However, the following important differences between the observations are apparent:

1. The present study revealed that the cells in the transition region were rather equiaxed, at least in the plane of view. Hu found that very narrow cells, elongated in the rolling direction, occurred in the microbands or transition bands.

2. Both the (001) and (111) regions of the present crystal (matrix bands) contained dislocation cells which, in many cases, were similar in size to the cells contained in the transition region. In contrast, Hu found that his matrix bands consisted of uniform, dense dislocation distributions much like those found in the (001) crystal of this experiment.

3. The present results indicate that recrystallization occurred by growth of subgrains in the matrix bands and resulted in recrystallized grains of orientations similar to the deformed crystal. On the other hand. Hu noted that recrystallized grains emerged from the microbands (or transition bands) and grew into the matrix-band areas, giving rise to recrystallization texture which differed from the deformed texture.

4. Though some TEM observations could be interpreted to indicate that subgrain coalescence occurred in the present experiment, they were quite scattered and were not felt to contribute greatly to the nucleation of recrystallized grains. Coalescence of subgrains was felt by $\mathrm{Hu}$ to be a necessary step in the formation of recrystallization nuclei whose orientation differed from that of the deformed matrix.

5. Recrystallization of Crystal 4-11 of Figure 83 was estimated from TEM results to be greater than $90 \%$ complete in 10 hours at $600^{\circ} \mathrm{C}$. Hu observed recrystallization to be complete in the rolled (001) [100] iron-silicon crystals in $17-25$ hours at $600^{\circ} \mathrm{C}$. (For iron-3 wt $\%$ silicon, $600^{\circ} \mathrm{C}$ is equivalent to $\mathrm{T} / \mathrm{Tm}=0.5$ and for tantalum $\mathrm{T} / \mathrm{Tm}=0.27$.)

Some of the differences between the present results and those of $\mathrm{Hu}$ may be due, specifically, to the different types of deformation structure noted in the transition and matrix-band regions. Dislocation cells and a high lattice curvature existed only in the microbands observed by $\mathrm{Hu}$. Thus, polygonization and migration of these cell boundaries would be expected to be quite rapid and result in nuclei emerging from the microband. In the present crystals, considerable lattice curvature together with dislocation-cell structures existed both within the matrix bands and microbands. Thus, recrystallization might have been expected to occur in both regions. However, during straining, the considerable orientation change accommodated by the transition or microbands in the tantalum crystals apparently resulted in dislocation-cell boundaries which were either slow to polygonize or relatively immobile. Normally, the greater misorientations produced within the transition bands would have been expected to result in subgrains with quite mobile boundaries. Therefore, by some process that is not well understood, recrystallization was able to occur in the $\{111\}$ and $\{001\}$-oriented matrix bands before it could in the transition band. Additional support for these ideas can be gained by comparing the microhardness and pole 
figures from the two studies. Both the microhardness and orientation spread of the crystals examined by $\mathrm{Hu}$ are lower than those observed in the present experiment. These comparisons suggest that the amount of stored energy of cold work is greater in the tantalum crystals and may also account for the much lower recrystallization temperature of these crystals (ie, room-temperature deformation in tantalum would correspond to sub-room temperature deformation in iron-silicon).

From the foregoing discussion it is clear that deformation banding may affect nucleation and recrystallization in many ways. Additional observations from the present experiment tend to reinforce this idea. It may be recalled that crystals of the (110) [110] orientation, which were rolled under moderate body conditions with higher frictional forces, showed a variation in both texture and microstructure from the top to bottom surfaces (see discussion of the (110) [1T0] crystal on Page 32). Pole figures from regions which contained optically resolvable deformation bands showed a much greater orientation spread than did pole figures from nonbanded areas (Figure 33). The microhardness of banded regions was also higher than those of nonbanded areas (Figure 64). Recrystallization occurred, first in the banded areas and much later in the nonbanded regions. These observations can perhaps be explained in terms of the deformation band model of Figure 81 . In areas of the crystals where bands were formed, both (001) and (111) orientations could be fairly clearly resolved in the pole figures [see Figures $27(\mathrm{a})$ and $33(\mathrm{a})$ ]. Regions which contained no resolvable bands either had a single orientation present (Figure 25) or the (001) and (111) orientations could not be clearly resolved, Figure 33(b). Unfortunately, transmission microscopy was not performed on nonbanded regions of the crystals. However, it is plausible that nonbanded regions reoriented wholly toward either (001) or (111). Thus, banding, as proposed by the model of Figure 81, never occurred. The creation of alternate $(001)$ and $(111)$ orientations (deformation bands), as opposed to single orientations, likely resulted in more lattice curvature being generated within the bands. Because of these factors, recrystallization occurred more readily within the deformation bands.

In summary, the nucleation of recrystallization in all of the crystals examined in this experiment can be explained on the basis of the "preformed-nucleus" model. Deformation banding was observed to effectively lower the recrystallization temperature of rolled (110) [110] single crystals. However, the widely differing observations of deformation banding in the present study and that of $\mathrm{Hu}^{(15)}$ point out the problems in trying to develop a model for nucleation which is applicable under all circumstances. In fact, it is likely that no single mode of nucleation exists which is capable of explaining all recrystallization behavior, especially in anisotropically deformed single crystals.

\section{CONCLUSIONS AND RECOMMENDATIONS}

This investigation was concerned with establishing the effects of orientation on the deformation and recrystallization behavior of rolled tantalum single crystals. Crystals

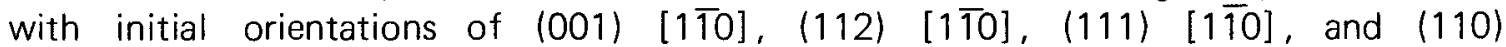
[1T0] were rolled to $80 \%$ thickness reduction and examined, using optical and electron metallography, X-ray line broadening, and pole figure analyses and microhardness testing. A summation of the important conclusions and some recommendations for related investigations follow. 
The (001)[1T0] and (112) [1T0] crystals maintained their initial orientation during rolling and produced microstructures of more or less uniform distributions of dislocations. Slight increases in $X$-ray line broadening and microhardness indicated that little lattice curvature and stored energy remained in these crystals after rolling. In addition, pole-figure analyses indicate that very little spread in orientation existed in the deformed crystals. During rolling, reorientation of the (111) [1T0] crystal was found by a 10-degree rotation toward the more stable

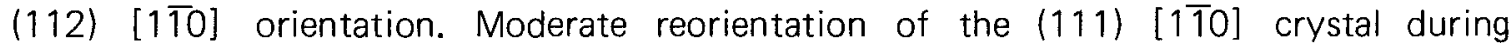
rolling created a fairly uniform dislocation cell structure, with more or less random misorientations throughout the crystal. Lattice curvature, as determined from both TEM and pole figure analysis, was greater than for the stable crystals. Microhardness and $X$-ray line-broadening measurements suggested that the amount of stored energy in the moderately reoriented crystal was greater than that in the stable crystals.

Significant reorientation occurred in the (110) [1T0] crystal with concomitant formation of deformation bands. Deformation bands consisted of alternate $\{001\}$ $<100>$ and $\{111\}<110>$-to- $<112>$-oriented regions separated by a transition band of mixed orientations. Orientations of alternate bands were affected by the rolling conditions. Microstructures within the bands were quite inhomogeneous, varying from dense, uniform dislocation arrays to a definite cell structure. Crystals which formed deformation bands during rolling exhibited the greatest increase in orientation spread and stored energy of any crystals.

Crystal stability and reorientation could be partly explained by assuming planestrain deformation and using the Taylor theory of plasticity as applied to pencil glide in body-centered-cubic metals. Reorientations produced from deformation banding could be better interpreted by applying Taylor's theory to the strain state of axisymmetric compression rather than plane strain.

Annealing of crystals with small amounts of lattice curvature or orientation spread produced large subgrains which were only slightly misoriented from one another. On the other hand, recrystallized grains were formed in those crystals which had sufficient lattice curvature to produce dislocation-cell structures. Crystals containing deformation bands of alternate orientation recrystallized at a lower temperature than those crystals which reoriented wholly to single orientations. The lowered recrystallization temperature was believed to be due to the increased lattice curvature generated by the presence of deformation bands.

Nucleation of recrystallized grains occurred by the polygonization and growth of dislocation cells in the deformed crystal. Growth and impingement of these nuclei resulted in recrystallized grains which had orientations that were originally in the deformed crystals.

Several additional areas of research have been suggested by the present study. This experiment has shown that different dislocation substructures can arise in deformed crystals which have different initial orientations. TEM of such crystals, as a function of rolling deformation, should aid in understanding how these different structures 
evolve. Identification of operating slip systems and resultant dislocation reactions might possibly assist in comprehending how and why various dislocation networks are formed during deformation and polygonization.

As an experimental check on Dillamore's treatment of the Taylor theory of crystal plasticity and reorientation, crystal orientations used in this experiment should be rolled under conditions which limit transverse widening. This work could be accomplished by rolling the crystals in a surrounding frame of material which would, at the same time, constrain and deform with the crystals. (94)

Results of this experiment suggested that there was a critical amount of lattice curvature necessary to cause natural recrystallization in rolled single crystals. The necessary degree of curvature could be found by carefully rolling and annealing crystals of orientations between (112) [1T0] and (111) [1T0]. (Much care must be taken in handling the crystals as severely deformed edges and scratches may lead to artificial nucleation. Artificial nucleation may be more difficult to suppress as the lattice curvature increases.)

Deformation banding occurred in the (110) [1 $\overline{1} 0$ ] crystal, but not in the (111) [1 $\overline{1} 0$ ] crystal. Thus, it appeared that there could be a critical orientation within this $35^{\circ} 16^{\prime}$ range, where banding would start. A study of crystals oriented within this range could add significantly to the present insight into the formation of bands of alternate orientation and their effects on recrystallization. 


\section{APPENDIX A}

\section{OPTICAL METALLOGRAPHIC TECHNIQUES}

Chemical and electrochemical etching techniques, ${ }^{(95)}$ used on recrystallized specimens left an uneven topography with considerable relief between grains and surface pitting. In addition, grain boundaries were frequently incomplete or sloping, making grain-size determinations inaccurate. In a search for a technique that would allow inambigious determination of the grain size without anodization by additional heat treatment, (96) it was fortuitously discovered that a very highly polished, scratch-free surface was optically active in polarized light. This surface was achieved by first wet grinding through $220,320,400$, and 600-grit silicon carbide paper to produce a flat, finely scratched surface. Mechanical polishing was performed, as outlined in Table A-1. It should be emphasized that control of the polishing solution $\mathrm{pH}$ was critical.

Table A-1

MECHANICAL POLISHING

\begin{tabular}{lll}
\hline Stage & \multicolumn{1}{c}{ Conditions } & \multicolumn{1}{c}{ Time } \\
\hline Polish & $\begin{array}{l}\text { 1. Vibratory polisher, with } \\
0.3-\mu \mathrm{m} \mathrm{Al}_{2} \mathrm{O}_{3} \text { in distilled } \\
\text { water with } \mathrm{NaOH} \text { to control } \\
\mathrm{pH} \text { at about 7, on a Pellon } \\
\text { bowl cover. }\end{array}$ & $\begin{array}{l}\text { To remove grinding } \\
\text { scratches. }\end{array}$ \\
& $\begin{array}{l}\text { 2. Vibratory polisher, with } \\
\text { O.06- } \mu \mathrm{m} \mathrm{Al}_{2} \mathrm{O}_{3} \text { in distilled } \\
\text { water with } \mathrm{NaOH} \text { to control } \\
\text { pH at about 7. on a Gamal } \\
\text { bowl cover. }\end{array}$ & $\begin{array}{l}\text { To remove previous } \\
\text { polish scratches, for } \\
\text { extended times of 48 or } \\
\text { more hours. }\end{array}$ \\
\hline
\end{tabular}

To verify that the grain structure observed was a true structure, one of the single crystals was given a light chemical etch that reproduced the polarized structure exactly. An effort was made to establish the nature of the apparently anisotropic, polished tantalum surface. Perryman (97) discussed the manner in which cubic, isotropic metals develop a polarized-light structure. Surfaces are either deeply etched, creating inclined grains, or they possess surface films induced by polishing or electrolytic anodization. Using ion microprobe analysis, the presence of a thin (1.5 to $6.0 \mathrm{~nm}$ ) layer of oxide on an "as-polished" surface of polycrystalline tantalum was established. For comparison, an acid-etched surface was analyzed and a nonpolarizing 40.0 to $160.0-\mathrm{nm}$ film of mixed oxides and fluorides was found.

Following a procedure developed by Perryman, it was further established that the surface film was anisotropic and did not depend on etching to produce polarization. If an oxide layer is anisotropic, a thin film of silver will obscure polarization; if surface topography gives rise to polarization, the silver film will faithfully reproduce the surface and polarization will persist. A thin vapor-deposited film of silver destroyed the polarization, confirming Dunn's (96) belief that the optical activity is the result of an epitaxial, anisotropic film believed to be $\mathrm{Ta}_{2} \mathrm{O} 5$. 


\section{APPENDIX B}

\section{DISLOCATION-CELL-AREA MEASUREMENTS}

Dislocation cells or subgrains were marked on transmission micrographs and measured individually as described under EXPERIMENTAL PROCEDURES. Figures B-1 through B-11 are histograms of the cell areas and the natural logarithm of the cell areas for annealed crystals. A summary of these data is contained in Table 6. 


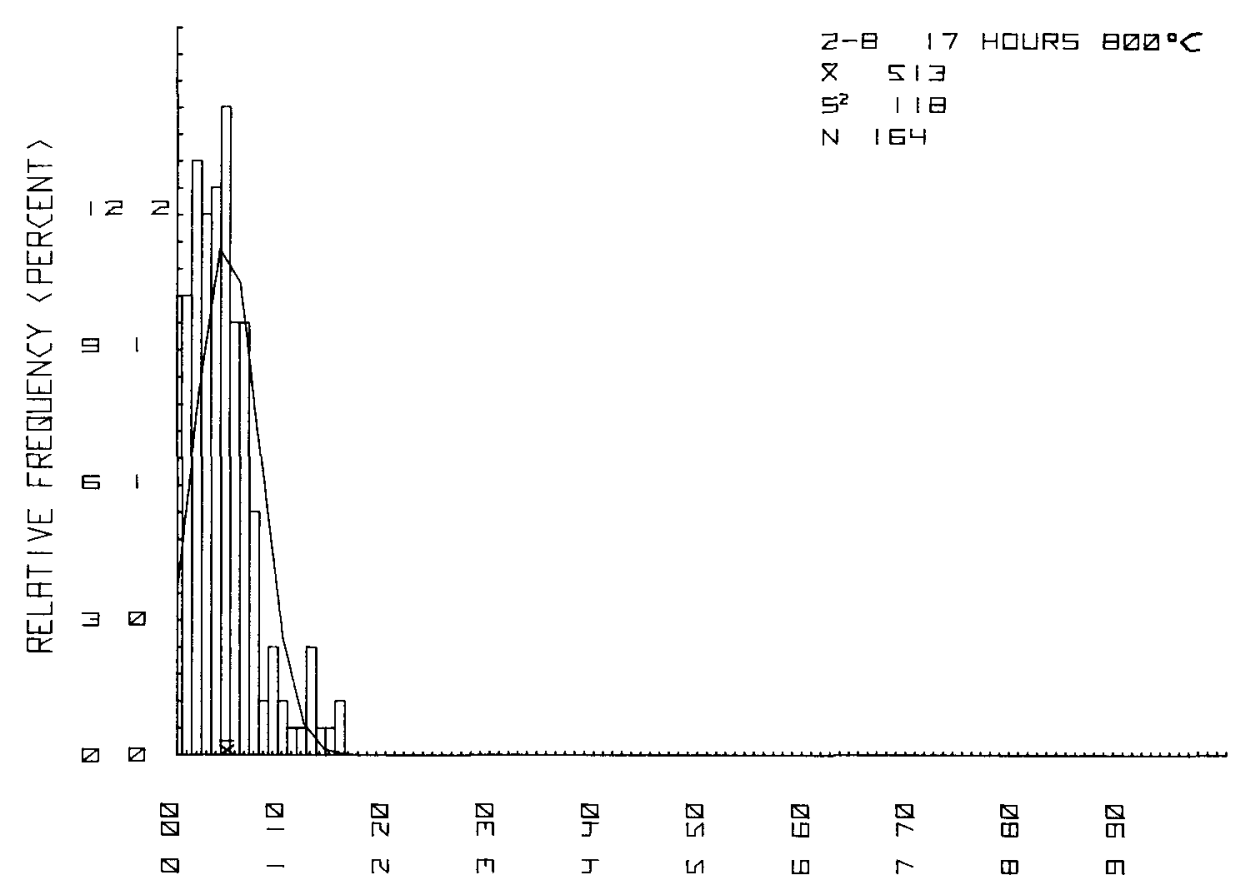

CELL FREF 〈SQUARE MICRDMETERS >

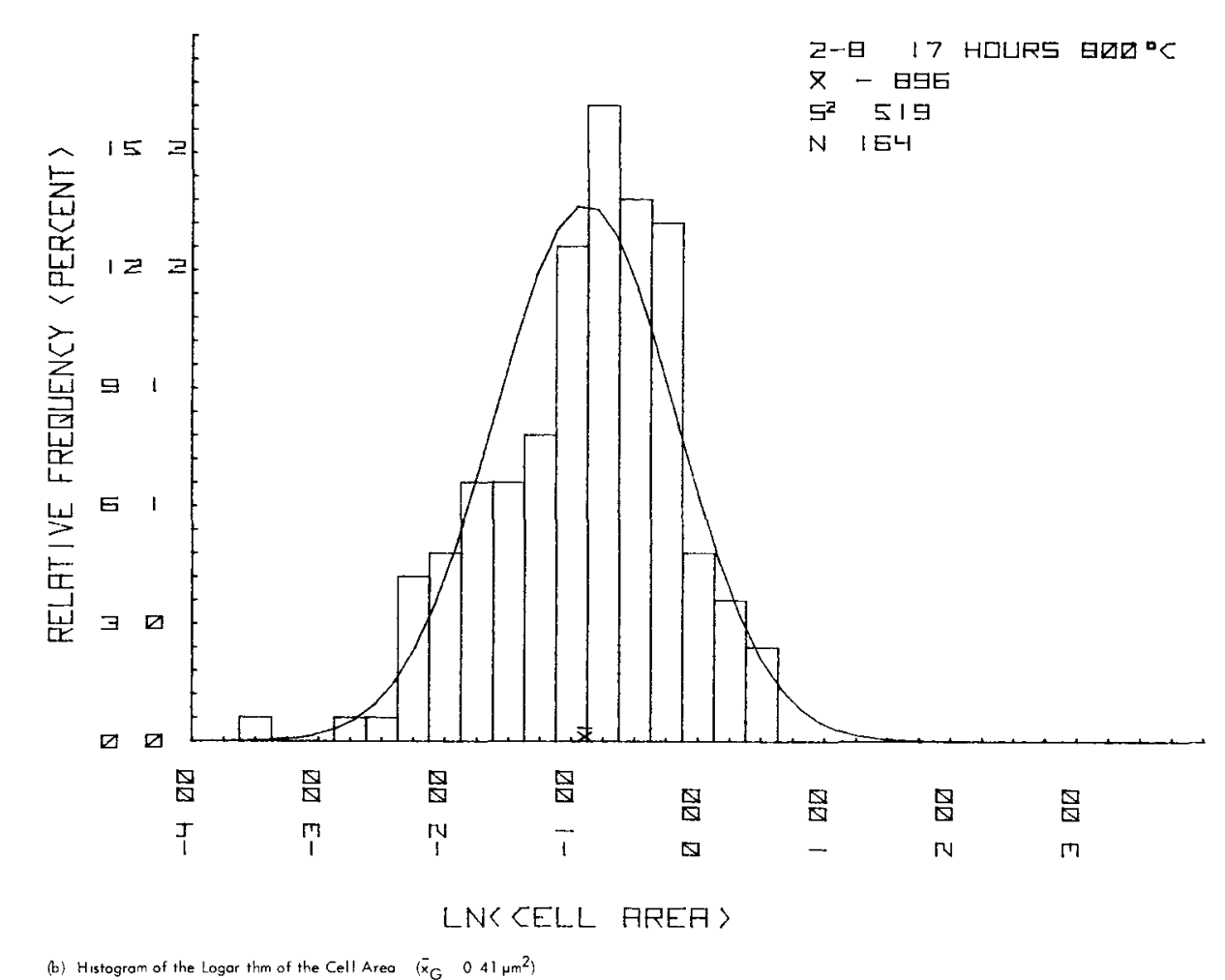
Figure B-1. HISTOGRAMS OF THE CELL-AREA MEASUREMENTS OF THE (112)[110]
CRYSTAL. (Annealed for 017 Hour at $800^{\circ} \mathrm{C}$ )
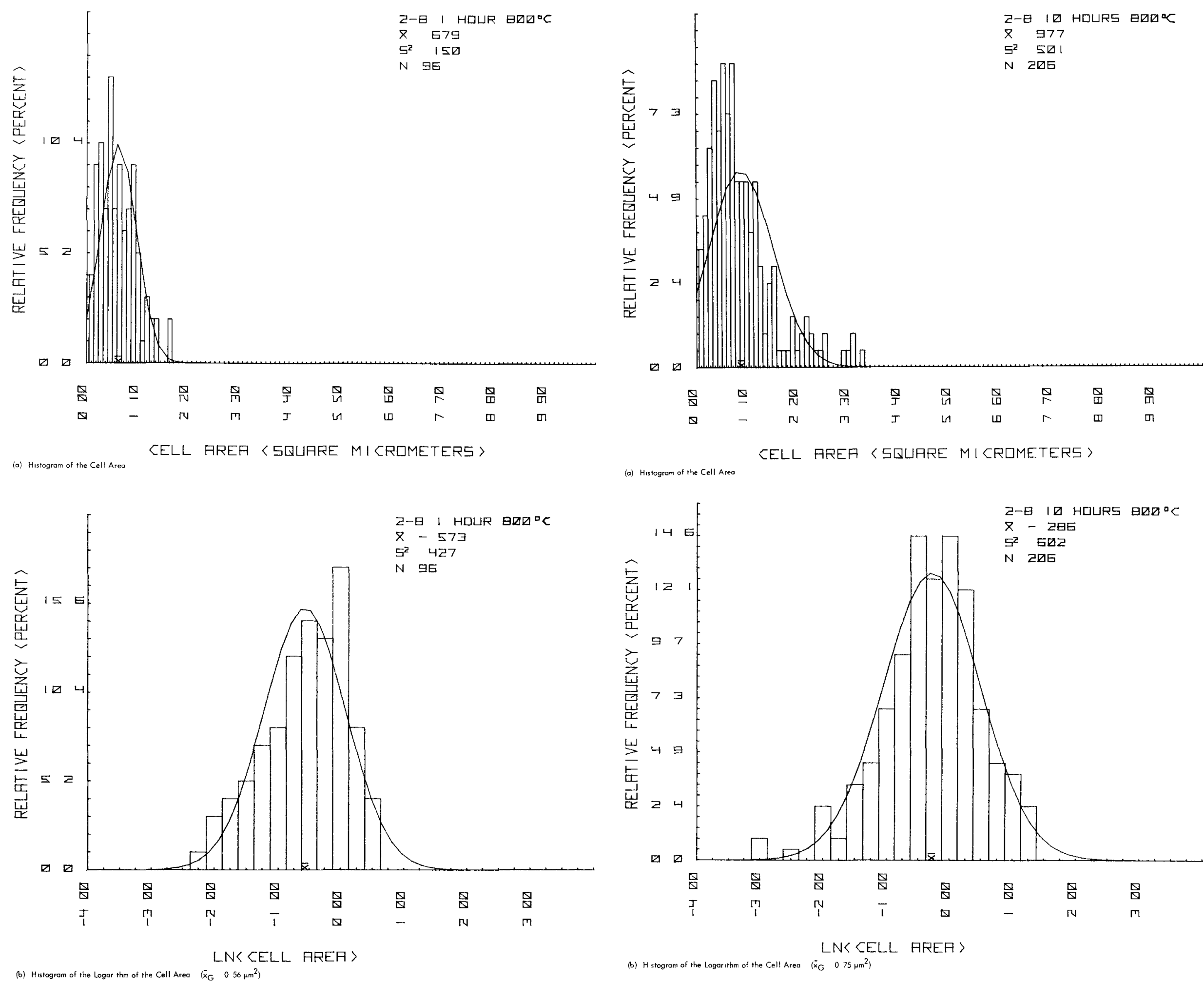

Figure B-2. HISTOGRAMS OF THE CELL-AREA MEASUREMENTS OF THE (112)[110] CRYSTAL. (Annealed for One Hour at $800^{\circ} \mathrm{C}$ )

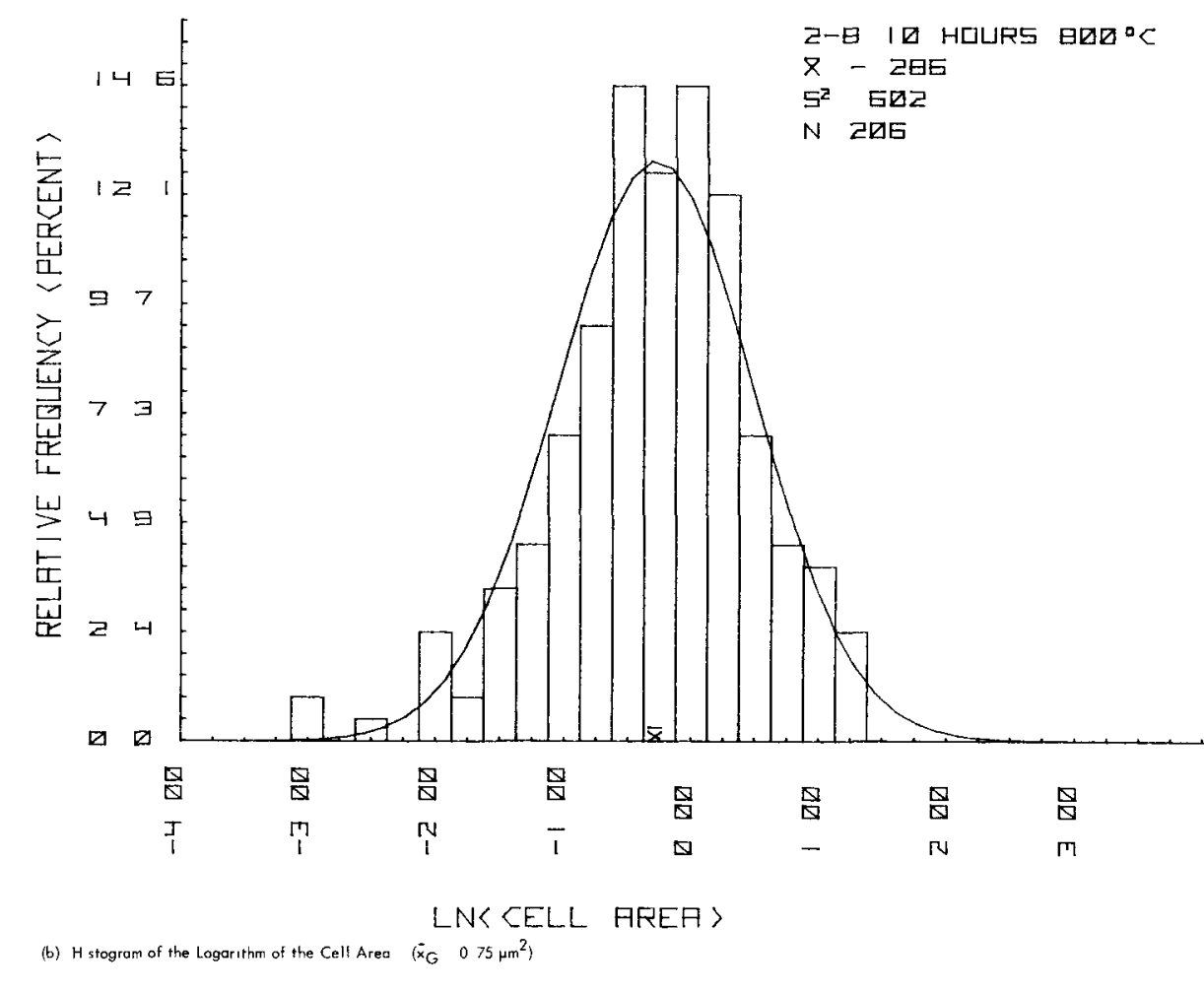
CRYSTAL. (Annealed for Ten Hours at $800^{\circ} \mathrm{C}$ )
Figure B-3 HISTOGRAMS OF THE CELL-AREA MEASUREMENTS OF THE (112)(110] 

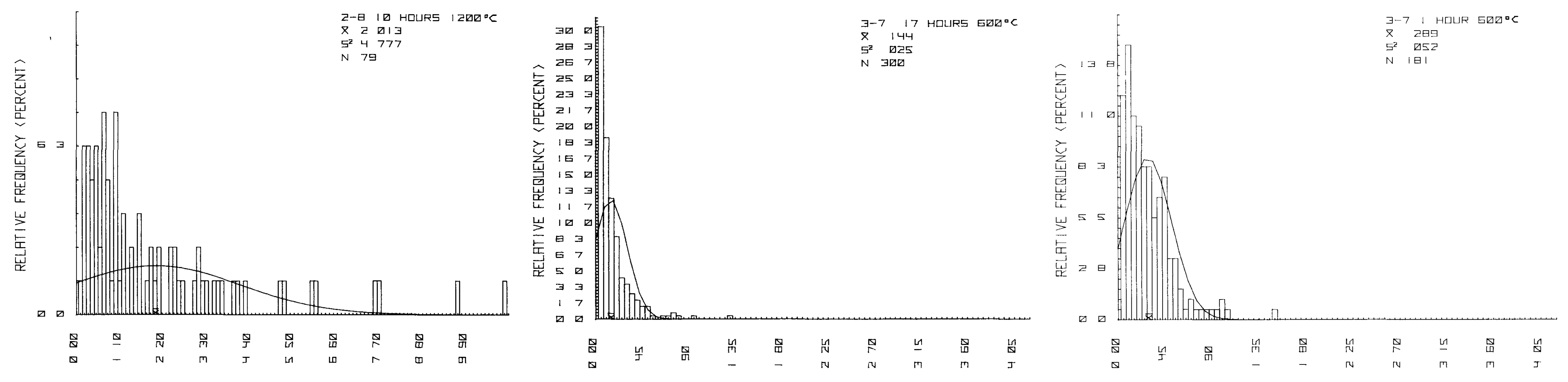

CELL ARER 〈SQURRE MICRDMETERS〉

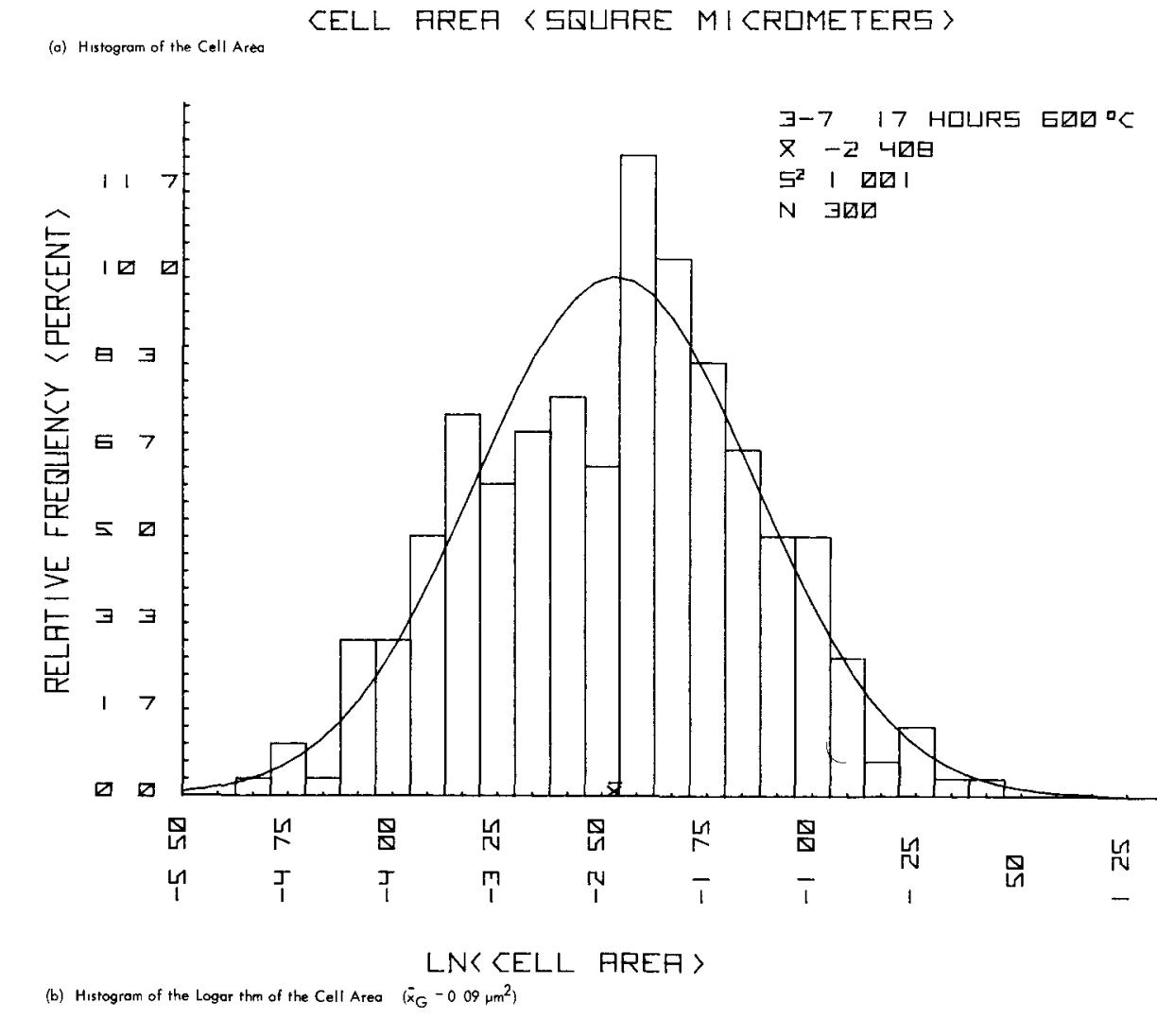
Figure B.5. HISTOGRAMS OF THE CELL-AREA MEASUREMENTS OF THE (111)!110
CRYSTAL. (Annealed for 0.17 Hour at $600^{\circ} \mathrm{C}$ )

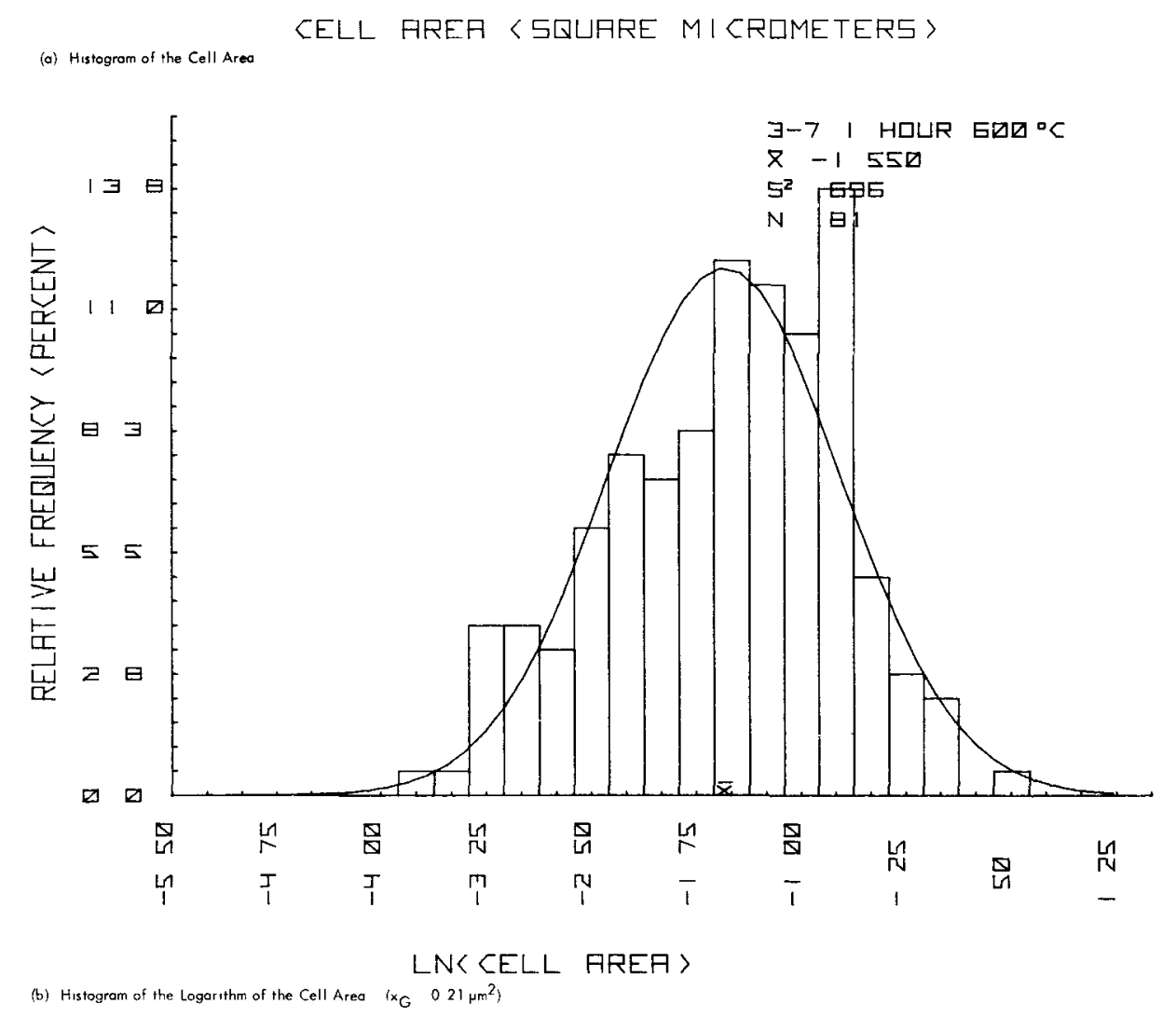

Figure B-6. HISTOGRAMS OF THE CELL-AREA MEASUREMENTS OF THE (111)[110] CRYSTAL. (Annealed for One Hour at $600^{\circ} \mathrm{C}$ )

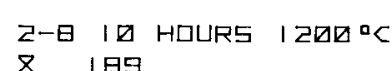

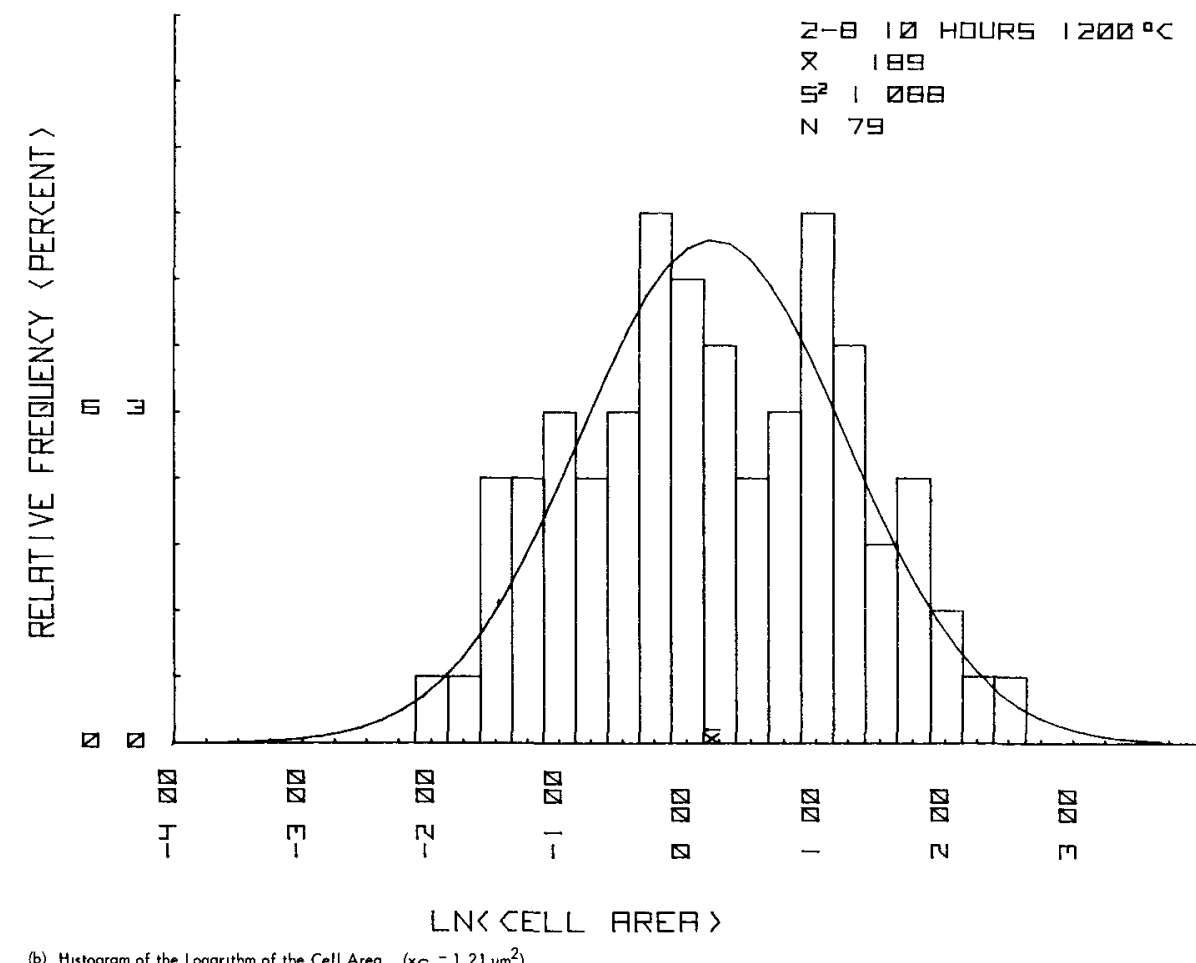

Figure B-4. HISTOGRAMS OF THE CELL-A
CRYSTAL. (Annealed for Ten Hours at $1200^{\circ} \mathrm{CI}$ 


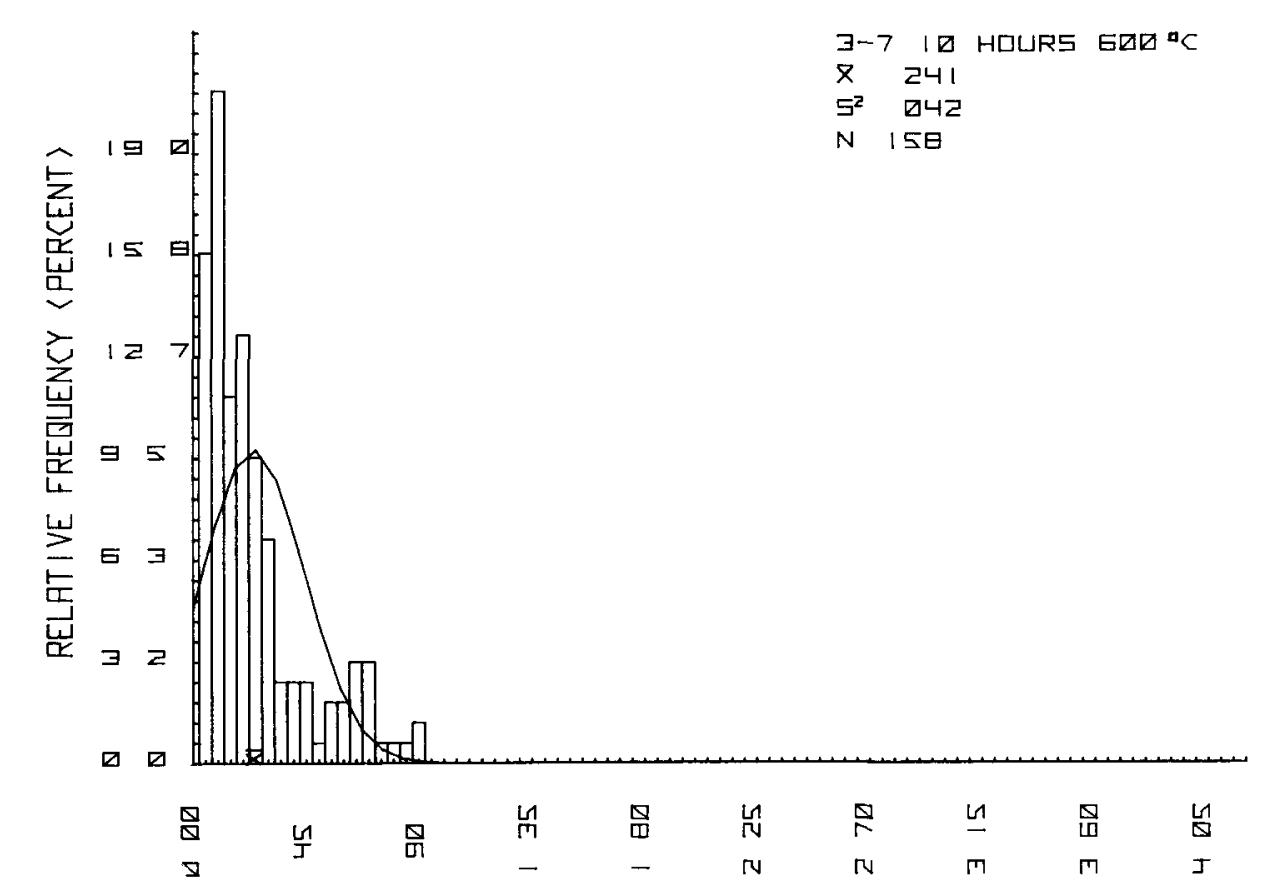

CELL RRER 〈SQUARE MICRDMETERS〉

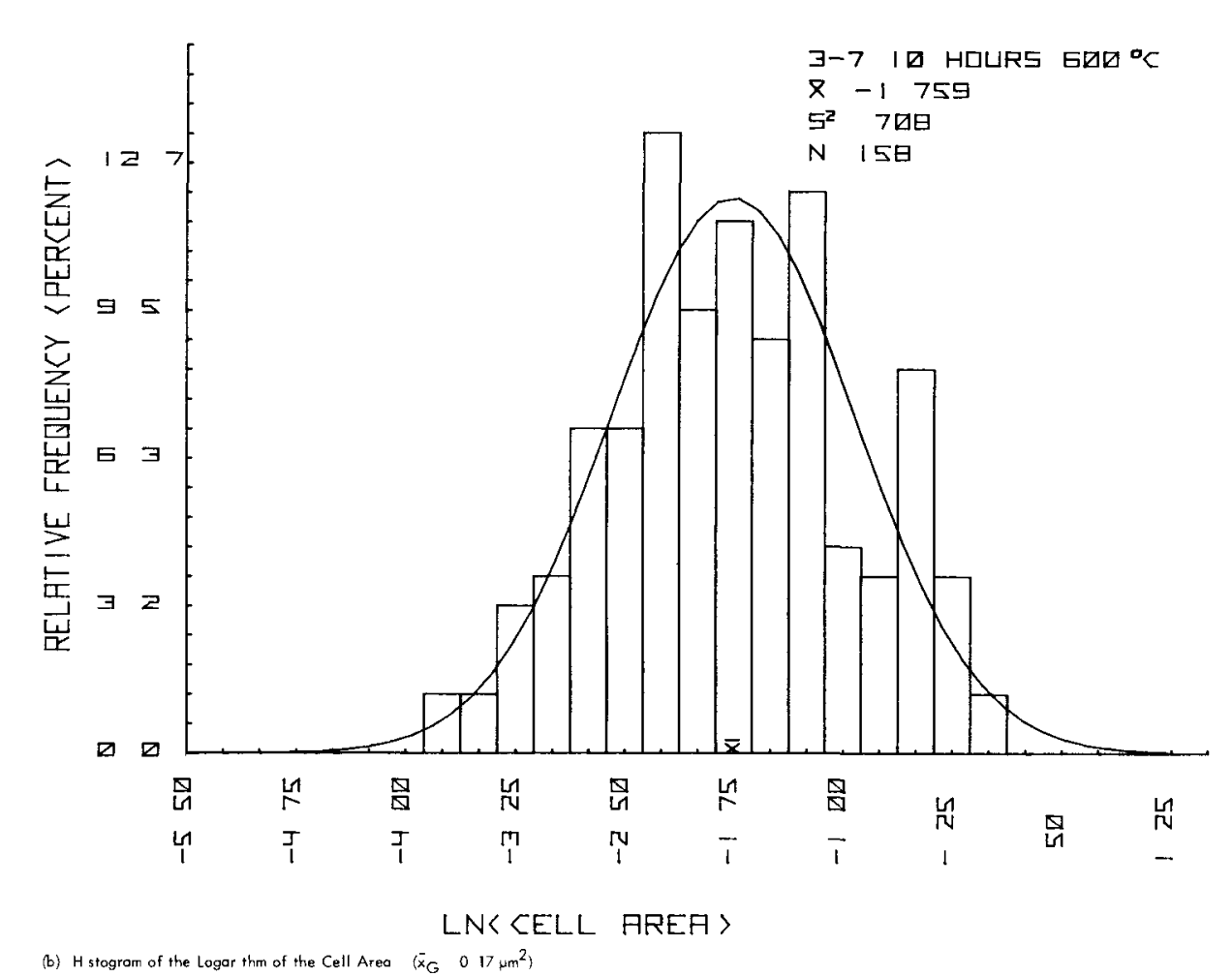
Figure B-7. HISTOGRAMS OF THE CELL-AREA MEASUREMENTS OF THE (1111)[110]
CRYSTAL. (Annealed for Ten Hours at $600^{\circ} \mathrm{C}$ )

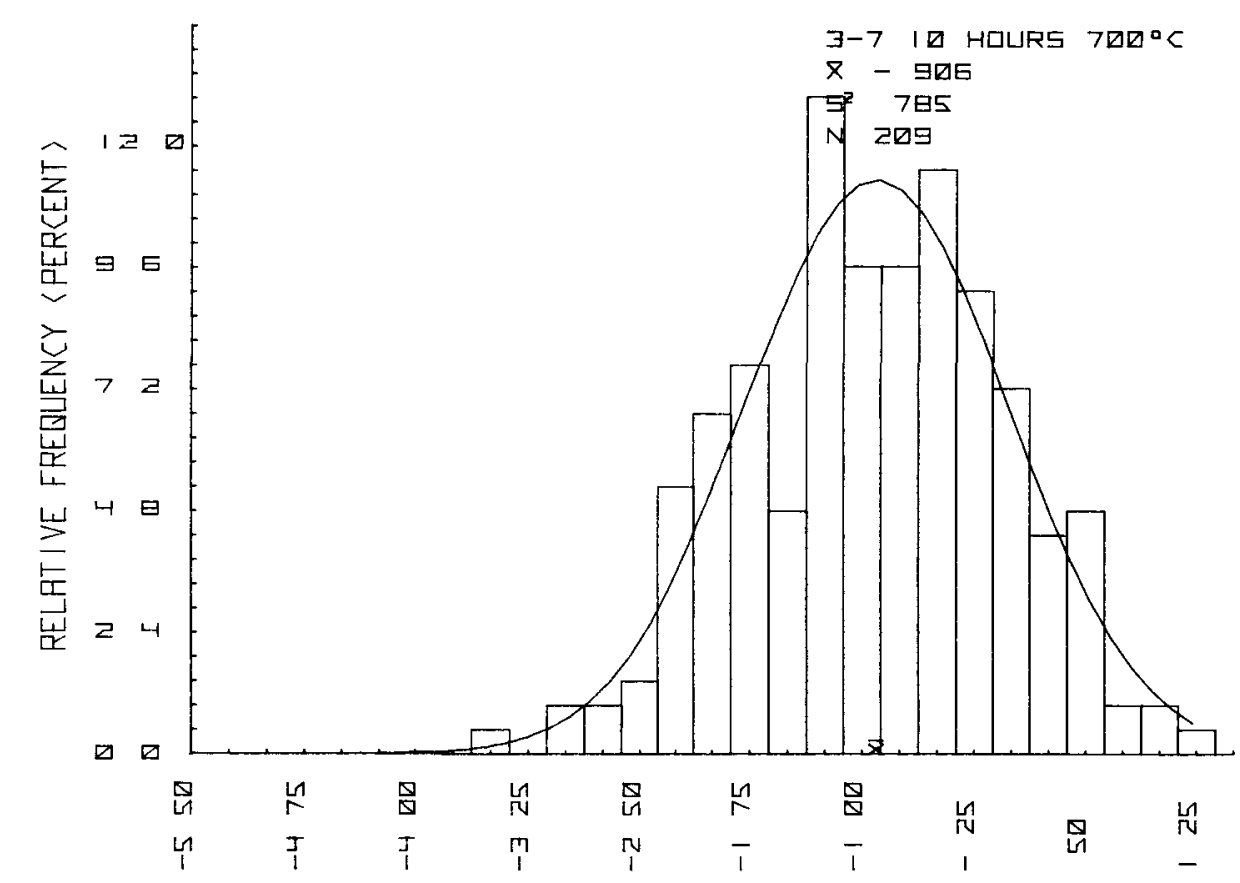

LN $C$ CELL FREA >

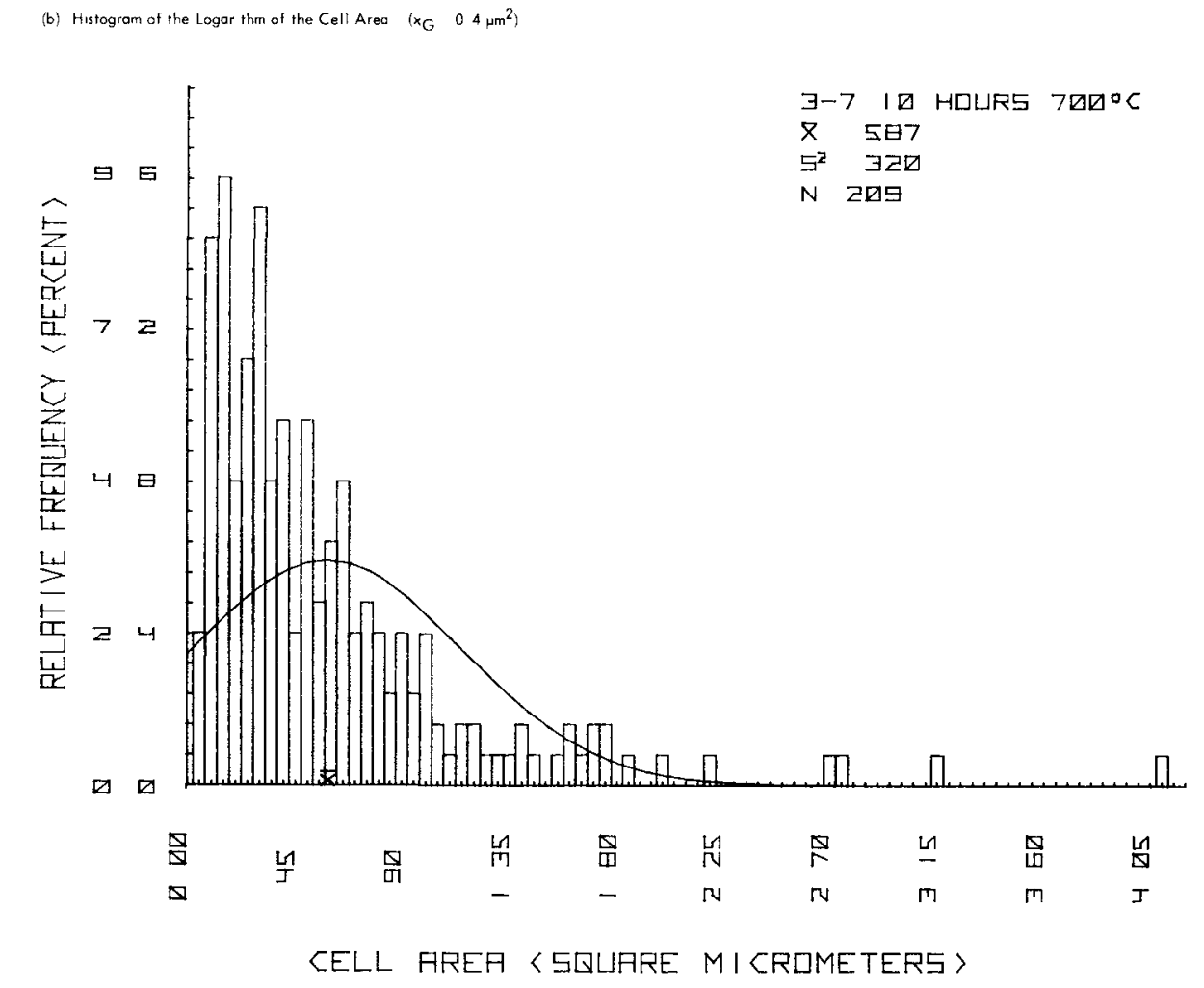

Figure 8-8. HISTOGRAMS OF THE CELL-AREA MEASUREMENTS OF THE (111)(110] CRYSTAL. (Annealed for Ten Hours at $700^{\circ} \mathrm{C}$ )

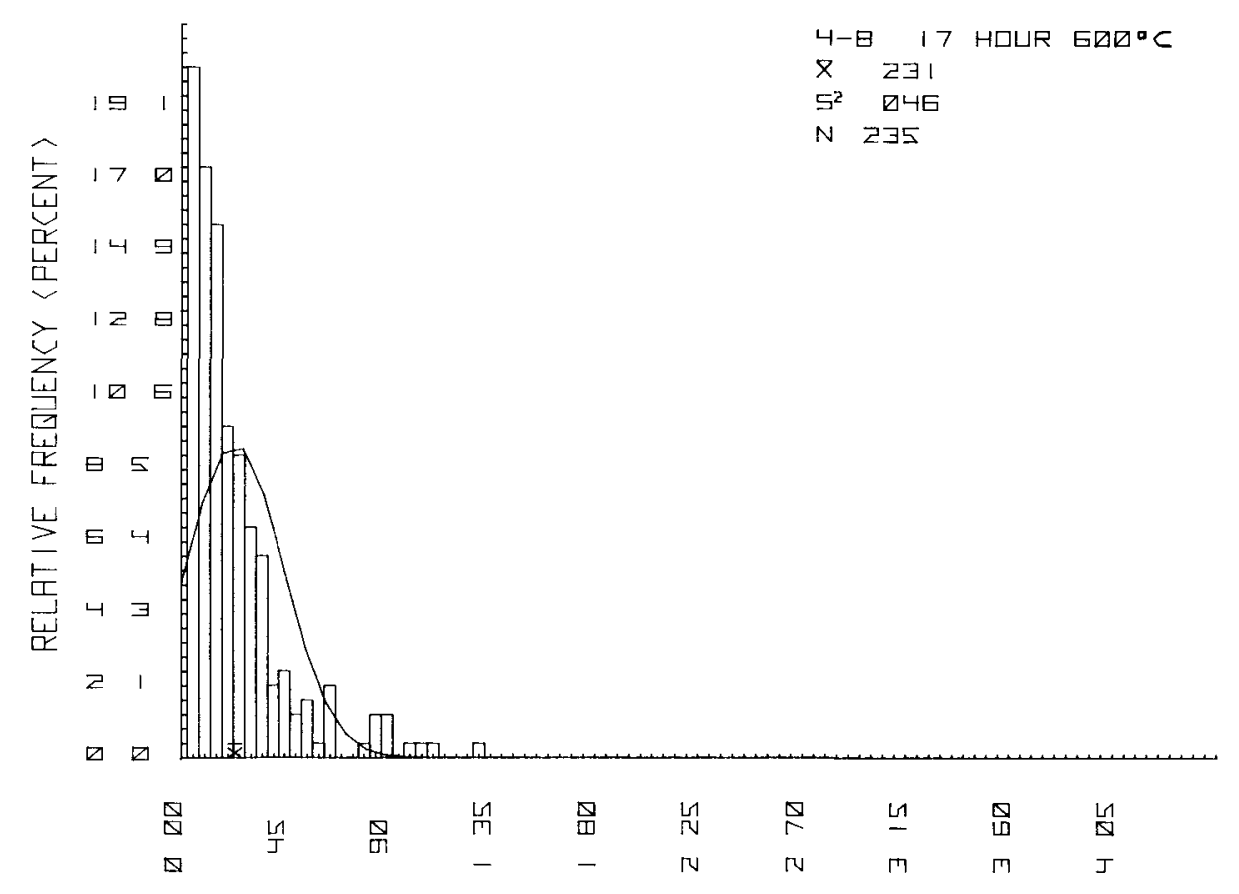

CELL AREA 〈SQUARE MICRDMETERS〉

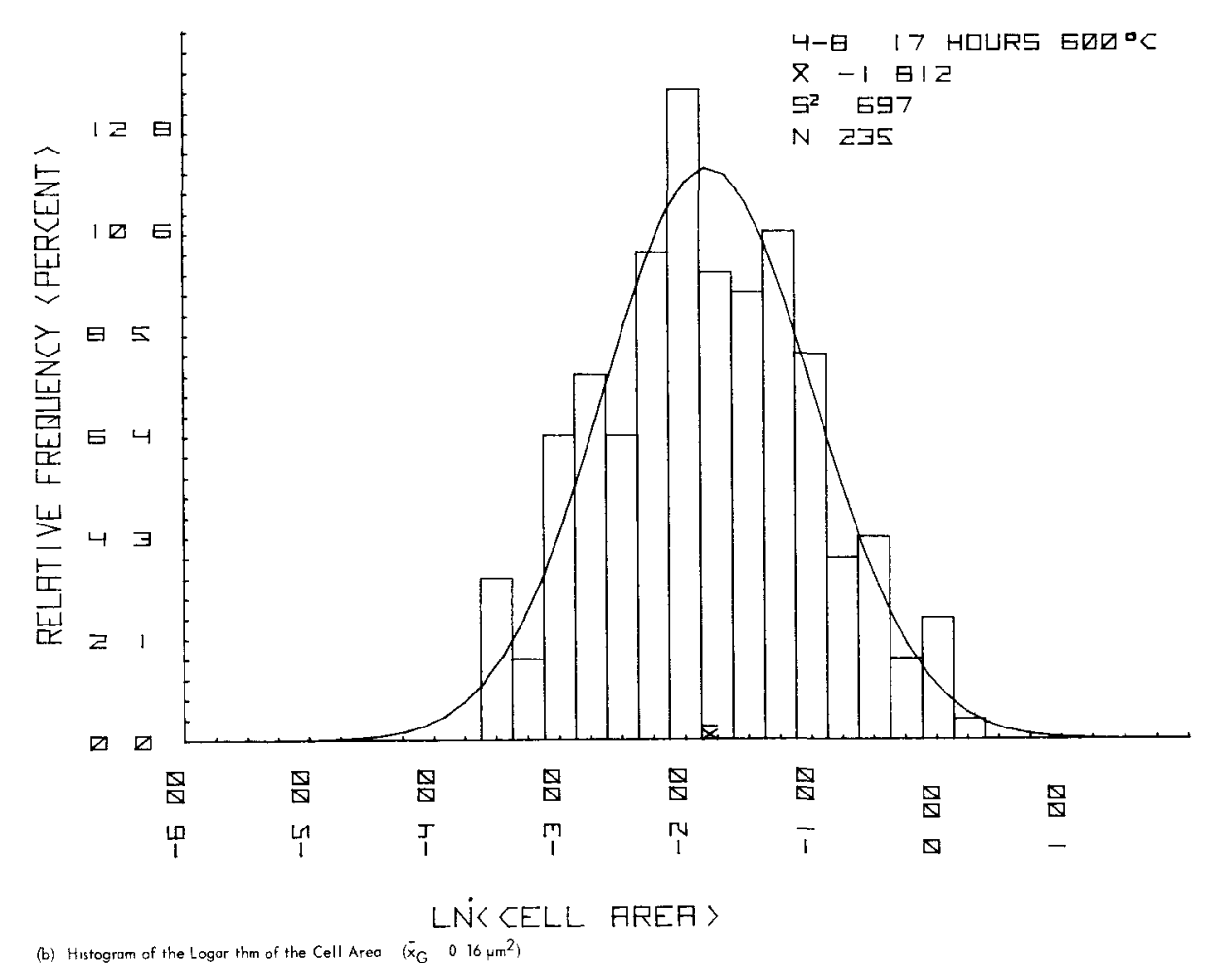

Figure B-9. HISTOGRAMS OF THE CELL-AREA MEASUREMENTS OF THE (110)[110] CRYSTAL. (Annealed for 0.17 Hour at $600^{\circ} \mathrm{C}$ ) 


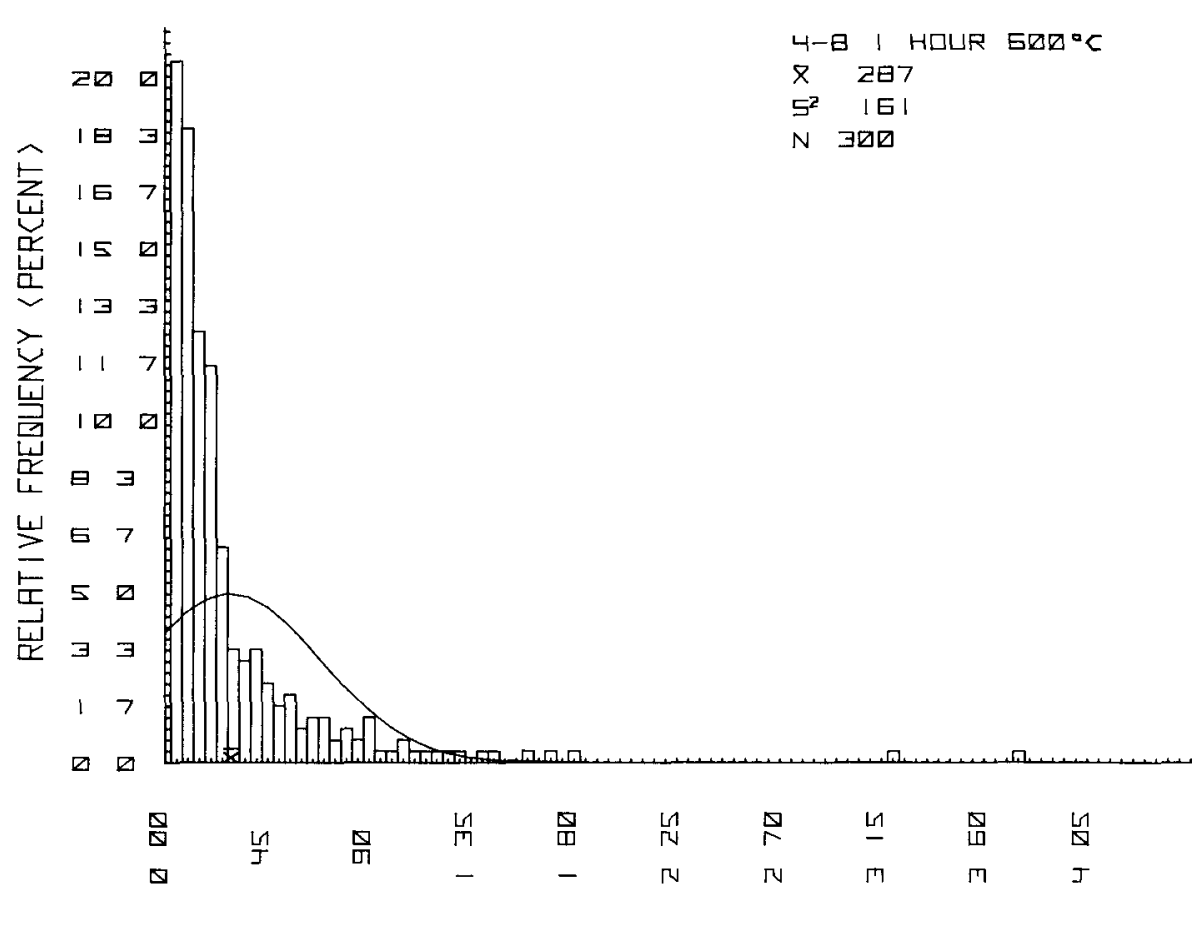

CELL AREA 〈SQLARE MICRDMETERS〉

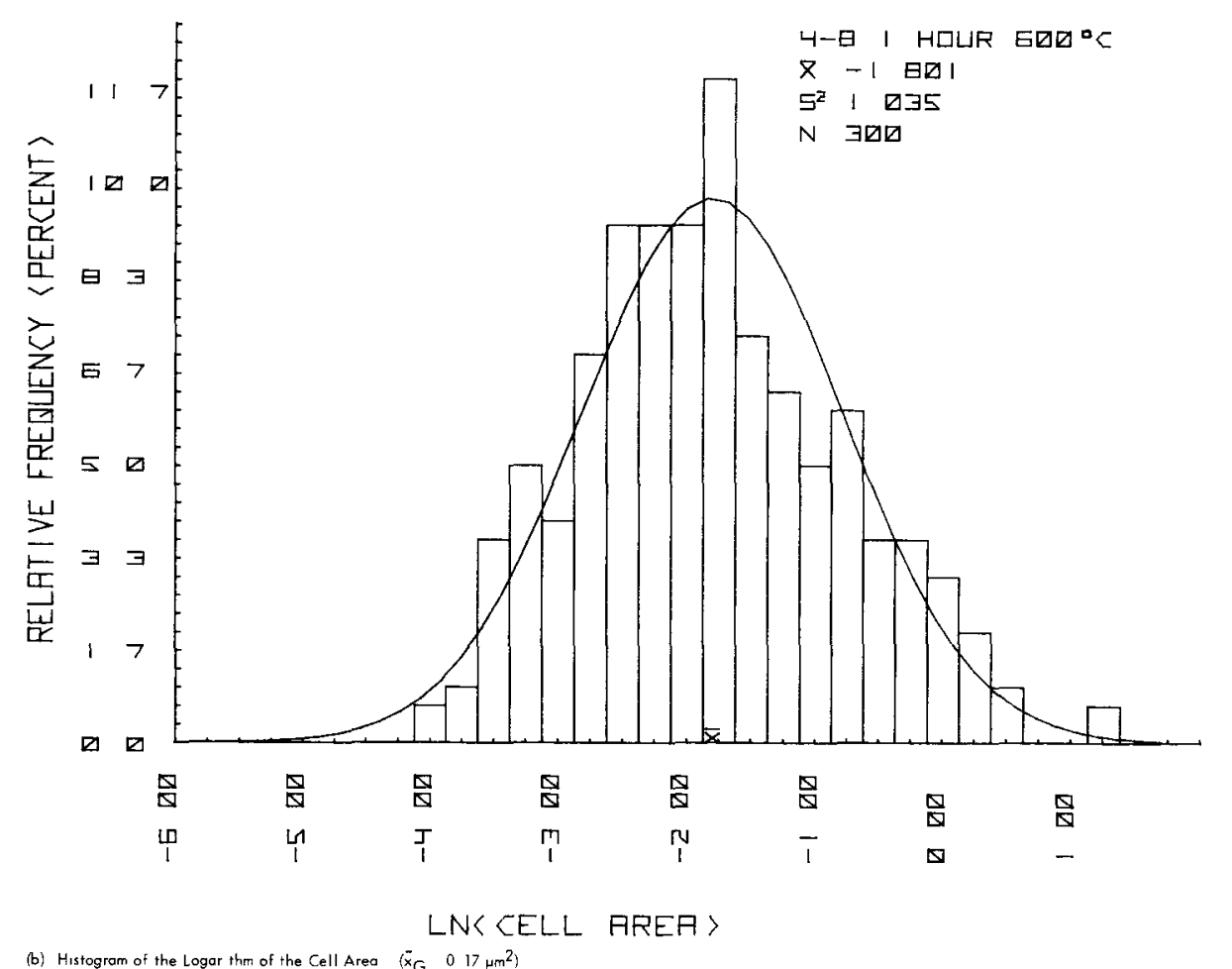
Figure B-10 HISTOGRAMS OF THE CELL-AREA MEASUREMENTS OF THE (110)[110]
CRYSTAL. (Annealed for One Hour at $600^{\circ} \mathrm{C}$ )

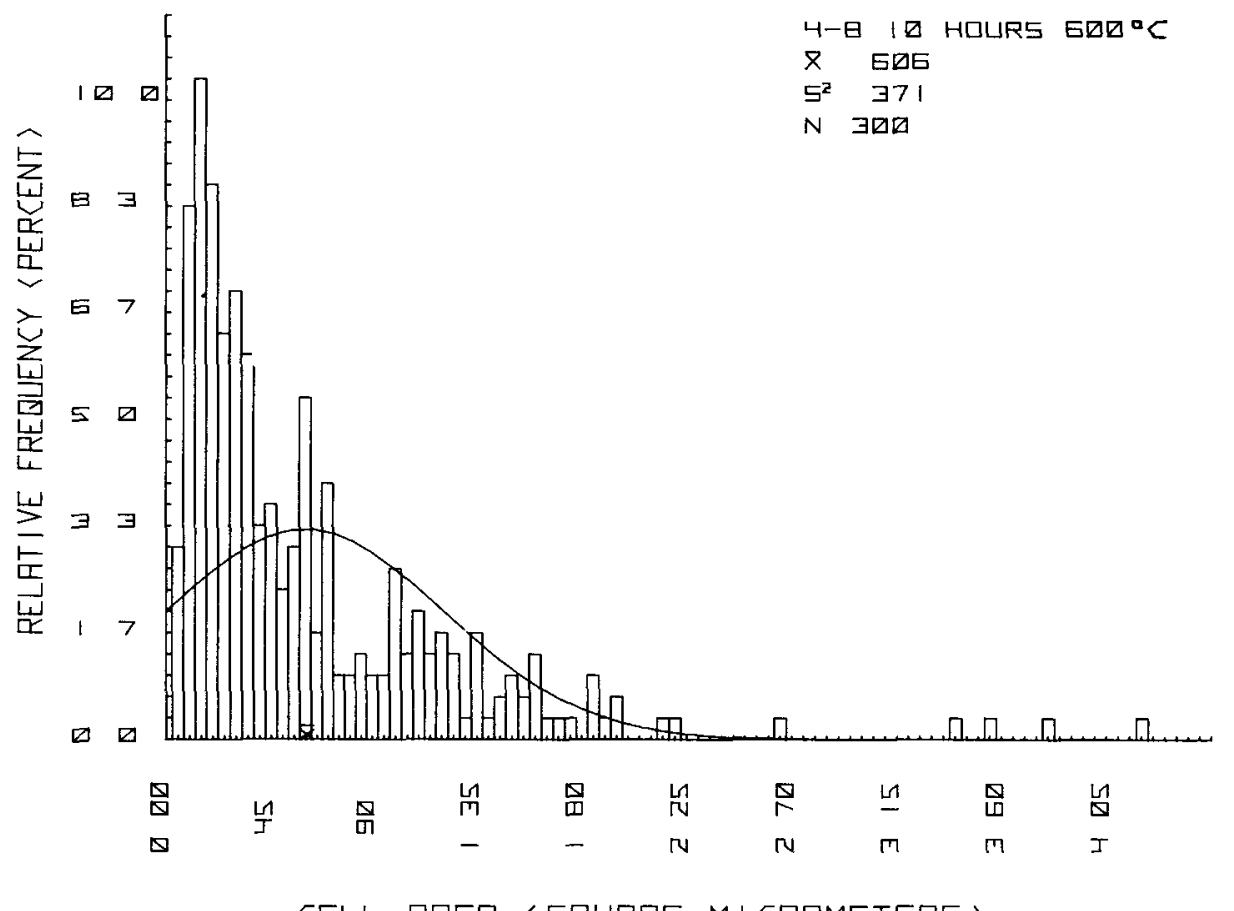

CELL AREA < SQUARE MICRDMETERS

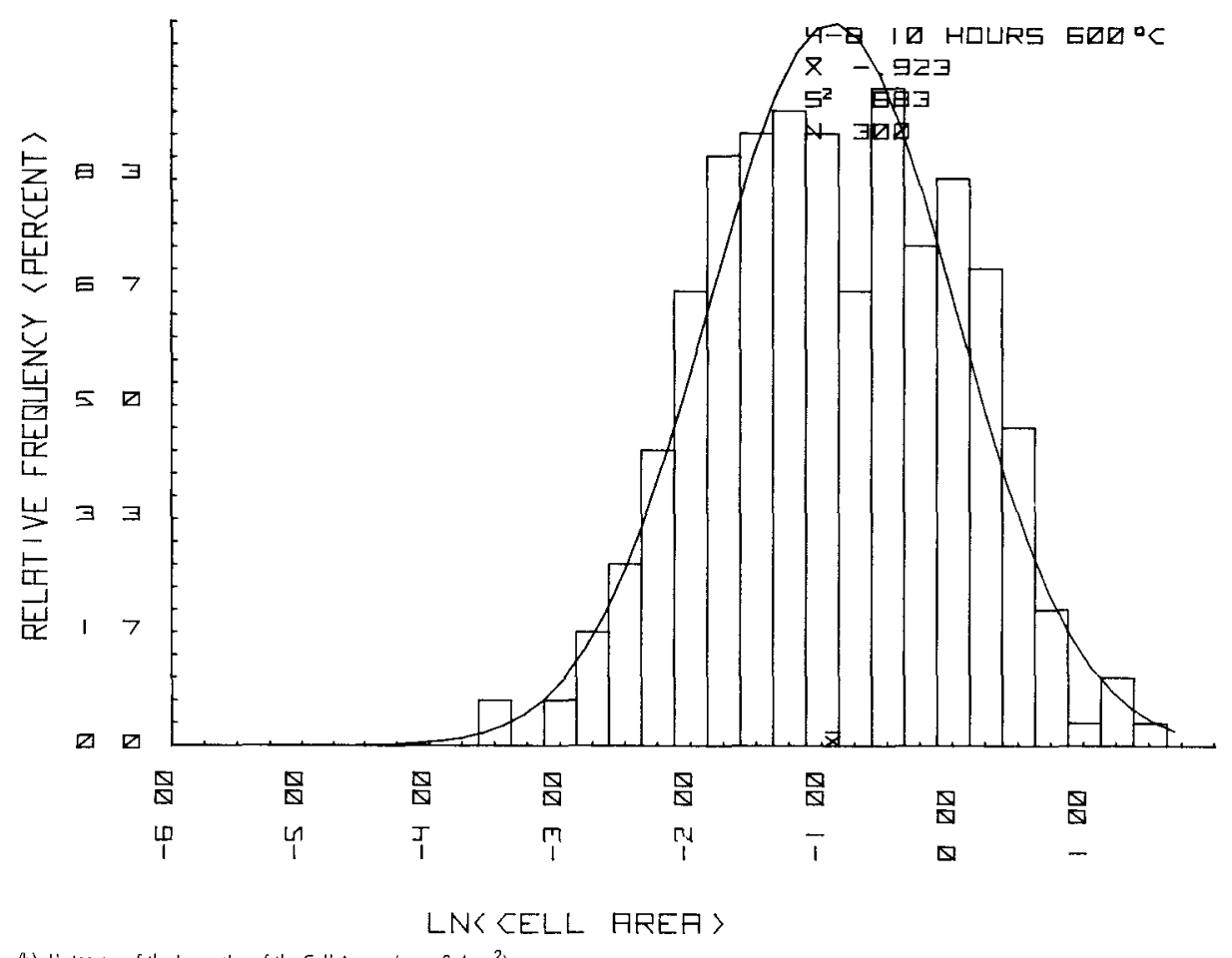
Figure B-11 HISTOGRAMS OF THE CELL-AREA MEASUREMENTS OF THE (110)[110]
CRYSTAL. (Annealed for Ten Hours at $600^{\circ} \mathrm{C}$ ) 


\section{REFERENCES}

(1) ASM Monograph on Recrystallization, Grain Growth, and Textures; Interscience, New York and London (1963).

(2) Weissmann, S., Lement, B. S., and Cohen, M.; in Refractory Metals and Alloys II; Interscience, Chicago (1967).

(3) Andrade, E. N. Da C. and Chow, Y. S.; Proc Roy Soc, London, A175, p 962 (1940).

(4) Elam,C. F.; The Distortion of Metal Crystals; Oxford Univ Press, New York (1935).

(5) Maddin, R. and Chen, N. D.; Prog Met Phys, 5, p 53 (1954).

(6) Rose, R. M., et al; J Metals, 13, p 679 (1961).

(7) Mordike, L.; Z Metallk, 52, p 587 (1961).

(8) Spitzig, W. A. and Mitchell, T. E.; Acta Met, 14, p 1311 (1966).

(9) Lement, B. S., et al; Substructure and Mechanical Properties of Refractory Metals, WADD TR, pp 61 - 181 (1961).

(10) Weissman, S., et al; Refractory Metals and Alloys //; Interscience, Chicago (1962).

(11) Guthrie, P. V.; An X-ray Diffraction and Transmission Electron Microscopy Study of Recovery and Recrystallization in Columbium and Columbium-40 Vanadium; PhD Thesis, University of Cincinnati (1971); also UCC-ND Report ORNL-TM-3882 (1972).

(12) Keh, A. S. and Weissman, S.; Electron Microscopy and Strength of Crystals; Interscience (1963).

(13) Barrett, C. S. and Levenson, L. H.; Trans AIME, 145, p 281 (1941).

(14) Dillamore, I. L. and Roberts, W. T.; "Preferred Orientation in Wrought and Annealed Metals", Met Reviews, 10(39), pp 271 - 379 (1969).

(15) Himmell L., Editor; Recovery and Recrystallization of Metals; Interscience, New York and London (1963).

(16) Blickensderfer, R., et al; Report RI 6539; US Dept of the Interior, Bureau of Mines (1964).

(17) Mochalov, G. A. et al; Physics of Metals and Metallography,27.(3), p 118 (1969).

(18) Raymond, L. and Neumann, J. P.; Trans AIME,233, p 1625 (1965). 
(19) Dillamore, I. L., et al; Proc Roy Soc, London, A329, p 405 (1972).

(20) Chin, G. Y. and Wonsiewicz, B. C.; Trans AIME, 245, p 871 (1969).

(21) Jago, R. and Hatherly, M.; Metal Science, 9, p 83 (1975).

(22) Dillamore, I. L. and Katoh, H.; BISRA Report MG/39/71.

(23) Taoka, T., et al; Trans Nat Res Inst for Metals, Japan, 9(4), p 155 (1967).

(24) Orowan, E.; Dislocations in Metals, AIME (1954).

(25) Beck, P. A. and Sperry, P. R.; J Appl Phys, 21, p 150 (1950).

(26) Bailey, J. E. and Hirsch, P. B.; Proc Roy Soc, London, A267, p 11 (1962).

(27) Bellier, S. P.; Unpublished Work; Cited by Cahn, Reference 31.

(28) Burgers, W. G. and Verbraak, C. A.; Acta Met, 5, p 765 (1957).

(29) Cahn, R. W.; Proc Phys Soc, London, 63A, p 323 (1950).

(30) Cottrell, A. H.; Prog in Metal Physics, 4, p 255 (1955).

(31) Cahn, R. W.; in Recrystallization of Metallic Materials, Dr Riederer-Verlag GMBH, Stuttgart (1971).

(32) Li, J. C. M.; J Appl Phys, 33, p 2958 (1962).

(33) Doherty, R. D.; Metal Science, 8(5), p 132 (1974).

(34) Hutchinson, W. B., et al; Acta Met, 21, p 1685 (1973).

(35) Ray, R. L., et al; Acta Met, 23, p 831 (1975).

(36) Bollman, W.; J Inst Metals, 81, p 439 (1959).

(37) Granger, F. and Haase, G.; Z Phys, 162, p 468 (1961).

(38) Dunn, C. G. and Koh, P. K.; Trans AIME, 206, p 1017 (1956).

(39) Stiegler, J. O., et al; Acta Met, 11, p 851 (1963).

(40) Fujita, H.; T Phys Soc, Japan, 16, p 397 (1961).

(41) Kochnov, V. Ye, et al; Phys of Metals and Metallography, 24, p 99 (1967).

(42) Ryan, N. E. and Johnstone, S. T. M.; J Less Common Metals, 10, p 77 (1965). 
(43) Raneda, Y.; Japan J Appl Phys, 4, p 16 (1965).

(44) Bartuska, P.; Czeck J of Physics, 14, p 765 (1964).

(45) Faivre, P.; Unpublished Work; Cited by Cahn in Reference 31.

(46) Viswanathan, R. and Bauer, C. L.; Acta Met, 21, p 1099 (1973).

(47) Dillamore, I. L., et al; Met Sci J, 1, p 49 (1967).

(48) DeHoff, R. T. and Rhines, F. N.; Quantitative Microscopy, p 240; McGraw-Hill, New York (1968).

(49) American Society for Testing and Materials, Book of Standards, Part 31, p 441 (1968).

(50) Schulz, L. G.; J Appl Phys, 20, pp 1030 - 1036 (1949).

(51) Chernock, W. P. and Beck, P. A.; J of Appl Phys, 23(3), pp 341 - 345 (1952).

(52) Williams, T. L.; UCC-ND Report Y-1860 (1972).

(53) Love, F. R.; UCC-ND Report ORNL-TM-2018 (1968).

(54) DuBose, C. K. H. and Stiegler, J.; UCC-ND Report ORNL-4066 (1967).

(55) Hirsch, P. B., et al; Electron Microscopy of Thin Crystals; Plenium Press, New York (1965).

(56) Thomas, G.; Electron Microscopy and Structure of Materials, p 470; Univ of California Press, Berkeley (1972).

(57) Brandon, D. G. and Komen, Y.; Metallography, 3, p 111 (1970).

(58) Heye, W. and Sattler, H. P.; Z Metallkunde, 62(5), p 386 (1971); also ORNL-TR-4011.

(59) Barrett, C. S.; Trans AIME, 233, p 1625 (1965).

(60) Hu, H. and Cline, R. S.; Trans AIME, 224, p 784 (1962).

(61) Bauer, R., et al; Textures in Research and Practice, in Proceedings of the International Symposium, p 136, Edited by J. Grewen and G. Wassermann, Springer-Verlag (1969).

(62) Vandermeer, R. A. and Ogle, J. C.; Trans AIME, 242, p 1317 (1968).

(63) Tarnovskii A. A., et al; Deformation of Metals During Rolling, Translation; Pergamon Press, New York (1965).

(64) Backofen, W. A.; Deformation Processing, p 89; Addison-Wesley (1972). 
(65) Vandermeer, R. A. and Ogle, J. C.; Trans AIME, 245, p 1511 (1969).

(66) Taoka, T., et al; Trans AIME, 239, p 13 (1967).

(67) Gindin, I. A., et al; The Physics of Metals and Metallography, 31, p 156 (1972).

(68) Dubovitskaya, N. V., et al; The Physics of Metals and Metallography, 30 (2), p 249 (1970).

(69) Boyd, J. D. and Embury, J. D.; Electron Microscopy and Structure of Materials, p 470; University of California Press (1972).

(70) Hirth, J. P. and Lothe, J.; Theory of Dislocations, p 645; McGraw-Hill (1968).

(71) Furubayashi, E.; Trans Nat Res Inst for Metals, Japan, 11 (5), p 243 (1969).

(72) Taoka, T., et al; Trans Nat Res Inst for Metals, Japan, 9 (4), p 187 (1967).

(73) Walter, J. L. and Hibbard, W. R., Jr; Trans AIME, 212, p 731 (1958).

(74) Hibbard, W. R. and Tully, W. R.; Trans AIME, 221, p 336 (1961).

(75) Kronberg, M. L. and Wilson, F. H.; Trans AIME, 185, p 501 (1949).

(76) Wonsiewicz, B. C. and Chin, G. Y.; Met Trans, 1, p 57 (1970).

(77) Hibbard, W. R. and Yen, M.; Trans AIME, 175, p 126 (1948).

(78) Dillamore, I. L. and Roberts, W. T.; Acta Met, 12, p 281 (1964).

(79) Dillamore, I. L., et al; Proc Roy Soc, London, A329, p 405 (1972).

(80) Dillamore, I. L. and Katoh, H.; Met Sci, 8, p 21 (1974).

(81) Dillamore, I. L and Katoh, H.; Met Sci, 8, p 73 (1974).

(82) Bunge, H. J.; Kristall und Technik, 5 (1), p 145 (1970).

(83) Gubernatorov, V. V. and Soholov, B. K.; Phys Met Metallog, 34 (6), p. 155 (1972).

(84) Zasimchuk, Ye E. and Maksimenko, Ye A.; Foreign Technology Division Report, FTD-HC-23-2463-74; Wright Patterson Air Force Base.

(85) Yastrebkov, A. A., et al; Phys Met and Metallog, 31 (4), p 156 (1971).

(86) Vandermeer, R. A.; Unpublished Research. 
(87) Christian, J. W.; Proceedings of the Second International Conference on the Strength of Metals and Alloys, p 35; American Society for Metals (1970).

(88) Hirth, J. P. and Lothe, J.; Theory of Dislocations, p 719; McGraw-Hill (1968).

(89) Li, J. C. M.; J of Australian Inst of Metals, 8(2), p 215 (1963).

(90) Read, W. T.; Dislocations in Crystals, p 197; McGraw-Hill (1953).

(91) Sherby, O. L.; Personal Communication.

(92) Aust, K. T.; "Textures in Research and Practice", Proceedings of the International Symposium, p 160; Edited by J. Grewen and G. Wasserman; Springer-Verlag (1969).

(93) $\mathrm{Hu}, \mathrm{H}$.; "Textures in Research and Practice", Proceedings of the International Symposium, p 200; Edited by J. Grewen and G. Wasserman; Springer-Verlag (1969).

(94) Hulsey, W. J.; Rolling and Recrystallization of Beryllium Single Crystals, PhD Thesis; University of Tennessee (1969); Also UCC-ND Report Y-1679 (1969).

(95) Kisilenko, N. I. and Parusnikov, V. N.; Elektron Teknika, Cited in Metals Abstracts, 57-0259 (1973).

(96) Dunn, C. G.; Trans AIME, 236, p 947 (1966).

(97) Perryman, E. W. C.; Polarized Light in Metallography, p 70; Academic Press, Inc, New York (1952). 


\section{ACKNOWLEDGEMENTS}

The author expresses his sincere appreciation to his advisor, R. A. Vandermeer, for suggesting the research topic and his advice throughout the investigation.

Thanks are extended to the following employees of the Oak Ridge Y-12 Plant and the Oak Ridge National Laboratory who contributed to this research: W. J. Hulsey, for his advice and guidance throughout the initial investigation; A. M. Ammons, for assistance in measuring and analyzing the dislocation cell areas; A. G. Dobbins, for the metallographic work; O. B. Cavin and D. A. Carpenter for the X-ray diffraction work, and D. H. Johnson, for the transmission electron microscopy work.

The author is indebted to J. O. Stiegler and members of the ORNL Electron Microscopy Group for use of their equipment and the helpful suggestions which they provided.

Special thanks are due to M. A. Russell for typing the final copy and to the $Y-12$ Technical Information Service Department for the preparation of the figures.

Finally, thanks are due to Union Carbide Corporation-Nuclear Division for the opportunity to participate in the Educational Assistance Program. 


\section{Distribution}

Aerospace Corporation-ARPA

Kendall, G.

Air Force Armaments Laboratory

Wilson, $\mathrm{L}$.

Air Force Materials Laboratory

Inouye, S.

Battelle Memorial Institute

Meyer, G.

Energy Research and Development Administration - Oak Ridge

Hickman, H. D.

Leed, R. E.

Zachry, D. S., Jr

Lawrence Livermore Laboratory

Fulton, F. J.

Nelson, W. E.

Woods, D. H.

Los Alamos Scientific Laboratory

Hoyt, H. C.

Kirby, R. S.

Sandstrom, D.

Oak Ridge Gaseous Diffusion Plant

Stieff, S. S.

Wilcox, W. J., Jr

\section{Oak Ridge National Laboratory}

Cavin, O. B.

Inouye, $\mathrm{H}$.

McHargue, C. J.

Ogle, J. C.

Stiegler, J. O.

Vandermeer, R. A.

Weir, J. R., Jr

\section{Oak Ridge Y-12 Plant}

Alvey, H. E.

Ammons, A. M.

Armstrong, R. C.

Bernander, N. K.

Burditt, R. B.
Burkhart, L. E./Mason, D. L.

Carpenter, D. A.

Dobbins, A. G.

Dodson, W. H.

Duggan, H. G.

Ebert, T. H.

Ellinson, R. D.

Evans, P. A.

Fraser, R. J.

Gritzner, V. B. Jackson, V. C. Jessen, N. C. Johnson, D. H. Jones, F. W.

Kahl, K. G.

Keith, A.

Kite, H. T.

Koger, J. W.

McElroy, B. D.

Mills, J. M., Jr

Myhre, T. C.

Northcutt, W. G.

Perkins, M. A.

Phillips, L. R.

Schreyer, J. M.

Smith, H. F., Jr

Smith, R.D.

Snyder, W. B., Jr (10)

Stoner, H. H.

Tewes, W. E.

Tilson, F. V.

Townsend, A. B.

Weathersby, W. E.

White, J. C.

Wilkinson, B. L.

Yaggi, W. J./Googin, J. M.

Y-12 Central Files (master copy)

Y-12 Central Files (route copy)

$Y-12$ Central Files (Y-12RC)

Y-12 Central Files (5)

Paducah Gaseous Diffusion Plant

Bewley, H. D.

Rockwell International - Rocky Flats

Jackson, R. S.

Sandia - Albuquerque

Eckelmeyer, K. H. 
Magnani, N. J.

Rohde, R.W.

Sandia - Livermore

Adolphson, D. R.

Mote, M. W.

Union Carbide Corporation - New York

Winters, Charles

Union Carbide Corporation - Parma Research Center

Chambers, W. E.

University of Tennessee-College

of Engineering

Stansbury, E. E.

US Army Ballistics Research

Laboratories

Bloore, E. W.

Gillich, W.

US Army Materials and Mechanics

Research Center

Greenspan, J.

Larson, F.

US Naval Weapons Laboratory

Crowe, $R$.

In addition, this report is distributed in accordance with the category UC-25, Materials, as given in the USERDA Standard Distribution Lists for Unclassified Scientific and Technical Reports, TID-4500. 